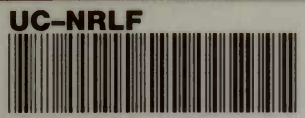

+ D 54 2? ]

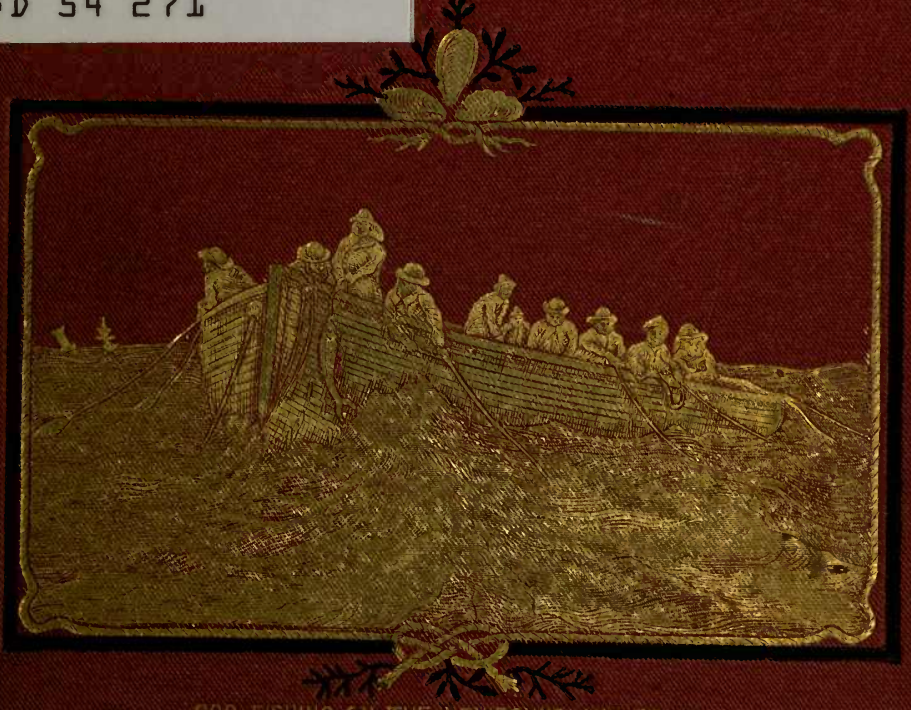

COD-FHIX ON THE NEW FEUNOLANO BANK

(1) 


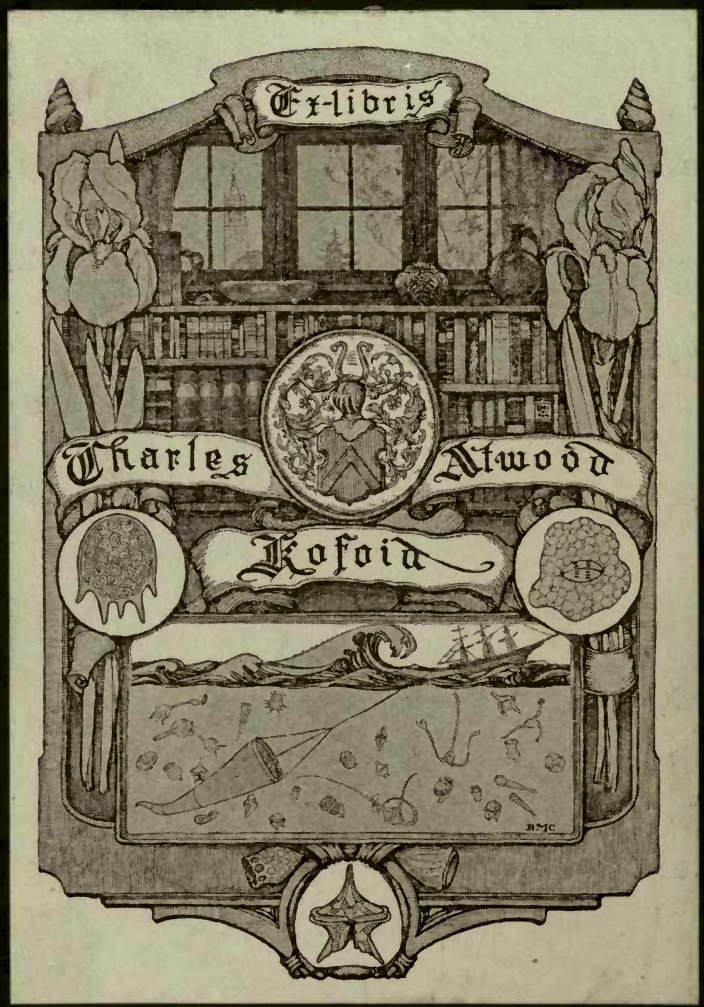




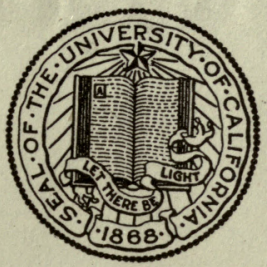

THE LIBRARY OF

\section{THE UNIVERSITY OF CALIFORNIA}

PRESENTED BY

PROF. CHARLES A. KOFOID AND MRS. PRUDENCE W. KOFOID 



\section{THE GREAT FISHERIES}

$$
\text { oF }
$$

$$
\text { THE WORLD. }
$$


$4+2=12=3$ 


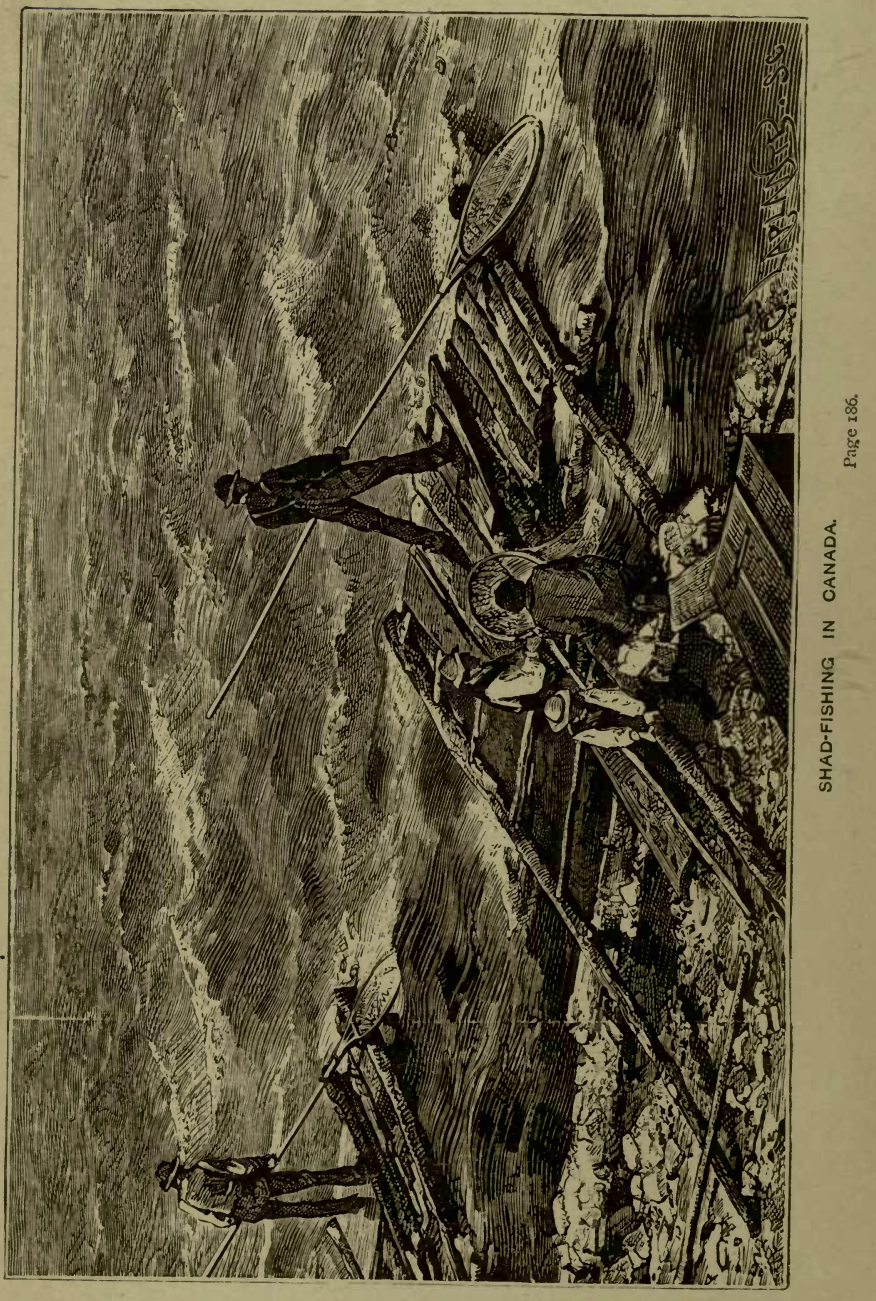




\section{THE GREAT L \\ FISHERIES OF THE WORLD,}

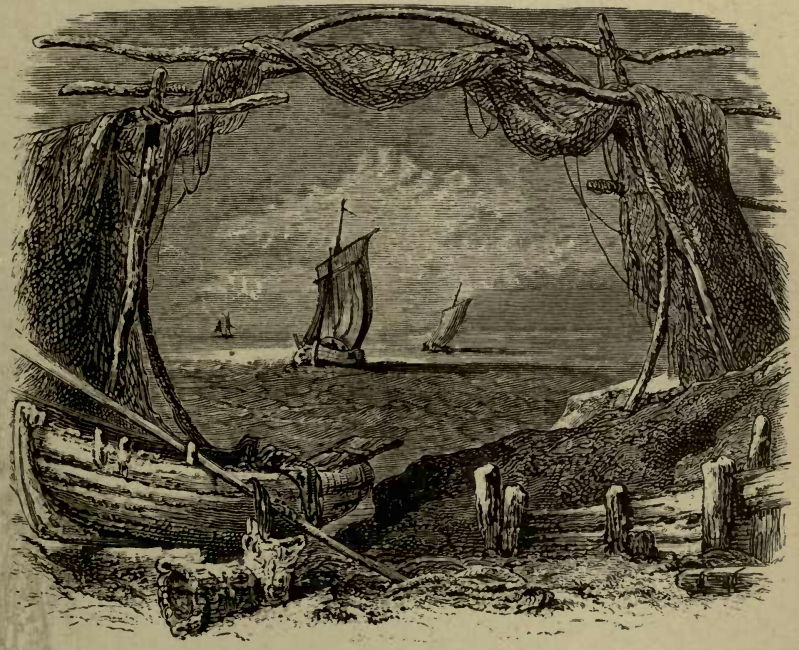

Thomat flelson and Sons, LONDON, EDINBURGH, AND NEW YORK. 



\section{THE GREAT FISHERIES}

Or

THE WORL D

DESCRIBED AND ILLUSTRATED.

\section{" And there we hunted the walrus, \\ The narwhal, and the seal; \\ $\mathrm{Ha}$ ! 'twas a noble game! \\ And like the lightning's flame \\ Flew our harpoons of steel."}

LONGFELLOW.

\section{LONDON:}

T. NELSON AND SONS, PATERNOSTER ROW; EDINBURGH; AND NEW YORK. 

a red herring, than by the connoisseur who "trifles" with turbot a la Béchamel.

It must be remembered, too, that our English fisheries are of considerable commercial importance; and that all along our coast, from St. Ives to Wick, populous and prosperous towns are dotted, which, but for these fisheries, would speedily cease to possess a lccal habitation and a name. Further: they breed a hardy and adventurous race of seamen, to whom, in time of war, the royal navy must look for its best recruits; self-reliant, skilful, patient, and mostly temperate men, such as are seldom to be found, now-a-days, on the decks of our merchant-vessels. They live a hard life; a life with many risks and small gains; and they take their changes and chances very quietly; seldom murmuring, and never going out "on strike," or "rattening." It is to be wished some competent writer would sketch the manners and customs of our fishing-population; for Mr. Bertram, in his valuable "Harvest of the Sea," has but lightly touched upon this part of his subject.

Of the great fisheries of the world, but more particularly of those in which British enterprise is engaged, the present volume attempts to offer a popular survey, which, the author trusts, will prove acceptable to the fish-loving reader. It aims at being comprehensive rather than exhaustive; and the design has been to furnish such information as would be useful and attractive to the general public, rather than to supply material for the investigation of the learned in pisciculture and piscicapture. For this reason its scope has been extended so as to include certain fisheries which are of commercial significance, though they do not add to our foodsupplies. The author has taken the greatest care in the collection of his facts; and would fain hope that the reader who takes the trouble to peruse his discursive pages will find in them something which he did not know before, and gain a stronger and enduring interest in the great fisheries and in the men who carry them on. 


\section{Gentents.}

\section{I.-THE SALMON}

The SALMon well known to the ancients-Its natural history-Salmonfishing-Spearing salmon-A "killing" fly-Contest between the angler and the fish-Salmon-spawning-Migratory instinct of the salmonSalmon in Alaska-Salmon-fishing in Canada-Salmon-rivers in Great Britain-Poaching: its evils-Economizing the fisheries-The sport of "harling" described-Catching salmon in Greenland-In Finland-In North-West America-In Lower Brittany - The angler's delight... . 9-49

\section{II.-THE GADID开 AND PLEURONECTID丑.}

"White-fish"-Description of the CoD-Its voracity-Its usefulness-Codcuring-Cod-fisheries in the North Seas-Trawling-Line-fishing for cod-Cod-fisheries of Newfoundland-A curious story-Value of the cod-fisheries-The Newfoundland fishermen-The "bultow" mode of fishing - The summer shore-fishery - Cod-fishing off Labrador-Codfisheries of Norway - The Shetland fishermen-The HADDOeK: its natural history - "Finnan haddies"- The WHITING: its natural history -The CoAl-fish and the PolLa CK-The HAKE described-The Pleuronectidæ, or "flat-fish"-The Turвoт, and its fishery-The SoLE-In good repute among the ancients-Brill and PlaICE - Natural history of the FLOUNDER - The HALiBuT - How caught by the Greenlanders...................................... $50-99$

\section{III.-THE SCOMBERIDA®.}

Characteristics of the Scomberidæ-The TuNNY : its natural history-Notes from the ancient writers-Tunny-fishing in the Mediterranean-Ancient modes of tunny-fishing-Modern modes-The "Tonnaire"-The "Madrague"-A scene in the Bay of Palermo-The MAckerel describedIts migrations - An anecdote from Pontoppidan-The SworD-FrsH-Its formidable weapon - Its hostility to the whale-Sword-fish in the Mediterranean-Catching sword-fish-Quotation from Oppian-The Sicilian harpooneer-Fishery in the Strait of Messina..............100-126 


$$
\text { IV.-THE HERRING. }
$$

Introductory remarks-HERRING shoals-Their supposed migratory movements--Different races inhabit different waters - Spawning season-Four stages of the herring's career...................127-135

\section{V.-THE HERRING-FISHERY.}

Animated scenes at a herring-port-Departure of the herring-fleet-Its adventures-Its return-Value of the herring-fisheries-Yarmouth and Loch Fyne herrings-The Loch Fyne fisheries-Trawl versus drift net-The Dutch fishery-Herrings at Yarmouth-The herring-fishery in Loch Boisdale-A scene at Wick-Red herrings-Once more at Yarmouth -A visit to a curing-house- "Ryving and speeting"-The Shetland herring-fishery - The Dutch fishermen at Lerwick - The controversy about trawling - Conclusion .....................

\section{VI.-THE PILCHARD, SPRAT, AND OTHER CLUPEIDÆE.}

About the PIlchard-Arrival of the pilchard-shoal on the Cornish coastSeine-fishing-Pilchard-curing-Pilchard-tucking-A picturesque spectacle-Seine versus drift-A scene at St. Ives-The pilchard fishermen - About the SPRAT-Natural history of the SARDine-The Whitebait -The ANuhovY - The Roman "garum"-About the SHAD .... 169-186

\section{VII.-THE STURGEON.}

The Sturgeon described-Its different species-Its various habitats-Why it enters the rivers-Its commercial value-Caviare: how made-The sturgeon-fishery on the Garonne-In Russia-How carried on in the Volga..................................... 187-198

\section{VII.-THE EEL-FISHERY.}

Celebrity of the EEL-Lake Copais-Modern "eeleries"-Reproduction of eels--Their habits described-Their physiological characteristics-Fishing for eels-Night-lines-Clod-fishing-The eelery at ComacchioCooking eels - A grand festival at Comacchio...............199-213

\section{IX.-THE LOBSTER AND THE CRAB.}

A " standing romance of the sea"-Natural history of the LOBSTER-Description of its segments-Its digestive system-Its annual exuviationsVarious kinds of lobsters-The CRAB-Various kinds of crabs-Their general characters-Lobster-traps deseribed-How lobsters are sent to

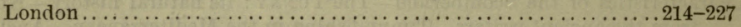

\section{X.-THE SHRIMP AND THE PRAWN.}

About the SHRIMP-A popular crustacean-Shrimping - The shrimp-fishery at Chausey-The "putting-net"--At Saint-Gilles-sur-Vic-About the Prawn .......................................... $228-237$ 


\section{XI.-THE OYSTER.}

The OYsTER a favourite with the ancients - "Oyster-enthusiasts"-Professor Wilson upon oysters-Scallop-shells and oyster-grottoes-Who first ate an oyster?-Physiology of the oyster-Its mode of locomotion - Depositing its spawn-Longevity of the oyster-Oyster-beds in the Thames-At Whitstable-In the river Colne-In the Firth of Forth-Irish oysterbeds-Fattening oysters - The science of oyster-culture-Oyster-farms in Itäly-At Lake Fusaro-In England-Facts about oyster-breedingOyster-farming in France-The Ile de Rhé "parks"-An oyster-farm at Arcachon-The secret of successful oyster-culture ...........238-268

\section{XII.-PEARLS, AND MOTHER-OF-PEARL.}

The PearL-oyster described - Where found-What is a pearl?--Value set upon the pearl-Its historical associations-Some famous pearls-How their quality may be improved-The pearl-fishery in Ceylon-Divers and their work - Sifting the pearls-British pearls - Concluding remarks .. 269-284

\section{XIII.-THE MUSSEI.}

Characteristics of the Mussed-Its "byssus" described-Its mode of locomotion-Mussel-culture-Story of the Irishman, Walton-Mussel-farm in the Bay of Aiguillon-What is a bouchot?-Mussel-culture the staple of an important industry - Fresh-water mussels............ 285-294

\section{XIV.-THE HOLOTHURIA, TREPANG, OR SEA-CUCUMBER.}

Natural history of the HoLOTHURIA, or SEA-CUCUMBER-How it is fished for-The fishery on the Australian coast-Its principal processes described--Trepang-fishery, in the Gulf of Manaar-The European holothuria ..........................................

\section{XV.-THE SHARK.}

Description of the SHARK - Rightly called the "ocean-pirate"-Held in abhorrence by the ancients-Pliny's account of the divers and the shark -General hatred with which it is regarded-A Sicilian scene-Characteristics of the shark-The construction of its eye explained-Sharks in British waters-The blute shark-Its voracity - The tenacity of lifeThe white shark described-A pathetic story-Fishing for sharks-An exciting event-The shark comparatively worthless-Its destructiveness -The neuse hound or cat-fish-- The thrasher or sea-fox-The Greenland shark-The basking shark-Hunting the sun-fish-Characteristics of the hammer-hear shark - "Sun-fishing" on the Irish coast-- A long chase"Glorions sport "................................

\section{XVI.-THE TURTLE.}

The TURTLE described - The green or edible turtle-How it is canght in the Bahamas-Green turtle in the Gallapagos-Turtle and turtle-catching at the Isle of Ascension-In the East Indies-Tortoise-shell-The hawksbill turtle-Some interesting facts-- The coriaceous turtle-The loggerhead turtle-Turtle in the South Seas............... 338-351 
XVII.-THE WHALE: AND THE WHALE-FISHERY.

Organization of the WHALE-Adaptability to the conditions under which it lives-Its three skins-Useful qualities of its blubber-Characteristics of the whale-Its remarkable respiratory ápparatus-Its caudal fin, or tail-Its "breathing" or "blowing"-Its senses-Its organ of hearing described-Moral character of the whale-Affection for its youngA whaling anecdote-Waller's "Battle of the Summer Islands"-Different species of Cetacea-The Greenland whale-Its "baleen" or whalebone-Its swiftness of motion-Its food-Anecdote illustrative of its maternal affection-Its principal products - The cachalot, or sperm whale-Spermaceti described-What is ambergris?-Formidable character of the cachalot-The whale-fishery-British whaling-ships-A whaling-vessel and its crew-Every one in his place-Pursuit of " a fish" -.."A fall! a fall!"-A swift chase-The capture-A narrow escapeDangers of whale-fishing-Anecdotes-Securing the prize-Cutting-up the whale- "Making-off" described-The king of fishes-The whalefishery at Vadsö-A new mode of killing-The dead leviathan-Whales at Shetland-The Shetland fishery--Stories of adventure and perilDanger and a rescue-The ship of death-The A merican whaler EssexA boat capsized-"We have lost Carr!"-Romance of the northAnother catastrophe-The herbivorous Cetacea-Tritons and mermaids -The manatee-The dugong......................... $352-425$

\section{XVIII.-THE SEAL: AND THE SEAL-FISHERY.}

General description of the SEAL-Its physiology described-Its sensesCapable of being tamed-The land of winter-Habits of the seal-Seals at home-Hunted by the Eskimos-The seal and her cub-The fur seal -The common seal-Hector M'Intyre and the phoca-The harp or Greenland saddleback seal-Its characteristics-The bearded seal-The marbled and the crested seals - The sea-lions of the South Pacific-The sea-elephant-The seal-fishery-The Newfoundland sealers-Seals in the Newfoundland waters-A seal-hunt-Hazards of the fishery-" Running ice"-Ships employed in the fishery - "Weighing and cutting"Antiquity of the seal-fishery - Value of the seal-An Eskimo sealbanquet - The Eskimo seal-hunters - Seal-fishing in the Baltic-The Shetland seal-hunters_Off Labrador..................426-464

XIX.-CORAL: AND THE CORAL-FISHERY.

What is CorAL? - What it was supposed to be, and what it is-Reproduction of the corallines-Three kinds of gemmation-Reproduction by fission -Formation of what is popularly called coral-Coral-banks, islands, and reefs-Gradual elaboration of a coral-reef-The coral-fishery-In the Strait of Messina-The divers and their hazardous pursuit-Their habits -Different kinds of coral-How coral is worked............465-497

\section{XX-CURIOUS FISHES AND MODES OF FISHING.}

Folcanic fishes-Prennadillas - Fish in Artesian Wells-Showers of flsh-The EcHENEIs, remora, or sucking-fish-Ancient fables about the remoraA story from Elian-A quotation from Oppian-Complex apparatus of the remora-How it works-Catching turtle with the echeneis-The pilot-fish-Geoffroy Saint-Hilaire, and what he saw. ........488-506 


\title{
THE TREASURES OF THE DEEP.
}

\section{CHAPTER I.}

\author{
T H E S A L M O N.*
}

"Let me wander beside the banks of the tranquil streams of the warm South, 'in the yellow meads of Asphodel,' when the young spring comes forth, and all nature is glad; or, if a wilder mood comes over me, let me clamber among the steeps of the North, beneath the shaggy mountains, where the river comes foaming and raging everlastingly, wedging its way through the secret glen, whilst the eagle, but dimly seen, cleaves the winds and the clouds, and the dun deer gaze from the mosses above. There, amongst gigantic rocks, and the din of mountain torrents, let me do battle with the lusty salmon, till I drag him into day, rejoicing in his bulk, voluminous and vast."-Scrope.

$$
\text { "See the fish }
$$

Cut with her golden oars the silver stream."-SHAK ESPEARE.

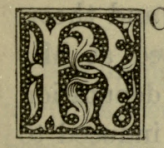

OWS of pointed teeth on the jaws, the palate, the tongue,-in fact, the most complicated mouth-armour or dental apparatus which is known; a wedge-shaped body, covered with thin small scales, which are embedded in the silvery spotted skin ; great muscular strength of body, and remarkable powers of swimming; a surprising fecundity;

* The materials of the following chapter have been derived from Russel, "The Salmon;" Stoddart, "The Angler's Companion;" Scrope, "Days and Nights," \&c.; Bertram, "Harvest of the Sea;” C. St. John; Yarrell; Sir J. Richardson; Deslandes; Badham, \&c.; and from personal observations. 
a delicious and highly-esteemed flesh, as much valued by ancient as by modern epicures, and furnishing a staple article of diet for many peoples; habits of unusual interest, and physiological phenomena which have suggested problems to a hundred naturalists; - such is the fish of fish, the lordly SaLmon !

Though there is much that we do not know about the natural history of the salmon, yet it is better known than that of any other of the two hundred and fifty kinds of fish which inhabit the seas and rivers of Britain; and this, as Mr. Bertram says, for three good reasons. It is of greater value as property than any other fish; its large size better admits of observation than smaller members of the fish tribe; and, in consequence of its migratory instinct, we have access to it at those seasons of its life when to observe its habits is the certain road to information. Yet not a few of the difficulties connected with its mode of reproduction and growth are by no means disposed of. Almost every day some evidence is offered of the unsettled state of our knowledge of these questions; and it may, we fear, be apprehended that they will hardly be answered to the satisfaction of all inquirers and theorists until some such course has been adopted as Mr. Russel humorously suggests. If, he says, a deputation of omniscient authors and witnesses could be induced to stay below water for a few months, going down say in November, taking their seat where they could observe the deposition and development of the ova,-_"sitting," like Milton's Sabrina, " under the glassy, cool, translucent wave,"-accompanying their charge to the sea, and returning to their native element in autumn, saturated 


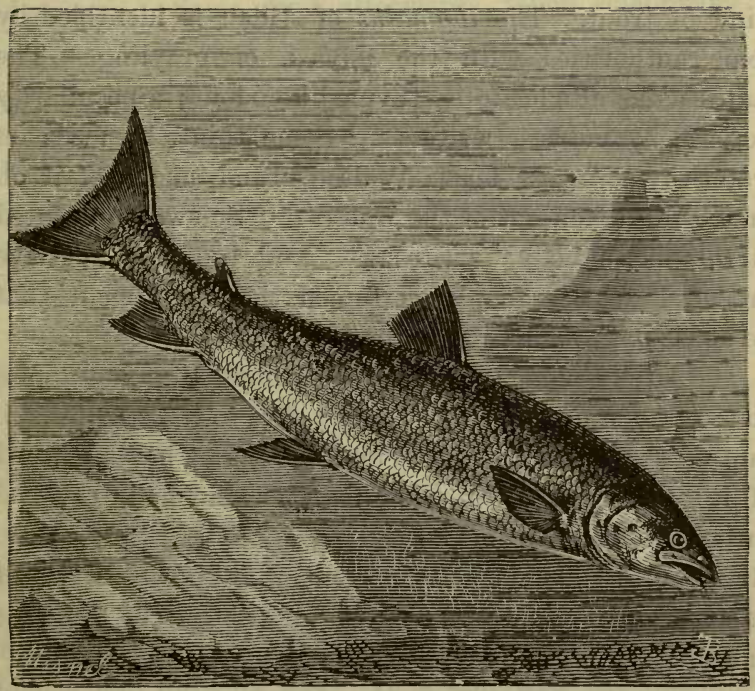

THE SALMON.

with information, they would then be competent to pronounce a conclusive deliverance on every perplexing point connected with the salmon!

Beginning at the beginning, we may observe that the ancients were doubtlessly acquainted with several members of the Salmonidoe family, though it was their misfortune not to know its noblest scion, the famous Salmo salar. We read in Alian of certain speckled fish which the Macedonians were wont to catch with an. artificial fly; and Athenæus speaks of a fish called pyruntes, "excellent for the table, easy of digestion, and found only in cold, clear, rapid streams,"-which were probably some 
kind of trout. The thymalus of Alian is identified by some authorities with the umbra, or grayling. The Latin name alludes to its thyme-like odour; a peculiarity noticed by modern writers. "Some think he feeds on water-thyme," says Izaak Walton, "and smells of it on first being taken out of the water." "So sweetly scented is this fish's body," writes St. Ambrose, "as to have procured for one highly perfumed the compliment, that he smelt daintily like a flower or a fish."

The later Romans seem to have known, but not appreciated, the Salmo salar. Pliny refers to it as an inhabitant of the rivers Dordogne and Garonne; having heard of it probably from Roman tourists who had travelled through Gaul, or from Gallic visitors to the Eternal City. Reference to it under its present well-known title first occurs in Ausonius, who also distinguishes it by different names according to its growth :-

\footnotetext{
"Nec te puniceo rutilantem visceri salmo

"Transierim."....

"Purpureusque salar stellatus tergora guttis."...

"Teque inter geminas species neutrumque et utrumque, Qui necdum salmo nec jam salar ambiguusque Amborum, medio Fario intercepte sub ævo."
}

Coming down to more modern times, we know that the salmon was highly prized by the princes, barons, and monks of the Middle Ages, and that it invariably obtained a conspicuous place in all sumptuous banquets. That it was much affected by the priestly order, we infer from an anecdote told by Fayot. A restaurant, or café, which formerly stood in the Cloitre St. Jacques de l'Hôpital, Paris, was famous for its Wednesday and Friday fish-dinners. A certain abbé, on one occasion, partook there so plenteously of salmon, as to induce a fit 
of dyspepsia. Some days afterwards, when celebrating mass, reminiscences of the delicious fish floated back upon his mind, and during the confiteor he was heard to murmur, as he quietly beat his breast, "Ah, ce bon saumon! ce bon saumon!"

Salmon is named among the dainty dishes placed before Arthur and the Knights of the Table Round in Hookham Frere's mock-heroic poem. It is included in the bills of fare recorded in the Earl of Northumberland's Household Book, which belongs to the reign of Henry VII. And, to conclude these notes, is it not immortalized in the "Noctes Ambrosianæ " of Christopher North?

The salmon is an inhabitant of northern climes. In autumn and winter it is a fresh-water, during the rest of the year a salt-water fish. It quits the "ocean-depths" about October for spawning purposes, and in immense shoals seeks the mouths of the rivers, up the channel of which it will force its way. It is said that the phalanx preserve a remarkable degree of military array in their movements; so that Olaus Magnus describes the shining procession, in their glittering panoply of scales, sweeping rapidly onwards like an invading army, as a spectacle well worthy of admiration.

On these occasions they swim as cranes and wild geese fly-in a wedge; the largest salmoness, it is said, forming the apex of the triangle, and the young males the base. According to Deslandes, when ascending a stream they keep as close as possible to the bottom, because there the current against which they are contending has less power; but in descending they rise to the surface, to profit by the force of the current, which is then going in the same direction as themselves. Some authorities assert that 
they can proceed at the rate of thirty miles an hour; and being, as quaint old Fuller says, "both bow and arrow, they will shoot themselves out of the water to an incredible height," - that is, to fourteen feet. The present writer has never seen a salmon rise above six or seven, but his opportunities have not been many. He can bear witness to the enjoyment the fish seem to take in their expedition, when they are sailing through a comparatively tranquil reach; they splash, and frolic, and tumble, like a group

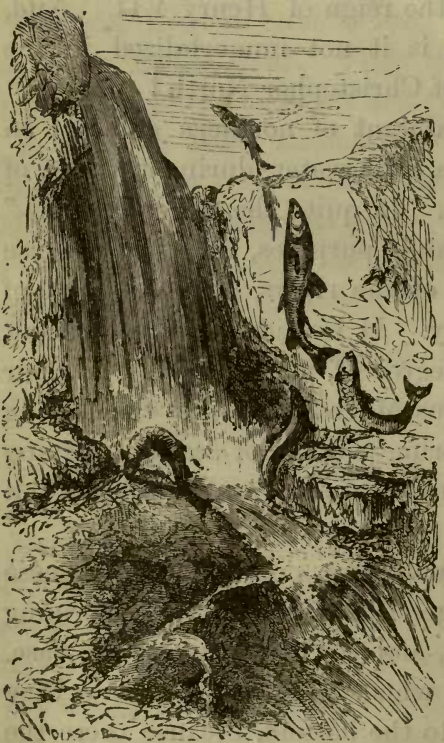

SALMUN LEAPING A WATEREALL of happy children in a summer pool. When they reach a fall or an embankment, they clear it by a leap, as a hunter takes fence, hedge, or ditch. The manner in which they do this is very curious : they bend themselves into the form of a bow, suddenly relax the body, and then, taking a sidelong eurve through the air, like a boomerang, alight on the other side of the obstacle. If baffled in the first attempt, they try again; and so again and again, until successful. Their perseverance is as great as that of Robert the Bruce's spider: we once watched a young salmon, at a point where the stream, - a Highland stream, - was coming down in 
spate, make eleven efforts before it succeeded. The poet Drayton describes this strange mode of locomotion with much graphic vigour, though, be it said, with some exaggeration :-

\footnotetext{
"Whenas the salmon seeks a fresher stream to find

(Which yearly by the sea comes hither of his mind, As he in reason grows), and stems the watery tract Where Tivy falling down doth make a cataract, Forced by the rising rocks that there her course oppose, As though within their bounds they meant her to enclose; Here, when the labouring fish doth at the foot arrive, And knows that by his strength but vainly he doth strive, His tail takes in his teeth; and, bending like a bow That's to the compass drawn, aloft himself doth throw, Then springing with his tail, as doth a little wand That, bended end to end, and flirted from the hand. Far off itself doth cast, - so doth the salmon vault ; And if at first he fail, his second somersault He instantly essays; and from his nimble ring Still yesting, never leaves until himself he fling Above the streamful top of the surrounded heap." *
}

It is an entertaining sight, in spring and summer; to watch the salmon making their way up a stream. Every high tide brings up a number of them, and they seem to have no other object than the youth in Longfellow's "Excelsior." In the shallow places, you may see them swimming, or, more correctly speaking, wading, in water two or three inches deep, so that half their glittering, sheeny body is exposed to view. On they go, however, scrambling up the fords, and making tho water fly to the right and left, like ducks at play. When the fish are numerous, you may catch sight of a dozen or so at once; and at such points they might be killed by spears, or even by a stick,-and, indeed, says Mr. St. John, many a salmon does come to his death in this way. The fishermen, when the river is low, escape much useless fatigue,

* Drayton, "Poly-Olbion," book xxi.

† C. St. John, "Wild Sports of the Highlands," p. 54, et sqq. 
and save their nets from injury, by working in a quiet pool immediately above a shallow, where they station one of their number, who watches for the ascending flotilla, and gives a signal to his companions on its coming within ken. Forthwith they put out their nets, and they are almost certain to catch the salmon. And in this way very few of the fish escape while the water remains low, but as soon as a slight flood rises they can get up unperceived. In the night, as in the day, it is easy to distinguish them, from the sparkle and sheen of the water as they struggle onward. Moreover, the noise they make is always detected by the acute ear of the experienced fisher.

There is something romantic, or, as lady novelists would say, thrilling, in listening during the "stilly night" to the hoarse cry of the watch when he discovers a fish, and the rushing sound of oars and boat immediately afterwards. Sometimes a stealthy otter suddenly appears in the shallows, having slipped quietly and unobserved through the deeper parts of the stream, until, for want of water to cover him, he is compelled to wade. As soon as he is descried, a general clamour is heard, for he is a daring poacher, and one of the fishermen's worst enemies. They endeavour to entangle him in the net,-and if they succeed he immediately falls a victim to their vengeance; but not infrequently he slips noiselessly to the side of the bank, hides in some hollow or reedy nook until the danger is past, and then glides away unperceived.

Mr. St. John is of opinion that neither sea-trout nor salmon ever seem happy, except when breasting their way against a stream. It is certainly astonishing what difficulties they are ready to encounter and overcome. 
In the Findhorn, owing to the impetuosity of the current, its frequent and sudden floods, and its shifting beds of gravel and shingle, no cruives, or weirs, are made use of : they would be swept away as fast as built. But in the Spey, and many other Scottish rivers, large cruives are erected, which prevent the passage of the fish, except on Sundays and in floods. A cruive is a dam, or embankment, thrown across the river, with openings at intervals, to permit the descent of the water in a strong stream. Through those openings the fish pass into a kind of wooden cage, and as the entrance is made after the fashion of a wire mouse-trap, they are unable to find their way out again. However convenient they may be for the fishermen, the angler regards them with any other feeling than that of satisfaction.

Salmon-fishing, as everybody knows, is conducted in a variety of modes : by the harpoon, by the line, by nets of various sizes and shapes. In the Tay the fishermen adopt the following procedure. The net being placed in the boat, one party begins to row slowly up the stream, while another party, carrying a rope attached to the net, proceed along the bank in the same direction. On arriving at a certain point, the boat rows across the river, the net is run out, and the crew pull down to the startingplace, making a complete sweep of a considerable stretch of water. The men on the bank in like manner turn round, and make for the rendezvous, hauling on the rope as they move along. In this way the passage of the river is completely barred against the ascending fish, which are enclosed in the meshes of the net as its two ends are brought together, and in due time hauled ashore. By this wholesale process, a considerable number of sal- 
mon are caught on favourable occasions; and the salmonfisheries in the Tay, and similar rivers, yield their proprietors very large returns.

Spearing salmon is now illegal, but it is a very exciting sport, as the reader, if he is acquainted with Sir Walter Scott's "Redgauntlet," will willingly acknowledge. Mr. St. John describes a scene of which he himself was an eye-witness. The night was calm and dark. The steep and rugged rocks through which the river made its way were illuminated in the most brilliant manner by fifteen or sixteen torches, carried by as many athletic and active Highlanders, which threw strange shifting lights on the surface of the stream, and gave a weird aspect to the whole procedure. Sometimes one of the poachers - for such they were-would remain motionless for a few moments, in eager yet patient expectation that a fish started by his companions would swim within reach of his spear, as he stood with it ready poised, like one of Homer's heroes, and his excited countenance lighted up by his torch as he bent over the water. Then came loud shouts and a confused hurrying to and fro, as a magnificent fish darted in among the group; noisy peals of laughter when some unlucky fellow, darting at his prey in the deep water, missed his balance and fell headlong into it. Every now and then a salmon would be triumphantly hoisted into the air, its shining body quivering on an uplifted spear. The fish, as soon as caught, was carried ashore, where it was quickly despatched by a veteran fisher deputed to this office.

The use of the leister, or spear, however, was prohibited by an Act of Parliament passed in 1859 . $\mathrm{Mr}$. 
Russel characterizes the sport as butcherly and destructive. "Night-leistering," he says, " with the glare of the pine-torches reflected from cliff, and wood, and water, with the yells, the laughter, and the immersions, was doubtless in some respects a fine sight, and a most exciting sport; but it was slaughterous and wasteful, killing more fish in a few minutes than would have sufficed for a season's sport-and killing them, too, just when they were most useful in the water, and most useless out of it. It was no uncommon thing, on some of the upper fisheries of the Tweed, to kill within an hour, on a February or November night, a greater number of fish than had been killed with the rod during the whole season (and the farther up the river, the greater or more entire becomes this truth), to say nothing of the far greater numbers killed by poachers with the same weapon, both in and out of the legal season." *

So Captain Francks, writing in Oliver Cromwell's time, exclaims :- "When the salmon goes to the shallows, that is the time the prejudicate native consults his opportunity to put in execution that barbarous practice of murdering fish by moonshine, or at other times to martyr them with the blaze of a wisp and a barbed spear. What! are these cannibals or murdering moss-troopers to surprise fish by the engine of fire-light? Such dark conspirators sprung from Fawkes or Cataline, or some infernal incubus."

The true angler, in his pursuit of this noble fish, will chiefly use the fly. He may occasionally resort to other bait, - such as salmon-roe, parr-tail, minnow, worm, - but

* Russel, "Tlie Salmon" (ed. 1854), pp. 160, 161. 
his chosen weapon of destruction will be the skilfullyfashioned fly. In his use of it will be shown his dexterity, his patience, his readiness of resource, his knowledge of the habits and character of the fish. In his making of it will be shown his ingenuity, his profound lore, his accomplished manipulation. We cannot enumerate here the various devices to which the fertile mind and hand may have recourse. Different rivers and different seasons need different treatment. The fly that kills in a shallow of the Tweed will fail in a pool of the Spey or Ness. So there are Tweed flies, and Spey flies, and Forth and Teith flies, and flies for the Urchay and the Awe. And there are also flies of special renown, such as the Childers, the General, the Dundas, the Butcher, the Doctor, the Parson, the Fail-me-never, and the Black Dog. For the benefit of the inexperienced reader, we will describe the wonderful composition of the Failme-never :-

The body is made of black mohair, black hackle, and silver twist; the wing, of mottled feather from the tail of the Argus pheasant; the shoulders, of a twitch of orange mohair; the tail is yellow.

Here is a recipe for a fly of extraordinary killing powers :-

Tie with well-waxed silk a portion of silkworms' intestines on a highly-tempered and finished Limerick-made hook. Now for the tail :-First come two turns of gold thread, then a tenth part of an inch of red floss silk. Next comes the tail, consisting of a bright gold feather from the crest of the golden pheasant. The body is now to be made of, alternately, a stripe of green, a stripe of blue, and the remainder of orange-coloured floss silk, 
with a double binding of gold thread and silver tinsel. The legs are concocted of a black barn-door cock's hackle, taken from him in winter, when the bird is in full plumage ; next to the wing is placed a turn of grouse's feather, and two or three turns of the purple-black feather which is pendent on the breast of an old cock heron. Now for the wing-which is composed of a mixture of feathers from the mallard killed in this country; from the teal drake, also a native; from the turkey-cock; the bustard, from India; a stripe or two of green parrot; a little of the tippet of the golden pheasant; a thread or two from the peacock's tail ; a bit from the Argus pheasant, and from the tail of a common hen pheasant; - all these mixed and blended together form an irresistible wing. Round the shoulder of it give a turn of the blue and black feather off a jay's wing. For the head, take a small portion of that substance called pig's wool, so mysterious to the uninitiated, wool not being recognized as one of the usual products of a member of the Suidae; then finish off with a few turns of black ostrich feather; not forgetting, as a final touch, a couple of horns of red and biue macaw's feather. Now all this labour, and all these heterogeneous materials, result in the production of a fly which, according to a veteran angler, no salmon in a taking mood (one can hardly suppose the fish swallows it at the impulse of hunger) can resist. Behold the noble Salmo salar as he mounts suddenly from the cool depths of the pool, balancing himself for a moment while the fly quivers before him in the swirling eddy, and then seizing the gaudy bait with a rapid spring, to retreat apparently well pleased with his success in fly-catching, until he finds himself abruptly checked, brought to a stand, and held 
fast, as in iron gyves, by the unexpected strength of the mimic insect!

Every angler can tell you a greater or less number of stories connected with his exploits in salmon-fishing; of the big fish he has caught, of the address displayed in eatching them, of the runs they have given him, of marvellous adventures in pool and rapid, and of hair-breadth 'scapes and romantic incidents. Brightly-coloured pictures of incidents such as these enliven the pages of almost every book devoted to the art of angling. Without borrowing from any personal experiences, we shall appropriate a description from the pen of Christopher North, which seems to us pre-eminent in accuracy of detail and picturesqueness of language. We do not doubt but that many anglers have enjoyed sport as good, and killed their fish under circumstances as exciting; but we are confident that none have ever related their doings with half as much effect.*

The angler is equipped, let us suppose, with a twentyfeet rod of Phin's, all ring rustling, and a-glitter with the preserving varnish, and lithe to its topmost tenuity as the elephant's proboscis,- the hickory and the horn without twist, knot, or flaw - from butt to fly a faultless taper, "fine by degrees and beautifully less," the beauideal of a rod by the skill of cunning craftsmen to the senses materialized! A fish-fat, fair, and forty! "She is a salmon, therefore to be wooed-she is a salmon, therefore to be won;" but shy, timid, capricious, headstrong, now wrathful and now full of fear, like any other fcmale whom the cruel artist has hooked by lip or heart,

\footnotetext{
* Professor Wilson, "Recreations of Christopher North," ii. 5, 6.
} 
and, in spite of all her struggling, will bring to the gasp at last; and then, with calm eyes, behold her lying in the shade dead, or, worse than dead, fast-fading, and to be re-illumined no more in the lustre of her beauty, insensible to sun or shower, even the most perishable of all perishable things in a world of perishing !

But the salmon, says our authority, has grown sulky, and must be made to spring to the plunging stone. Then suddenly, instinct with new passion, she shoots out of the foam like a bar of silver bullion; and, relapsing into the flood, is in another moment at the very head of the waterfall! Give her the butt, give her the butt, or she is gone for ever with the thunder into two fathom deep! Now comes the trial of your tackle. Her snout is southwards - right up the middle of the main current of the hill-born river, as if she would seek its very source where she was spawned! She still swims swift, and strong, and deep-and the line goes steady, boys, steady. There is yet an hour's play in her dorsal fin-danger in the flap of her tail-and yet may her silver shoulder shatter the gut against a rock. Why, the river was yesterday in spate, and she is fresh run from the sea! All the lesser waterfalls are now level with the flood, and she meets with no impediment or obstruction. The coast is clear; no tree-roots here, no floating branches, for during the night they have all been swept down to the salt loch.

In medio tutissimus ibis - ay, now you feel she begins to fail-the butt tells now every time you deliver your right. What! another mad leap! yet another sullen plunge! She seems absolutely to have discovered, or rather to be an impersonation of, the perpetual motion.

But our quotation has extended to such a length that 
we must pass over the further phases of the struggle between the angler and the fish, and come to the final scene.

The salmon is languidly lying afloat on the foam, as if all further resistance were vain, and she were bent on gracefully surrendering herself to death. But, put no faith in female; she trusts to the last trial of her tail. Sweetly workest thou, O reel of reels; and on thy smooth axle spinning sleepest, even as Milton describes her, like our own worthy planet..... The gaff! the gaff! Into the eddy she sails, sick and slow, and almost with a swirl, whitening as she nears the sand. There, she has it! The gaff has struck right into the shoulder, fairer than that of Juno, Diana, Minerva, or Venus, and she lies at last in all her glorious length and breadth of beaming beauty, fit prey for giant or demigod angling before the Flood!

We must now turn our attention to the natural history of the salmon.

The parent fish deposits her spawn in October, November, and December, ascending the fresh-water streams for that purpose; and the spawn quickens into life about April or May. The young fish are of course exceedingly helpless, and are seldom seen during the first week or two of their career, when they carry about with them as a provision for their sustenance a portion of the egg from which they sprung. At that time they measure about half an inch in size, and their appearance is so singular that certainly no one would suspect they could eventually develop into fine grilse or salmon. The animal, in fact, does not assume the shape of a perfect fish for about fifty days, after which it may be seen hovering 
about the vicinity of its birthplace, weak and timid, hiding arnong the stones, and always apparently of the same colour as the "surroundings" of its asylum. Speedily the transverse bars of the parr begin to show themselves, and the fish grows with considerable rapidity, - especially if it is to be a twelvemonth's smolt.

The young fish continue to grow for a little longer than two years before the whole number reach the second stage in the life of the salmon, and develop into smolts; after which they descend the rivers, and seek the salt water. It is to be noted, however, that half the quantity of any one hatching begin to change at a little over twelve months from the date of their birth : hence arises the anomalous circumstance of fish of the same hatching being partly grilse, weighing four pounds, and partly parr, weighing barely half an ounce. The smolts of the first year return from their sea-voyage while their brothers and sisters are still gambolling among the shallow waters of the upper streams, not only showing no desire for change, but not being in a condition to endure it.

What the salmon feeds upon while in the salt water has not been discovered; it assimilates its food so rapidly, that none is found in its stomach when it is captured and opened. As it thrives apace, however, its feeding must be nutritious, - and probably consists of crustaceans, herrings, sand-launces, and other small fish.

The parr were at one time supposed to be a distinct species; but Mr. Shaw, of Drumlanrig, in 1834-36, by a series of experiments, proved that they are neither more nor less than young salmon; and this fact has been confirmed by observations taken at the Stormontfield breeding-ponds, on the Tay. 
It has been ascertained that smolts returning from the sea within six or eight weeks of their first migration will weigh from three to five pounds. They are then known as grilse. Some reascend the rivers when weighing only a pound and a half or two pounds ; and these, in many places, are known as salmon peal.

Thenceforth the salmon passes its life in annual migrations to the sea, returning to the rivers to spawn, or for other reasons, in the autumn, and frequently remaining during most of the winter. It revisits, if it can, the stream in which it has spent the earlier part of its existence; and the fish belonging to any particular river always exhibit some characteristic difference from those belonging to other rivers. It is surprising to what a distance from the sea they will force their way; ascending the Rhine to the Falls of Schaffhausen, and the Elbe to Bohemia. Their rate of speed is extraordinary; they can travel fifteen hundred feet in a minute, or four hundred miles in a day; but this is only in what an oarsman would call occasional "spurts." Still, with all the difficulties in their way, they will make twenty to twentyfive miles in as many hours. As we have already stated, the greatest perpendicular leaps they seem able to achieve do not exceed twelve or fourteen feet. If they attempt more, they fall back exhausted, and perish on the neighbouring rocks. But they can carry themselves up rushing and broken cataracts of a much more considerable elevation by a series of characteristic bounds or boomerang springs.

As spawning-time approaches, they undergo considerable changes of colour, and both male and female assume a general duskiness. In this state they are called "foul 
fish," and their capture is illegal. After the spawning is completed they are known as "kelts," or "spent-fish :" the males are also termed "kippers," in allusion to the "kip," or cartilaginous hook of the under jaw; and the females " shedders" or "boggits."

Let us recapitulate. The young fry, when first hatched, are known as parr; when a twelvemonth old, they are smolts; after their first migration, they become grilse; thence they develop into the full-grown mature "salmon," which, after spawning, is called a "kelt."

Mr. Bertram is surely right in saying that the most remarkable characteristic of the Salmo salar is its extraordinary instinct for change. After the parr has grown into a smolt, its desire to visit the sea is so intense, especially if it has been bred in a breeding-pond, that it will leap from its place of confinement in the hope of attaining at once its salt-water goal. The instinct of river-bred fish on this point is not less strong. They rush towards the sea with as much eagerness as Xenophon and his Greeks, who saluted it with the famous cry of "Thalassa! Thalassa!" Various opinions are advocated as to the cause of this migratory mania; at which, by the way, it would be very unbecoming in Englishmen to sneer. Some people affirm that in the pasture-grounds of Poseidon the fish finds that nutritious food which adds so rapidly to its size and weight. There cannot be the shadow of a doubt that sea-water ripens it to its prime condition; the river fish not being equal in savouriness, crede experto ! to the noble specimens caught or netted in the briny estuaries. They lose in weight and deteriorate in quality from the moment they enter the fresh water. It is a curious fact, we may add, and an instance of the 
wonderful prevision of nature, that the eel, which is also a migratory fish, descends to spawn in the sea at the very time that the salmon ascends to spawn in the river: Were it otherwise, the roe of the salmon would be absolutely destroyed.*

Spawning-time is from the end of autumn to the beginning of spring, or even the beginning of summer. In different rivers it differs considerably - owing probably to differences of temperature, caused by the higher or lower latitude, the absence or neighbourhood of forests, low warm valleys, or snow-covered mountains

The spawning takes place on beds of fine gravel where. the water is tolerably shallow; the same beds being used for this purpose year after year. The spawning female approaches the bed, escorted by at least one male, sometimes by more than one; in which case they fight lustily with their kips. In the gravel she makes a furrow with lier tail, and in the furrow deposits her spawn, on which the male afterwards pours the vivifying milt. The eggs, when deposited and vivified, are covered by a movement of the female's tail. The time occupied in these processes varies from three to twelve days.

The ova have to run the gauntlet, as it were, of a host of enemies - trouts and other fishes, ducks and other water-fowl, and insect larvæ-which greedily devour them. Moreover, a spate in the stream may wholly sweep away the nursery and its contents, or overlay the eggs with gravel to such a depth that they are never hatched, or, if hatched, the young cannot emerge to the "light of day." It is improbable, therefore, that the number of eggs hatched can bear any reasonable proportion to the number deposited.

* Bertram, "The Harvest of the Sea," p. 188. 
Salmon abound in the rivers of Alaska,-the territory in North-West America which Russia ceded a few years - ago to the United States. So plentiful are they in the spring-time as to impede, it is said, the passage of boats ; and when a strong "south-easter" rises, it drives them ashore, where they lie in putrescent heaps! In the neighbourhood of Sitka, extensive fisheries existed, and from one hundred thousand to one hundred and fifty thousand salmon were annually exported to the Sandwich Islands and elsewhere. Immediately, says Mr. Whymper, on the arrival of a boat-load of fish at the wharf, a number of the poorer women, some of them Indians, arranged themselves in two long lines, and cleaned and gutted the fish with wonderful expedition. A few buckets of water were then thrown over the heap, and they were carried to the vats, and put in brine at once, to be ready for exportation. Each woman's payment was a large fish, weighing twenty or thirty pounds, and worth-just nothing! For salmon-listen, ye epicures!-is the commonest of common fish in all the rivers of the North Pacific, and esteemed accordingly as food fit only for those unhappy individuals who can get nothing better. How much it is to be desired that those abundant supplies of a nutritious "comestible" could be utilized for the benefit of our swarming populations in England and Scotland !

In the river Yukon are found at least two, and perhaps three, varieties of salmon. The largest kind sometimes measures five feet; and boots are partly made with its tough skin. They are caught all down the river in weirs set in shallow places, in circular hand-nets, or by spearing. A flotilla of light birch canoes may be seen ascending the river in regular array; and at a given sig- 
nal the owner of each dips his round hand-net into the river, -and if, when he raises it, a big salmon comes up floundering and struggling, as is generally the case, the helpless prisoner is hailed with a shout of derisive triumph. The enthusiastic angler cannot do better than undertake a trip to Alaska, if he would participate in salmon-catching on a large and easy scale !

Salmon frequent most of the North American rivers, but especially the St. Lawrence and its tributaries. An American writer says that they are most plentiful on the north shore, and, as might be supposed, in those streams which are still outside of the confines of civilization. The noble fish usually makes his appearance about the 20 th of May, and continues in season for two months. Nearly all the streams we speak of are interrupted in their course by waterfalls; but there are few of these which offer any effectual obstruction to his upward progress, and the stories related of his leaps are truly wonderful. The average weight of the Canadian fish is about fifteen pounds, but monsters weighing full forty pounds are not infrequently captured. The common mode of fishing is with a stationary net, set just on the margin of the river at low-water. When the tide rises, the salmon commence running, and becoming entangled by their gillcovers in the meshes of the net, are taken out dead by the fishermen at low-water. Formerly, as many as three hundred would be captured in this way at one time; but either they are less plentiful, or they have profited by the lessons of a long and severe experience.

The Indian mode of taking them is identical with the Scotch leistering. Two Indians embark in a canoe, and while one paddles it stealthily along, the other stands erect, 
with spear uplifted. A torch at the prow of the boat attracts the attention of the fish. They come within range, and are immediately speared.

From an episode narrated by an American angler, it may be inferred that salmonfishing in Canada is attended by much the same adventures as in Great Britain.

Describing an expedition he made with two companions to the St. Margaret River, he says that they started from $\mathrm{Ta}$ lousac at nine, and reached their place of destination at twelve. They found the river uncommonly high, and a little "rily." Making a desperate effort. however, they threw their line about three hours, capturing four (502)

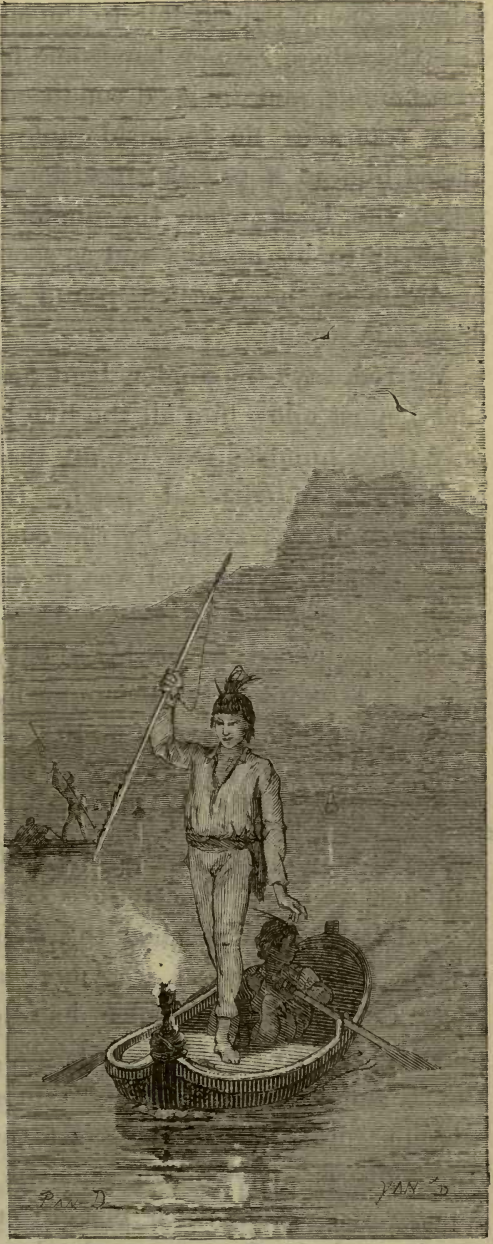

INDIAN MODE OF TAKING SALMION. 
salmon, one of which fell to the share of our authority. $\mathrm{He}$ (the salmon) was a handsome fellow, weighing seventeen pounds, and in good condition; he afforded his captor's comrades no inconsiderable amount of fun, and placed him in a peculiar position. For the salmon had taken the hook when the angler was wading in swift water up to his middle, and as soon as he discovered his predicament, he wheeled round suddenly, and started down the stream.

My rod, says the angler, bent nearly double, and I saw that I must allow him all the line he wanted; and having only three hundred feet on my reel, I found it necessary to follow him with all speed. In doing so I lost my footing, and was swept by the current against a pile of logs. Meantime my reel was in the water, and whizzing away at a tremendous rate. The $\log$ upon which $I$ depended happened to be in a balancing condition, and when I attempted to surmount it, it plunged into the current and floated down the stream, leaving your humble servant astride at one end, and clinging to it with all his might. Onward sped the salmon, the log, the fisherman! At last the log drifted into an eddy, and while it was gyrating in incessant circles I abandoned it, and fortunately reached the shore in safety. My life having been spared, I was more anxious than ever to carry off the salmon which had led me into so much danger; and so I held aloft the rod, and continued down the stream, over an immense number of logs and rocks, which seemed to have been set there for my particular discomfiture. On coming in sight of the fish, I found him in still water, with his glittering belly turned upwards, and, in fact, " completely drowned." I imme- 
diately drew him up on a neighbouring sand-bank, and received the congratulations of my friends on my peculiar mode of taking salmon.

The principal salmon-rivers in Great Britain are the Tweed, the Tay, the Spey, the Esk, and the Severn. Unfortunately, of late years, through over-fishing and poaching, our salmon-fisheries have suffered a grievous decay, and the interference of the Legislature has been invoked to prevent the resort to improper modes of capture, and to confine the fishing to those seasons of the year most suitable to the habits of the fish. In several places, moreover, salmon-breeding, according to the most improved principles of fish-culture, has been introduced, and with a degree of success which justifies the hope that streams now depopulated may once more yield an abundant supply. The salmon is of some importance as an addition to our food-resources. It is difficult, or almost impossible, to obtain any accurate statistics on this point; but Mr. Russel tells us that in 1862, apparently an ordinary year, three Irish railways conveyed about 400 tons of salmon, or about 900,000 lbs.,-being equal in weight and treble in value to 15,000 sheep. In Scotland the Tay alone furnishes about $800,000 \mathrm{lbs}$.,--being equal in weight to 20,000 and in value to 60,000 sheep. The weight of salmon produced by the Spey is not inferior to the weight of mutton annually yielded to the butcher by each of several of the smaller counties. The diminution in the supply of food caused by the decay of the Tweed fisheries, is about 200,000 lbs. a year. And, as Mr. Russel reminds us, in making comparisons between the supplies of fish and of flesh, we must recollect that 
fish, or at least salmon, though higher in money value, cost nothing for their "keep," make bare no pastures, hollow out no turnips, consume no corn, but are, as Franklin expressed.it, " bits of silver pulled out of the water."

The Tay salmon-fisheries are owned by various private proprietors and corporations, and yield an annual rent of about $£ 18,000$. On the Spey they may be said to be worth $£ 15,000$ - which is chiefly, if not wholly, paid to the Duke of Richmond. The rental of the Esk we estimate at $£ 10,000$, and that of the Tweed at $£ 8000$, but it varies considerably. It is fair, however, to compute the annual yield of the British salmon-fisheries, as a source of rental, at $£ 70,000$.

Mr. Bertram, referring to a recent Report of the Inspectors of the English Fisheries, which embraced a summary of the condition of ninety rivers, says: "I gather from it that considerable progress has already been made in arresting the decay of these valuable properties, and that there is every prospect of the best rivers being speedily repeopled with salmon to an extent that will secure them, under proper regulations, from again falling into so low a condition. A careful perusal of this report shows that fixed nets have been nearly abolished; that portions of rivers not hitherto accessible to fish have been made so, passes and gaps having been created by hundreds. Poachers have been caught and punished with great success ; and, according to a review of the report in the Field, a journal which is well-versed in fishery matters, "salmon have been seen in large quantities in places where they have not been seen these forty years.'"

The following table shows the quantity of salmon imported into London, in boxes weighing each $112 \mathrm{lbs}$., 
from 1850 to the end of 1865 , when the Legislature put an end to the open fisheries :- $*$

\begin{tabular}{|c|c|c|r|r|r|}
\hline Year. & Scotch. & Irish. & Dutch. & $\begin{array}{r}\text { Norwe- } \\
\text { gian. }\end{array}$ & Welsh. \\
\hline 1850 & 13,940 & 2135 & 105 & 54 & 72 \\
1851 & 11,593 & 4141 & 203 & 214 & 40 \\
1852 & 13,044 & 3602 & 176 & 306 & 20 \\
1853 & 19,485 & 5052 & 401 & 1208 & 20 \\
1854 & 23,194 & 6333 & 345 & None & 128 \\
1855 & 18,197 & 4101 & 227 & None & 59 \\
1856 & 15,438 & 6568 & 68 & 5 & 28 \\
1857 & 18,654 & 4984 & 622 & None & 220 \\
1858 & 21,564 & 6429 & 973 & 19 & 499 \\
1859 & 15,630 & 4855 & 922 & None & 260 \\
1860 & 15,870 & 3803 & 849 & 40 & 438 \\
1861 & 12,337 & 4582 & 849 & 60 & 442 \\
1862 & 22,796 & 7841 & 568 & 87 & 454 \\
1863 & 24,297 & 8183 & 1227 & 180 & 663 \\
1864 & 22,603 & 8344 & 1204 & 837 & 752 \\
1865 & 19,009 & 6858 & 1479 & 1069 & 868 \\
\hline
\end{tabular}

The lover of salmon cannot regard without feelings of apprehension and indignation the condition of the Tweed fisheries; indignation at the manner in which they are spoliated, apprehension lest exhaustion should be the result of the spoliation. Recent legislation appears to have done but little good. A new Government inquiry is promised, however; and it is to be hoped, rather than expected, that it will remove all grievances, and restore the fisheries to prosperity. If the stranger inquire of a Tweed fisherman what is the fons et origo mali, he will be told it is the systematic "poaching" that is carried on in spite of watchers and constables; and he will come to the conclusion, perhaps, that the best remedy for so serious an evil is not a Government Commission, but the diffusion of knowledge, and the growth of a healthy

* Bertram, "The Harvest of the Sea," p. 222. 
public opinion. Poaching has been called an "abject trade," but it is certainly a profitable one; and a large portion of the population seem unwilling to believe that the rights of property extend to river-waters. They appear to appreciate intensely-

"The good old rule, the simple plan,--
That they should take who have the power,
And they should keep who can."

Lord Minto asserts that "not one man in a hundred believes himself to be violating any moral law when he offends against the Tweed Acts." And the improved condition of the salmon-fisheries has given a fresh stimulus to poaching by largely increasing its gains. The salmon being a migratory fish, ascending from the depths of ocean to the sweet waters of some sequestered woodland pool, falls an easy victim to its human enemies, and perishes by hundreds every year just at the time when it is most valuable; for, however costly a thirty-pound salmon may be on the slab of a Bond Street fishmonger, it is infinitely more precious when on the point of multiplying and replenishing its kind.* Few persons have any idea of the multitudes of fish captured and killed by the poachers. It is on record that a gang of these men (and occasionally women) have taken a hundred salmon from the spawning beds in one night. To bestow any sympathy on such ignorant and destructive plunderers is surely ridiculous!

The salmon is beset by natural enemies, and nature has so carefully guarded against its unlimited increase, that we do not need to step forward and wage an exterminating war against it when it is unfit for food, and preparing to reproduce its kind. It is a well-known fact

* See The Times, August 27, 1874 : “The Tweed Fisheries." 
that a given area of water will breed and feed only a given number of fish. The interference of the poacher is therefore an offence against economic as well as moral laws. Yet in 1872-73, 327 persons were accused of violations of the Tweed Acts; 164 of whom paid the fines in which they were mulcted, while 41 were imprisoned, 44 absconded, and 60 were acquitted. No fewer than 235 various engines of capture were taken from poachers during the same period.

"The poacher's argument,"* says a contemporary, "is just the old-fashioned one which has often been made to do duty, - that as a river is, generally speaking, the property of twenty or thirty people, the salmon moving up and down its stream cannot be the property of any particular person. But there is one crushing reply to this proposition, which must be obvious to the meanest comprehension; it is that by no species of logic can the salmon in the Tweed and its tributaries be considered the property of the poacher......As a plain matter of fact, not all the Queen's army could effectively watch a great salmon-river if there were an extensive population in its course. The Tay proprietors are fortunate; that river flows through a land where there is no population to disturb its finny treasures. On the Tweed and its many tributaries there is a considerable population, many of whom have but a slight knowledge of 'mine and thine,' and all of whom have a taste for salmon and a strong

* A dour Scotch "wabster" once argued with the writer that the water in the Tweed, as it was constantly flowing, could not belong to Lord _ or the Duke of - We asked him to whom the bed of the river would belong, if it suddenly dried up? Further, observing a water-butt in his garden, we requested him to state to whom its contents belonged when filled by the rain, which no more belonged to him than to his neighbour. Our friend shook his head, but made no "articulate" reply. 
desire for gain. The cost of protecting the Tay salmon. fisheries is only about a fourth of what it costs the Commissioners to protect the river Tweed." It must not be supposed, however, that no poaching takes place on the Tay.

The worst of it is, that the public themselves are growing impatient of a legislation which is designed for their benefit, simply because they hear so much of it! In Scotland the river-fisheries are regulated by about twenty Acts, and have been the subject of more Government inquiries than we care to count. The consequence is, that people who know little or nothing of the economy of the fish, or of its natural history, have come to regard the favour shown to this particular inhabitant of the waters with something like annoyance. At the bottom of this feeling, we suspect, lurks a kind of undefinable prejudice against the salmon as the rich man's fish. Its present price renders it a rare dish at the table of the householder of average means ; and as for the peasantry, most of them say, we fancy, what a villager once said to ourselves, "Saumon is na for the likes of we!" They grudge, therefore, the care and attention bestowed upon it, and hate the supervision exercised by the police force.

Their prejudices would disappear if their ignorance were enlightened; if they could be made to understand that a regulation of the fisheries is essential if the salmon is to be preserved as a British fish, and that efficient regulation means increased supply, and increased supply reduced prices. The salmon is a valuable article of food, and with proper care ought to be brought within the reach of the average purchaser. There is no reason why it should not become much cheaper than meat; for which. 
at times, it would then be an agreeable substitute. Formerly, it was so common an article of diet in Scotland, that farm-servants and others, on engaging with new employers, would make it a condition that it should appear on their tables only a certain number of times a week. Otherwise, they would have breakfasted on salmon, dined on salmon, and supped on salmon, every day! No immediate fear need be entertained of any very early return of such unlimited salmon-consumption.

What would become of the salmon, it has been asked, if they were abandoned to the cruel mercies of the poacher? The answer is easily given. To judge from the experience of the past, in ten years not a Salmo salar would be found in our streams! It is certain that at one time the salmon-fisheries of Great Britain were nearly annihilated through greed and want of management and indiscriminate fishing. It is equally certain that the prudent legislation of recent years has done much to recuperate them, and that a steady persistence in the present course cannot but be productive of the best results. "The philosophy of the whole question," says an enthusiastic writer, "lies in a nutshell. If the man who causes two blades of grass to grow where only one grew before is a benefactor to his race and his country, the same may be emphatically said of him who rears two salmon to-day for the one he reared twenty years ago."

There is no end to the destructive appliances which man has brought to bear against this lordly fish; and it is a matter for wonder that any who once ascend our rivers should find their way back into the sea. Nor would they do so, but for the admirable institution of 
"close-time." The most fatal of all these "military engines" is the common sweep-net, which in many of our streams is in use for miles and miles on both banks, and at the same time; so that the fish needs be cunning which would get in safety to the retirement of the upper waters. Not less deadly is the still-net, the stake-net, or the hangnet. Further, the pole and the basket anxiously await the sentimental or over-active fish that finds an amusement in jumping up waterfalls. By the way, a good story is told of Lord Lovat, the Jacobite rebel. It is said that when luncheon-time approached, he would betake himself to a "fall" on his estate famous for its leaping fish, and place a caldron of boiling water in such a position that a salmon missing its spring would tumble into it, and thus cornmit "salmonicide" after a novel and original fashion! Whereupon the cynical nobleman would eat his lunch with peculiar gusto.

Numerous are the ingenious and stealthy deceptions which practise on the credulity and curiosity of the fish, or on his hasty greediness. Slowly sailing up the fresh breezy stream, he catches sight of what seems a bit of rainbow, a flash of many colours; darts at it merrily, and finds himself impaled on a horrid hook at the end of an oiled line, which tugs at him, and plays with him, and holds on to him in spite of all his efforts to get free! He plunges into a deep pool, and rests awhile; then, thinking his enemy is away, he seeks to glide down the river. In a moment he finds himself checked; pulled up suddenly at the will of some mysterious and powerful creature, whose formidable shadow he sees reflected on the waters. Away he goes again with a jerk; but this creature is as cunning as he is powerful, and all his manœuvres are anticipated 
and foiled-until, at length, he suffers himself, palpitating and shuddering, to be hauled out of his native element, and stretched upon the "flowery mead,"-a victim !

It may be that Salmo salar is hungry, and affects a little bit of fish; for he too has epicurean sympathies. Well, in the very nick of time a shy little minnow makes his appearance; now dangling right before his jaws, now receding into the distance, now approaching him again, until he is tempted to dart at and seize it - to find himself befooled by his appetite. "And," adds a lively writer, " as if a man could not do harm enough with one rod and line, which a providential arrangement of hands has made the full complement of his offensive armoury, he gets him a boat if he be suitably situated, and hangs him out astern therefrom three rods, each with its line and lure. A second conspirator-the boatman-tacks quietly across and across the stream, thus drawing the lines through the water, while the first sits cat-like in the stern. Suddenly a reel rattles, the boatman shouts a husky 'therrum,' and the contest between brains and instinct commences; sometimes, it is true, to the discomfiture of the brains. The number of rods renders it possible to pander to so many tastes at once, that the salmon falls a frequent prey to this great sport of 'harling.' "

For this sport of "harling," which is both exciting and effective, it would seem necessary that the stream should be broad, so as to afford space for the movements of the boat; and the current quick, in order that the lines may be kept always in new water as the boat drops slowly down. In a romantic burn, where the water tumbles and flashes over rocky ledges or eddies, and whirls round great 
boulders, a boat, of course, is useless ; nor is it needed, as under such circumstances the salmon always rise quickly enough to the fly. But the fly cannot be used advantageously in an ample river, or loch, or estuary, while in either place harling may safely be adopted.

The Greenlanders catch the salmon with the hand, or with a forked stick, groping among the great stones where the fish conceal themselves. But the method most commonly adopted is this :-They erect an embankment at the mouth of those streams which discharge their waters into the sea. The embankment is built of stones, so arranged as not to obstruct the flow of the stream; and for the facilitating this flow, a small sluice is opened up in it. When the tide rises, it easily covers both dyke and sluice, and the salmon has no difficulty in passing: it ascends the stream to a considerable height, and very frequently "forgets itself" in the fresh water; so that, when the tide ebbs and the sluice closes spontaneously, the salmon finds itself imprisoned in a reservoir whose embankment it cannot cross. In a short time it lies almost dry, and the Greenlanders capture their prize without any difficulty.

In Iceland, the fishermen, stationing themselves on the two banks of a water-course, extend a net right across the latter; then advancing against the current, they impel before them the unlucky salmon, which, when no longer able to retreat, spring upon the shore. As many as two hundred at a time are caught in this fashion.

In Finland, the noisiest and most turbulent point of the river is selected, and the waters are pent up in a 


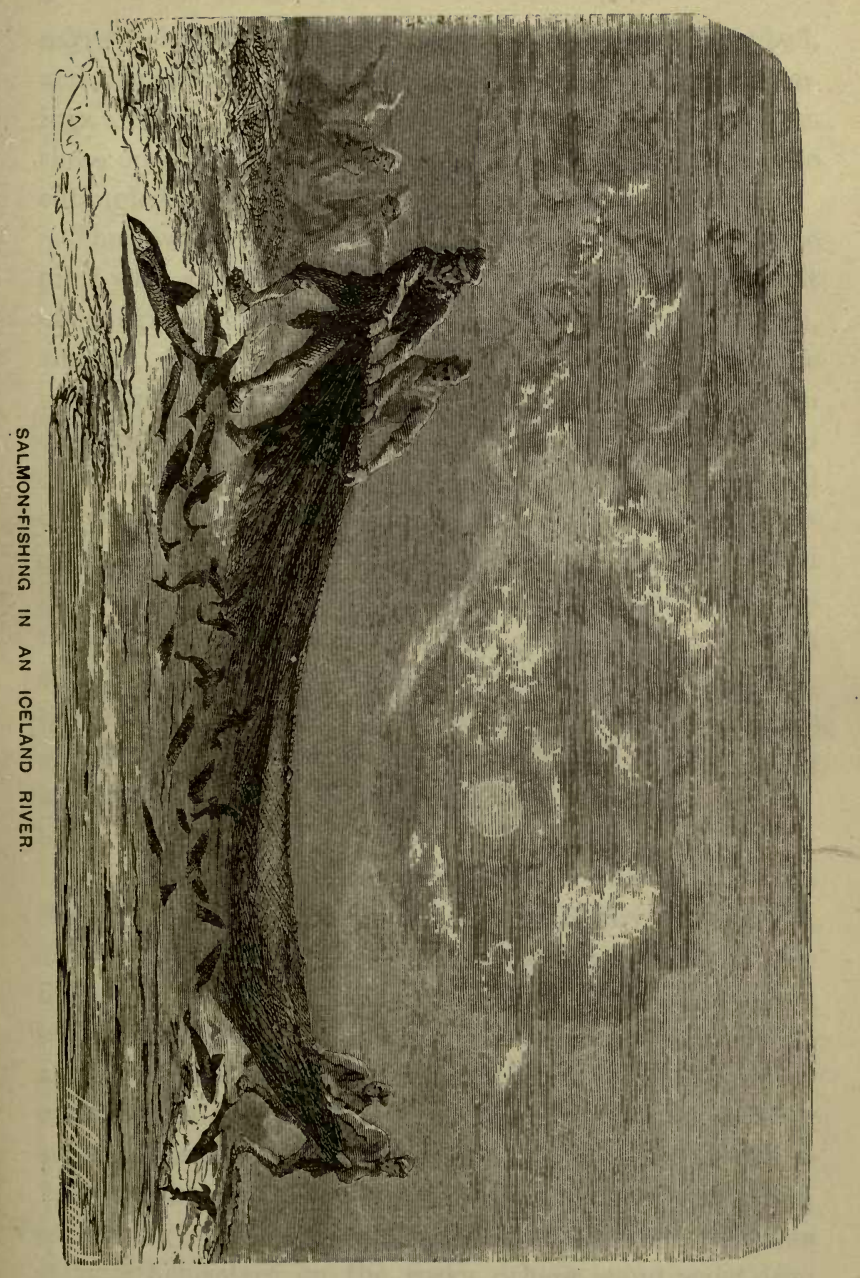




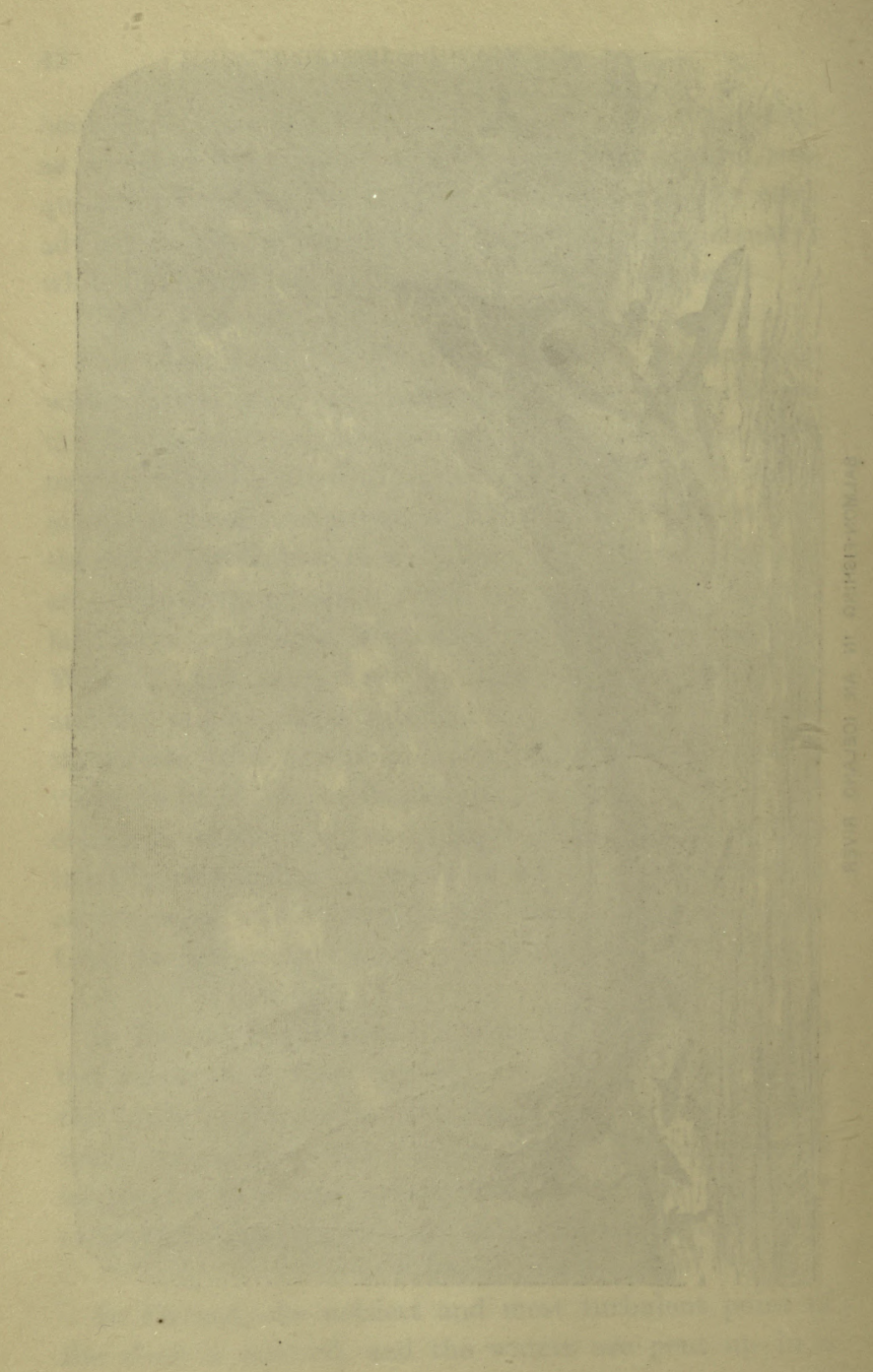


narrow channel formed by piles sunk deeply in their bed, and bound together by branches of trees. A few openings are left through which the fish can pass; but across these openings stout nets are extended, and the fish, once entangled in the snare, is unable to extricate itself.

The riverine peasants, says Acerbi, walk upon these piles with a truly wonderful address, though the current often agitates them in a very perceptible manner. Men, women, children, - all leap from pile to pile with the most singular agility. We felt desirous to assist them in drawing their nets; we were rash enough to cross a third of the palisade; but the sight of the water swirling and eddying beneath our feet turned one of my companions giddy, and had he not been checked in time he would have fallen into the river. The children, and even the men, confide too rashly in their nimbleness, and it is seldom a year passes without one of them falling into the water at the risk of being drowned, since the violence of the current precludes all possibility of a boat being kept within reach to render assistance.

The Shoshony Indians, who dwell on the bank of the Serpent River, to the west of the Rocky Mountains, devote themselves entirely to the salmon-fishery. There is a place named the Salmon's Fall (Chute-du-Saumon); it is a succession of rapids, with a perpendicular cascade above them of fully twenty feet. An incredible number of salmon is caught here. They begin to leap soon after sunset, reascending the course of the river. Some of the Indian fishermen then plunge into the midst of the rapids, swimming with equal strength and dexterity. Others station themselves on the rocks, others stand waist-deep 
in the waves; and all, armed with spears, strike death to the salmon as the latter attempt to leap, or fall back in the water. It is a continual massacre.

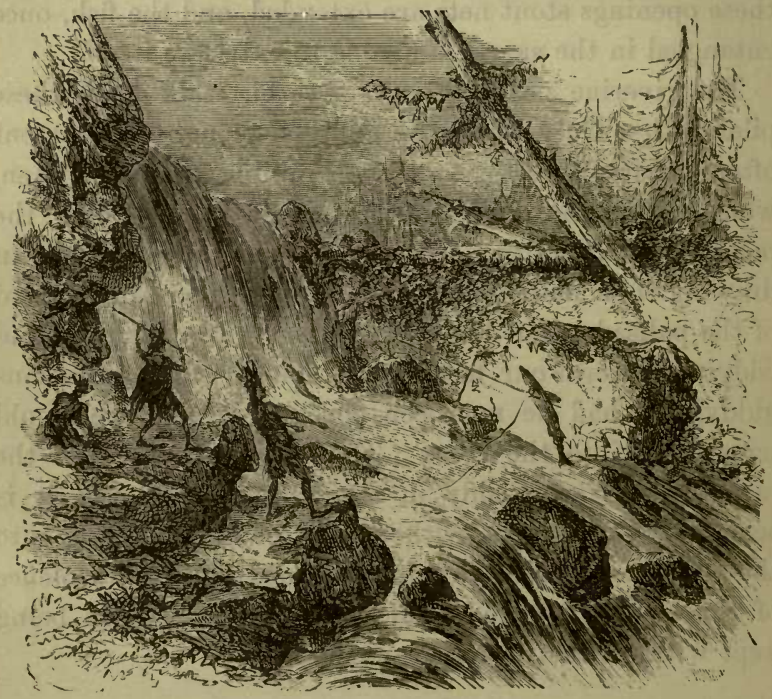

INDIANS SPEALING SALMON.

The spear of which these Indians make use is singularly constructed. It is armed with a fragment of eland's horn, perfectly straight, and about seven inches long, to the point of which an artificial barb is attached with some well-gummed thread. The iron is fastened by a stout rope, some inches long, to a great willow pole. If the fisher's aim be good, the lance-head frequently traverses the body of the fish. He afterwards detaches it easily, and leaves the salmon struggling with the rope in its body, while the fisherman grasps the pole. But for 
this arrangement, the willow rod would be broken by the weight and struggles of the fish.

Several thousand salmon are caught in a single day's fishing. A traveller, who was present on one occasion, asserts that he saw a salmon make a leap of nearly thirty feet from the point where the water began to foam up to the summit of the fall!

The fisheries of Châteaulin have been graphically described by Deslandes. Châteaulin is situated in Lower Brittany.

The fishing-station consists, he says, of a double row of closely-planted poles, which cross the river from bank to bank, and being sunk to an equal depth, afford a kind of practicable causeway. To the left, down the river, is a kind of grated reservoir, measuring fifteen feet square, and so constructed that the river current flows into it of its own impetus. In the midst of this reservoir, and almost on a level with the water, may be seen an aperture of eighteen to twenty inches in diameter, surrounded by blades of tin slightly bent, which are shaped like isosceles triangles, and open and shut easily. As a whole, they are not unlike the mouths of those mouse-traps made of iron wire. The salmon, guided by the current towards the reservoir, enters it without difficulty by pushing aside the tin plates it meets on its way, and whose bases are set round the hole. These plates, when drawn in together, form a cone, but on opening out assume the shape of a cylinder. On emerging from the reservoir the salmon enters a basin, from which it is drawn by the fishermen in a net attached for this purpose to the extremity of a pole. Their skill is so great that they never (502) 
fail to bring out immediately the particular fish on which they set their choice.

Salmon do not always come in the same abundance. If they arrive one by one they all repair to the reservoir, and from the reservoir to the basin, without ascending further; but if they arrive in numerous shoals, the females attracting the males, who redouble their strength and ardour to follow them, then they sweep through the piles which form the causeway with an incredible velocity; the eye can scarcely follow them. In this way a great number of salmon would escape the fishermen if they did not take care to embark in small flat boats and float along the causeway, spreading out nets whose meshes are extremely close ; every fish entangled in these is immediately conveyed into the reservoir, where it disgorges its food, and acquires a more exquisite flavour.

This fishery begins about the end of September, and reaches what we may call its climax towards the end of January. Prodigious quantities of fish are then captured. It grows slack in May, and entirely ceases in the month of July.

The value of salmon, either as a means of sport or as an article of food, depends largely on the part of the river where he is captured. If he is hooked near the tidal waters, he is usually in good condition for sport, and in equally good condition for the table. But if taken in the higher waters, unless he is a fresh-run fish, still invigorated by his ocean food, he is comparatively an ignoble. prey.

There is no enjoyment for the true angler, however, like fly-fishing; and the hero of a hundred fields probably 
never feels half the pleasure in his victories that the angler feels who has hooked, and played with, and captured his salmon. Away with your nets; take the pliant rod, the well-oiled line, and the cunning bait,and set out to match your skill against the salmon's instinct. You find a suitable spot-a quiet pool within hearing of the music of a woodland waterfall ; dexterously you cast your fly, and then you wait and watch. What minutes of delightful suspense! At last your patience is rewarded. A bite-a quiver-a plunge, and away up the middle of the river darts the wounded fish.

The angler hastens after her; away she goes, swift and strong, and fresh ; but the line holds true, and, spite of her leaps and plunges, gains upon her efforts. She slackens her pace; by degrees her exertions are less strenuous; as the reel is carefully wound up, she yields more and more to approaching fate ; and now her silver side brightens on the foamy stream, and, utterly spent, she surrenders herself to death.

In this way are salmon caught and won 


\section{CHAPTER II.}

THE GADIDE AND PLEURONECTIDAE.

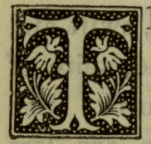

HE Gadidae family is very numerous, and includes some of the fish most important from a commercial point of view, and most valued as additions to our food supplies. It belongs to the sub-order Anacanthini (or "soft rays") of the order Teleostei; and its principal members are the cod, the haddock, the whiting, and the ling. These are popularly known (as well as the Pleuronectidae) as "white-fish." Let us deal with them in the order in which we have named them.

The CoD (Gadus morrhua, or Morrhua vulgaris) is so well known as scarcely to require description; but the distinctive features of the genus to which it belongs are the three dorsal fins, two anal fins, and a barbule beneath the chin. It is a large, plump, solid fish, frequently attaining the weight of one hundred pounds; but, whether large or small, is always nutritious and well-flavoured. Its reproductive power is enormous ; the roe of the female has been estimated to contain from four to nine millions of eggs; * a reproductive power rendered necessary to

* Leuwenhoeck counted 9,344,000 eggs in a single female. 
compensate for the havoc committed among its kind by its numerous enemies.

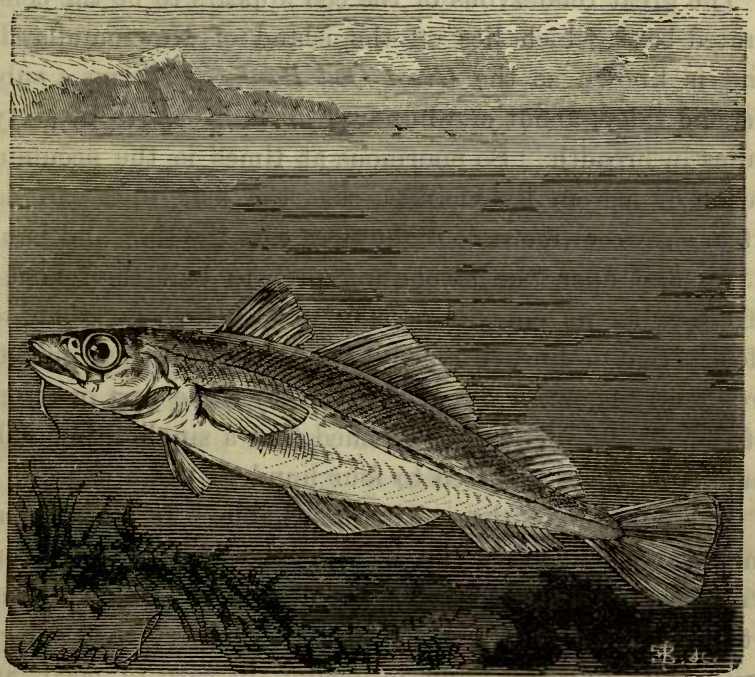

THE COD.

We meet with this valuable fish in all the waters of the northern hemisphere between the 40th and 60th parallels of latitude. It would seem, as an old writer puts it, that Providence has willed the cod should abound in the temperate and northern regions; in Denmark, Norway, Sweden, Iceland, the Orkneys, and "many parts of Muscovy," as well as in other countries where cereals cannot be cultivated on account of the inclemency of the climate. And where the fishery is successful the inhabitants not only make its products, either fresh or dried, their great substitute for food, "but sell them in large 
quantities to foreign merchants, who convey them into the interior of Europe."

The great rendezvous of the cod appears to be the celebrated bank which lies off the island of Newfoundland, and is known as the Great Cod Bank. It forms a submarine ridge, about one hundred miles in length by sixty miles in breadth. So enormous at times is the accumulation of fish in its vicinity, that the fishermen can do little else from morn to night than cast the line, and haul it in, and open the struggling prey to bait their hooks afresh with its entrails. They are packed together so closely that a line, dropped haphazard into their midst, frequently hooks a dozen or more by some part or other of their body. And it is affirmed that a single fisher will take from three hundred to four hundred fish a day.

The voracity of the cod is remarkable. It feeds upon molluses, crustaceans, the herring, the whiting, and even its own kind, besides an infinite variety of smaller fishes. It flings itself indifferently on every object that comes within its purview; not despising, in case of need, an ounce or so of lead. And, according to Anderson, nature has endowed it with a facility - which, indeed, this voracity renders almost indispensable - of vomiting, so to speak, its stomach; of turning it inside out, in front of its mouth; and after emptying it, and cleansing it in the sea-water, returning it into its proper position, after which it recommences eating. And its digestive organs act with so much rapidity that in less than six hours it assimilates any kind of food, however indigestible. We conclude, therefore, that dyspeptic complaints are unknown among the Gadidæ!

Almost every part of the cod, as Cuvier tells us, is 
adapted for the nourishment of man and animals, or for some other purposes of domestic economy. The tongue, for instance, whether fresh or salted, is a great delicacy; the gills are carefully preserved, to be employed as baits in fishing; the liver, which is large and good for eating, also furnishes an enormous quantity of oil, which is an excellent substitute for that of the whale, and useful for the same purposes; the swimming-bladder furnishes an isinglass not inferior to that yielded by the sturgeon; the head, in places where the cod is taken, supplies the fishermen and their families with food. The Norwegians give it with marine plants to their cows, for the purpose of stimulating a greater production of milk. The vertebræ, the ribs, and the bones in general are given to their cattle by the Icelanders, and to their dogs by the Kamtschatdales. These same parts, properly dried, are also em. ployed as fuel in the desolate steppes which border on the Icy Sea. The roe furnishes a table dainty, and is also used, or, more correctly speaking, wasted, as ground-bait for the sardine-fishery, as we shall see hereafter. Codliver oil (oleum jecoris aselli) is recognized as a very valuable therapeutic agent, and in the earlier stages of consumption and scrofulous affections of the joints and bones acts almost as a specific. The reader will see, therefore, that the cod is a fish which in its time plays many important parts, and will appreciate its commercial and economic value.

In Lent, and on Fridays, dried or salted cod is much eaten by Roman Catholics and others; but there can be no doubt that, to do justice to the fish, it ought to be eaten fresh. Cod-curing, however, is a staple trade at Newfoundland, and is practised also in many of the 
fishing-towns of Scotland. There is no particular difficulty in the process. First, catch your fish. Next, cure it as soon as possible after it is eaught. Split it open from head to tail ; cleanse it thoroughly from every particle of blood; drain it, after cutting away a portion of the back-bone ; deposit it with other fish, similarly prepared, in a long vat or trough, and cover it well with salt, placing a heavy weight upon it to keep it down in the pickle.

Take your fish, when sufficiently pickled, out of its repository; drain it; wash and cleanse it ; and bleach or pine it by exposure to the sun and air on the open beach. After a while it will acquire a peculiar whitish appearance, technically known as the bloom. Then your labour is over, and your dried cod is ready for the store, closet, or the market.

Ling is cured in the same manner; and both ling and cod are very palatable when thus prepared, either boiled and served up with sance, or toasted like a Finnan haddock.

Fresh cod are in season from September to March; they are in finest condition in the months of November, December, and January.

The largest cod-fisheries are carried on in the North Sea and off the banks of Newfoundland. To the latter we shall presently refer. The cod-bank at the Faroe Islands has been almost ruined by over-fishing, and the same is true of the once celebrated Dogger-Bank. There are immense supplies, however, on the west coast of Iceland, which, as yet, have been scarcely touched. At present the greater proportion of the white-fish sent to the London market comes from the North Sea fishinggrounds, and the fishery is conducted after the following fashion:- 
The modern cod-smack is built for speed, with large deep wells for carrying her cargo alive; she costs $£ 1500$ or more, and is usually manned by a crew of eleven men and boys. Her average expense per week is $£ 20$ during the long-line season, but rises considerably if she is unfortunate in losing lines. The number of these taken to sea depends on the numerical strength of the crew. Each man has a line of 50 fathoms (or 300 feet) in length; attached to it are about a hundred "snoods," with hooks already baited with mussels, and pieces of herring or whiting. Each line is laid clear in a shallow "scull," or basket, so that it can run out freely as the boat forges ahead.

When they reach the fishing-ground the men heave overboard a cork buoy, with a flag-staff fixed to it about six feet in height. This buoy is kept stationary by a rope, called the "pow-end," which is dropped by means of an anchor or heavy stone to the bottom. To the powend is also fastened the fishing-line, which is then paid out as fast as the boat sails; or, if the wind be unfavourable, is propelled by the rowers. When the line is exhausted the end is allowed to drop, and the boat is carried back to the buoy. Here the pow-end is hauled up, and the fishermen carefully haul in their line with whatever fish it may have hooked. It is not often that it comes up unproductive. The booty, however, varies. Sometimes as many as seven or eight hundred fish are caught in a single haul; seldom fewer than two hundred; but occasionally the cod are eaten off the line by dog-fish and other enemies, and all that comes up to the fisherman is a "beggarly array" of empty hooks, or a few. fragments of flesh and is skeleton or two. 
Mr. Bertram tells us, and tells us truly, that hungry cod-fish will seize any kind of bait; and for the long or great lines we have been describing, you may use bits of whiting, herring, haddock, and of almost every fish which swims in the sea. For hand-lines, however, the best bait is mussels or white whelks, and the next best lug-worms. If the reader should spend a few weeks in the later autumn at any of the coast-towns of Fife or Haddingtonshire, he cannot do better than arrange for a brief experience of "deep-sea fishing." He need not venture further out than the Isle of May, in the Firth of Forth, or the Bell Rock. Bait will be provided by the fishermen; or, if he takes his spade or three-pronged fork, he can dig up a supply of lug-worms on the sands. The lug is about five inches long and half an inch thick. The only part used as bait is the head part. Mussels or white whelks are caught by a line ornamented with a number of pieces of carrion or cod-heads, and laid along the bottom in a locality where they are known to be plentiful. The whelks fasten upon the cod-heads, are pulled up, stowed away in bags, and preserved in the well of the boat until wanted.

The English fishers largely employ the trawl-net in their white-fish fisheries, though the practice is sometimes described as injurious to the fishing-grounds.

The trawl-net is worked from a boat called a trawler; generally a vessel of about thirty-five to fifty tons, manned by a crew of five or six men and two or three boys, who frequently share both the risk and the profit on the cooperative principle. Each yawl is furnished with two masts, and three sets of sails to suit various states of 
weather. The trawl-rope is seven hundred and twenty feet in length, and six inches in circumference; and to this rope are attached the different parts of the trawling apparatus - namely, the beam, the trawl-heads, bag-net, ground-rope, and span or bridle; the whole being hauled in and worked by means of a capstan. The beam, made of heavy elm wood, is thirty-eight feet long, tapers at either end, but is about eight to ten inches thick in the middle. At each extremity is fixed an oval ring (or "trawl-head"), measuring four feet by two feet six inches. The upper part of the bag-net, which is about one hundred feet long, is fastened to the beam, the lower part being attached to the ground-rope, while the ends of the ground-rope are brought round the trawl-heads. These being allowed to fall quite slackly, the mouth of the bag-net forms a semicircle when dragged over the ground.

We trust the reader who has never seen a trawl-net is now able to form a tolerably accurate conception of one. $\mathrm{He}$ has then to think of it as fastened to the trawl-rope by means of another rope, which is of about the same thickness, and about double the length of the beam; this is the "span" or "bridle." Each end of the span is attached to the beam so as to form a loop, and to this loop is knotted the trawl-rope.

The ground-rope is usually an old rope, as, in case the net should encounter any obstruction in the water, it is desirable this rope should break, and allow the remainder of the gear to be hauled up. If the warp broke instead of the ground-rope, the trawling apparatus would be left at the bottom.

The trawl-boat, while the net is out, sails along at the rate of two to three knots an hour. 
The fish thus caught are turbot, brill, haddock, skate, sole, and other flat fish, besides occasional cod. Herrings are also trawled for on the English coast. It is unquestionably a wholesale system of fishing, yielding large returns; but, from the manner in which it sweeps the bottom clear of everything that comes within its meshes, there can be no doubt that it is injurious in many localities, -and it ought not to be allowed too near the shore. Another remedy for over-fishing generally would be to legislate for the cod, haddock, and the like, as we legislate for the salmon; and to establish a close-time for each fish, according to the occurrence of its spawning season.

We are indebted to Mr. Cobb for the introduction of a new and improved mode of line-fishing for cod. $\mathrm{He}$ fixes a small piece of cork about twelve inches above the hook; this keeps the bait afloat, and shows it more plainly to the hungry fish. The fishermen, when not busy with the great or long-lines, fish with hand-lines, each armed with a couple of hooks, and each hook suspended in the water by its little buoy of cork. A heavy weight attached to the lower extremity of the line keeps it steady near the ground; and in this way enormous quantities of cod, as well as of haddock, whiting, hake, ling, pollack, and coal-fish, are caught in British waters. It is related that four hundred to five hundred and fifty cod have been taken in ten hours by a single fisher; and off the Dogger-Bank a couple of men have caught eighty score in one day.

A great portion of the dried cod which reaches our markets is imported from Newfoundland, where codcuring is carried on as an extensive and profitable trade. 
It is shared by both English and French tishermen : the former establishing their curing-houses at St. John's, the chief town; the latter at Saint-Pierre and Miquelon Islands. The curing processes adopted by both are very similar.

A shed - a chauffunt -is raised upon piles, standing one half in the water and one half on shore; it is constructed of planks and posts, through which the air circulates freely, but roofed in with old canvas or sailcloth. Here the fish are opened and washed, the intestines removed, the liver carefully set aside; after which the split fish are packed between thick layers of salt, drained, and dried upon the open strand.*

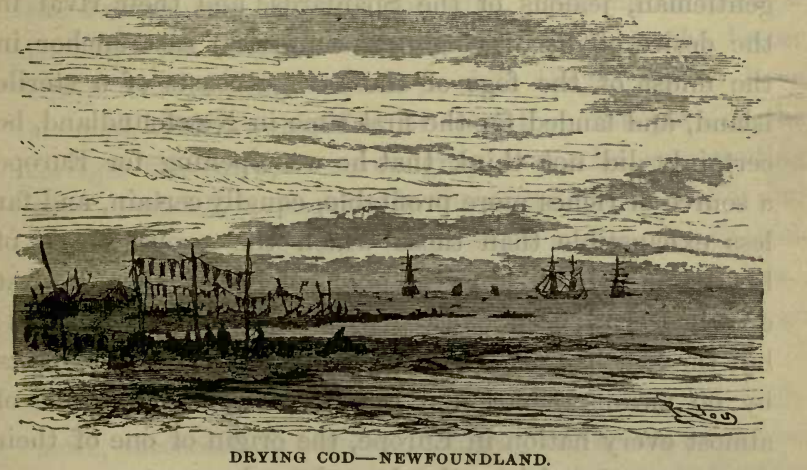

The oil pressed from the liver is received into a caldron sunk in the earth, and covered by a roof nine feet in height. When carefully prepared, and strained off into the casks, this oil is perfectly pure, almost without smell, and, literally, clear as crystal.

$$
\text { * Gobineau, "Tour du Monde," } 1863 .
$$


Drying-sheds are used in many parts of the Newfoundland coasts. They are built of stone, and so situated as to obtain all the sunshine available in that region of fogs, and to admit of a free current of air. The sun's heat is desirable, but not its rays ; and these are warded off by an arrangement of branches, which can be shifted so as to prevent them from striking directly on the fish, while the wind is still at liberty to blow upon it. The wind dries, say the Newfoundlanders, but the sun scorches.

It would be difficult to exaggerate the value of this nutritious and most useful fish. When, writes an accomplished author, towards the commencement of the sixteenth century, Gaspard de Cortereal (a Portuguese gentleman, jealous of the Spaniards, and their rival in the desire of discovering new countries) cast anchor in the midst of the fogs of the savage coasts of a sterile island, and landed for the first time in Newfoundland, he certainly did not think that he was opening for Europe a source of riches more profitable, equally certain, and far less exhaustible than those which the proud rivals of his nation derived from the mines of Potosi, the conquest of which had been effected with such effusion of blood; but the fact has so turned out, and a fish in other respects by no means remarkable has become, in the hands of almost every nation in Europe, the origin of one of their most assured and lucrative branches of commerce.

We agree with our author's reflections, but dispute his facts. The discovery of the Terra de Baccalhaes, or " Codfish-land," was made by John, not Gaspard, Cortereal ; and took place in or about 1463 , not towards the commencement of the sixteenth century. The Portuguese would seem to have commenced the cod-fishery soon after 
the discovery of the island; which, in 1496 , was rediscovered by John and Sebastian Cabot, and named Prima Vista. Early in the sixteenth century they employed in this new branch of commerce upwards of two hundred vessels ; but the sturdy English soon put in their claim for a share, and they too, in turn, were followed by French and Dutch, Norwegians and Danes, and Spaniards. Hoare, an English merchant, made an attempt to colonize Newfoundland in 1536, but failed disastrously; Sir Humphrey Gilbert, however, was more successful in 1583. About this time the English vessels employed in the fishery numbered fifty; the Spanish, one hundred; the Biscayan, twenty or thirty; the Portuguese, fifty; and the French, one hundred and fifty. Among all these, it is said,* the English were distinguished by the better equipment of their vessels; while they seem to have claimed, without objection or denial on the part of the foreign fishermen, a sovereignty over the surrounding seas - founded, it may be, on the discoveries of Cabot and Davis. Towards the close of Elizabeth's reign, the English fleet resorting to the Newfoundland banks mustered two hundred sail, and employed upwards of eight thousand seamen.

In 1623 Sir George Calvert, afterwards Lord Baltimore, succeeded in planting a colony in the south-eastern part of the island, which he named Avalon, and of which he appointed his son governor. Two years later the English fishery had assumed such large proportions that the ports of Devonshire alone employed one hundred and fifty ships, which disposed of their fish to Spain, Portugal, and Italy. In the reign of Charles II. a tax

* Harris, "Collection of Travels," ed. 1753, vol. ii 
which the French had been accustomed to pay to England for the privilege of fishing off Newfoundland was remitted, and our trade began to decline, while that of France proportionately increased. This result was necessarily displeasing to Englishmen, and a sturdy cod-merchant, in 1676, determined to give his rivals a lesson. Taking with him one hundred and two twenty-gun ships, and a couple of ships-of-war, he succeeded, in spite of French fortifications, in capturing as many cod as yielded him the noble sum of $£ 386,400$.

What France failed to gain by open force, she next attempted to win by stealthy encroachments; and though the Treaty of Utrecht in 1713 had formally recognized Newfoundland as a British possession, she had made such progress that in 1721 she had no fewer than four hundred vessels trading in cod, and had almost driven us out of foreign markets. After a long series of aggressions, she consummated her audacity in 1762 by seizing upon the island; only, however, to be driven out of it in the following year. For another century the fishery continued to be a source of contention between the two nations; but in 1857 the English and French Governments executed a convention by which certain privileges were surrendered and given on both sides, and the French obtained permission to cure their fish on the small islands of St. Pierre and Miquelon, with the understanding that they should erect no fortifications.

All about the cod-fishery at Newfoundland, we may learn from the elaborate pages of Lacépède, who begins by informing the reader that nets were first employed till it was found that these were liable, not only to be rent 
and shattered, but to be swept away by " ocean-monsters" imprisoned in the mesh-work; when the fishermen adopted the plan, now universally pursued, of "long-line" fishing. The depths to which these lines are sunk varies with the time of year,-being from five to twenty fathoms during the season of shore-fishing, which begins in April; and from thirty to forty fathoms when the crews follow the fish as they recede from the shore, and continue to take them at these great depths until December, when winter arrests their energy. In spring the traders approach the banks as early as practicable, with the view of securing a good station; and as soon as the vessels have cast anchor, the surrounding waters literally seem alive with the boats sent out to procure bait. Various kinds are used, but, owing to the voracity of the cod, all succeed; it will swallow not only every kind of fish and shell-fish, whole or in fragments, fresh or salted, but even bits of wood or red cloth.

In reference to this voracity, Mr. Badham tells a curious story. A fish, which once on a time furnished the University of Cambridge with a religious feast, was the occasion of a tract entitled Vox Piscis, or the Book Fish, containing three treatises, found in the belly of a cod in Cambridge market, Midsummer Eve, 1626. It is said that this learned fish was caught in Lynn Deeps, and carried to the Vice-Chancellor by the beadle on the discovery of a book within it. As it made its appearance at the Commencement, the very time when good learning and good cheer are expected, it was quaintly remarked that "this sea-guest had brought his book and his carcass to furnish both." But, as Badham observes, it is to be hoped the learning he brought in his belly was (502) 
not so out of season as he himself must have been at midsummer!

In spite of the rivalry and contention between the fishing-crews, they all adhere rigidly to certain bye-laws devised for the common good. Among these it is provided that the man who catches fewest fish,-a point easily settled by counting the tongues,- - shall clean the deck, and throw the heads overboard; and to avoid a task so cold and so fatiguing, the tars are all eager to anticipate each other, and to apply themselves as early as may be to the morning's work. No sooner has a fish been hooked and hauled up-and sometimes, in his greediness, he is caught by two fishermen at once, when he falls to the lot of him who hooks nearest the eye-the captor removes the tongue, and hands him to a second operator (in French, the décolleur), who passes him on to a third. He, cutting open the body, and cleansing it of the liver and intestines, puts him into the hands of the trancheur, that he may remove with his exceedingly sharp knife the ribs and upper part of the vertebræ, and then either split him open from the head to the caudal fin, and dress him a plat; or else from the gills to the anal fin, a la rond. Next, having been carefully sponged and dried, he is handed over to the salter, who rubs the body with onesixth of its weight of salt, and then gives it over to the last man, who arranges all the carcasses in rows, and finally packs them in barrels.

The first part of these complex operations is described by Lacépède "with the precision of an historian describing the execution of some state prisoner." He says :-

"L'étêteur saisit d'abord la morue, en place à faux la tête sur le bord de la table, la cerne avec un couteau à 
deux tranchans, nommé couteau à étêter; quand la morue est décollée, l'étêteur enlève toutes les entrailles, et ayant fini son opération il pousse le corps à l'habilleur, qui le saisit de la main gauche et qui tient de la main droite le couteau à habiller, dont les fonctions consistent à l'ouvrir depuis la gorge jusqu'à l'anus."

All the fish, however, are not salted; stock-fish are simply dried in the sun, and a considerable quantity are brought to Europe alive in welled vessels.

Stock-fish, a name also given to ling and haddock when similarly cured, are so called, either because they are stretched across transverse sticks in the drying, or because they are as hard as a stick, and require to be bastinadoed before they are dressed.*

The supplies of cod poured into our British markets we have no means of estimating; but some years ago a calculation was made of the quantity sold in Billingsgate in the course of a year, which may afford the imaginative reader a starting-point for any computations he may feel inclined to indulge in. Of live cod, it was reckoned that 400,000 , weighing $4,000,000 \mathrm{lbs}$., were annually disposed of ; of dried salt cod, 1,600,000, weighing 8,000,000 lbs. ; and of barrelled cod, 15,000 barrels, each containing 40 fish, and weighing in the whole $4,200,000 \mathrm{lbs}$. We may assume that these figures have of late been largely exceeded; and if the reader remembers that extensive supplies are sent direct to Glasgow, Edinburgh, Hull, and Liverpool, he will find occasion to marvel at the immense extent and productiveness of the cod-fishery.

The wealth of Newfoundland lies in the surrounding

* Badham, "Ancient and Modern Fish-Tattle," p. 343. 
waters, which annually yield rich harvests to its bold and experienced fishermen. Especially do they furnish an apparently inexhaustible resource in their supplies of cod; and, accordingly, the cod-fishery employs the greater number of the population. Some idea of its value may be gained from the fact that the annual average export for the last twenty years has amounted to one million quintals, or hundredweights, realizing fully $£ 900,000$. But even these figures do not sufficiently illustrate its extent, for they do not include the quantity-about 150,000 quintals-used every year in Newfoundland itself, nor the vast haul of the French, Nova Scotians, Canadians, and Americans, who constantly resort to the Newfoundland banks. Probably, the total would in this case rise to $1,650,000$ quintals, equal in value to $£ 1,485,000$. And then we must add the value of the oil extracted from the liver of the cod-fish, which, estimating the yield at $1,250,000$ gallons, would be $£ 200,000$.

Such figures may well astonish the reader; but his astonishment will increase when he is told that, notwithstanding this enormous annual drain-a drain which has continued for upwards of two centuries - the supply seems inexhaustible; and that while the whale and seal fisheries have largely declined, while the herring-fishery is subject to considerable variations, the cod-fishery shows no symptoms of diminution, and annually responds with recuperative energy to the demands made upon it.

We have already glanced at the various processes employed in the capture of the cod. The Newfoundland fishermen adopt the hook and line, the seine-net, the bultow, and the American trap-net.

The seine does not differ from that employed in other 
quarters. It is neither more nor less than a large net, which is flung into the midst of a shoal of fish when opportunity offers. It can be used only near the shore, or some convenient place for hauling it in. The moment the "finny spoil" is entrapped, both ends of the seine are brought ashore and made fast, and the fishermen haul in the bottom until it touches the ground, so as to enclose the fish completely, and prevent their escape. They are then taken out of the net with all possible speed, split open, salted, and packed in barrels; these operations being effected generally on a kind of stage or platform erected for the purpose, but sometimes in the fishing-boat. The net varies in size from 70 to 120 fathoms long, and from 50 to 100 feet deep, according to the character of the locality in which it is used. An average haul amounts to about 200 quintals; but in the largest seines, under favourable circumstances, as many as 1000 have been collected.

Some experienced fishermen strongly object to the employment of the seine, on the plea that its use in any locality has the effect, after a time, of driving away the fish ; and they point to places formerly celebrated as the haunts of immense shoals which the cod have of late years deserted. But if the cod have been spirited away, it is not perhaps the seine that should be censured, but its accompaniments - the noise and motion of the men as they pass to and fro, and the throwing overboard, or from the stage-heads, of the entrails and heads of the fish after they have been split and headed. At all events, the seine is so simple in its use, and so remunerative, that it will not be abandoned except under strong legislative compulsion. 
The Newfoundland fishermen, however, are excoodingly partial to the hook and line. They sally forth in their wellbuilt boats, generally in crews of ten to twelve, but sometimes singly. The bait employed is, in the early part of the season, herring, then eapelan, next the squid, and later in the year herring again. Fish thius eaught are superior in quality to those captured by the seine; for in the latter ease, when a large haul is made, much of the fish falls into a very indifferent oondition before it ean be earried ashore, and consequently, when cured, will not bear eomparison with the produce of the hook and line.

The "bultow" process of fishing may be thus deseribed. Several short pieces of line are attached to a long line at intervals of four to eight foot. To these short pieces hooks are fastened; and when they have been baited, the whole apparatus (that is, the "bultow") is dropped into the water, and allowed to sink. Mooring lines, with buoys, indioate its position, and provide a ready means of taking it up when wanted. On the celebrated Nowfoundland banks the bultow is almost exclusively adopted, and it invariably seoures the finest and largest fish. An opinion is put forward, that if no bank fishing were permitted the shore fishing would be much more profitable; but many fishermen eontend that the fish eaught on the banks belong to a different family, as it were, from those eaught on the shores, and would in no eiroumstanees desert their traditional "feeding grounds." This is probably true, for there ean be no doubt that fish in their choiee of resting places are governed by certain fixed laws of instinot or eustom. The fishing-vessels which frequent the banks are of all sizes-from 50 up to 500 tons - the 


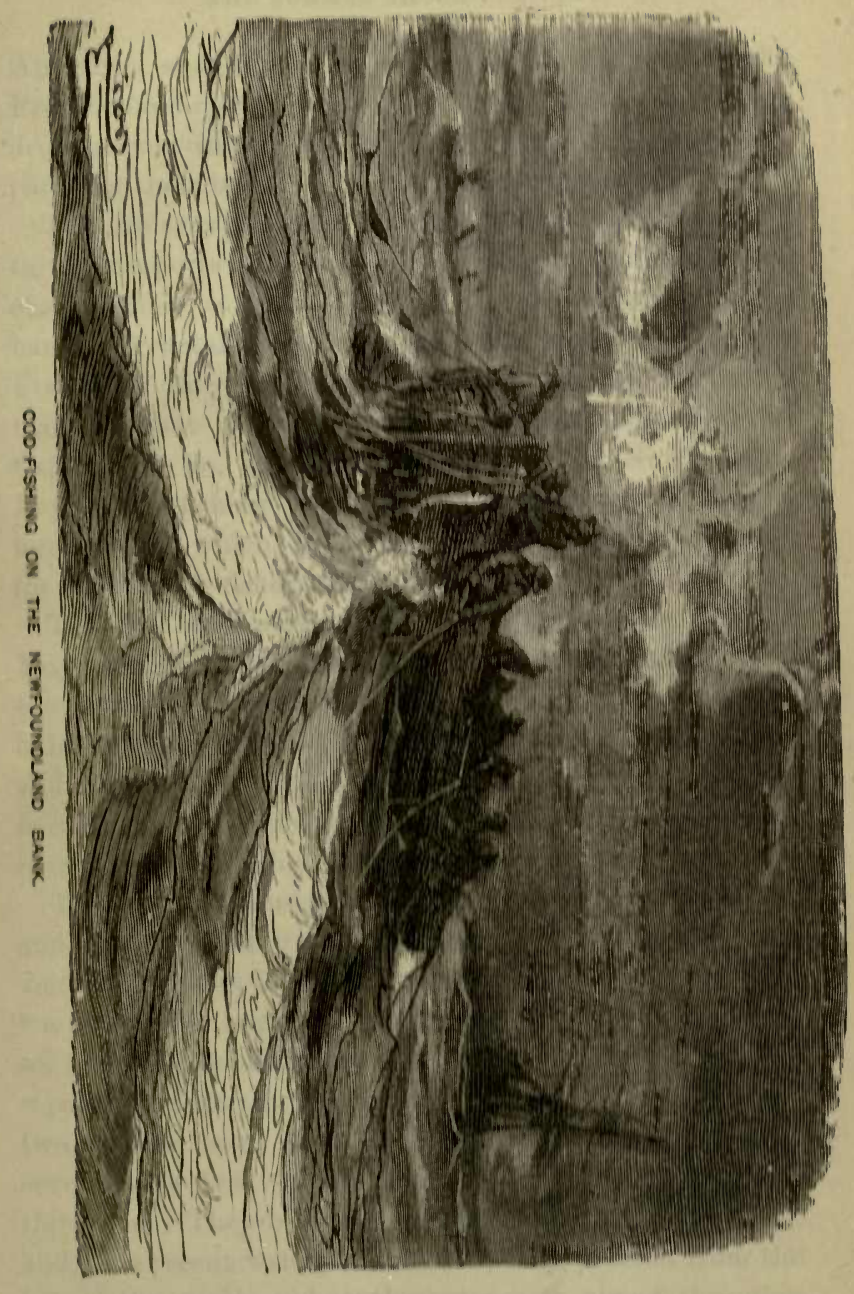




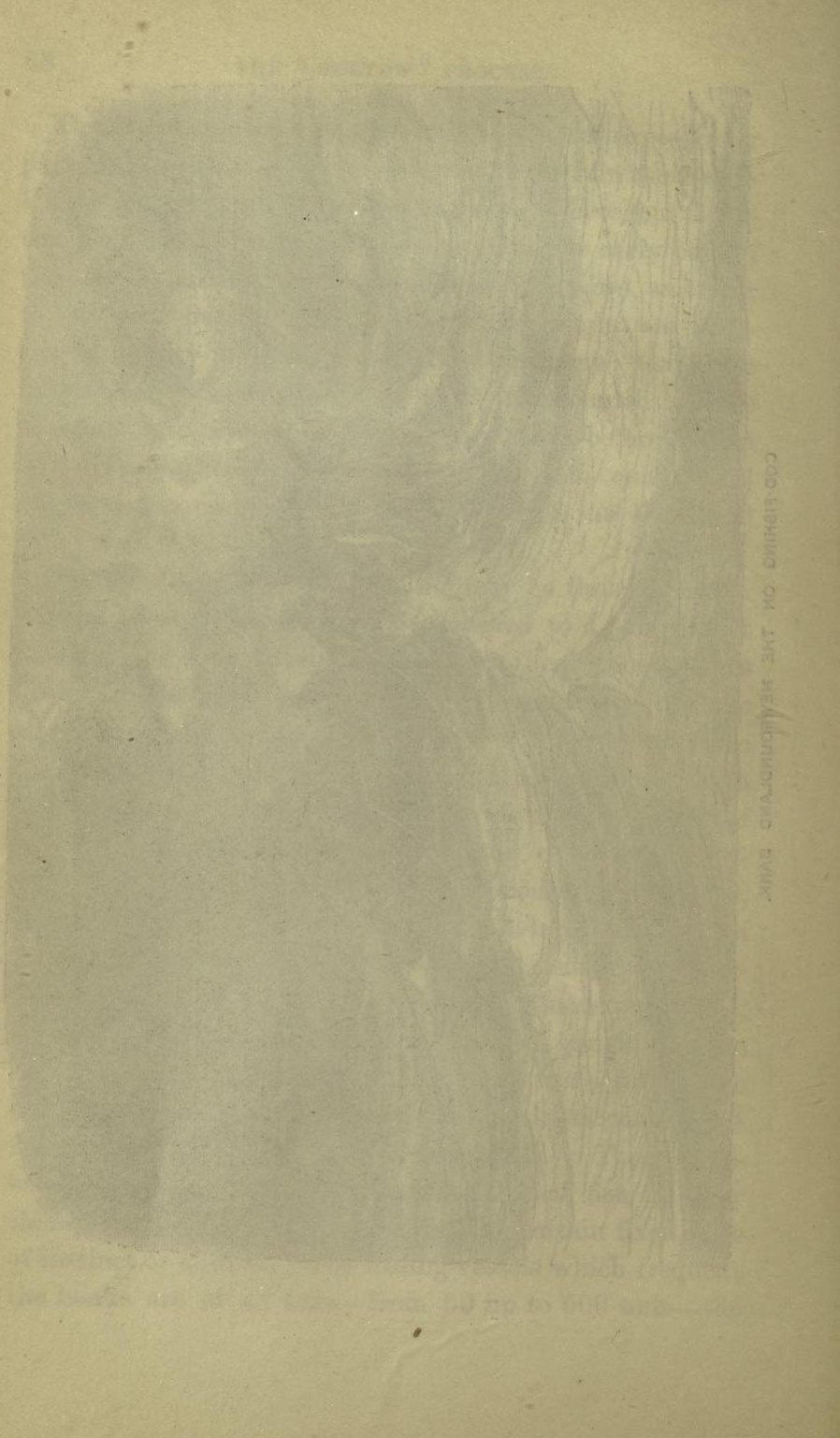


American and Canadian being the smallest, and the French the largest. On arriving at the fishing-field they drop anchor, using hemp instead of ehain cables, and despatching their boats to lay down and bait the bultow.

The Americans and Canadians, when loaded, proceed to the sea-ports of Nova Scotia or Newfoundland to discharge their cargoes, after which they return to the banks,-generally making three trips in a season. The French, if they fish on the northern part of the banks, make for that part of the French shore which begins at Cape St. John, the northern headland of Notre Dame Bay; those fishing further south proceed to the Miquelon Islands, which, by treaty, were reserved exclusively for the French fishermen.

The first appearance of the cod-fish is made early in May, and the fishing season lasts until November, when the shoals pass away into deeper waters for their winter habitat. But on the north-west coast of Newfoundland, and particularly in the vicinity of Cape Ray, the fishery is carried on "all the year round," and even in the winter is of a very profitable character.

The summer shore fishery is prosecuted in skiffs, punts, and the so-called "western boats." The punts do not venture far from land; and as their crew consists only of "a man and a boy," it would not be safe for them to do so. The skiffs are generally decked, well-equipped, and capable of riding out a tolerably severe gale. They carry two to four men. The "western boats" are manned by seven to twelve veteran "salts," and usually fish with the seine. They belong principally to Conception Bay; and, as a recent writer informs us, they proceed from the bay to the south and south-west coasts, always bringing 
to their homes their catch when their boat is loaded, and returning again to any place where they may find the best fishing. They prosecute their laborious avocations until the month of July, when, after leaving the fish to be dried and salted by their wives and families, they make all sail for the Labrador coast to join in the herringfishery. Whether a "life on the ocean wave" is quite so joyful and pleasurable as the poets represent, may well be doubted; but it is assuredly the life to which these hardy and adventurous fishers devote themselves. It is their custom, we may add, to dispose of the day's catch with undeviating regularity, all hands setting to work to split and salt the fish, and stow them away in the hold. "Carpe diem" is a motto for which they have a great admiration. Cod-fish always "cure" most satisfactorily when split and salted as soon as possible after being caught. Every hour's delay injures their quality.

The fish are generally allowed to remain in salt for fully ten days, then washed, and afterwards dried on the beach or on hurdles, small boughs, or sticks. Fish dried on hurdles, or boughs, are always the best, the wind passing freely over and under them, and drying them thoroughly. The wind, it should be observed, is more eflectual than the sun as a "desiccating agent;" and, indeed, in days when the wind is not blowing, the hot sun injures the fish-burning it up, and destroying its succulent properties. The fish-curing process is much influenced, therefore, by the weather. With warm, westerly winds it may be finished in a week; often it takes much longer.

We have already spoken of the method of extracting the oil, which adds so considerably to the value of the 
fish. The common cod-oil of commerce, we may mention here, is obtained from the liver, which, when the fish has been split, is taken out, stowed in puncheons, and exposed to the heat of the sun. The oil, as it distils, is drawn off into casks, and sells at about $2 \mathrm{~s}$. $6 \mathrm{~d}$. to $3 \mathrm{~s}$. per gallon. Cod-liver oil, so highly esteemed as a therapeutic, is procured by a cleaner and more costly process. The livers, after being carefully washed, are subjected to the action of steam or boiling water; and the oil then given forth is filtered through bags of different textile materials, until it is perfectly clear and free from any extraneous admixture. This oil is worth about 6 s. per gallon.

An extensive cod-fishery exists along the Labrador coast, and in the month of June a flotilla sails from the Newfoundland bays-St. John's, Conception, Trinity, and Bonavista - to take part in it. The vessels comprising it range from the smack of 30 tons to the schooner of 180 or 200 , and the crews necessarily vary in numerical strength. As they frequently take with them their wives and families, it is not uncommon for one of the larger vessels to have as many as two hundred souls on board. Nor are the women and children useless. While the men catch the fish, and split, and wash, the women head, and salt, and dry it. They do not all belong to one crew. A fishing crew, or gang, or company - the reader may choose which term he likes-consists, at the most, of nine or ten men, assisted by three or four girls, or it may number only two or three men and one girl. Consequently, several crews or gangs are included in the complement of each vessel. A crew is under the 
direction of a head man, called a "planter," who provides all the supplies necessary for the voyage. His hands are generally sharers in the speculation, and are remunerated by one-sixteenth or one-twelfth of the haul made by the seine-net-which is used in the early part of the seasonand by one-half of the catch, when the hook and line are employed. The planter provides boats, nets, hooks, lines, bait, salt, and provisions, and also defrays the expense of smoking the fish. He gets all the oil, which is considered to pay for the salt, and eleven-twelfths, or thereabouts, of the haul, and one-half of the catch in the boats. $\mathrm{He}$ also receives from each fisherman $20 \mathrm{~s}$. to $60 \mathrm{~s}$. as berth-money. On the other hand, he pays the wages of the boys and girls; and it seems evident, when his expenses and risks are taken into the account, that he does not fare so well as his men.

These details we borrow from an interesting article in the Scotsman; and the writer, who is apparently well informed, adds that the sharemen often make considerable wages, - as much as $£ 73$ in some seasons, and seldom less than $£ 35$. The men engaged to split and salt the fish receive from $£ 18$ to $£ 27$, and their foreman-if the post is not taken by the planter himself-from $£ 28$ to $£ 40$. The old men and boys are paid from $£ 12$ to $£ 18$, and the girls from $£ 4$ to $£ 10$; the period of service extending from early in June until the 31st of October.

The Labrador cod-fish is not equal in quality to that caught in the Newfoundland waters. It does not cure so hard, and is less nutritious; hence its price is from 2s. $6 \mathrm{~d}$. to $5 \mathrm{~s}$. per cwt. under that of the Newfoundland cod. Many of the fishermen of Trinity, Bonavista, and Notre Dame bays, carry on the Newfoundland shore-fishing 
until July, and then sail for the Labrador coast, where the spoil is most abundant in the fall of the year. These men preserve their catch in salt, and bring it home to be washed, dried, and cured.

Towards the end of October, when the dark shadows of approaching winter rapidly gather over the sombre Labrador coast, and the huge ice-fields accumulate in the northern waters, the fishing-fleets forsake their stations, and steer for the various harbours of Newfoundland to which they belong.

From Labrador a great quantity of fish is exported to the European markets, according to the demand. The "hard dry cured" goes to Spain, Portugal, Italy, and other parts of the Mediterranean basin; the softer and rich "full fish" to England and Scotland. The fish not thus got rid of, and the cod-oil, are brought to Newfoundland, where they are sold to the merchants, and shipped off at favourable opportunities.

Most of the medium-sized and best-cured fish is sent to Brazil in "drums," each containing 128 lbs. To the West India Islands and Demerara it is despatched in large casks, each containing $480 \mathrm{lbs}$., or in "drums" of the same weight as those sent to Brazil. To British and European ports the fish is shipped "in bulk," and makes a "good, safe, and buoyant cargo."

A considerable stock of fish is kept in hand until after the close of the year, and then exported to Roman Catholic countries, so as to reach the markets before the Lenten season begins, when the demand is necessarily very active. Thus the Roman Catholic custom of eating salt fish in Lent proves a source of profit to the Protestant fisher-folk of Newfoundland. 
Fish-cargoes vary greatly in extent, according to the burden of the vessels employed in the trade. To Brazil they range from 2400 to 3500 drums; to the West Indies from 350 to 600 casks ; to England and Spain, and the Mediterranean ports, from 2500 to 5000 quintals. Nearly all the cod-liver oil finds a market in England.

The fish and fish products exported from Newfoundland in 1873 were of the value of $7,569,497$ dollars, or, in round numbers, $£ 1,515,000$. We are referring here to their value in Newfoundland; their value in foreign markets it is difficult to estimate, from the great differences existing in price, and the variations of the demand; but allowing that the trader was content with a profit of one-fifth, the total realized would be $£ 1,800,000$. Probably it is no exaggeration to say, if we include the local consumption, and the captures of the French and American fishermen, that the Newfoundland fisheries add to the wealth of the civilized nations engaging in them an annual sum of $£ 3,000,000$.

We have omitted to mention a portion of the cod-fish which figures in the island's exports-namely, "cod-roes." What, the reader will ask, can be made of these? We answer: the roe is pickled, barrelled, and exported almost entirely to France, where it is in great demand for groundbait in the sardine-fishery. Here a digression is necessary. We shall have to speak of sardines in due course, but we may record that no fewer than 13,000 boats on the coast of Brittany are employed in the capture of sprats, young herrings, and young pilchards, which are duly cured and tin-cased as sardines. It is estimated that $10,000,000$ of the well-known hermetically sealed tin boxes are annually sent from Brittany to all parts of 
the world. This fact will enable the reader to form a conception of the vast quantity of cod-roe required as bait for the immense number of so-called sardines these boxes must contain; and he will not be surprised to hear that the French expend a yearly sum of $£ 80,000$ in its purchase. It is a curious reflection, that the sardines we discuss with so much relish at our breakfast-table, in London or Edinburgh, were caught off the romantic coast of Brittany with cod-roe bait brought from the shores of Newfoundland!*

The cod-fisheries of Norway are very extensive. The Loffoden Islands, in the winter, are the centre of a really important campaign, vigorously carried on by the stalwart descendants of the Norsemen against the ill-fated Gadidæ. Upwards of 3000 boats and 16,000 men are engaged, and the produce reaches nearly $20,000,000$ of cod-fish - a large proportion of which are despatched to the British markets.

On the coast of Faroe an important cod-fishery has been thriving for many years, and the Shetlanders alone send thither a fleet of between fifty and sixty smacks and schooners; well-formed boats, built and equipped on the most improved principles, and manned by no unworthy descendants of the old Norse Vikingir. Each smack carries a crew of about fourteen men; so that the Faroe fishery employs about seven hundred and fifty Shetland seamen, besides a large number of men, women, and boys profitably engaged in curing the fish at home. The fish-

\footnotetext{
* A considerable portion of the roe thus used is imported, however, from Norway.
} 
ing-season begins early in April, and ends about the middle of August; during which time each vessel generally accomplishes three trips to Faroe. The fishingground is either "on the coast,"--that is, in the bays, and in the channels which intersect the archipelago,-or "on the bank," a famous resort for cod, about sixty miles south-west of Faroe. This bank is about forty-five miles long by thirty broad.

The fish are caught on "hand-lines," of two hooks each, baited with various kinds of shell-fish. The "buckies," as those chiefly in use are called, are dredged before the smacks leave Shetland, and preserved alive in small perforated boxes, hung alongside the boat, or at all events kept in a position that allows the free passage of saltwater. Some of the smacks, however, are furnished with wells, which has been found a capital arrangement for keeping the "buckies" in good condition, as well as for carrying the cod alive to market. But Dr. Cowie states that it is only on rare occasions, as at the end of a season, when there are other reasons for sending a welled smack to a southern port, that live cod are sold. "The ordinary practice is to gut, split, and wash the cod as they are caught, and stow them in the hold amongst salt. They are further cleaned, scrubbed, pressed, and ultimately dried on the beach, after the smacks return home." We are inclined to believe, however, that a greater preference is every year being given to welled smacks, and that the quantity of live cod sent to the markets is constantly on the increase.

There are three kinds of fisheries pursued by the hardy Shetlanders : the deep sea or ha'ag, to which we are now alluding, the coast, and the herring, - the last being al- 
most entirely in the hands of Dutch vessels. As for the coast fishery, it lasts throughout the year. But the great and all-important fishery is that which centres in the cod. We need not repeat the details already given, but some account seems desirable of the fishery carried on at a distance of from twenty to forty miles from the Shetland coast. The boats engaged in it are not so large as those which fish off Faroe. They are Norway yawls, with eighteen feet of keel and six feet beam, and manned by no more than six men. Each has between seven and eight miles of line and one thousand hooks. The lines are set in the evening; and if the first haul is not successful, they are generally baited again, and a second venture is made. Sometimes the men remain out for a couple of nights-living upon oat-cakes and water, or, occasionally, on fish and potatoes.

When the fish are brought to shore, they are handed to the curer, who weighs and keeps an account of the spoil. Then they are split up and boned; washed in sea-water; and put into a vat, with alternate layers of salt. After a couple of days they are taken out, washed a second time, and piled into stacks for a day or two. Next they are spread out on the open beach until thoroughly dry, after which they are stored up in airtight sheds, to be shipped for market when opportunity offers.

These light yawls are ill-fitted to brave a heavy storm, and therefore seldom a season passes without some sad tale of disaster. And when a boat is lost, the calamity is all the more severe because its crew are usually members of the same family. Ah, little do we " who sit at home at ease" think of the suffering experienced and the peril 
confronted by the brave men who go down to the deep in ships !

The HadDock (Gadus, or Morrhua Aglefinus) enters more largely into general consumption, perhaps, than even the cod, and its flesh is more digestible, more nutritious, and of far superior flavour. It is what we should call a sociable or cosmopolitan fish, for it figures on the table of the artisan or peasant as well as on the splendid board of the wealthy Apicius ; and it is as abundant in American as in European waters. Observe, however, that it keeps to high latitudes, and is found neither in the Baltic nor the Mediterranean. It frequents our British coasts in immense numbers, though different species appear at different points, and all are not of equal excellence. Those caught on the east coast and in Dublin Bay bear away the prize for "good eating." Owing to over-fishing, the haddock is not found so near the shore as of old, but vast shoals still inhabit the deep waters, and are caught both by trawl-nets and lines.

The haddock, like the cod, has three dorsal and two

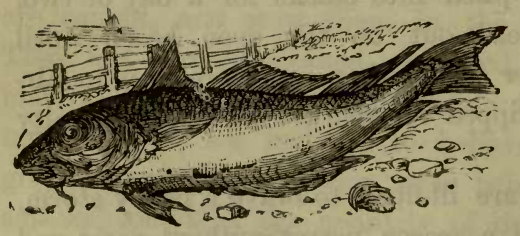

THE HADDOCK. anal fins, and a barbule at the point of the lower jaw. It is brown on the back, silver-white on the belly; the lateral line is black, and behind each of the pectorals is a black spot, the two sometimes extend. ing so far as to meet on the back. An absurd legend attributes these spots to the finger and thumb with which 
St. Peter held the fish when he took from its mouth the tribute-money; as if a marine fish, like the haddock, would be found in the fresh-water lake of Gennesaret!

Formerly it was believed of the haddock, as of the herring, that it was a migratory fish, which appeared periodically in immense shoals about mid-winter; but it is now known that it frequents certain localities in the deep waters, and draws nearer the coast at the approach of its spawning-season. It is said, but we cannot ascertain on what ground, that in stormy weather it refuses every kind of bait, and retires for shelter among the marine plants of the ocean-bed in its deepest parts.

The haddock is not a large fish : its usual weight is about five pounds. Enormous quantities are converted into "Finnan haddies," - a luxury of the breakfast-table which is popular in every civilized country. Genuine Finnans, however,- that is, haddocks smoked by'means of peat-reek,-are, unhappily, limited in number, and the British householder is compelled to feast upon inferior, but, sooth to say, very palatable imitations.

To make the trade a profitable one, says Mr. Bertram, they are cured by the hundred in smoking-houses built for the purpose, and are smoked by burning wood or sawdust-which, however, does not give them the proper gout. In fact, the wood-smoked Finnans, except that they are fish, have no more the genuine flavour than Scotch marmalade would have if it were made from turnips instead of bitter oranges. Fifty years ago it was different; then the haddocks were smoked in small quantities in the fishing villages between Aberdeen and Stonehaven, and entirely over a peat fire. To the peat-reek they owed the peculiar flavour which secured their popularity. The 
fisher-wives along the north-east coast used to pack small quantities of these delicately cured fish into a basket, and give them to the guard of the "Defiance" coach, which ran between Aberdeen and Edinburgh, and the guard brought them to town, confiding them for sale to a brother who dealt in provisions; and it is known that out of the various transactions which thus arose, individually small though they must have been, the two made, in the course of time, a handsome profit. The fame of the smoked fish spread far and wide; so that cargoes came to be despatched by steam-boat; and now the much-coveted edibles are carried by railway to all parts of the country, the demand being so great that, in order to meet it, almost any kind - of fish is substituted for the original haddie, and various devices are adopted to imitate the colour and flavour. Good smoked haddocks of the Moray Firth or Aberdeen cure cannot be obtained at the present time, even in Edinburgh, under the price of sixpence per pound.*

The Finnan haddock obtains its distinctive name from Findon or Finnan, a small fishing-village in the parish of Banchory-Devenick, about six miles to the south of Aberdeen. Here the curing process was first adopted, or else was executed so dexterously as to secure a special celebrity for the fish sent out for sale from this port.

At the magnificent coronation-feast of Katherine of Valois, celebrated on the 24th of February 1420-21, - a feast which, according to Fabyan, was "all of fish, for, Lent being entered upon, nothing of meat was there, saving brawn served with mustard,"- - figured stewed eels, and bream of the sea, and crayfish, lampreys, roasted

* Bertram, "Harvest of the Sea," p. 290. 
porpoises, carp, turbot, tench, and, before all and above all in delicacy and digestibility, whiting.

The Whiting (Merlangus vulgaris), which well deserved to adorn a royal banquet, is one of the most valuable

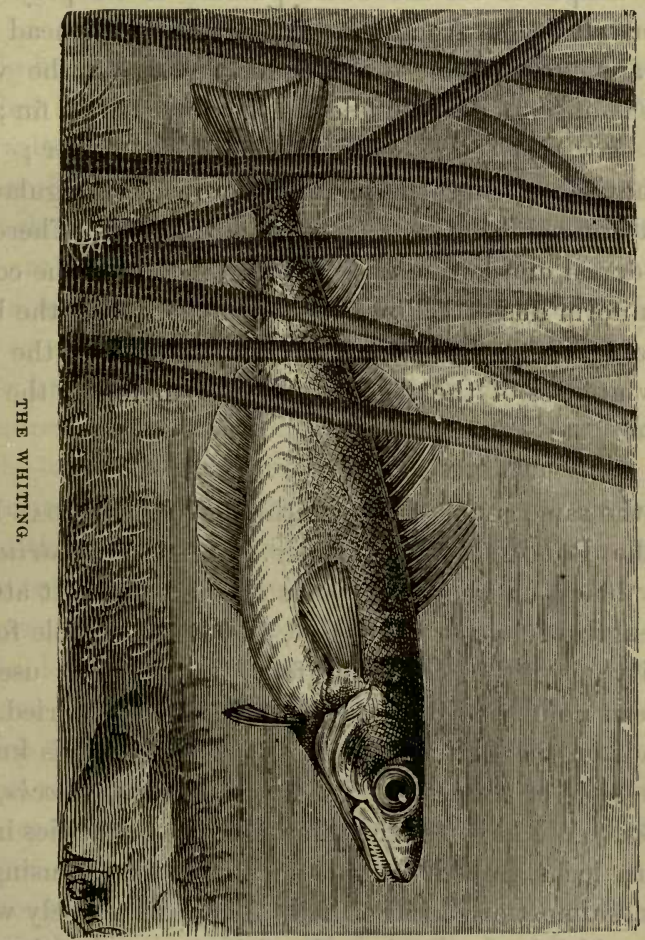

of the Gadidæ, and, fortunately for English fish connoisseurs, it abounds on our British coasts. Not much, however, is known of its natural history. It deposits its 
spawn in March, and the eggs appear to occupy about forty days in hatching.

The whiting differs from its congeners in having no barbule on the nether jaw, and in its slenderer form, which adapts it for the swift pursuit of its prey at a greater elevation from the sea-bottom. Its head and body are compressed; the deepest part is at the vent, which is opposite the middle of the first dorsal fin; the upper jaw projects slightly beyond the lower; both jaws have long sharp teeth, and there is a triangular set of teeth on the palate. The scales are small. There are three dorsal and two anal fins. On the back the colour is a uniform dusky yellow, paling on the sides ; the belly is silvery white, - to which circumstance, or to the delicate whiteness of the flesh, is due the name of the fish, whiting.

To the same genus as the whiting belong the CoAL-Fish and the Pollack. The former (Gadus carbonarius) is nearly black on the upper parts of the body. It attains the length of two or three feet, and is remarkable for its voracity; is rather coarse as food, but is much used in northern countries both fresh and salted, or dried. It abounds on the British coasts. In Scotland it is known as the sethe or saithe, and its fry as podleys, sillocks, and cuddies. We have caught them in large quantities in the western lochs, from August down to November, using the rod and almost any kind of bait. They are scarcely worth the trouble, however; but the fishermen take them for the sake of the oil obtainable from the liver.

The Pollack (Merlangus pollachius), known in Scotland as the lythe, is far superior in flavour to the coal-fish, 
especially if caught young. It is readily taken withartificial flies, - the best being a bit of white worsted or a white feather tied to a common bait-hook. It has a longish body, a long under jaw, a forked tail, and three dorsal fins.

We have no space to descant on the LiNG (Lotu molva), another of the Gadidæ, which is highly valued both fresh and salted;* or the Donse (Morrhua callarias); or the Biв or Pout (Morrhua lusca); nor is it necessary, since their characteristics differ little from those of the cod, and they are captured by the same means. But we must devote a few lines to the HAKE (Merlucius vulgaris), if it be only to express our regret that so valuable a fish is not better known, or, at all events, better appreciated. It is a denizen of our British seas; and fine specimens are caught off the Devonshire coast, where, from the havoc it accomplishes among the herrings and pilchards, it is called the "herring hake." It is generally taken by lines or by trawling, and is frequently dried and salted under the general name of "stock-fish."

The hake has no barbules, but carries two dorsal fins and one anal. It is sometimes identified with the ancient sea-fish asellus - that is, the donkey-fish, of which Pliny and Alian record such wonderful stories; but, more probably, the sea-tench (Phycis Mediterranea) should have that honour.

The hake, like all the Gadidæ, is gregarious. His greediness is excessive, and he will demolish a dozen clupeans, or a young codling, or one of his own kind, in an incredibly short period. He is found in the Mediter-

\footnotetext{
* The burbot, or coxey-fish, is a fresh-water ling.
} 
ranean, and figures conspicuously in the fish-markets of Naples, and in Irish waters he appears in immense shoals. Galway Bay is called the "Bay of Hakes." In Mount Bay, Cornwall, forty thousand have been caught in a night.

We now pass to the Pleuronectida, or flat-fish. These consist of two distinct classes : in one, as in the skate, the body is flattened downwards or vertically; in the other, as in turbot, plaice, sole, flounder, it is compressed from side to side. They are designated Pleuronects, or side-swimmers, because they usually move through the water on one of their flat sides. The genera are numerous, and these are unequally distributed in different parts of the globe, and in greater or less variety, according to the latitudes,diminishing towards the north. In England, according to Yarrell, there are sixteen species; in the parallel of Jutland and the islands at the mouth of the Baltic, thirteen; on the coast of Norway, the number is reduced to ten; at Iceland, to five; whilst Greenland possesses three species only.

We shall give, in our description of the Pleuronects, the first place to the regal TÚBвOT (Rhombus maximus), which has always enjoyed a distinguished gastronomic reputation.

Need we describe it? Is there any one ignorant of its peculiar appearance? Will not all our readers be aware that it has (as, in truth, its Latin appellation signifies) a rhomboidal body, with a dorsal fin commencing immediately above the upper lip, and stretching almost to the tail-fin? 


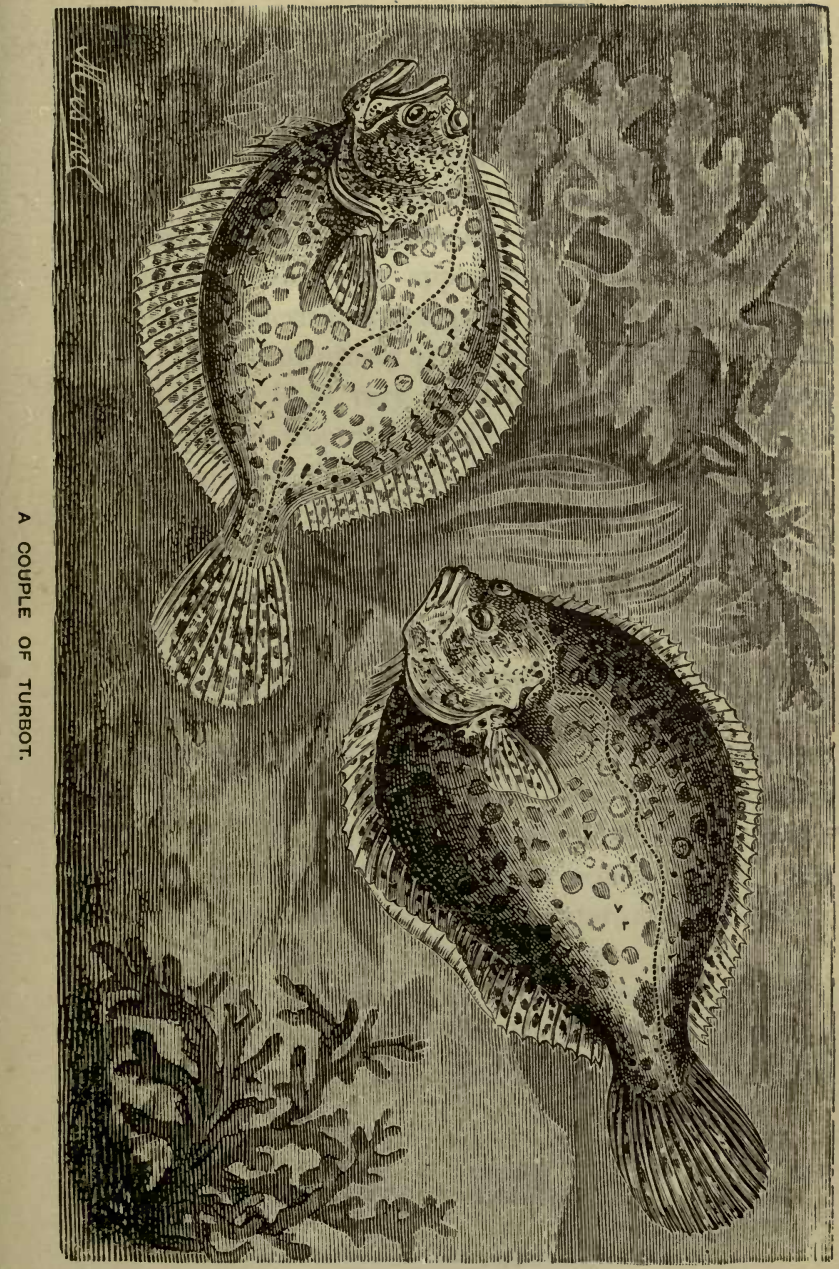


28

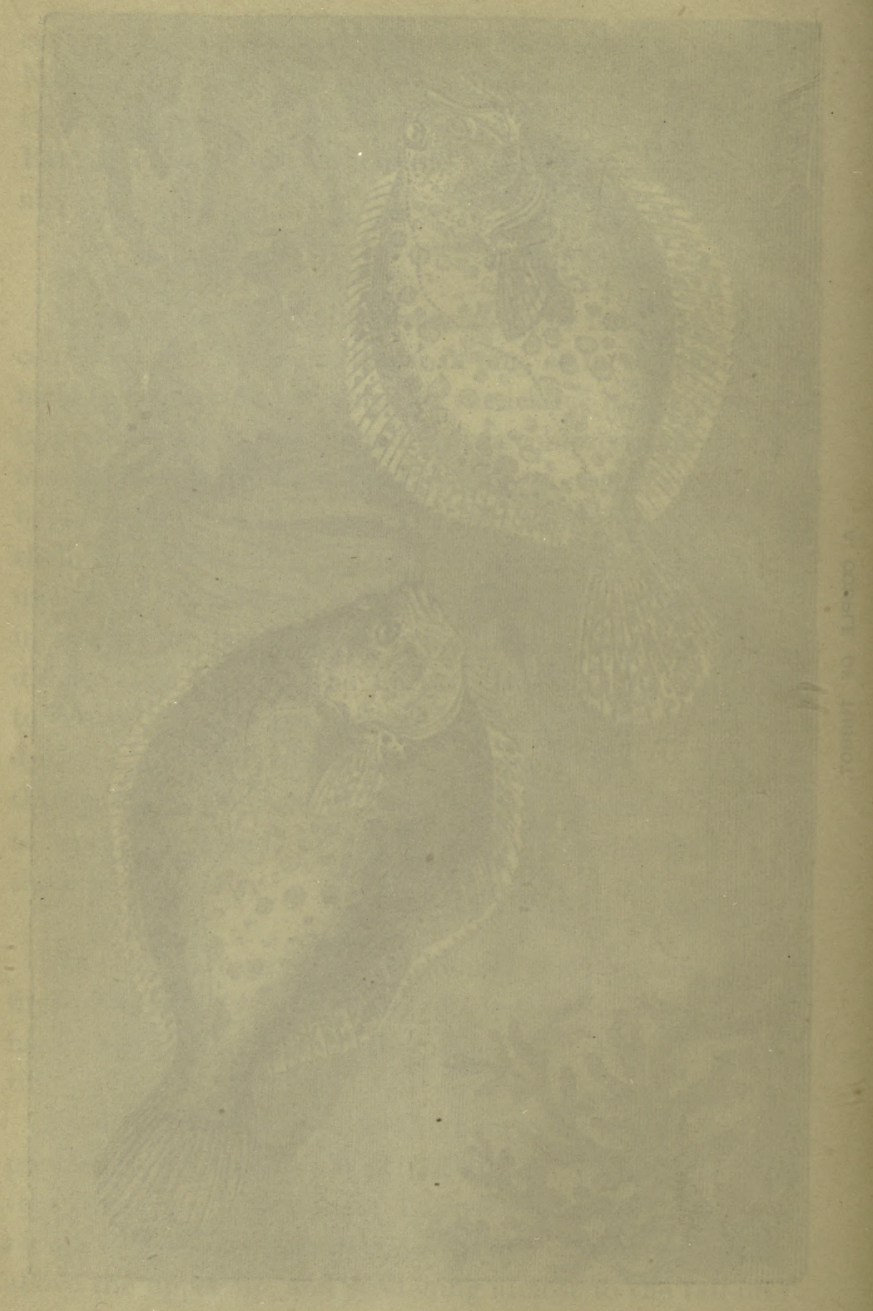


Do they not know that its eyes are generally on the left side? - a peculiarity which, however, does not seem to inconvenience it. It is not an elegant fish, judged by the usual laws of harmonious proportions; but then its flesh is so delicious, that the epicure readily pardons its deficiency in this respect! It attains a considerable size,-in fact, an aldermanic size, very appropriate in a fish so much esteemed at aldermanic banquets; frequently it weighs seventy, eighty, or ninety pounds. On our English and Scottish coasts it is very plentiful ; our markets being largely supplied from the sand-banks lying between our eastern shores and Holland. It is also known in the seas of Greece and Italy.

The Dutch turbot-fishery begins about the end of March, a few leagues to the south of Scheveling. As the season advances the fish proceed northwards, and in April and May are found in great shoals on the banks called the Broad Forties. Early in June they swarm around the crumbling shores of Heligoland, where the fishery continues to the middle of August, and then terminates for the year. At the beginning of the season the trawlnet is principally used; but on the occurrence of warm weather the fish retire to deeper water, and the fishermen must then have recourse to the line.

The turbot was well known to, and highly valued by, the ancients, who thought their banquets incomplete unless it "smoked upon the board." Horace alludes to its size and costliness :-

\footnotetext{
"Grandes rhombi patinaeque

Grande ferunt una cum damno dedecus."

"Great turbots and late suppers lead

To debt, disgrace, and abject need."
} 
And we read of one purchased by the Emperor Domitian, the size of which almost defied the skill of the imperial cooks; they did not know how to dish it up!

The reputation enjoyed by the SoLE (Solea) is well deserved, for its flesh is succulent, savoury, and easily

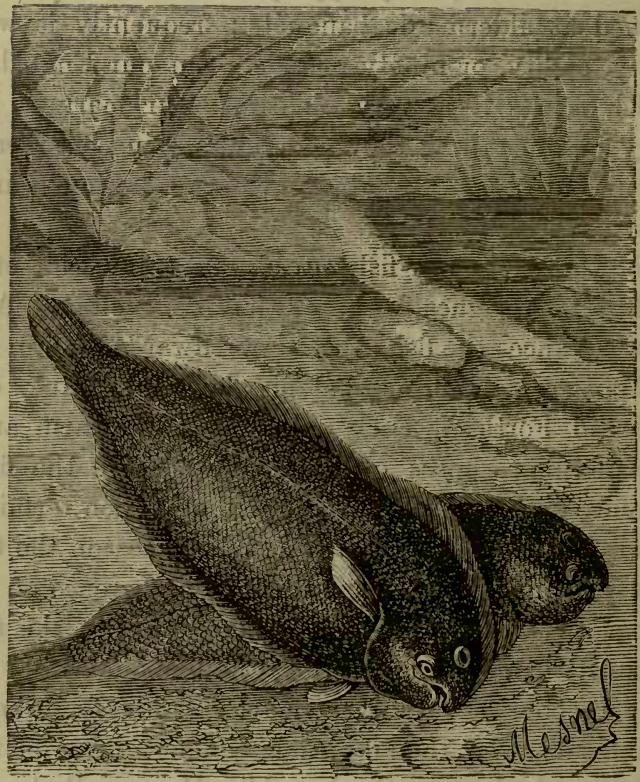

SOLES.

digested. Moreover, it is available for the bill of fare throughout the year, except for five or six weeks in February and March, its spawning-time.

It is of an oblong form, with a rounded muzzle, 
which almost always projects beyond the mouth; the said mouth being twisted to the side opposite to that on which the eyes are situated-namely, the right; though, by the way, individuals are occasionally found with both eyes and mouth on the left. The teeth are very small in both jaws ; there are pectoral fins on each side ; the dorsal and anal fins extend to the tail, but do not join the tailfins.

The common sole inhabits all the European seas, except the most northern. Its average weight is one and a half to two pounds, but some individuals bulk to five, seven, and even nine pounds. The upper side of the body is of an almost uniform dark brown; the under part, white.

It is a ground fish, and therefore caught by trawling. It frequents the sandy bottoms round the coast, feeding on the smaller crustacea, and on the spawn and young of various kinds of fish.

Soles have a very extensive range. You may take them at the Cape of Good Hope; in the seas of Japan; off the coast of North America; and in the Mediterranean. And though sea-fish by birth, they will live and wax fat in fresh water, frequently ascending rivers to a considerable height.

They were well known and equally well appreciated in days of old. According to the Greeks, they made suitable sandals for the ocean nymphs, who, when thus shod, had certainly soles to their feet. One of the epigrammatists, describing a banquet, says the slaves

Served up those slippers of the foamy sea Which agile Nereids, sent on errands fleet, Apply protecting to their tender feet.

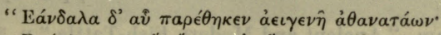

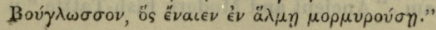


And it would seem that the ancient cooks, like the modern, fried them :-

"The cook brought forth upon a spacious dish Hot frizzled soles-those all-surpassing fishSkilfully browned, and wafting through the room, While sputtering still, their rare and rich perfume."

They were also served under the name citharus in an appetizing sauce. They figured as one of the side-dishes at Hebe's nuptials ; an amateur, "cithari sciens," sings their praises cooked in a compost of cheese and oil, when

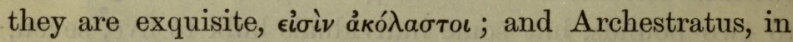
his poem on "Good Cheer" (Hedypathy), says, to the same purpose, they can hardly be served too elaborately.*

BRILL (Rhombus vulgaris), which we ought to have mentioned in connection with its cousin-german, turbot, is, like the sole, in season all the year round. It resembles the turbot in appearance, but is not so broad, has a soft dorsal fin, is of a reddish sandy-brown colour on the upper part, and seldom exceeds eight pounds in weight. Though often passed off upon the unwary for turbot, it is far inferior in flavour.

It is said that in London alone upwards of $35,000,000$ of plaice are sold every year. Plaice (Platessa vulgaris), a species of flounder, is a broad flat fish, found on sandy and muddy banks on most parts of the British coasts, as well as on those of continental Europe. It feeds on worms, molluses, small crustaceans, and young fishes ; attains an average weight of five to seven pounds; and is taken both by trawl-nets and lines. The upper part of the

\footnotetext{
* Badham, "Ancient and Modern Fish-Tattle," p. 366.
} 


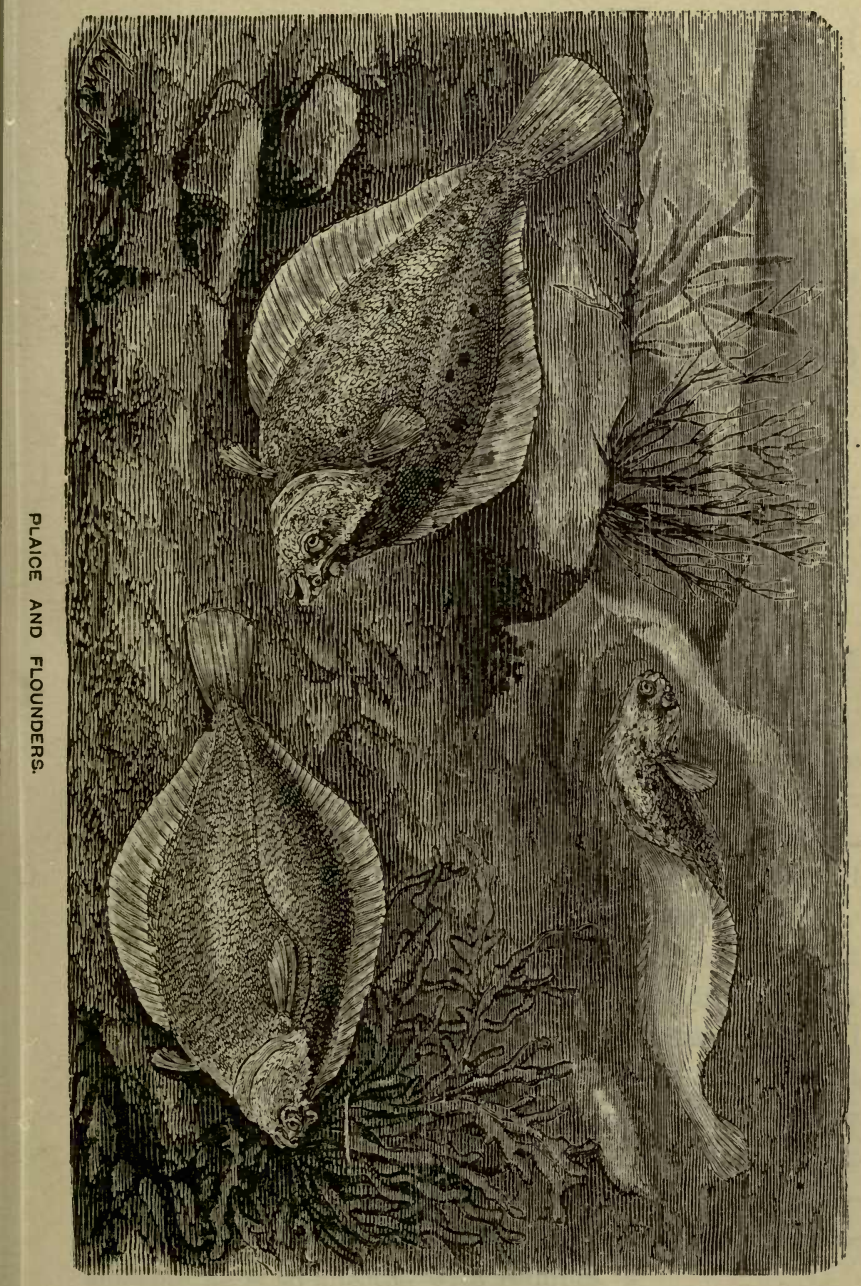



body and the fins are of an olive-brown colour, marked with numerous large bright spots of orange.

The Flounder (Platessa flesus) is readily distinguished from the plaice by a row of small tubercles on each side of the lateral line. Its greatest breadth, excluding the fins, is about one-third of its whole length. It is found in comparatively shallow water, with muddy or sandy bottom, on our own shores, and on the coast of almost all Europe ; thriving equally well in perfectly salt, brackish, or perfectly fresh water. In Sweden it is known by the name of flundra; in Scotland, by that of fleuk, or fluke. $\mathrm{He}$ is a greedy and audacious fish, and the best time for taking him is at early dawn, when he prowls about in quest of a morning meal :-

\footnotetext{
"He that intends a flounder to surprise, Must start betimes and fish before sunrise."
}

Franks, quoted by Badham, says of the Flesi:- "These fish are bold as buccaneers, of much more confidence than caution, and so fond of a worm that they will go to the banquet though they die at the board: they are endowed with great resolution, and struggle stoutly for the victory when hooked; they are also more than ordinarily difficult to deal with by reason of their build, which is altogether flat, as if it were a level. The flounder, I must further tell you, delights to dwell among stones; besides, he is a great admirer of deeps and ruinous decays, yet as fond as any fish of moderate streams ; and none beyond him, except the perch, that is more solicitous to rifle into ruins, insomuch that a man would fancy him an antiquary, considering he is so affected with reliques." 
The DAB (Platessa limanda) is of the same genus. It may be distinguished from the plaice and flounder by its

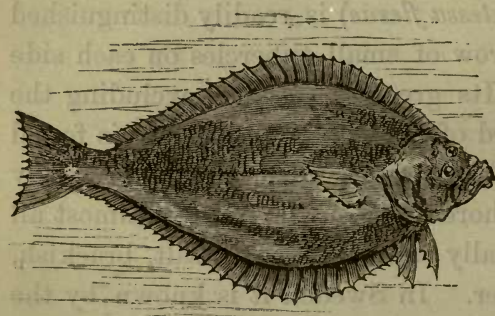

THE DAB. more uniform and lighter brown eolour, its rougher scales, and the greater curvature of the lateral line. The fishermen on the Fife coast call it the "salt-water fluke." It is found on all the sandy parts of our coasts, but in deep water; and it never ascends the rivers. There are five species.

The Halibut or Holibut (Hippoglossus vulgaris), one of the largest kinds of Pleuronects, abounds in the northern seas of Europe (except the Baltic) and America, and is plentiful in British waters. It is a bold, strong fish, and requires good tackle to hold it. Individuais have been captured measuring nearly eight feet in length, but we ourselves have never seen them exceeding five feet; and of these the flesh is coarse, and, we should think, not nutritious. The Greenlanders, who have stronger stomachs (ilia dura) than Britons, value the halibut exceedingly. They embark in their light kajacks, and spear them with great dexterity; or fish with hook and line, after the fashion described by Crantz :- *

"At certain seasons the Greenlanders catch great numbers with large fish-hooks, fastened to whalebone

* Crantz, "History of Greenland," i. 92, 93. 


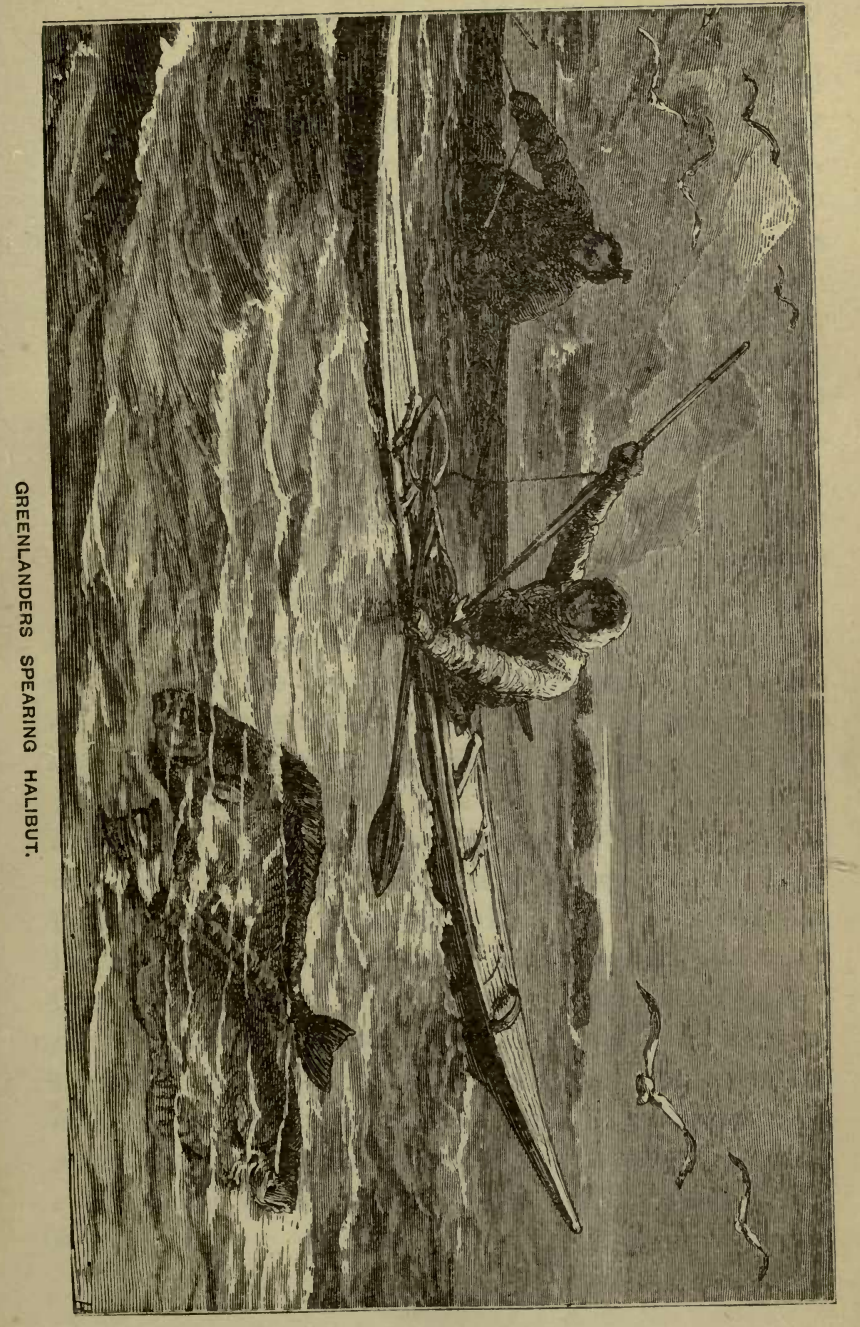




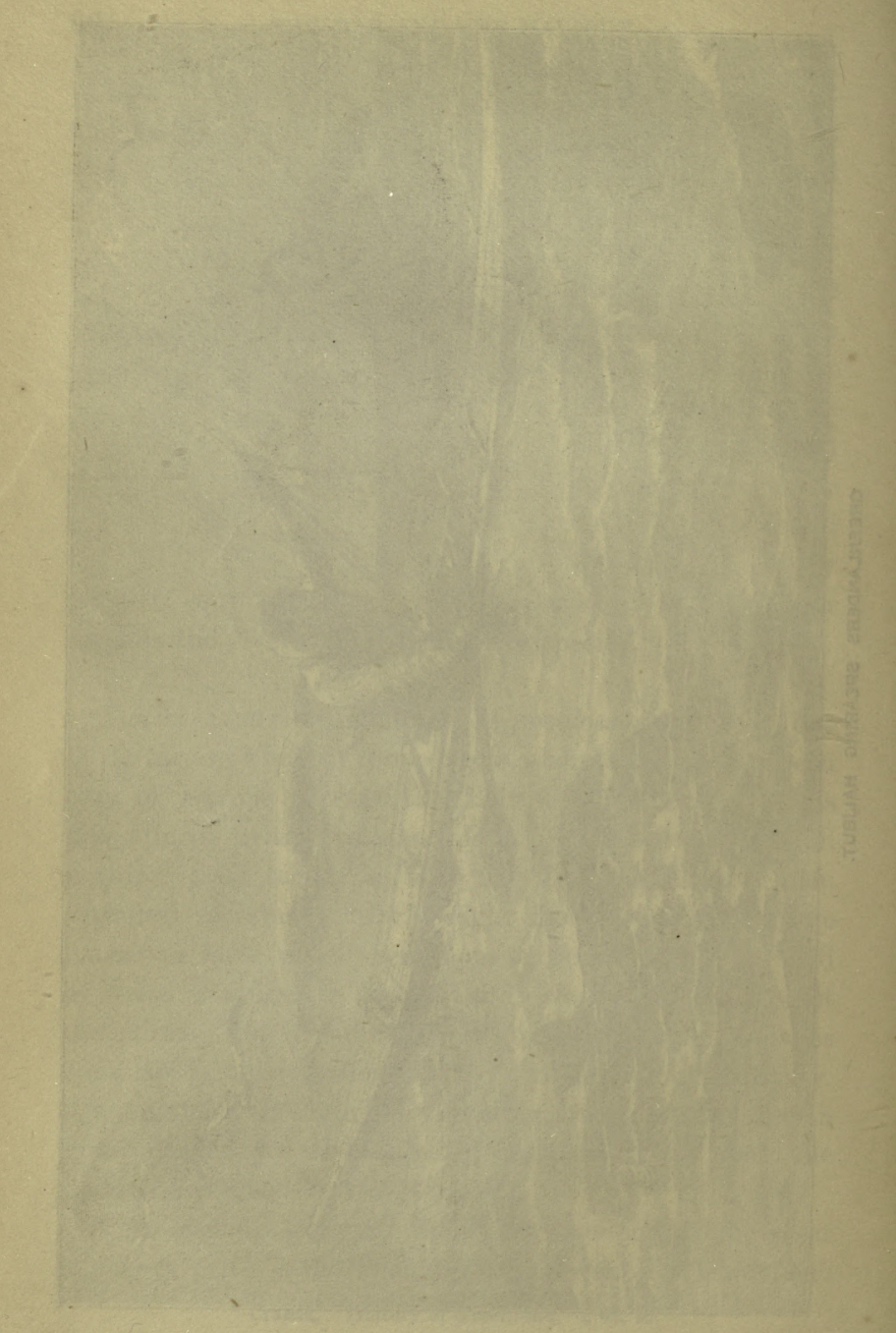


or sea-gut thongs from a hundred to a hundred and twenty fathoms in length; the largest are four feet and a half to six feet in length, about half as broad, and a full span thick; they weigh from a hundred to two hundred pounds and upwards." The Norwegian halibuts are said to be so large that a single one, when salted, cannot be contained in a barrel. They have a smooth skin, white below, and speckled with dark gray on the back; the eyes are larger than those of the ox, and furnished with a kind of eyelid; the mouth is not large, but has a double row of sharp teeth, bent inwards. In the gullet are two pointed gills, besides those in the mouth. Close to the head two small pectoral fins are inserted; and two longitudinal fins descend from head to tail. The peculiarity of this genus is, that one side appears to represent the back, and the opposite side the abdomen. Both the eyes are always situated on one side of the head; some species having them on the right, others on the left side. They swim laterally, with that side in which the eyes are seated uppermost. Their principal food is crabs, and on that account they generally reside in deep water. Their flesh is coarse and lean, but white and well-tasted, and has a large quantity of delicate fat, especially under the fins. "Of this fat," says Crantz, "the inhabitants of the north make raf - which is cured by smoke; and they cut the lean flesh into long slices, which they dry in the air, and eat raw; and this they call rekel. The remainder is salted, and laid up for winter. The Greenlanders, however, cut the whole into small slips, and dry them in the sun." 


\section{CHAPTER III.}

THE SCOMBERID A.

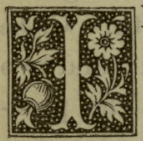

$\mathrm{N}$ connection with our food-supplies, it may be assumed that the Scomberidce family among fishes rank next in value and importance to the Gadidæ and Clupeidæ. They belong to the sub-order Acanthopteri, in the great order of the Teleostei; an order which includes the larger majority of fishes popularly so called - that is, fishes with a wellossified internal or endo-skeleton.

The Scomberidæ are all distinguished by the smoothness of their body, which is covered generally with small scales, and often very richly and brilliantly coloured ; by the largeness of the tail-fin, and the powerfulness and muscularity of the tail. The sides of the tail, it should be remarked, are frequently carinated, or keeled, and armed with sharp-keeled scales. The front spines of the anal fin are usually detached, and sometimes those of the first dorsal fin; while the second dorsal fin is often represented by numerous finlets, as in the mackerel.

To the Scomberidæ, which are all marine, belong the tunny, the mackerel, the sword-fish, the bonito, the albacore, and the seir-fish. We shall attempt a brief descrip- 
tion of them, and of the methods adopted for their capture, in the order in which they are here put forward.

The Tunny (Scomber thynnus) has been called the "fish of many names ;" an appellation it will be considered to have deserved by readers familiar with the old zoologists, who designated it, according to their individual fancies, thynnis, pelamys, sarda, auxis, xanthias, triton, thusites, cheladonias, melandrya, synodon, and the like. Its now

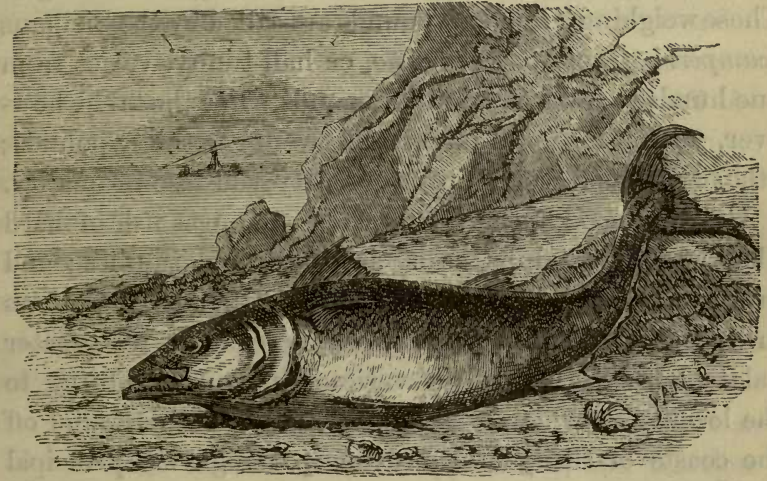

THE TUNNY.

accepted name of "tunny" comes from the Greek Ovivvos through the Latin thynnus, and may be traced to the verb Ovielv, "to bound furiously;" in allusion, perhaps, to the violent motions of the fish when persecuted by its parasite, the marine cestrus, a kind of bot-fly, or parasitical insect.

The tunny is distinguished from the mackerel by the following characteristics : Its first dorsal fin continues to its second, while in the mackerel an interval occurs be- 
tween the two; further, it is of considerably larger size; and, finally, its body is fashioned like a wedge. There are some noble fellows among the tunnies! Aldrovandi records the particulars of a monster which measured thirtytwo feet in length, and sixteen feet in girth at its broadest part! We may be pardoned a little scepticism in reference to this colossal scomber : but Pennant speaks of one, caught off the coast of Inveraray, which weighed a hundred and forty pounds; and Atti positively affirms that specimens have been caught of eighteen hundred pounds weight. Those weighing a hundred pounds are called by the Sicilians scamperri; their mezzo tunno, or half-tunny, varies from one hundred to three hundred pounds. For the table, however, your fish should not exceed twenty to thirty pounds; otherwise, what you gain in quantity you lose in quality.

Galen, a good authority, includes amongst fish of hard fibre whales, dolphins, seals, and large old tunnies; and pronounces the last as almost equal to either of the others in indigestibility, though he acknowledges its greater palatableness. But tunny varies in flavour according to the locality in which it is caught. The best is found off the coasts of Sicily and Provence, though the principal tunny-fisheries of the ancients were carried on at Byzantium and off the shores of Spain. Archestratus, a Greek epicure of renown, who travelled over the world "for his stomach's sake," has left it upon record, to benefit posterity, that the tunny of Constantinople, Carystium, and Sicily are not to be despised, though those of Hipponium, in Italy, are superior in merit; while he has panegyrized the Samian specimens as ineffably good, and only fit to be put upon Jupiter's table, or-his own.*

* Badham, "Ancient and Modern Fish-Tattle," p. 206. 
Among the ancients, the part of the fish most relished was the belly; and, from a Greek epigram, it would seem to have fetched a very high price :-

\section{" Bass, conger's head, and tunny's under side,} Are luxuries to slender means denied."

Athenæus recommends it $\dot{\epsilon} \nu \mu v \tau \tau \omega \tau \hat{\omega}$ - that is, stufled with onions, and some other of the more acrid condiments, to which, for indigestibility, our goose and onions must be a light dish. The Ligurians, says Jovius, as quoted by Badham, eat it under the name of "azeminum," stewed in oil and Corsican wine, with pounded pepper and chopped onion; a capital recipe, if there were not too many known already, for nightmare. "All the carcass was salted and pickled, and sold under various names. The best part for pickling was the belly, already mentioned as the best part fresh. The next in esteem was the 'omotarichum,' or pickled shoulder ; lastly came the dry parts, 'cybias, melandrias and uræas :' the first and last were lumps, generally in cubes, cut out of the back or tail ; the other, yet served in oil by dirty stewards on board Mediterranean steamers," may be described as "like veneers of mahogany in appearance, and tasteless as any wood."

The tunny is a handsome fish in appearance; its back is of a deep lustrous blue, like the tint of polished steel ; its belly flashes all over with silvery gleams.

It is very voracious in its habits ; particularly partial to sardines, pilchards, and mackerel; not sparing even its own species-the cannibal! But, by a just law of compensation, it is not spared in its turn by the shark or the sword-fish, to say nothing of its prime enemy, Man. 
From a very early time, tunny-fishing has been a source of wealth to the riverine peoples of the Mediterranean. It was esteemed so important in its influence on the national interests, that the Greeks, before embarking in it, endeavoured to secure the good-will of their deities. They offered a tunny as a sacrifice to Neptune, imploring him to preserve them from the disastrous " joint-stock operations" of the sword-fish ; and if the expedition proved successful, they renewed the sacrifice as a token of their gratitude. It must be admitted, however, that a couple of fishes was hardly enough to bribe the favour of Poseidon.

Naturalists formerly believed in the migrations of the tunny, as they did of the herring. It was asserted that the shoals which teem in the Mediterranean entered its waters in the spring season through the Strait of Gibraltar; that then they divided into two great bodies, one of which followed the coast-line of Africa, and ascended as far as the Bosphorus - the other skirting the shores of Spain, France, and North-western Italy, passing between the islands of Elba and Corsica, and halting in the waters of Sardinia to deposit their spawn.

These migrations, however, were absolutely imaginary. It is now known that the tunny always inhabits the same region, simply changing its position according to the season of the year-now advancing towards the coast, and now retiring into deep water.

The ancients resorted to various devices for the capture of this famous fish. One way, and a very direct one, was, according to Aristotle, to spear it as it basked, like a pike, on the sunny surface of the waves. Another, which Oppian describes as practised by the Thracians, 
consisted in piercing the fish, as they lay in their winter mud-baths at the bottom of the Euxine, with a short, thick, leaded log, armed on the under side with a complete arsenal of barbed and serrated spear-heads. This formidable weapon was slung by a long rope to the bow of the boat, whence it was hurled headlong, causing terrible execution among the unsuspecting tunny.

\footnotetext{
" Swift through the gloomy regions of the bay, The leaded engine lights upon its prey ; And soon a hundred barbs, in galling chains, As many victims hold in writhing pains."
}

The tunny is noted for its timidity. It is also exceedingly stupid ; a feeling due, we suppose, to its small brain, which does not exceed $\frac{1}{3744}$ of its total bulk. The slightest noise in the water will so fluster and confound a whole shoal, as to drive them headlong into the fishermen's snares. Taking advantage of this intellectual defect or idiosyncrasy, the ancients, under cover of a dark night, wculd row with muffled oars to the spot where the fish were suspected to be lying. There, a vast apparatus of mesh-work was run out silently, and the crew pulled vigorously to one side, until they got in the rear of the shoal. Then, what a clamour arose! How they yelled and shouted! How they beat the waters with their oars, and filled the air with a chaos of discordant sounds! Frightened by the phosphorescent gleam on the surface, and by the din and clash echoing all around, away dashed the timid fish in the direction of the net, in whose open abysses they took refuge as in a secure asylum! The clatter being constantly kept up, they made no attempt to leave their dangerous retreat; and the crew, rowing towards the shore, carefully and dexterously towed the 
net behind them, and generally had good cause to rejoice over a splendid harvest.

Alian describes another method of tunny-capture.

Some time, he says, before the shoals make their ap-

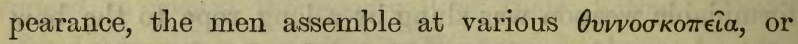
tunneries; select the most experienced of their number to the office of thynnoscopus, or tunny-overseer, and build for him a watch-tower, or station him on a commanding rocky headland. No sooner does his practised eye discern the advancing column, than he signalizes to the watchful crew below the direction in which they are to prepare for its reception. As they recognize the signal, with " all the precision of a troop of disciplined soldiers, or a band of well-trained musicians," the mariners put to sea, each boat in command of its captain ; and with great regularity and swiftness they shoot their nets in advance of the fish. In this way a vast hempen wall is flung ath wart the course of the shoal, which, proceeding in a direct line, and never looking before they leap, are surrounded and captured.

Now-a-days, tunny-fishing is carried on both with the line and the net. Little is done in the former way; in the latter, the practice varies among the French and Neapolitan fishermen.

For instance, there is the tonnaire, which may be thus described :-

As soon as the look-out men announce the approach of the tunnies, a flotilla of boats traverses the sea in the form of a semicircle, and, throwing out their nets, gradually make for the shore, contracting the area enclosed by the nets as they advance, and, consequently, driving the shoal in front of them. When close to the land, and in 
shallow water, they spread out an immense net, closed at one end; in this they imprison the frightened, struggling, drifting tunnies, and pour them out in shining hosts upon the beach, where they are straightway killed.

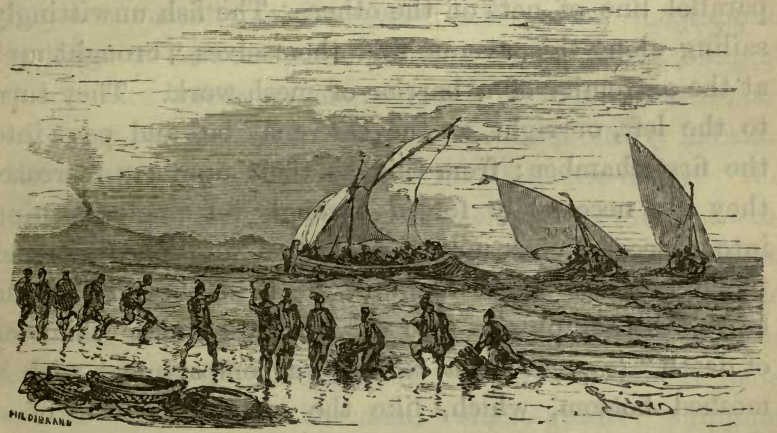

TUNNY-FISHING ì LA TONNAIRE.

In this way no fewer than two thousand to three thousand quintals are caught at a single haul. The tonnaire, as it is called, is in vogue upon the coasts of Provence, and, to some extent, in Calabria and Sicily.

The more complicated process of the madrague is, however, more generally practised ; and, as Duhamel says, no other combination of meshes can convey such an idea of human ingenuity and skill in the "retiary art" as this. So enormous is the quantity of fish it sometimes secures, that in the archives of the active little fishing-town of Couilloure is preserved the registration of a single night's spoil -namely, one hundred and sixty thousand tunny, each of an average weight of $25 \mathrm{lbs}$, but many reaching $120 \mathrm{lbs}$. The madrague is, in fact, a vast floating decoy, permanent, 
and always available for use. By means of nets deeply sunken with heavy stones, a number of compartments or chambers is constructed in the sea, and connected with the shore by a long broad avenue, of a quarter to half a mile in length, formed by the shore on one side and a parallel line of nets on the other. The fish unwittingly sailing along this avenue find themselves "brought up " at the extremity of a barrier of mesh-work. They turn to the left, or right, as the case may be, and pass into the first chamber; from this, as their numbers increase, they are necessarily forced through its single opening into a second enclosure; and so, on and on they find themselves compelled to move, until at the end of the labyrinth they plunge into what is called the "chamber of death" (camera della morte), -a compartment with a meshed bottom, which, like the mezzanine floor of a theatre, can be raised at will, and when it is raised brings with it to the surface a host of unfortunate victims. In vain do they seek to escape from the indiscriminate massacre; they perish by hundreds.

From the reports of independent observers, we gather that there is something singularly exciting in witnessing the wholesale capture of a herd of these great black fish ; more particularly as the Provencals and Neapolitans regard the occasion as a festival, and come out in their gayest attire and with their brightest looks; while musicians always attend, and mingle their merry strains with the shouts of the eager fishermen and the applause of the impulsive spectators. The following minute description of a day's tunny-fishing may, therefore, interest the reader :- *

* Quatrefages, “Journal of a Naturalist;" Badham, " A ncient and Modern Fish-Tattle." See also Lacépède. 
It is early morning; the morning of a bright, glowing August day, whose lustre falls freshly on the blue waters of the Bay of Palermo, and the cactus-crowned heights of Monte Pellegrino. We enter our baccarole, and push forward to the tonnaro, where the madrague lies, about a mile from shore. All is calm, smooth, and brilliant to seaward; and not a ripple vexes the oleaginous surface before us, mapped out, like the ground-plan of a new town, with floating corks, which clearly indicate the structure and divisions of the immense decoy. We pull from end to end of the long enclosure to the first submarine barrier, and gliding over it, row swiftly, between lines of buoys and floating corks, to the spot whither some boats in advance of our own have been driving a shoal of scared and confused tunnies. "Ecco la camera della morte !" exclaim our boatmen, " siamo giunti !" shipping their oars, and staring down into the depths, as if they were bent on seeing what scenes were being enacted in them. But the dark blue waters are impenetrable; our men resume their oars; and in a few seconds we bring up alongside one of the two barges which guard the "chamber of death." The other serves as the point d'appui for the nets.

These boats are filled, as we see, with a crowd of fishermen, half naked, with athletic, sinewy limbs, of the colour of bronze, and dark eyes flashing under Phrygian caps of brown or scarlet; some of them hauling in the sieve-like flooring of the " death chamber," - others standing ready, with iron-pointed weapons, to deal destruction among the tunnies as soon as they rise to the surface.

But presently a shout is heard: "La pipa, la pipa!" A sword-fish, or pipa, has entered the decoy with the 
miserable shoal, and is now in the net. Haul away, my men, and we shall soon make short work of him! As the flooring continues to rise, the pipa swims to the surface, puzzled by such an unusual movement in the tranquil deep ; and no sooner is he seen than three tremendous vociferations welcome him. Frightened by the noise, he darts now in one direction and then in another; rises to the top, plunges down again; and, in fact, behaves like a pipa clean gone out of his senses. $U_{p}$ he comes once more, to escape from the mass of tunnies struggling at the bottom of the net; makes a swift, sudden sweep around the enclosure to find an opening,and finding none, rushes against the barrier, and with his long weapon rends the meshes. In vain; he is now hopelessly entangled in the wreck, and in a minute half a dozen harpoons quiver in his body. He struggies violently in his pain, but blow after blow is rained upon him; the water around is "incarnadined ;" and in less time than it takes us to tell the story the great scomber is hauled on board. The shouting grows terrific; irregular, excited, rapid shouting, such as proceeds only from an Italian crowd. "Five scudi, my lads, for our share," cries one of the leading captors ; and "Bless the Virgin and St. Anthony," exclaims another, "he has done but little damage to the net!"

"Now," say our boatmen, "now, signor, we shall presently see the tunny;" and accordingly, as the movable floor of the camera della morte comes to within a few feet of the surface, a motley host of large fish, chiefly of the scomber family, all in violent agitation at the unusual sights and sounds, dash and splash about, and beat the waters into foam. The work of slaughter commences, 


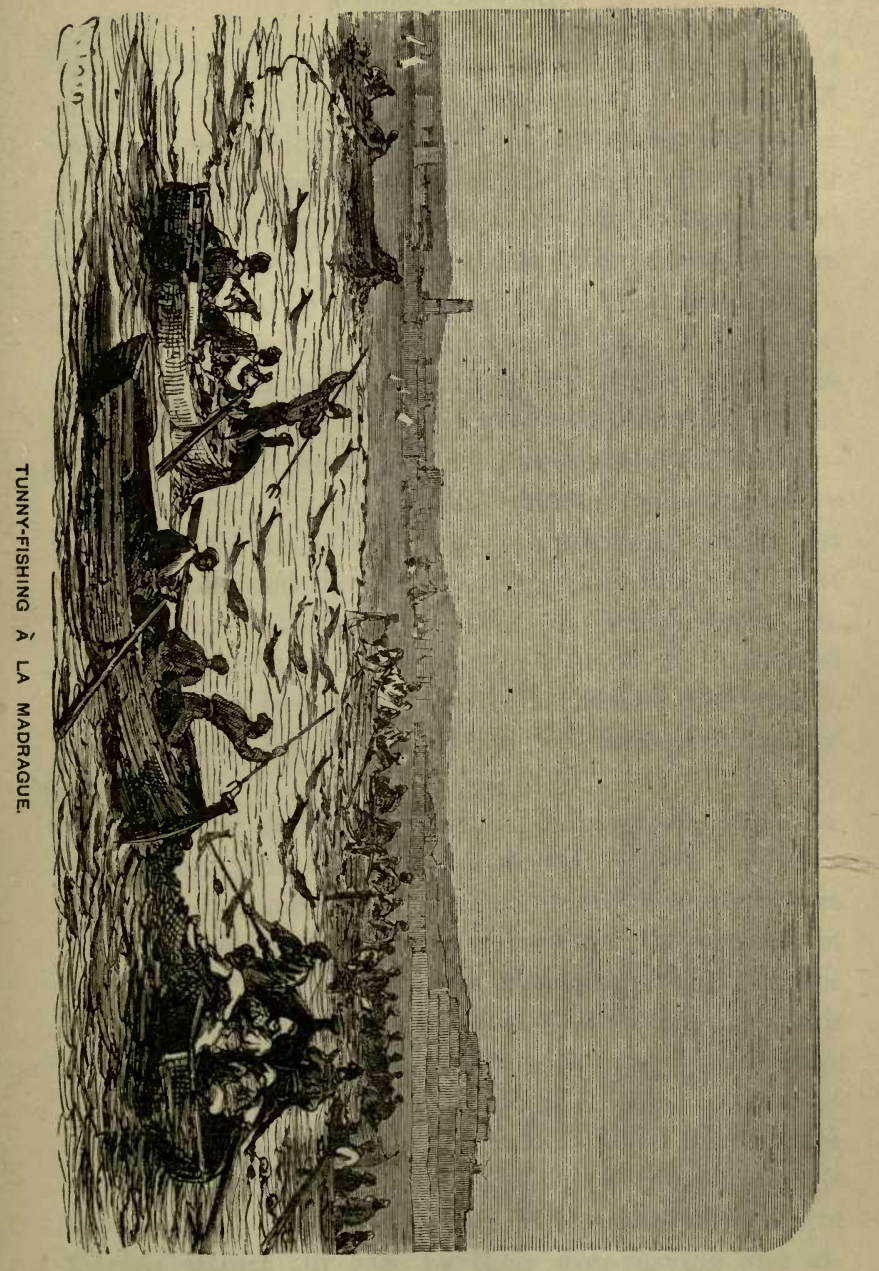



and still the flooring continues to ascend. The entire shoal, or host, of tunnies is discovered. Jostled and pressed one against another, you see these monstrous fish flinging themselves desperately against the sides of the enclosure, exposing their black backs besprinkled with large spots of yellow, or clearing the crimson waters with their great crescent-shaped fins. In their midst a few stray sword-fish leap and tumble like frantic gymnasts. Intoxicated by the immensity of the spoil before them, the fishermen ply their weapons with the greatest animation, until the spectacle becomes one of indiscriminate butchery. To an English onlooker, less impulsive than the Italians, it ceases to be attractive; the contest between man and the fish is so obviously unequal. But no relenting weakens the arms of the Sicilian fishermen. Victim after victim falls under their blows, and is hauled on board the two barges, until the camera is emptied, and lowered for the reception of another batch of prisoners.

We follow the barges to the landing-place, and, disembarking, join the noisy procession which, led by a couple of drummers, files off to the Mercata Reale, where we find numbers of great eyeless tunny (the produce of a still earlier haul) piled up in ensanguined heaps on the flags. Here, too, are alalongas, whose long pectorals have been draggled in the mire, with many other large and curious fish, and the long-bladed heads of two or three sword-fish fixed on end in the upper part of the woodwork of the same stalls, while their huge bodies lie below, cut up into great masses; and whole hampers of labridce attract our gaze by their ever-varying and exquisitely beautiful tints. 
Here we may close our narrative, and dismissing this coarse and ill-flavoured fish,* pass on to a consideration of that daintiest and most appetizing of scombers, the Mackerel.

A smooth, elongated body, covered with excessively small scales; the back of a fine metallic blue, streaked with black; the upper part of the head also blue and

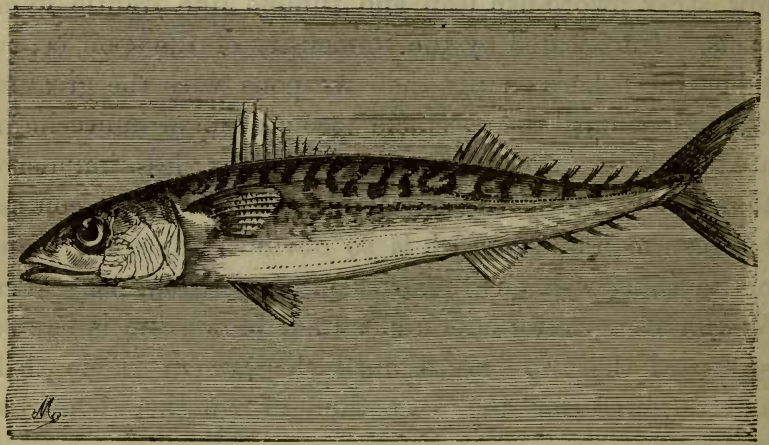

THE MACKEREL.

black ; the rest of the body of a pearly or silvery white; and the dorsal fins separate,-by these signs may the reader recognize a fish which is truly one of the "treasures of the deep."

Geographically speaking, the mackerel extends over a very wide range of sea,-embracing the whole of the European and American waters, and stretching as far southward even as the Canary Islands. It appears off

* There is an American tunny (Thynnus secundo-dorsalis), found on the New York coast and off Nova Scotia, whose flesh is of a much better quality. It also yields a large quantity of oil. The Albacore (Thynnus albacorus), a native of the West Indian seas, and the Bonito (Thynnus pelamys), the Tropical enemy of the flying-fish, belong to the tunny genus. The Mediterranean owns two species of bonito, Pelamys Sarda and Auxis vulgaris. 
the British coasts early in the year-that is, in January and February; and individuals are always to be found in our seas. It was formerly asserted that they passed the winter in the Icy Ocean, burying their heads deep in mud and sea-weed; that towards the spring they migrated southward, skirting the coasts of Ireland and Scotland ; that then they poured into the Atlantic Ocean, and divided into two columns, one of which sailed away for the Mediterranean, while the other made for the English Channel. All this is now exploded. It seems to be true of the mackerel, as of the herring, that it retires usually into the depths of the sea, but rises to the surface and moves towards the coast as its spawningseason approaches, which occurs earlier or later in the year according to locality.

On this point we may quote Mr. Yarrell :-

It does not appear, as he remarks, to have been sufficiently considered by the advocates of the migration theory, that, inhabiting a medium which does not greatly vary either in its temperature or productions, locally, fishes are removed beyond the influence of the two principal causes which make a temporary change of situation necessary. Independently of the difficulty of tracing the course pursued through so vast an expanse of water, the order of the appearance of the fish at different places on the shores of the temperate and southern countries of Europe is the reverse of what would have happened had the aforesaid theory of migrations been true. "It is a fact beyond dispute that the mackerel is caught, though not plentifully, on some parts of our own coast in every month of the year. We may conclude that it inhabits all or nearly all the European seas; and the law of 
nature which obliges them and many others to visit the shallower water of the shores at a particular season, appears to be one of those wise and bountiful provisions of the Creator, by which not only is the species perpetuated with the greatest certainty, but a large portion of the parent animals are thus brought within the reach of man; who, but for the action of this law, would be deprived of many of those species most valuable to him as food. For the mackerel dispersed over the immense expanse of ocean, no effective flshery could be carried on; but, approaching the shore as they do from all directions, and roving along the coast collected in immense shoals, millions are caught, wilich yet form but a very small portion compared with the myriads that escape."

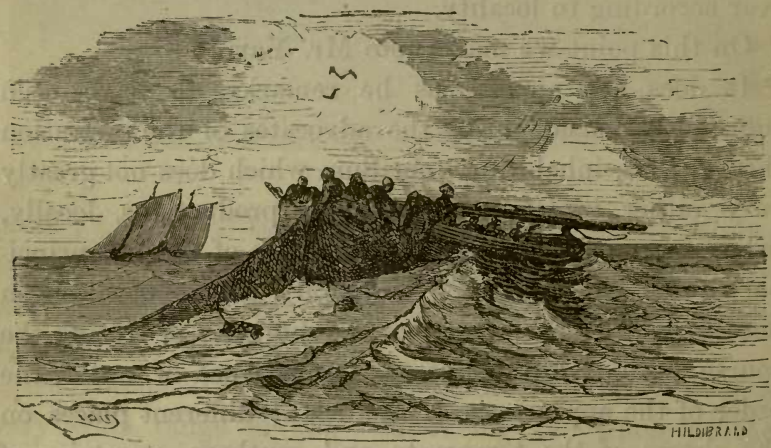

MACKEREL-FISHING.

Mackerel are caught with the line and with the seinenet, - that is, much in the same way as the pilchard. In fishing with the line, almost any kind of hook may be used. The great point is to carry the fish to market in the freshest possible condition, as it speedily deteriorates 
on removal from its "native element." Welled boats are largely employed, therefore, in its transit from the fishing-grounds to the nearest port.

Mackerel are exceedingly voracious, and if one might believe an anecdote told by Pontoppidan-that most credulous of bishops ! - we might suppose that they would "turn the tables" with a vengeance and prey upon man himself, if they could secure the chance. He tells a story of a sailor bathing off the coast of Norway, who was carried off and almost devoured by a shoal of mackerel! At least, he would have been devoured, had not his comrades succeeded in helping him into the boat, where he shortly afterwards expired, through loss of blood, exhaustion, and terror. The Norwegian mackerel, we suspect, are bolder than the British, if Pontoppidan is to be considered an authority!

The intestines of the mackerel formed part of the famous garum, or fish-sauce of the ancients, which, according to Galen, was worth two thousand pieces of gold per quart. From what is known of its composition, a modern connoisseur would scarcely accept it as a gift.

Another important member of the Scomberidæ is the well-known SwORD-FisH, which frequently attains a length of sixteen feet, and is armed with an extraordinary weapon for purposes offensive and defensive. This weapon is none other than a broad, sharp, heavy blade of bone, hard as steel, and frequently eleven feet long, forming a prolongation of the upper jaw. Taken in conjunction with its owner's size, strength, and agility, it renders him so formidable an adversary even to the hugest denizens of the salt waters that we need not 


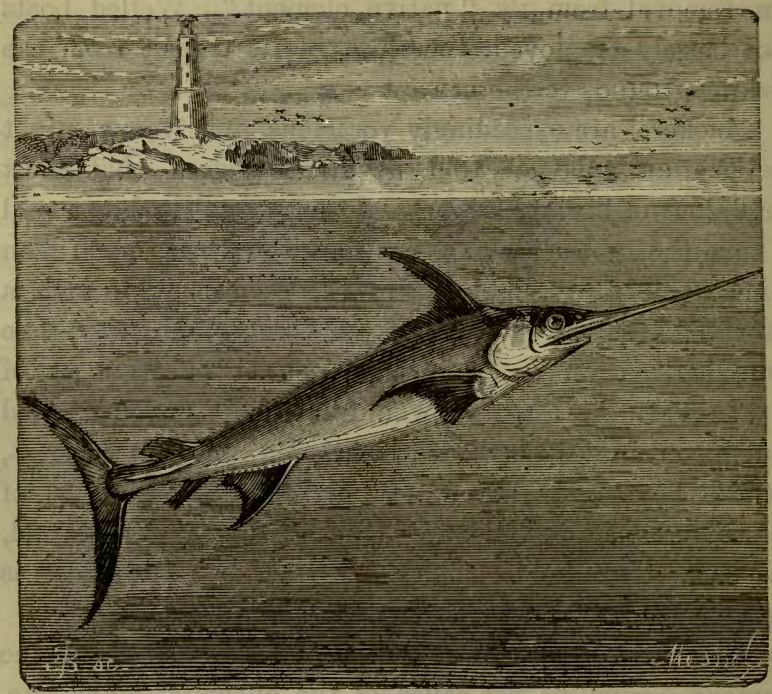

THE SWORD-FISH.

wonder he was formerly called "the Emperor." * It might well be supposed that he exercised a kind of imperial authority over the inhabitants of the deep. The ancients seem to have regarded him with a curiosity which had something of terror in it; and we find Sophocles exclaiming :

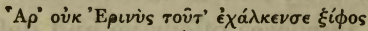

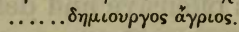

What Erinnys, or what evil-doer, Armed thee, O Xiphias, with thy pointed sword?

His temper is as keen as his weapon. He is the most quarrelsome of ocean monsters, the most pugnacious of

* He may also have been designated "imperatore," in allusion to his powerful weapon; the Roman imperators, in their pictures, being always represented sword in hand. 
fishes; whence Ovid, or some other Latin poet,* describes him as being as unrelenting as the sword he carries-

\section{: "Et durus Xiphias ictu non mitior ensi."}

We are told, indeed, that nothing alive or dead escapes lis fury; that he attacks, almost indiscriminately, the larger fish and marine mammals, boats and bathers, and even, when baffled in his assault, will spend his violence on the very rocks. If he falls in with a shoal of tunny, he rushes into their midst, like a wolf among a flock of sheep, and plunges his "reeking weapon" in rapid succession in their bleeding flanks. Should any hapless bather lie in his course, he dashes at him, and runs him through the body - as happened, indeed, some forty years ago, to a man while swimming near the mouth of the Severn. But against whales, in particular, his rage is so excessive, that some authorities have supposed his wild onslaughts against rocks and ships to originate in an error of judgment; that they are intended to punish the ocean leviathan, but have failed in their aim owing to the imperfection of vision from which the sword-fish, like other scombers, suffers.

The sword-fish is described as specially partial to whale's tongue. At all events, he pursues the huge cetaceous mammal without intermission. The latter, having only its tail to defend its colossal bulk, attempts to crush its assailant with a blow; but the nimble scomber generally eludes it, darts aside, and swiftly returning, transfixes the whale with its keen sword; the "multitudinous sea," by its "incarnadined waves," quickly reveals the fatal issue of the fight. Captain Crow, cited by Mr.

\footnotetext{
* We owe the quotation to Badham.
} 
Yarrell, relates that in a voyage to Memel, one tranquil night, when off the Hebrides, he called up his crew to witness a curious encounter between some "thrashers" (Carcharias vulpes), a genus of sharks, and a sword-fish, leagued together against a whale. No sooner was the vast back of the monster raised a little above the surface than the thrashers sprang several feet into the air, and descending, struck it with their tails, the blows resounding like the peal of distant ordnance. Meantime, the swordfish attacked the whale from below, getting close under its belly, and attacking it with a vigour and effect that did not leave the result of the combat doubtful.

Numerous instances are on record of the sword-fish having transfixed the timbers of a ship with its powerful blade.

He fights obstinately with the saw-fish and the shark, and is usually victorious; but is himself the victim of a miserable little enemy, a crustacean parasite-the pennatula filosa - which eats into his flesh, and almost maddens him with pain.

The spere spada, as the Italians call him, is often found on a very large scale, and monstrous specimens occasionally visit our own coasts. An individual stranded on the Essex shore measured ten feet in length, a third of which belonged to the osseous blade. This, however, was a comparatively diminutive example ; for several naturalists speak of Mediterranean spadas which weigh four hundred pounds, and measure from twelve to fourteen feet; while Cuvier supposes eighteen or twenty feet to be within their range of development. These Anaks of the race, however, are of infrequent occurrence; the spadas caught in the Mediterranean, and exposed for sale in the Sicilian 

fish-markets, averaging from four feet to six. The flesh, which is much valued by the better classes at Palermo, is dressed in nearly as many ways as the tunny, but fetches a higher price. Its fibre is delicately white, and the round segments, as they lie in rows along the stalls, resemble so many fillets of veal; and the resemblance is equally apparent when they are served at table.

Oppian records a curious device to which the ancient fishermen resorted for the purpose of entrapping the spada. They made use of boats constructed like the

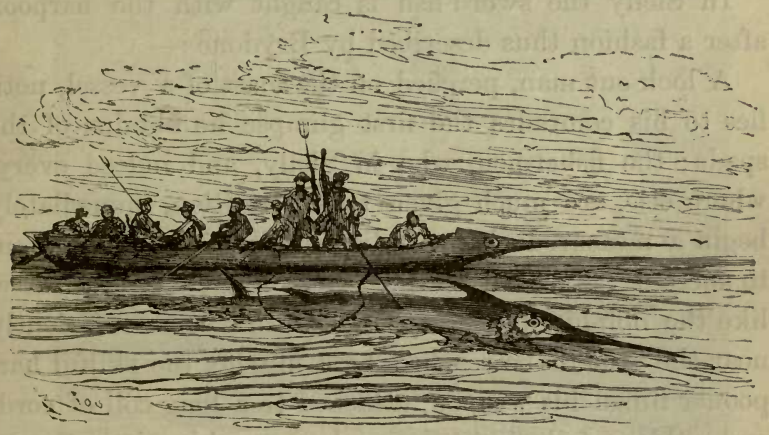

CATCHING SWORD-FISH IN THE OLDEN TJME.

sword-fish, with a long prow to resemble its beak, and painted with the deep colours peculiar to it. The scomber, which is reputed to be a dull fish, approached these shams in confidence, mistaking them for new acquaintances of their own kind, and did not discover the mistake until it was too late.

\footnotetext{
"To fishy form, the artistic builders lend Mimetic fins, and wooden sword protend. With social joy each xiphias views his friends, And kindly instincts aid man's treacherous ends.
} 


\begin{abstract}
Anon the crafty boatmen, closing round, The trident hurl and deal the deadly wound. The goaded fish, experience bought too late, Escapes, but oft still battles hard with fate ; Unvanquished, summons to his instant aid The oft-tried prowess of his trusty blade ; Selects some boat, and runs his puissant sword Full many an inch within the fatal board. Then held no more, the doughty weapon yields, And crimsons with his blood the briny flelds."
\end{abstract}

Such is Oppian's story. All we can say is, that, if true, the spadas were more foolish of old than they are now-a-days!

In Sicily the sword-fish is caught with the harpoon after a fashion thus described by Brydone :-

A look-out man, perched on the mast of a vessel, notifies to his comrades the first glimpse he obtains of the spada; the fishermen, who in Sicily, and indeed everywhere else, are much given to superstition, immediately begin a measured chant, indispensable, in their opinion, to success. As soon as the spada, enticed by the ditty, like the dolphin by Arion's music, has come sufficiently near the boat to be reached by a missile, the skilful harpooner flings his weapon, attached to a long coil of cord, and seldom fails to strike and secure his victim, even though at some distance. This siren song, the only tune ever employed on these occasions, is so efficacious, say the sailors, that the spada cannot retreat while it continues; but should the enchanted "sea-monster," before he is struck with the harpoon, hear a word of Italian, the spell is instantly broken, the charm dissolved, and down he plunges into the "vasty deep," whence no further summons or incantations will again evoke him!

The weapon used by the harpooner is a spear made of elm, - a tough, tenacious wood,- about thirteen feet in 
length, and terminating in an iron head measuring seven inches. It is also provided with a couple of iron oreilles, or "ears," which move up and down, and consequently increase the severity of the wound made by the pointed shaft of the harpoon.

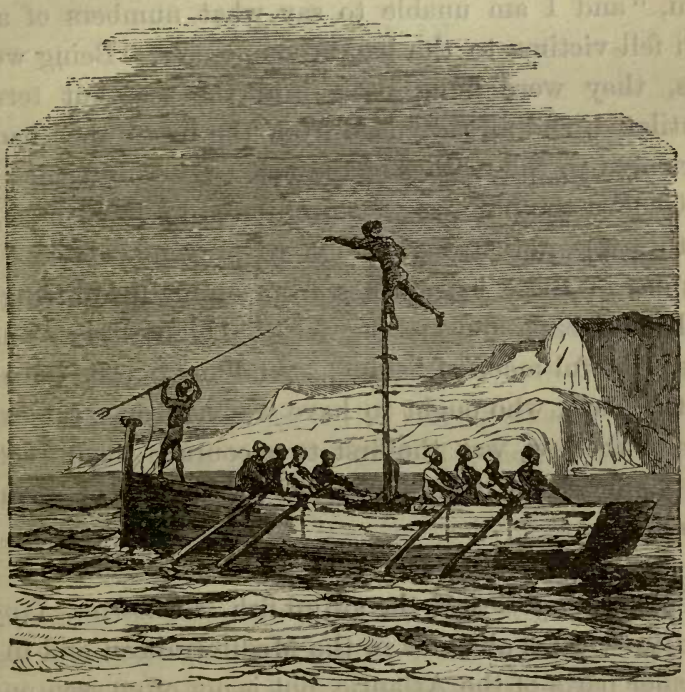

SPEARING SWORD-FISH.

In the Strait of Messina the spada-fishery is also carried on with the net. For this purpose, the net employed is about forty feet long and ten feet wide, with stout, compact, and small meshes, made of the strongest twine; it is locally known as the palimadara.

The fishery begins in mid-April, and continues until the end of June, along the whole Calabrian coast. Later 
in the year, it begins on the Sicilian coast. Between two large boats, propelled by lateen sails, the net is lowered to the bottom of the sea; and as, under a press of canvas, the brigantines dart onward, the rushing net catches up everything it encounters in its course. "I was present several times at this fishery," says Spallanzani, "and I am unable to say what numbers of small fish fell victims to the barbarous process. - Being worthless, they were flung back into the sea, but terribly mutilated, and already dead from the terror they had experienced in the meshes of the net. I was informed that at Geneva the practice was prohibited by law; if so, the statute was not strong enough to prevent three or four couples of these brigantines from annually quitting the Gulf of Spezzia and making for the high seas to pursue this wasteful mode of fishing. And more: the governor of the place, who ought to have watched over the execution of the law, was the first to encourage its infraction, his acquiescence being purchased by the gift of a sum of money."

Only one species of the sword-fish is known-Xiphias gladius - which abounds in the Mediterranean and in the warmer parts of the Atlantic, but is not often seen on the British coasts. Its body is elongated and covered with very small scales. It has no teeth. There is one long dorsal fin, but there are no finlets, and the ventral fins are wanting. The sides of the tail are strongly keeled or carinated. The tail fin is large and forked. On the upper part of the body the colour is a bluish-black, on the belly a silverish-white, but the one blends gradually with the other. 


\section{CHAPTER IV.}

\section{THE HERRIN G.}

T is almost unnecessary to describe a fish which is so widely known and so generally popular as the Herring; which is a welcome dainty on the tables of the rich, and a common article of daily food among the poor. We may note, however, two or three peculiarities. Its belly is carinated, or keeled, and protected by strong scales, whence we may conclude that it is " a ground-feeder." Its air-bag is of unusual size, and its pectoral fin is also very large, whence we may conclude that it can swim with ease and rapidity. There is reason to believe that it preys upon its own young, or upon the roe of its kind, when other nutriment is scarce; but, as a rule, it feeds upon acalephce and minute crustaceans, as well as upon small fishes. Its lobes of roe or milt are larger in proportion to its body than those of any other fish, and its fecundity is remarkable. It deposits its ova in comparatively shallow water; always selecting, with admirable instinct, a locality where they will adhere with facility, and where the young, when hatched, will find an abundance of nourishment.

The herring (Clupea harengus) belongs to the malacopterous family of the Clupeidae. When alive, its 
colours are a glaucous green on the back, and silvery white on the belly and sides; when dead, the green changes into blue, and in a dark place the whole body is invested with a kind of phosphorescence.

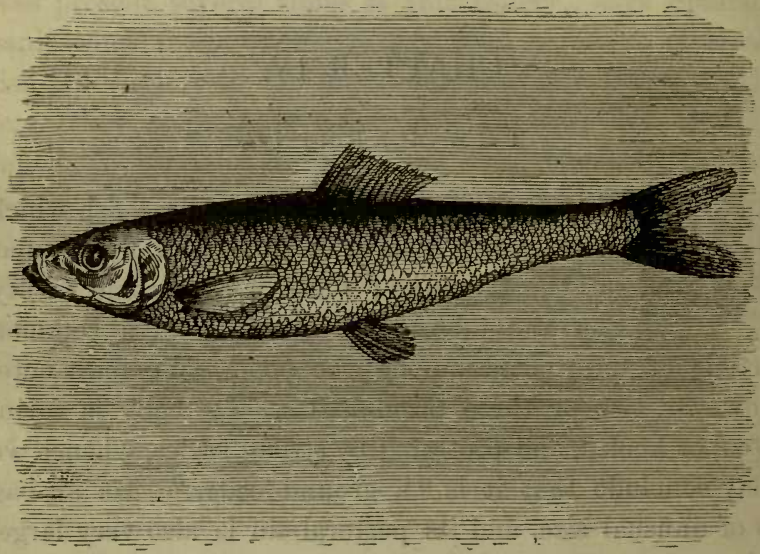

THE HERRING.

The herring inhabits the waters of the Northern Hemisphere, and is found in every sea from the North Pole to the 50th parallel of latitude, but it is specially and particularly a fish of the temperate regions. It is gregarious; and at certain seasons it leaves the deep water in immense shoals, or banks, of several leagues in extent, and of an extraordinary compactness, and approaches the shore. These banks are sometimes so dense that the fish composing them literally suffocate themselves by thousands in the shallows; and the nets of the fishermen are torn asunder by the weight of their capture. 
The track of the herring-shoal is indicated at night by a bright and continuous phosphoric gleam ; in the day, by the gulls and other sea-birds which pursue them. These are not the only enemies of the herring; the hake, the dog-fish, the porpoise, and, it is said, the whale and the shark, consume them in enormous quantities. And when we reflect on the millions which are caught for the use of man, we shall own that their fecundity was a wise

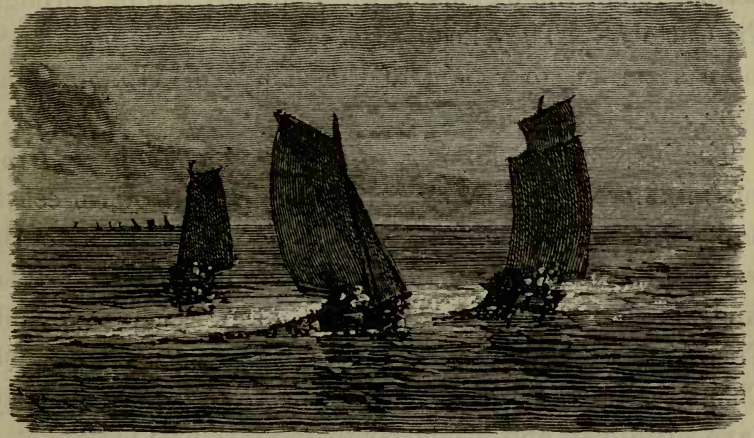

PHOSPHORESCENT SHOALS OF HERRING.

provision of Nature. It enables the product to keep pace with the consumption, as many as 68,606 eggs having been counted in a single female. We may add that the females outnumber the males in the proportion of seven to two.

It was anciently believed that the herring was a migratory fish, and some of the earlier writers trace with the most curious particularity the route it was supposed to follow. Thus they say that the great caravan which every January starts from the icy regions of the Pole 
divides into two main branches: of these the right wing steers towards the west, and arrives in March on the coasts of Iceland; the left wing moves eastward, and, in a certain latitude, breaks up into several shoals. Some repair to the Newfoundland Bank; others make for the coast of Norway, and pass through the Sound into the Baltic Sea. Others progress towards the northern point of Jutland, and after remaining there for a considerable period, rejoin the legions of the Baltic by sailing through the Cattegat. They keep together for a while, and once more separate, to repair to the shores of Holland, the Texel, and the Zuyder-Zee.

The heer, says Pennant, which moves westward, is the most numerous. Having arrived off the Scottish coast, it divides into two columns, - one of which sails southward to the English waters, and those of Friesland, Zealand, Brabant, and France; the other visits Iceland. Finally, the scattered shoals meet together in the English Channel, severely weakened by the immense losses they have sustained, and disappear in the Atlantic Ocean.

It is added that each shoal or battalion measures five or six miles in length, and three or four miles in breadth; and is led, in the belief of the fishermen, by herrings (probably the alice and twaite shad) of superior size and sagacity.

But to this theory we must advance some very forcible objections. It is obvious, for instance, that if the main heer, having started in one vast body from the Arctic Seas, separate in the latitude of Iceland into two columns, one of which makes for Europe and the other for America, these two columns should arrive at nearly the same time on the coasts of the Old and New Continents. But, on 


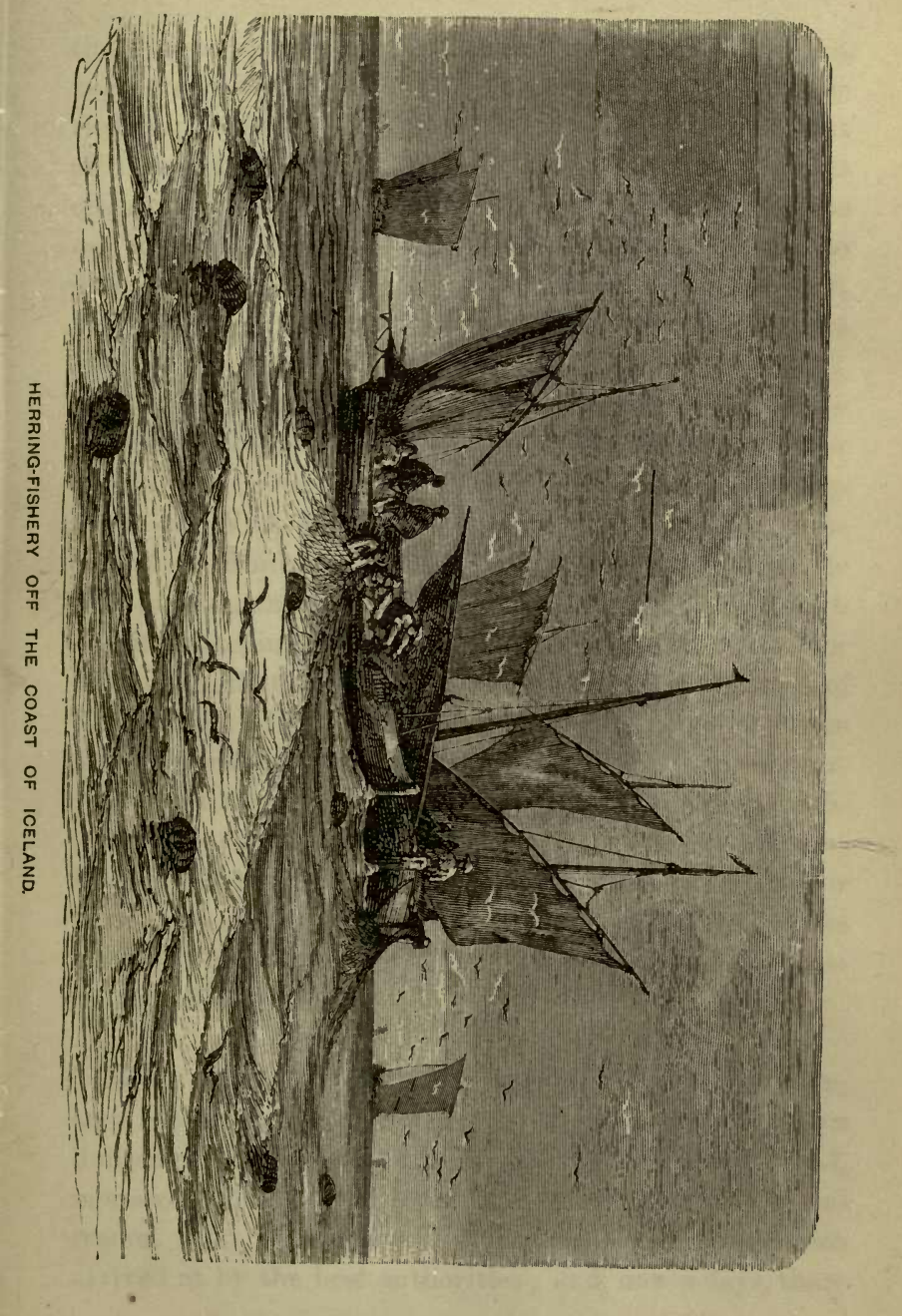



the contrary, the herring-fishery in America does not begin until April, while in the Firth of Forth it is carried on in winter. Again, the American herring is not of the same species as the European. The fact is, recent observation has very clearly proved that the herring is not a migratory fish; that different species belong to different localities, and that their only movement is one, at certain periods of the year, from the deep waters towards the shore.

Mr. Bertram is of opinion that the herring exists in distinct races, which arrive at maturity month after month. It is well known, he says, that the herrings taken at Wick in July are quite different from those caught at Dunbar in August or September; indeed, he goes further, and asserts that even at Wick each month has its changing shoal, and that as one race ripens for capture another disappears, having fulfilled its mission of procreation. It is certain that the herrings of these different seasons vary considerably in size and appearance ; and we know that the herrings of different localities are marked by distinctive features. Thus the famous Loch Fyne herring is essentially different in its flavour from that of the Firth of Forth, and those taken in the Firth of Forth differ again in many particulars from those caught off Yarmouth.

Much discussion has been suggested by the question, at what periods of the year the herrings spawn. Our limited space prevents us from entering into details ; and, moreover, these would be of little interest to the general reader. It is our business to state the conclusions arrived at by the best authorities ; and, now-a-days, there 
seems a consensus of opinion that the spawning-seasons are two, spring and autumn. Taking all parts of the British coast together, February and March would seem to be the great months for the spring spawning, and August and September for the autumn spawning; but gravid herrings have been caught in every month except June and December.

The spawn is deposited on the surface of the stones, shingle, gravel, and old shells which make up the oceanbed, and appears to be hatched within five or six weeks after deposition. The rate of growth of the young fish is not exactly known, but we may assume that it reaches maturity in about eighteen months, and can reproduce its kind in about three years.

Many trustworthy authorities incline to the opinion that the sprat (Clupea sprattus) * is not, as some writers assume, a distinct species of fish, but the young of the herring. We cannot help thinking, however, that the specific differences between them are fatal to this hypothesis. For instance, the ventral fins in the sprat begin immediately beneath the first ray of the dorsal fin, and not, as in the herring, beneath the middle of it. Again, its ventral fins have no axillary scales. Its dentition is different, and it has a serrated instead of a carinated belly. In truth, the only argument advanced in support of the hypothesis is based on the circumstance that it is not common to find sprats full of roe; but this is due to the fact that they are caught before they are full-grown.

The herring is found under four distinct conditions :1st, Fry or sill ; 2nd, Matres, or fat herring; 3rd, Full

\footnotetext{
* Also known as Harengula sprattus.
} 
herring; 4th, Shotten, or spent herring. To the first denomination belong all herrings under five or six inches in length. The second class is the best fitted for food purposes; and it is unfortunate that the herring should be taken in any other condition. In the course of three months the matre develops into the full or spawning herring. At the spawning-season they come together in immense shoals, and hasten to the "spawning-grounds" in the shallower and warmer waters of the coast. The magnitude of these shoals can hardly be appreciated by one who has not seen them. Sometimes they are driven ashore in such numbers that the inhabitants of the neighbourhood are absolutely unable to cure them, and the adjacent markets are completely overstocked. They may be caught in baskets or buckets, half a dozen at a dip. On the 16th of October, in the year 1873, an extraordinary influx of herrings took place at the mouth of the river Exe. As fast as the boats could be unloaded, a hundred men, women, and children were engaged in stowing the fish in hampers to be sent by the South Devon Railway to London for sale. The herrings were piled on the beach in heaps two feet thick, while many were floating dead in the water, as the nets had broken in drawing them ashore. The neighbouring villagers hastened to the spot with their baskets, and some in donkey-carts, to secure as many as they were able to carry off; a large quantity was taken by the farmers to be used for manure. 


\section{CHAPTER V.}

THE H E R I N G - F I S H E R Y.

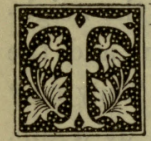

HE fishing-boats generally start on their expedition an hour or two before sunset, their crews consisting of four men and a boy, besides the skipper and owner. Sometimes both owner and skipper are combined in one individual. The stores on board do not occupy much space : a loaf of bread or hard biscuit and a keg of water can be stowed away in any corner. The sail, a great brown stretch of coarse and weather-beaten canvas, marked with the registered number of the boat, is soon hoisted, and away the fishers go, quickly leaving the shore and its sparkling lights behind them. There is genuine excitement, we can assure the reader, in an expedition of this kind, and whoever visits one of the herring-ports in the herringseason should make interest with a skipper, in order to gain an experience of a novel and exhilarating phase of life. The evening draws in apace; darker and darker grows the western sky, as the last pale reflections of the sunset are lost in the deep clear blue of night. All around, the waves are dotted with shifting gleams, as the herring-boats, rocked by the ripple and sped by the 


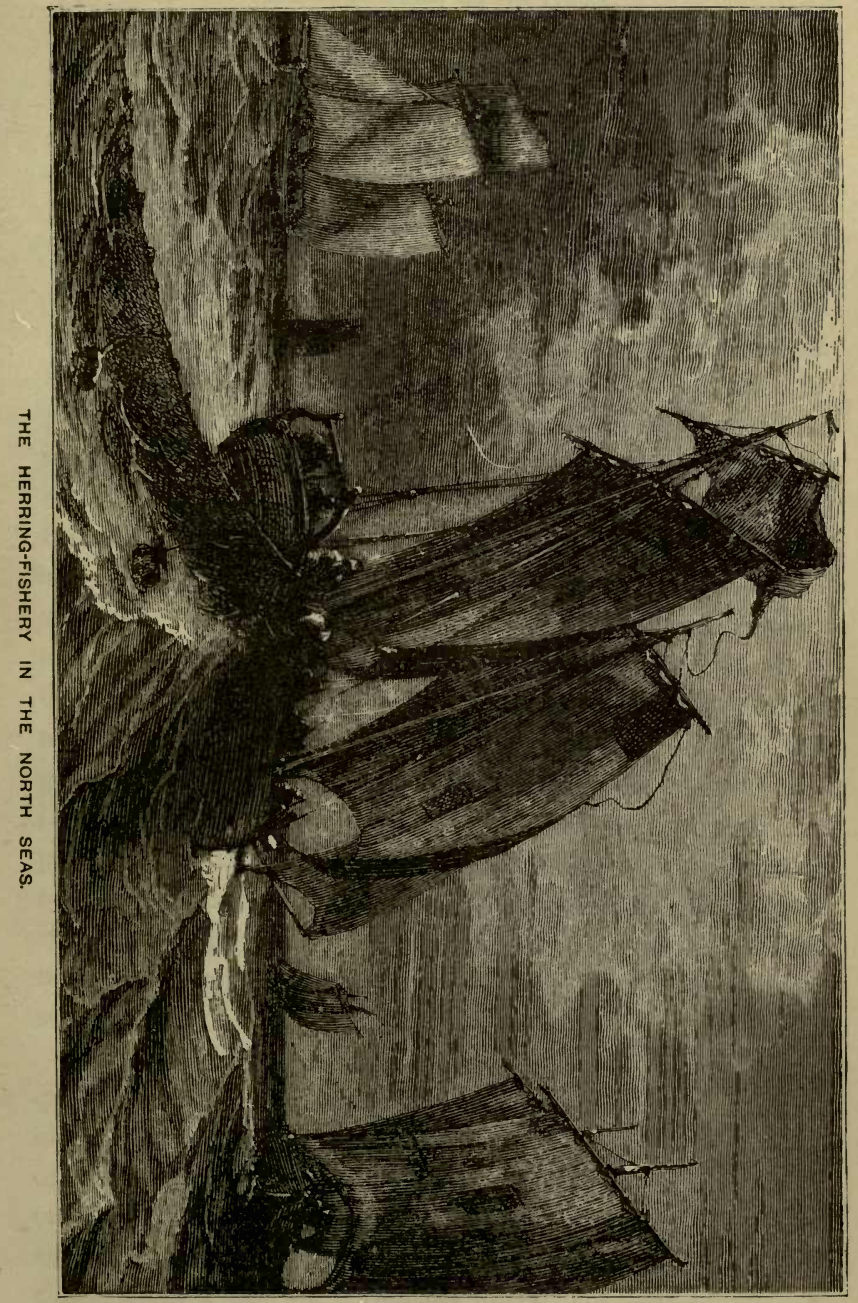




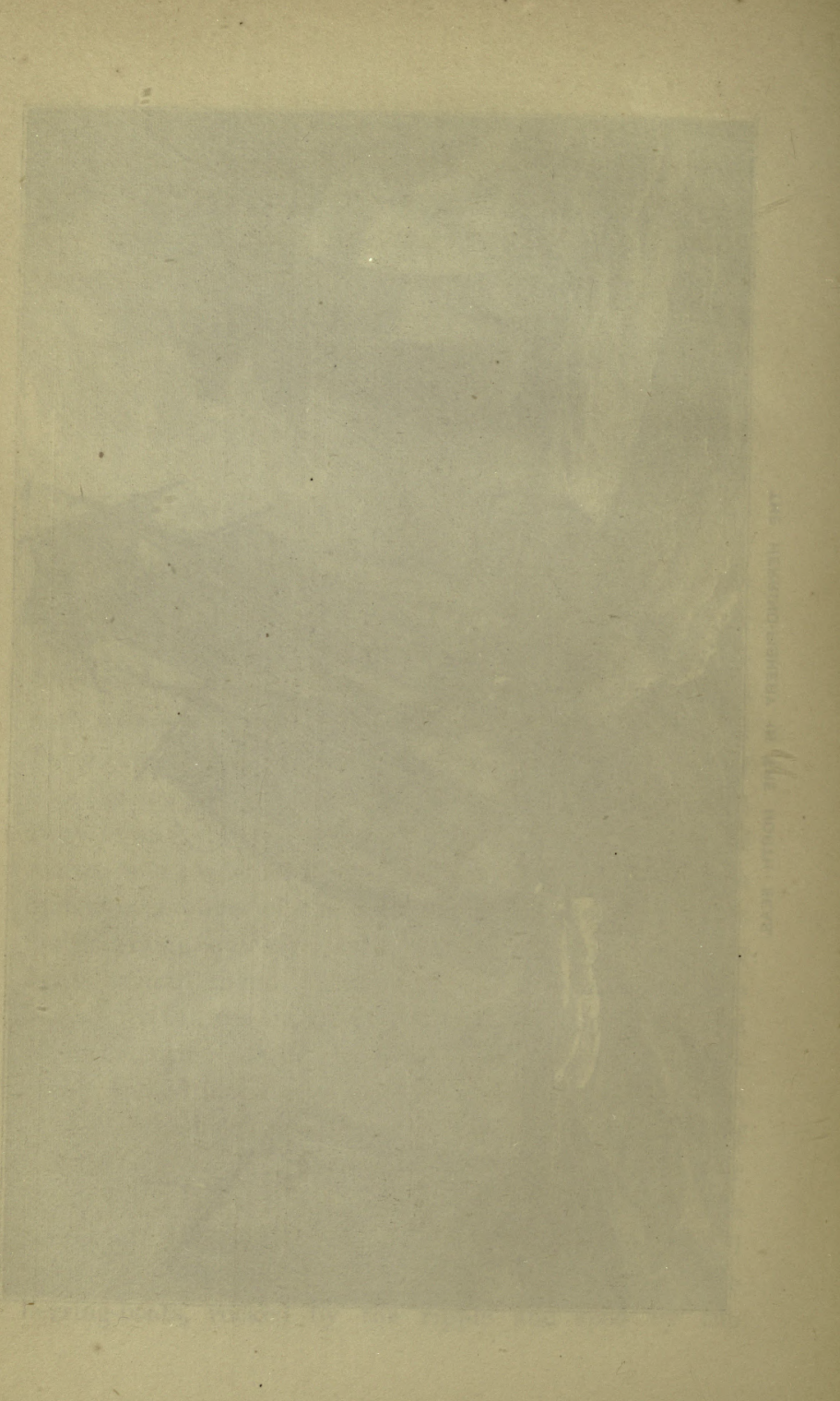


breeze, toss their lanterns to and fro. These gleams are scattered more and more apart as the little fleet gets further out to sea, and each bark pursues its independent route. At last the coast-line is no longer discernible, and the steady light at the harbour-mouth has vanished. We tack hither and thither in the solitude, uncertain where to take up our position, until our skipper becomes aware of an oily lustre on the water, and a phosphorescent sparkle on each undulating crest, which tell of the presence of the shoal. Then he jumps up, and orders all hands to work. The other boats, warned by the same signs, close in around, and the hoarse wailing cries of the gulls are an indication that they too are coming in search of booty. "Look alive, my men! Out with the sinker !" Overboard goes yard after yard of net, breadth after breadth, as fast as the men can pay them out, each division being indicated by a large painted bladder, until about a mile of "mesh-work," many feet in depth, is let go ; the further end being shown by the "dog," an inflated skin of considerable size - and the general disposition of the nets being traced by a long zigzag row of bladders, which, as it floats on the waves, and rises and dips with the motion of the tide, resembles nothing so much as the "dorsal ridge" of a great seaserpent!

And now the crew and their passenger may take a quiet sleep, "rocked in the cradle of the deep;" or chant old sea-songs, weird and strange; or muse on the mysteries of the sea, and the countless stories of romance and enterprise associated with it from the time when Jason and his adventurers embarked in the Argo to the stirring times when Vasco da Gama led his gilded galleys across 
the unknown waters to "far Cathay;" or they may watch the first faint coming of the day as the gray light breaks upon the eastern horizon. The skipper, however, is on the watch, for as the herring-fleet moves onward with wind and tide, his nets may become entangled with those of other fishermen, or be torn by a passing boat. At last the time comes for hauling in the nets; the bobbing down of some of the bladders, and other signs perceptible to the initiated, demonstrating the welcome fact that our lahour has not been in vain. The men haul in the swing-rope with a -will. The coiled net-work soon reaches the boat's side. "In with them, men!" Breadth after breadth is tumbled on board, and the quivering fish, each flashing like an arrow of silver, are shot to the bottom of the boat, there to breathe their last feeble gasp. We calculate our cargo at forty crans; not an excessive one, yet by no means to be despised.

And now the sail is hoisted; the boat's head is put about, and we steer for the distant harbour. When we reach the shore, all the lights are out; the glow of day is upon the landscape, and illumines the green hills and the leafy woods and the picturesque outline of the rocky coast. The quay is thronged with spectators, who welcome each loaded boat as it arrives with obvious interest. But such is not always the cheering spectacle. After a stormy night, pale faces will be there with anxious eyes, straining to eatch sight of the boat of husband, son, or brother: the boat, perchance, that never comes; that during the darkness has gone down with all on board; or that, if it comes, comes with battered sides and canvas rent and lost nets, a messenger of poverty, suffering, and want. 
As a source of national wealth, the herring-fishery is of signal importance. In Scotland and the Isle of Man it employs nearly 300 vessels, manned by 1200 men and boys; while the total number of boats, decked or undecked, is about 10,000, manned by 45,000 fishermen and boys. Add to these the coopers, gutters, packers, netmakers, and other labourers, dependent more or less directly on the herring-fishery, and it would seem probable that it supports 90,000 persons in Scotland alone. The value of the nets in use exceeds $£ 400,000$, and of the herring-boats $£ 300,000$.

In England the herring-fishery, it is well known, has been carried on since the beginning of the eighth century. In Normandy it commenced before the eleventh. Holland owes its prosperity in no small degree to this fishery, which the Dutch have always prosecuted with great energy. Towards the middle of the seventeenth century they almost monopolized it, employing in it 2000 boats; while it is computed that this single branch of industry supported 800,000 persons in the two provinces of Holland and Western Friesland. They have been distanced, however, by the British fishermen, and find formidable rivals in the Americans, Norwegians, and French.

The Scotch herring-fishery is regulated by special Acts of Parliament, and controlled by a Board, known as the "Commissioners for the British Fisheries." This Board allows of no other method of taking the fish than by a drift-net,-_ "trawling" being illegal in Scotland. The drift-net is composed of fine twine worked into meshes of an inch square, and measures 50 yards in length and 33 feet in depth. These nets are joined together, and let into the water in a straight line, where they are kept 
perpendicular by a number of bladders or cork floats, balanced by a few slight weights of lead. A single boat will often draw after it a "drift" - a series of nets-extending fully a mile in length.

We now proceed to describe the different aspects of the fishery, as carried on in different localities, premising that the cargo of a herring-boat is measured by crans, each cran containing forty-five gallons.

The reputation enjoyed by the Yarmouth herrings in England, belongs in Scotland to the fish caught in Loch Fyne, a great arm of the sea which cuts into the west coast between the Mull of Cantire and the Island of Bute, striking inland as far as Inveraray, the chief town of the territory of the Campbells. Loch Fyne herrings, however, are celebrated "furth of the kingdom." Sam Slick panegyrizes them as "Glasgow bailies ;" a sobriquet alluding to the circumstance that, of old, the finest specimens were presented to the Bailie of the River Clyde,-locally known as the "Skate Bailie,"- by the vendors who disposed of their wares on the Glasgow quay. As early as 836 the Dutch fishermen frequented Loch Fyne in order to purchase its savoury fish ; and for centuries they traded largely with the herring, curing such enormous quantities that many a fortune was built up by its means even in Amsterdam itself,-which, according to the ancient proverb, was erected on herring-bones. It has been pointed out that this enrichment of the Dutch meant the spoliation of the West Highlanders, who were foolish enough to look upon the whale-fishery in Arctic seas as preferable to the herring-fishery in their own waters. Not, says a writer in Once a Week, that they altogether despised the 
herring ; for it appears that a Lord Breadalbane, in 1590, received a portion of his rent from a Loch Fyne tenant in Loch Fyne herrings. At length they became aware of the full importance of the wealth which circulated to and fro in their great sea-loch, and undertook the herring-fishery with so much vigour that they gradually got it wholly into their own hands, and raised it to the position of a national interest. In Loch Fyne alone the annual value of the fishery is computed at $£ 25,000$; and whoever has ascended in the Iona-that most luxurious of river steamboats - to Ardrishaig, must have seen the large fleet of dusky boats which are engaged in it.

The waters of Loch Fyne formerly teemed to such an. extent with the herring-shoals, that the Gaelic fishermen were wont to say the loch was one part water and two parts fish. We may remark, in passing, that the word herring alludes to the abundance of the fish. It comes from the German heer, a legion or army. As many as 20,000 barrels, each containing from 500 to 800 fish, and each worth about fifty shillings, have been cured in a year in the Loch Fyne district. In fact, the demand now exceeds the supply, and the West Highland fishermen have never any difficulty in disposing of their cargoes.

At the head of the peninsula of Cantire, completely shut in by bare and rugged mountains, stands the little town of East Tarbert, with its small but secure harbour opening into Loch Fyne. A secure harbour when once you are in it; but the approach, through broken and sombre rocks, the resting-places of scores of gulls and gannets, is so intricate, that no one but a Loch Fyne fisherman could possibly carry his smack through the labyrinth! As Lord Teignmouth says, - "The rude outworks of the (502) 
rocks apparently barring access, the overhanging keep of the ruined castle, the village, and the innumerable fishing-boats choking up every nook and crevice, form a scene singularly picturesque." But what is picturesque is not always convenient. However, East Tarbert is, and always has been, one of the chief ports for the Loch Fyne fishers ; the other, on the west coast of the Mull, is Campbelton.*

About a hundred years ago Campbelton was of more importance in this respect than Tarbert; but as its whisky-distilleries sprang up its fisheries went down-and though the latter are now prosecuted with considerable energy, they have not recovered their ancient prosperity. In 1863 a company was formed in Campbelton for

* Mr. Black furnishes an animated description of the departure of the Loch Fyne fishermen. "A fine sight it was," he says, "that setting out of the herring-fleet in the yellow afternoon, with the bronzed and varnished hulls of the boats shining like so many spots of brownish-red on the calm blue of the lake. Here, too, were none of the tattered and pot-bellied fishermen of Brighton, living on occasional hauls of mackerel and occasional shillings got from visitors-but crews of lithe and stalwart men, big-boned and sparefleshed, who plied the enormous oars with a swing and ease that told of splendid physiques, hard exercise, and tolerably good living. The wind had entirely gone down, and the various boats that left the harbour in straggling groups formed a strange sort of picturesque regatta, their oars scarcely troubling that still plain of blue. Here and there a brown sail hung half-mast high, just in case a slight breeze might be got at the mouth of the bay ; but each boat had its four enormous oars regularly rising and falling as they all drew away from us. And we could hear the laugh and jest come across the still water, as two of the boats would get within speaking distance; and now and again a verse of some shrill Gaelic song would float towards us, the notes of it keeping time to the oars. The further the boats drew out towards the broad bosom of the loch, the deeper grew their colour under the warm and level light of the sun, until many of them seemed like rose-coloured buoys placed far out on the smooth plain. And then, as they reached a line of darker water on the loch, we could see them, one by one, run up the broad brown sail to catch the light breeze. And while we sat still and wondered how they would spend the long and dark night, and what songs would be sung by the side of the stove, and whether rain would compel them to make the sail into a tent, and what sort of take they would bring home with them in the cold gray hours of the dawn, lo! the boats had disappeared as if by magic."-Mr. Pisistratus Brown in the Highlands, pp. 41, 42. 
carrying on the herring-fishery, and in their first year they built and despatched twelve boats, at a cost of $£ 400$ each. In May 1863 twenty-seven other boats sailed from Campbelton for the Stornoway herring-fishery; and on the morning of the $3 \mathrm{rd}$ of June, says a writer already quoted,* it was a beautiful sight to see, in that lovely land-locked harbour, one hundred and forty boats laden with those silvery gems and phosphoric splendours for which the herring is so remarkable.

In May 1868, the fleet that sailed from the Cantire port numbered thirty-six smacks. One of these brought in thirty maze (a "maze" contains six hundred) of trawled herrings-from six to eight maze being the number taken with the drift-nets. The best fish were retailed at threehalfpence each ; then at eight for sixpence-with inferior fish at fifteen for sixpence; but the profit on these sums went to the women who sold the fish, as they were purchased from the boats at three shillings and three shillings and sixpence per hundred.

As to the method of taking the herring, the law has laid down a very strict rule: the herring must not be trawled, but taken with a drift-net. Such is the rule, at least, which obtains in Loch Fyne ; for trawling is allowable on the eastern coast of Scotland, and north of Ardnamurchan Point on the western coast : an anomaly for which the fishermen do not echo the old cry, "God bless the Duke of Argyll!" Yet, in defiance of the law, trawling is largely practised in Loch Fyne; and the steamers convey many barrels of trawled herrings from Cantire to Glasgow. The trawling is accomplished, as explained in our remarks on the White-Fish Fishery,

* Once a Week for 1869, p. 39 . 
by means of a seine-net, to which a "sole" or bottom rope is attached ; and it is not so expensive to the fishermen as, while it is decidedly more productive (and, some say, destructive) than, the drift. In Loch Fyne the trawlnet is managed by three or four boats' crews, who row round in a circle, immersing the net to a slight depth in the water, and dragging it until they can join its two extreme ends, the shoal of fish being swept into the middle. The slower process of the drift-net, as the reader knows, requires it to be paid out by the "buss" or smack in a direct line, its course being indicated on the surface of the waves by corks, bladders, or "bows" made of tarred sheep-skins. But then the fish thus caught are not crushed, pressed, or otherwise injured; and though the process is less expeditious and more costly than that of the trawl-net, it is probably more profitable in the long run-and an experienced purchaser can at once detect the legal drift-net herring from the illegal trawl-net herring.

Everybody knows that the herring is chiefly caught during the night, when it approaches nearest to the surface of the water. Its phosphoric properties, or "blaze," - to use the fishermen's vernacular,-render the shoals visible in the deepest darkness, and give to the rippling waves a magical appearance of floating, flashing gems. The fishermen appear to dread what they call "scoroders" and "buckers" more even than the official police-boat, which watches the fishing-grounds to prevent any breach of the legal regulations. The "scoroders" are the jellyfishes which block up their nets, and the "buckers" are large porpoises which tear the nets and prey upon the herrings.

Though an experienced fisherman seems intuitively to 
determine the position of a herring-shoal, he has no unerring signs to guide him. As his boat glides along, however, his crew will give a rapid stampede with their feet, or rattle the anchor, and the noise frightening the fish, the look-out man knows at once by the phosphorescent "blaze" where to let down his net. But the shoal may drift away too quickly, or its numbers may be scanty, and it is always a matter of uncertainty whether the net will return from the depths well or ill loaded.

In Holland the herring-fishery is guarded by very minute regulations. On setting out for the expedition, the sailors pledge themselves not to lower a net before the 25th of June, nor after the 1st of January; nor, during the fishery, when the herring is in its prime, to make use of any nets but such as are of the size of mesh regulated and fixed by Government; and that they will adopt every precaution to secure to the Dutch herring its time-honoured celebrity.*

As the herrings taken differ very much in quality, even in the same haul, they are carefully sorted, and rubbed with finer or coarser salt according to their merits. The salt, which is procured from Spain, is first dissolved to get rid of impurities, and the solution subsequently evaporated in the sun; the crystals thus obtained are of different sizes : the prime fish are treated with "gros sel" and the inferior with "petit sel ;" and the greatest care is taken that the two shall not get mingled. The dimensions of every pickling cask, as well as the seasoning of the wood, are under the strictest supervision; and a man, says Badham, would be held a traitor to his country who

* Badham, "Ancient and Modern Fish-Tattle," pp. 324, 325. 
should put one poor fish in a barrel devoted to the superior kind, or disobey in the slightest particular a beneficent code of laws, framed alike for the advantage of himself and of the world at large: a big official seal stamped upon each barrel coronat opus, and vouches to the public that no precaution has been neglected or pains spared; and if it should ever happen, which is not within the range of probability, that a bad barrel bore such a seal, the national faith of Holland would be considered irretrievably compromised.

The Scotch herrings, however, are similarly "branded;" and we are of opinion that their best "brands" are equal to any which Holland produces. Few herrings equal, says Badham, and none can surpass in flavour, a "Loch Fyne fresh ;" whilst for those who like savoury salt provisions, a "Yarmouth bloater" may be recommended in preference to any Dutch or other foreign bronzed clupean of distinction.

Yarmouth sends one hundred herrings, baked in twenty pies or pasties, to the Sheriff at Norwich, to be delivered to the clerk of the Royal Kitchen. The Popes, it is said, are sagaciously partial to them, and recommend them strongly to the faithful. Whence the fishermen at Yarmouth and Lowestoft are accustomed to drink the following liberal toast :-

"Here's to his Holiness the Pope, with his triple crown, With nine dollars each for each cask in the town."

A very considerable herring-fishery is carried on in the Hebridean waters, and more especially off Skye, Barra, and Long Island. At one period the herring appeared in immense shoals in every loch and bay which intersect these isles, and the natives caught it in large 
quantities both for home consumption and exportation. Now the fishers have to go further out to sea in quest of spoil, and for several years this branch of industry underwent a disastrous decline. But of late the attention of capitalists has been directed to its importance, and the inhabitants of Lewes and South Uist derive their chief subsistence from it. Loch Boisdale, a deep inlet on the east coast of the Long Island, is in the herring-season a scene of the liveliest activity. At all other times, truth to tell, it is desolation itself; but when the spring-time brings with it the silvery shoals, smacks, skiffs, open boats, and wherries make the narrow waters shady: not a creek, however small, but holds some boat in shelter. A small fleet congregates in the far-away misty loch : the Leven boat, from the east coast, with its three masts and three huge lug-sails; the Newhaven boat, with its two lug-sails; the Isle of Man "jigger;" the beautiful Guernsey "runner," handsome as a racing yacht, and powerful as a revenue cutter; besides all the numberless fry of less noticeable vessels, from the solid west-country smack down to the rude-built two-masted Arran wherry. Swarms of sea-gulls are cradled on the crest of every wave, though the loch is so incrusted with the oily fishy deposit that only a strong wind can break up its tranquil surface. Everywhere on the barren shore and heathery hill-sides, and on the innumerable rocky islets sprinkled up and down the inlet, rises the smoke of the fishermen's encampments. Busy men and women and children, bronzed with exposure to the salt air, surround the curinghouses and the inn, while weary fishers are stretched fulllength upon the beach, dreaming away the hours till nightfall. About three or four o'clock they spring to 
their feet, nimble enough, however, and wide-awake; and soon afterwards the herring-fleet melts slowly away upon the horizon, not to reappear until long after the hills have welcomed the first rays of morn.

Herring-fishing in Loch Boisdale is practised in exactly the same fashion as herring-fishing in Loch Fyne, or off the east coast; but the reader may not be disinclined to spend another night in quest of the "silver fish," and make acquaintance with a west-country smack. We ourselves have never tried the western waters, but a writer in All the Year Round, who evidently knows them thoroughly, gives us the benefit of his experience in a very graphic and lively fashion, and we propose to avail ourselves of his narrative :-

Imagine yourself, then, on board a west-country smack, running out of Boisdale harbour with the rest of the fleet. It is afternoon, and a nice fresh breeze blows up from the south-west. Crouching in the stern, by the side of the helmsman, you look around with all the interest of a novice. Six brawny fellows, in picturesque attitudes, lounge about the great, broad, open hold, and another is down in the forecastle boiling coffee. It seems a lazy business, so far; but wait! By sunset we have run fifteen miles up the coast, and are about eight miles east of the $\mathrm{Ru}$ Hamish lighthouse; many of the fleet are still around us, and on the waters their shadows brood like birds. How thick the sea-gulls gather yonder! Hark! that plash ahead of the boat was the dive of a solan-goose. That the herrings are hereabouts, and in large numbers, you might be sure, even without the strange, enticing, phosphorescent light which travels in patches in the water to leeward. And now the whole crew dart into sudden 


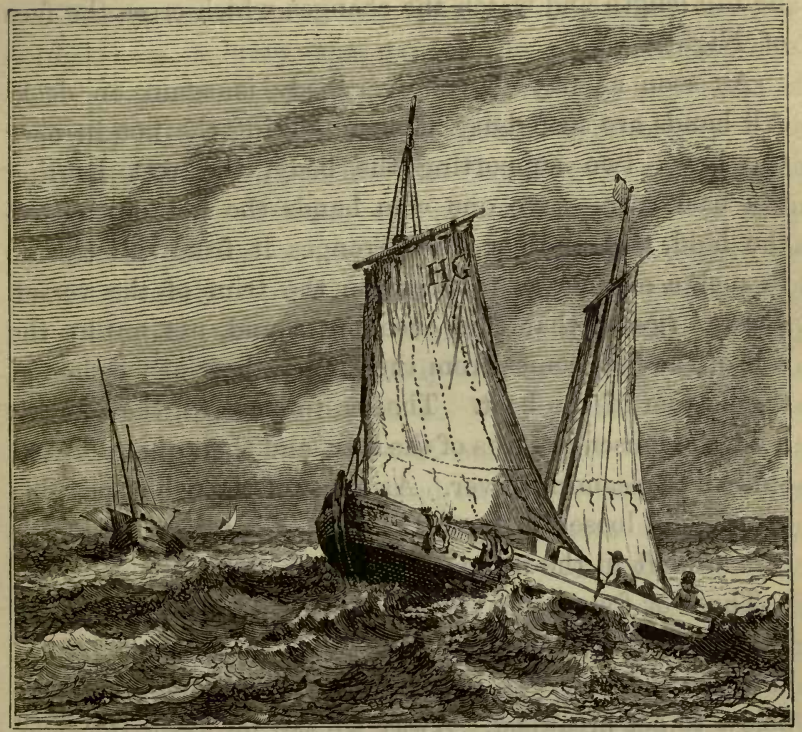

THE FISHING-SMACK.

activity. The boat's head is brought up to the wind, the sails are lowered, one man grips the helm, another lays out the back rope of the net, a third the "skunk" or body, a fourth stands ready to heave out the buoys, the rest áttend forward, keeping a keen eye open for other nets, and prepared, should the boat run too fast, to steady her by dropping the anchor a few fathoms into the sea.

All the nets are run out, the boat is brought bow on, and the mast lowered, secured, and made all taut and trim for hoisting at a moment's notice. Then the crew turn in below for a nap, leaving one to look out on deck; and you too turn in, or you sing snatches of old songs, or you 
lie full-length and watch the changes which cross the face of Night.

As soon as day dawns everybody is again on deck. All hands are soon busy at work, taking the net in over the bow; two supporting the body, the rest hauling the back-rope-save one who hands the net down into the hold, and another who arranges it from side to side in such a manner as to preserve the trim of the vessel. Tweet! tweet ! that thin cheeping sound, not unlike the call of the bat, comes from the hapless herrings dying at the bottom of the boat. The sea to leeward, the smack's hold, the muscular arms of the men, and their quaint attire, shine like gleaming silver. As many of the fish as possible are shaken loose during the process of hauling in, but the rest are left in the net until we make the shore.

Three or four hours pass in this wet and weary work. But at last the nets are all drawn in, the mast is hoisted and the sail set, while the cook pro tempore plunges below to get breakfast. Away we sail for Loch Boisdale. Our good smack makes excellent progress-

$$
\text { "She walks the waters like a thing of life," }
$$

and outstrips many of her comrades, bound as she is for the harbour-mouth. The anchorage is reached, but the work is not quite finished, for the fish has to be measured out in cran baskets, and delivered at the curing-station. By the time that the crew have got their morning dram, have arranged the nets snugly in the stern, and have had some herrings for dinner, it is time to be off again to the harvest-field. Half the crew turn in for sleep, while the other half hoist sail and take the vessel out again to sea. 
The aspect of one of our fishing-ports during the herring-season is very singular to the unaccustomed eye. The place smells of herring, thinks of herring, talks of herring. Of what importance to its inhabitants are the contest between Pope and Kaiser, the struggles of the Revolution in France, or even the banter between political parties at home, when weighed with the amount of the "take" of last night, or the prospects of a good haul to-morrow? These herring-towns, as they may appropriately be called, are dotted all along the east coast from Yarmouth to Wick. The herring, be it remembered, is a native of our British seas, and can be captured all the year round on the shores of the three kingdoms. But the fishery is either more abundant on the east coast, or is there pursued with more activity, and it is the eastern towns which furnish our markets with their principal supplies. And so it is to Yarmouth, Dunbar, Buckie, Fraserburgh, Banff, or Wick that you should go, if you would see the herring-commerce in all its fulness. Wick is the chief seat of the fishery, and it is to Wick we shall accompany Mr. Bertram* to gain some idea of its appearance in the height of the season.

It is morning, and the fleet of herring-boats is making all sail for the harbour. Everybody in the town is astir; there are no idlers; and everybody seems to have come down to the pier or beach. Various quaint utterances in the vernacular reach our ears as the boats arrive, and are recognized by those interested. "Yon is Sandy Macallister's!" "Hoot awa, man! Alick Macpherson's is gaining fast upon him!" "Here comes old Donald Ferguson's! I ken her by the clout on her old sail !"

* Bertram, "The Harvest of the Sea." 
But the boats arrive, and drop alongside the quay; and in less than an hour we are surrounded by herring. Herring seems to fill the air, as it certainly occupies the mind of every Wickian. Yonder we see innumerable basketfuls being poured into the huge gutting-troughs, and in another direction basketfuls, also innumerable, are being carried from the three to four hundred boats moored on that particular side of the harbour; and behind the troughs more basketfuls are being conveyed to the packers. For, as the reader knows, the herring is sent to market either fresh or cured; and those intended for immediate consumption are packed as rapidly as possible, and removed to the railway station.

All around, the atmosphere is humid; the sailors are dripping, the herring gutters and packers are dripping, the spectators are dripping; everything and every person appears wet and comfortless; and as you wander along you splash into lakes and rivers of brine.

Meantime, the bright scaly fish are being shovelled about in the large shallow troughs with immense wooden spades, and without ceremony. Strong, dour-looking men pour them from the baskets on their shoulders into the aforesaid troughs; and other stalwart, dour-looking men dash them about with more wooden spades, and then sprinkle salt over each new quota as it is poured in, till a sufficient quantity has accumulated to warrant the commencement of the important operation of gutting and packing.

Men are hurrying about with note-books, in which ever and anon they record mysterious computations. Carts, filled with dripping nets, convey them to the "links" and fields to dry. In all directions are piled 
up stacks of herring-barrels, and stacks of billet-wood ready to be converted into staves for more barrels. The scene is one of confusion, yet with a certain order in it ; and of coarseness, yet not without an element of the picturesque.

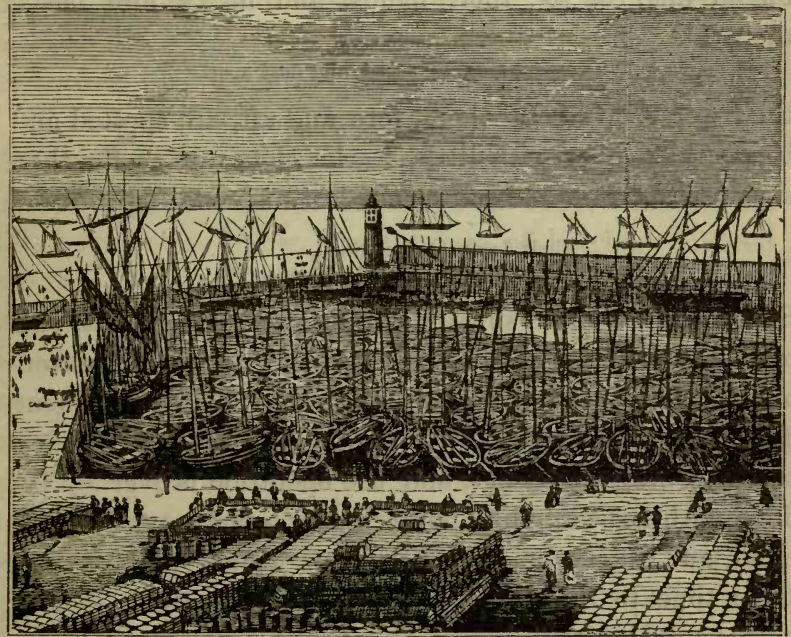

WICK HARBOUR DURING THE FISHING-SEASON.

When a sufficient quantity of fish has been emptied into the troughs, the process of evisceration (vulgo, "gutting") commences. This is performed by females, hundreds of whom in this way contribute to defray the household expenses and to keep the "bairns" at school. It is an unclean business, however, to say the least of it, and soon effects a complete "transmogrification" in the appearance of the buxom, stalwart females who, prior to the arrival of the fish, had loitered about the curing-yard in gaily- 
striped petticoats and dashing shawls; for, of course, they have now assumed a more suitable attire-generally a kind of oilskin gabardine. Behold them, then, about ten or eleven o'clock in the forenoon, when the gutting scene is at its height, and after they have been at work for an hour or so: their hands, and necks, and busts, their

"Dreadful faces thronged, and fiery arms,"

their every bit about them, fore and aft, are spotted and besprinkled over with little scarlet clots; or as Southey says of Don Roderick, after the last and fatal fight-

" Their flanks incarnadined, Their poitral smeared with blood."

See yonder trough, surrounded by a ferocious host, two of them wearing the weeds of widowhood! How dexterously they ply the knife! With a downward movement they seize the herring, with an upward movement they throw it into the basket, and the operation is over! 'Tis done with lightning-like dexterity by a mere turn of the hand, and thirty or forty fish are "gutted" before you have time to count sixty ticks of your watch. These ruthless widows seize upon the dead herrings as if to revenge upon them their lost husbands, who are sleeping full many a fathom down in the "salt ooze;" and they scatter about the entrails as if they had no "bowels of compassion."*

There are fresh herrings and there are pickled herrings, and both are excellent in their way, - savoury, and, it is said, nutritious ; but there are also "red herrings"

* We borrow these details from Mr. Bertram, for we confess that, in our visits to the herring-ports, we have never cared for this scene in the drama. 
and "bloaters." The latter are prepared at Yarmouth in immense quantities. The fish are run through the gills with thin spits, and exposed to the smoke of small logs of oak. As they swell during the curing process, they have come to be called "bloaters." They are more or less smoked and salted according to the particular narket for which they are designed. They are packed in barrels, each containing seven hundred and fifty fish.

Yarmouth has long been celebrated for its herringfishery; and, probably, the barrels of salted fish which caused the Battle of the Herrings in 1429,* came from this busy port. When the "statute of herrings" placed the fishery under the control of the Crown, it was then its principal depôt. A century ago it owned 200 boats, which employed, in one way or another, 6000 persons. It now possesses double the number. $\dagger$ Each boat or "buss" carries from 15 to 20 lasts of herrings,-each last comprising 10,000 to 13,000 fish,- and is manned by twelve to fourteen men and boys. About 10,000 tons of salt are annually consumed in the curing processes; and the quantity of fish sent off by railway exceeds 36,000 tons.

A " curing-house" or "smoke-house" is a large oblong building, some forty or fifty feet high, without a flocr between ground and roof, and divided above into transverse compartments three or four feet wide, by partitions of horizontal rails, beginning at about seven feet from the base of the walls. These open partitions, or racks, are called "loves," $\ddagger$ and support the "speets" - that is,

\footnotetext{
* When the Duc de Bourbon was defeated in an attempt to surprise a convoy of salt fish on its way to the English camp before Orleans.

t Some of these are employed in the mackerel-fishery and the deep-sea fishing. The capital invested in them is estimated at half a million.

† Probably from louvres, which they resemble in appearance.
} 
the sticks or laths, long enough to lie across from one to the other.

The carts arrive with supplies of fresh herrings from the boats. The fish are thrown into a bricked recess,. sprinkled with salt, and left "to pickle" for periods varying from twenty-four hours to ten days. The shorter suffices for the herrings caught eariy in the season, and intended for quick sale and speedy eating; the "Straits'-men," which are exported in thousands of barrels to the Mediterranean, lie longer; and longest, the "black herrings," which are famous for their fine, ham-like flavour. Whatever the kind, the fish are washed and spitted by gangs of women, whose nimble fingers hang them one by one, transfixed through gills and mouth, upon the "speets." These women are ealled "ryvers," because they ryve or rend the gills with their thumbs to make way for the sjeet; and a gang of eight will speet eight lasts a day,-each ryver earning about three shillings and ninepence. As fast as the speets are filled they are placed, resting by the ends, on the topmost loves, by men who ascend the racks, until the upper tier is full; then the next below is filled; and so on from top to bottom, till every compartment is occupied and all the herrings are hung. Then the fires of oaken logs are lighted underneath, and as there is a small space left between fish and fish, the rising smoke envelops all alike. The oil speedily begins to drop, and the herrings turn yellow, orange, red, or black, according to the duration of their exposure. Bloaters are allowed to hang only until they bloat or swell. The Straits'-men, and others that bear close packing, are "struck"-that is, taken down; and with a skilful movement the packer, dropping 
the end of the speet into the barrel, pushes off the herrings in the order in which they are to lie, radiating from the centre, until each barrel contains seven hundred and fifty, and appears gorged to repletion. Then the barrel is removed to a press, which packs the fish closer, and all is ready for the final operation of " heading up."*

The principal herring-season is during the autumnthat is, from August to October-when the seas all round our coasts are covered with herring-boats, - stout, sturdy barks, each with its single sail, square or "leg-of-mutton" shaped. At this time every little bay which varies the outline of our shores sends forth its tiny flotilla. Such boats as do not belong to a local fishery proceed from the small "fischar-villages" which are dotted here and there in the shadow of our ancient cliffs. In fact, says a Scotch writer, who is deservedly esteemed a standard authority on this subject,-wherever an enterprising curer sets up his stand, there the boats will collect around him ; and the boats draw there, as by a kind of magnetic attraction, all sorts of miscellaneous people: dealers in salt, dealers in barrel-staves, vendors of "cutch," Prussian herring-buyers, buxom lasses from the inland districts " to gut," and men from the Highlands desirous of employment as " hired hands." Itinerant ministers and revivalists appear on the scene, and deliver occasional "discourses" to the hundreds of devout Scotch people, who are always ready to join, to their honour be it said, in a "diet of worship;" and in this way many a quiet little village develops into a prosperous town, which in due time has its railway station, and its provost and

$$
\text { * Walter White, " Eastern England," i. 145-147. }
$$


magistrates, and everything respectable about it. "As the chief herring-season comes on, a kind of madness seizes on all engaged, ever so remotely, in the trade; as for those more immediately concerned, they seem to go

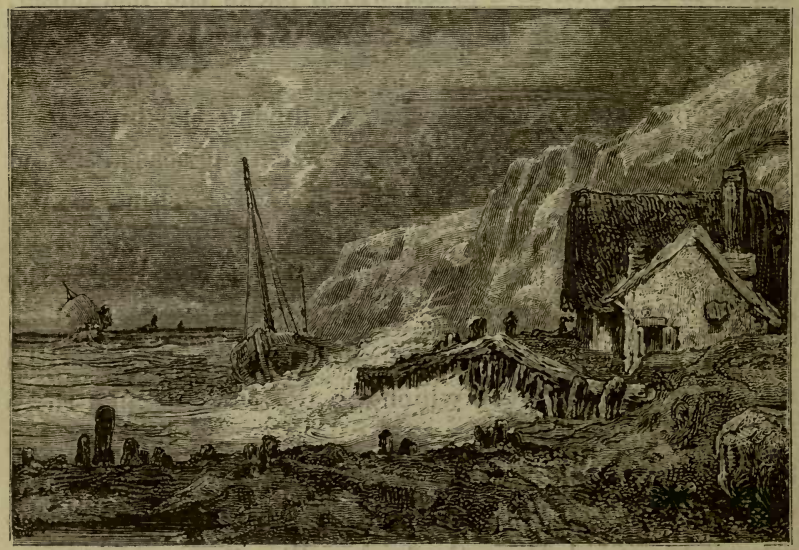

A FISHING-VILLAGE.

completely ' daft,' especially the younger hands. The old men, too, come outside to view the annual preparations, and talk, with revived enthusiasm, to their sons and grandsons about what they did twenty years agone; the young men spread out the shoulder-of-mutton sails of their boats, to view and repair defects; and the wives and sweethearts, by patching and darning, contrive to make old nets 'look amaist as weel as new ;' boilers bubble with the brown catechu, locally called 'cutch,' which is used as a preservative for the nets and sails; while all along the coasts old boats are being cobbled up, and new ones are being built and launched." 
The Shetland herring-fishery must next engage our attention. As originally carried on by the Dutch, it was, for them, an undertaking of truly national importance, and yielded annually a revenue of $£ 3,000,000$. A trustworthy authority asserts, that while it flourished in their hands they drew from the waters washing the coast of Shetland not less than $£ 200,000,000$. In 1633, Captain Smith, who was employed by the English Government to report on the extent of the Dutch fishery, recorded that it employed as many as 1500 "herringbusses," each of 80 tons burden-with 20 armed ships, carrying 30 guns each-and a fleet of "dogger-boats" to the number of 400 , each 60 tons burden. Indignant and amazed that his countrymen could remain

"Shamefully passive, while Batavian fleets
Defraud us of the glittering finny swarms
That heave our friths, and crowd upon our shores,"

he exclaims :- " If the king would send out such a fleet of vessels for the fishing-trade, being in our own seas, and on our own grounds, and all strangers were discharged from fishing in those seas, that the subjects of the three kingdoms only may have it, it would make our king rich and glorious, and the three kingdoms happy,-not one would want bread, and God would be praised, and the king loved." His advice, however, which would hardly approve itself to political economists, was not followed, and the Dutch continued their fishery. But owing to the great wars in which Holland was afterwards engaged, and the rapid decline of her naval power and commercial pre-eminence, the fishery ceased to be prosecuted with the same vigour. In 1774, the number of Dutch vessels engaged in it was only 200 . Then came the wars of 
the French Revolution, followed by Britain's paramount supremacy at sea. British enterprise began to cultivate the resources that lay close at hand in British waters, and so it has come to pass that the number of Dutch herring-boats now frequenting the shores of Shetland seldom exceed forty or fifty.

Yet, though it is no longer possible, as it was of yore, to cross Bressay Sound on a bridge of busses, the arrival of the Dutch boats is still an important event in the annual history of Lerwick. They make their appearance in June; and while they remain in port, the Dutch seamen spend most of their time on "the wall," as they term the shore. In face and form they bear a curious family resemblance - the former being Teutonic, and the latter emphatically "Dutch." A greater variety is observable in their dress; for while some wear a neat striped cotton blouse, with cloth cap and trousers; and leather shoes, others wear enormous "sou'-westers," blouses of canvas, capacious knickerbockers, or even "petticoats," all of canvas, and wooden sabots, "clogs," or "chumpers," not unlike their own vessels in shape. The streets of Lerwick present a very animated appearance, when paraded by these quaint, amphibious creatures, with their hands everlastingly in their pockets, and their long pipes everlastingly in their mouths. It is no unusual thing to see them, in a burst of frolicsome affection, throwing their arms around each other's burly neck, and shouting a chorus in praise of "De Vaterland," to the noisy accompaniment of a concertina. As a rule, however, they are peaceable, well-conducted, good-tempered fellows, seldom the worse for drink, and always careful to give no trouble to the Queen's lieges. 
During their sojourn in Lerwick they invariably devote a day to the enjoyment of equestrianism; and the " "Dutchman's riding-day," as it is called, presents some truly amusing features. "Dozens of those Shetlanders who have horses," says Mr. Kerr, "assemble, steeds in - hand, on a piece of ground above the town, and thither, too, betake themselves the horsey portion of the Dutchmen for twopence worth of equestrianism-which consists of a gallop out for half a mile or so and back again. For the most part women and boys are in charge of the steeds, with every conceivable kind of halter, from the decent leather to the old and apparently rotten rope; some with saddles and stirrups, some with saddles but without stirrups, some with an unambitious piece of coarse cloth or straw mat. Here a great tall fellow goes up to a very little pony, pays his twopence-it is always prepaid-and prepares to mount. But how is he to get the sabot, with a point like the prow of his own buss, into the stirrups? It certainly can't be done. Off go the sabots - a shake is all that is necessary - and he gets into the saddle. At first he grasps only the bridle; but as the pace quickens-and it soon does that, for he means to have his twopence worth-you see his hand slip round to the back part of the saddle and take a firm hold. This is all very well, but the saddle itself is shaky, and the pony's back short, so he must have more leverage by grasping the tail. There, now, he's all right; but the motion is neither graceful nor easy, and his hat flies off. This was expected, for the woman or boy in charge follows behind, for the double purpose of increasing the pace by whipping, and picking up anything that may be shaken loose. And now that he gets towards the end of his ride, 
heel, bridle, and lash are pressed into service. One hand is required to hold on either by saddle or tail, the other is needed for the lash. How, then, can he dispose of the bridle? In his teeth, of course, and there he holds it. On he comes full swing. The road is very rough and downhill now. His legs are well extended, and he is making no prehensile use of his knees. This can't last long. Hallo! there he's off rolling, with little harm done.

Such are the amusements of the Dutch fishermen on shore. At sea their demeanour is much graver; and it is to be said in their praise that they keep themselves and their busses wonderfully clean. The celebrated village of Brock is hardly more a miracle of neatness than a Dutch herring-boat! Each buss carries seventy nets (eighteen fathoms long), and a crew of fourteen men. The nets are got on board by means of rollers at the sides of the ship and of the hold; and the masts are jointed near the deck, so that they may be lowered for the purpose of lying-to when the hauling-in process eommences. The herrings are cleaned and barrelled as fast as they are removed from the nets; and when the whole fleet has barrelled as much as will make a ship's cargo, a yagger is immediately despatched to the home-port, returning empty for another load.

It has been justly said that the herring is the same in all our seas; that its habits are the same whether it frequents the east coast or the west, collects in the waters off Shetland, or penetrates into the depths of Loch Fyne. Yet we know very little about it_much less than about the salmon. Various authorities give widely different 
periods for its full development. One says the fish is in its prime in three years; another delays maturity until seven. Others, again, assert that it becomes reproductive in two. All this is mere guess-work. What is certain is, that different races are constantly coming to maturity, and that some of these fish are engaged in spawning in nearly every month of the year. It is when they are thus engaged that they fall into the power of man. When they are not spawning, or not assembling for the purpose of spawning, they retire to places which the naturalist knows not of. And then, to perplex us still further, they are subject, as we have seen, to the most extraordinary vagaries? They haunt a certain locality year after year, and then suddenly take their leave of it -why, no man knows-for a considerable period. Then they return to it again, as capriciously as they had left it; or, in some few cases, they return to it no more.

'This strange fit of absenteeism was formerly attributed to the mode of fishing, but it is now believed that there is no more connection between the two than between Tenterden church-steeple and Goodwin Sands. "Trawling," however, was long made the bugbear of the herringfishers. As we have described the operations connected with it, we need say no more than that it is just the same thing as "seineing," which has been pursued for centuries on the Cornish coast without frightening away the pilchards. It began in 1838, and in a few years became very general; for as a trawl-net can be had for $£ 50$, and a drift-net costs $£ 250$, the cheaper method necessarily obtained the larger number of patrons. About 1846 , when the herring grew scarce on the west coast of Scotland, the " drifters" began to agitate against trawl- 
ing, and so far succeeded in their agitation that, by an Act of Parliament passed in 1851, it was declared illegal. The Act was constantly evaded, however, until about 1861, when fresh measures were put in force for the suppression of the obnoxious system. The drifters gained their end by loudly declaring that seineing scared away the shoals, that immature fish were caught, that the spawning-beds were injured, and that the fish caught were unfit to be cured. The trawlers, on the other hand, asserted that their mode of fishing was at once the least injurious and the most productive, and that it was admirably adapted for a Highland loch or an arm of the sea. The disputes between the two factions continued so loud that Government appointed a Commission of Inquiry, who reported in favour of trawling; and the Acts of 1851 and 1861 were accordingly repealed in 1867 . But the drifters have once more opened up the question; another Commission of Inquiry has been appointed; and what may be the issue is at present uncertain.

No one, however, who has seen both trawling and drifting, can doubt that the former is the quieter as it is the more economical mode of fishing; and we agree with a recent writer in The Times, that the casting into the waters every night, at a fishing-station like Wick or Fraserburgh, of a thousand miles of drift-nets, is quite enough to alarm the largest shoal of herrings which ever tempted man's cupidity. The contrast, as he says, between the capture of a shoal of pilchards at St. Ives and of a few thousand barrels of herring at Wick-or Fraserburgh, is very striking. We shall describe hereafter the Cornish seineing; the ease and quiet with which the captured pilchards are carried ashore at the leisure of the 
captors, or, if need be, left imprisoned for a few days within the enclosed area of the seine-net. But on the Scottish coast what a difference! All is hurry, all is turmoil; and everybody seems bent upon doing his work at a maximum of speed, too often with a minimum of result. If the herring did not take fright at the clamour, it would deserve a tribute of admiration as the calmest and most composed of fish !

Economic fishing, says the writer already quoted, is the one grand point of the fishery. "To capture as many herrings as possible, without deranging the economy of the shoal, ought to be the study of all engaged in the adventure. But economy cannot be very well studied in such a game of chance as the Scottish herring-fishery, when the skipper of a boat rushes out his mile of netting without knowing whether he will be rewarded by the capture of a single fish. Seineing has this advantage, that the net is not shot on chance. The men of Cornwall and their imitators on Loch Fyne know that there is a body of fish on the spot before they commence their labours. For the last year or two the Scottish herringfishery has been wonderfully productive, but the take has been, on the whole, not commensurate to the extent of the netting and the number of boats in use. Remarkably prolific as the herring is known to be, it is feared by economists that it is still possible to exhaust or so disturb the economy of certain shoals as to render them unproductive."

The disadvantages of the drift-net are very serious. The fishermen using it may shoot it twice in a night, and each time on an unproductive spot. It is only by the result they can tell whether they have or have not hit the 
herring; whether they have secured a boat-load or only a single barrel. The fishing is all a lottery. One boat may not secure sixty fish; another may be loaded up to the gunwale. For with the drift-net you cannot obtain your fish if they do not strike against it, and involve themselves in its meshes. Now the net may float above the shoal, or it may have sunk below them, or it may have been shot at some place where the Clupeidæ are not. Thus, one lucky boat may complete its two hundred crans in the first week or so of the season, while the others do not secure fifty all the time the fishery lasts.

The reader, we hope, will now be of M. Lacépède's opinion, that everything connected with this fish is full of interest: " Le hareng est une de ces productions dont l'emploi décide de la destinée des empires." He will say, with Badham, that all men who tar their fingers in the "clupean service" are public benefactors, and the agents of unmixed good. They add to our food-resources and our national strength. "Men-of-war and merchantmen," writes Sir Roger L'Estrange, "consume men and breed none; the collier brings up now and then an apprentice, but still spends more than he makes; the only and common nursery of seamen is this fishery, where every buss brings up (it may be) six, eight, or ten new men every year, so that our fishery is just as necessary to our navigation as to our safety and well-being." 


\section{CHAPTER VI.}

THE PILCHARD, SPRAT, ETC.

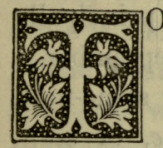

the Clupeidæ family belong, besides the allimportant Herring, the Pilchard, or Gipsy Herring (Clupea pilchardus), and the Sprat, or Garvie (Harengula sprattus).

By some naturalists the pilchard is referred to the same genus (Clupea) as the herring; by others to the same genus (Alausa) as the shad. It is nearly of the same size as the former, but thicker, and with a straighter back and belly; its scales are larger and fewer ; and its dorsal fin is placed more to the fore. The upper part of its body is a bluishgreen ; the sides

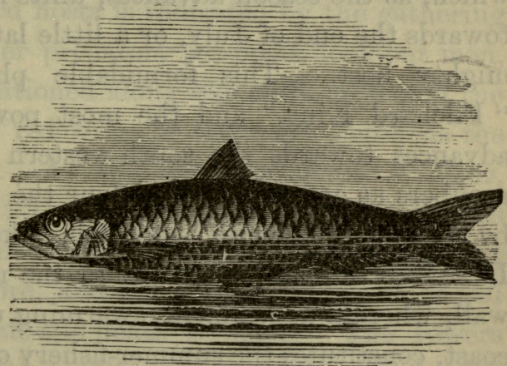

THE PILCHARD.

and belly are silvery white; the cheeks and gill-covers tinged with golden yellow, and much streaked; the dorsal fin and tail are dusky. It was formerly supposed to 
be a migratory fish; but its habits are now known to resemble those of the herring, and when it approaches the coast it does so for spawning purposes. It frequents a lower latitude than the herring, and on the British coast it is seldom found in any quantity except in Devonshire and Cornwall. But it occurs in the Atlantic waters of France, Spain, and Portugal, and in the Mediterranean Sea.

The English pilchard-fishery is regulated by several Acts of Parliament, the first of which dates from the reign of Elizabeth. The capital invested in it is probably little less than $£ 1,000,000$ sterling. It is principally carried on during the months of August and Septemberthe fish being caught either with drift-nets or seine-nets, but principally with the latter. Each seine, or sean, measures 360 feet in length, and 36 feet in depth.

About the middle of the spring the pilchards rise from the deep water, and congregate together in small shoalswhich, as the season advances, unite into larger ones, and towards the end of July, or a little later, assemble in one mighty host. This formidable phalanx, led by the "Pilchard King," and the most powerful of the tribe,* advances towards the south-western shores in such vast numbers as actually to discolour the water, and pursued by a legion of enemies, - dog-fish, hake, cod, and sea-birds. It strikes the land generally to the north of Cape Cornwall, where a detachment, swarming up the north-eastern coast, constitutes the summer-fishery of St. Ives, while the main body steers between Scilly and the Land's End, and spreads as far north as Bigbury Bay and the Start Point. The spectacle of this vast fish-army, as it passes the

* Couch, "Report of Penzance Natural History Society," 1847. 
Land's End, is described by local writers in language of great enthusiasm, and, unquestionably, must present many features of interest.

In the beginning of October, the " north coasters" and " winter fish," as they are called, make their appearance on the north-east shore of Cornwall, and in such hosts that no fewer than twelve millions have been caught in a single day.

The drift-net, and the seine have each their advocates among the fishermen. The former is employed out at sea, and only between sunset and sunrise. The seine fishing is the more general and the more successful, because it encloses the fish in shoals.

The boats employed in it are three in number: the seine-boat, which carries the great net, or seine; the volyer, or follower, in which the thwart, or stop-net, is stowed; and the lurker, under the direction of the master seiner, whose duty it is to keep a vigilant eye on the movements of the fish. When the season has arrived, and the approach of the pilchard hosts is indicated by the gathering of the gulls and other predatory sea-birds, look-out men, called huers,* are stationed along the cliffs, to watch the sea until a peculiar red tinge of the water betokens the presence of a shoal. At the welcome shout of Heva, heva, heva! ("found!") a scene of great excitement takes place in every fishing-village; the inhabitants rushing frantically to the shore, and the boats pushing off at full speed as if for a life-and-death struggle. The rowers bend to their oars with a will, guiding their boats by the gestures of the huer. No sooner do they reach the "happy hunting-ground" than the great seine, which is

* From the French verb huer, to shout. 
usually one hundred and sixty fathoms in length, is let out by three of the crew, as the boat is rowed softly round the shoal. With so much dexterity is this operation performed, that the whole net is often "shot" in less than five minutes. The volyer, meantime, has kept the net taut at the other end, and as soon as it is in the sea both extremities are warped together, and the lurker takes up its post at the opening, so as to drive back the fish from the only aperture by which they can escape. The moment the ends come in contact, the thwart-net is dropped across, and the seine, being raised cautiously, is quickly tacked together. Then, if the bottom be free from rocks, and the water not too deep, the spoil is quickly secured; and the men proceed at their leisure to count over the number of their captives prior to drawing the seine into shallow water.

At low tide, another company of men, called regular seiners, proceed to effect the operation of "tucking;" that is, they remove the fish from the seine into a smaller net-the "tuck-net"-and from the tuck-net lift them by flaskets into boats which convey them ashore.

When once they are safely landed, the pilchards are carried in corvels, or wheeled in barrows, to the curing-

- cellars, where they are piled up edgewise in great heaps, - each tier, as it is completed, being sprinkled with baysalt. We have used the word "sprinkled," but it is scarcely broad enough in meaning, for the salt and the pilchards are so thickly accumulated as to form separate layers, like courses of masonry - first salt, then pilchards, then salt again, and so on. In this condition they are left to drain for about six weeks, after which they are thoroughly washed and cleansed, packed in hogsheads- 
each containing about 2400 fish-and pressed together for the purpose of extracting the oil, which is valuable as a commercial staple.

It now remains to head up the casks, and they are ready for exportation. The principal buyers are found in Italy-whence the fishermen's toast, "Long life to the Pope, and death to thousands." A brisk trade is also carried on with Spain; and there, as Fuller quaintly says, "under the name of fumadoes ('fair maids'), with oil and a lemon, they are meat for the mightiest don." About 3500 hogsheads are annually caught and cured, and of these some 6000 to 7000 are retained for home consumption.

The ancient Greeks looked upon the pilchard as a fish unfit for the table; but the Romans had a more catholic taste, and ate it with pine-nuts for a relish. The more important clupea, the herring, was not known either to Greeks or Romans. As Dr. Doran jocularly remarks, it was the Scots who "discovered" this fish, and the Dutch bought, pickled, and sold or ate them. The story goes that Charles V., in 1536, ate a herring upon the tomb of Beuckels, the genius who first taught men how to salt and cure it, and thereby enriched his country with a new source of wealth.

The appearance of a "school" of pilchards is a welcome sight on the Cornish coast, and their threefold value has been commemorated in a local rhyme-

\footnotetext{
"Meat, money, and light, All in one night"-
}

which must be of considerable antiquity. "Meat" and "money" they still supply; but pilchard-oil is now very little used for "light." There are many better substi- 
tutes ; and, moreover, pilchard-oil finds a good market at Bristol, whence it comes forth again under the name (it is said) of " cod-liver oil." But whether for meat, or money, or light, the pilchards are always welcome; and never more welcome than now, when the treasures of the earth are beginning to fail the Cornishman, and he is glad to avail himself of the treasures of the sea. Let us be joyful with the rest, and hasten down to the shore to see the pilchards "tucked."

The "seines" have been shot before we arrive at the scene of action, and now close in two circular ramparts round their respective takes. For there are two in hand, each measuring about 150 fathoms in length, and from 4 to 5 fathoms in depth. Each is carried out in a large boat, which is attended by a "cock-boat." As soon as the huers stationed on the cliff give the auspicious signal, the seine-boat pulls vigorously out to sea, shooting the seine as it goes, the cock-boat keeping at the other end. The fish, striking against the net, invariably follow the seine ; and hence the object of the fishermen is to pull so far ahead of the "school" as to be able to turn it, and, by rejoining the cock-boat, complete a line of circumvallation. If they succeed in this, the school will be shut up in about one acre of water, marked out by the corks which float the upper edge of the net. When the two boats have joined, the men make a tremendous splashing in order to drive the fish back, and then haul up and fasten the two ends of the seine, so as to complete the circle. Then they proceed with much care and patience to draw it tighter.

And now, says an eye-witness, * the tucking is begun

* "Pilchards and Pilchard-Catchers," in Blackwood's Magazine, No. Docvir. 
as soon as possible. Step into that little boat that is just going out, and you will be in time to see the tucknet cast. The tuck-net fits inside the now contracted seine, much as one's two hands, set scoopwise, would fit inside a small wash-hand basin. At the thumbs are two "hooks," or foot-ropes; where the fingers touch is a "cork-rope;" where the wrists touch, a " brace," or rope, which is to be pulled in to the "hooks" as soon as the loose, baggy end of the tuck has sunk under the fish. A boat lies close by the two "hooks," and the fish are kept away until the bag is formed beneath them, by the simple process of bobbing up and down a big " boulderstone." Then the bag is lifted, and all its treasures are emptied out into the boats, the utmost care being taken not to break the fish, which, unless quite sound, are unfit for bulking. A tuck-net will hold as many as seven hundred hogsheads; but for this reason the men do not care about lifting more than two hundred at once-preferring, if the take be large, to tuck twice or thrice before they empty the seine. Sometimes they "miss tuck" - that is, the fish sink, or else escape between the hooks; in which case they must try again, hoping the weather will keep calm. Now and then, it is said, a "school" has been kept in seine till salt for bulking has come over from France ; but occasionally a close-packed "school" will nearly all get crowded to death if they are kept. in too long.

When the boats begin loading, the spectacle is as attractive as it is curious. The silvery mass flashes brightly in the sunshine, and heaves and struggles "as if it were one being, instead of myriads of collective lives." We have often gazed upon it with interest, and felt something (502) 
of the excitement which animates the fishers themselves. Every moment it seems as if the imprisoned host would extricate themselves from the hands of their eaptors, as some struggling fish leaps suddenly back into the water with a splash. Surely the net cannot endure the strain put upon it! Or else the men, strong and brawny as they are, will lose their hold! But no; the thing is done-and, in less time than you would suppose possible, the scaly victims are heaped into the boat.

On shore, meanwhile, all is expectation. From far and near the population flock to assist in the profitable labour. Young and old, miners and "bal-girls," are all assembled, either to do a little bit of honest "gleaning" - for by standing near an unloading boat it is easy to pick a string of "windfalls" out of the water-or to earn a few pence by carrying to the bulkers. The boys who take the fish along the boulder-pier and up to the yard, receive threepence each journey; the girls and women who supply the bulkers, fivepence an hour. The gulls, thronging the reefs with dusky wings, are also expectants; their share will be the broken fish, and the refuse of those cleaned preparatory to being salted.

As soon as the first boat reaches land, the work begins. Boys and men stagger along under loaded baskets. These are emptied into garries, or hand-barrows, which the girls wheel up to the bulking-houses. Then the bulkers, or curers, carefully arrange the fish in rows, with their noses outside, and between each row interpose a good layer of salt. When the fish are piled up high enough, boards are placed on the top, and kept down by heavy weights. Then the oil begins to flow, or rather trickle- "virgin oil," the first outcome, much more valuable than the 
thicker fluid afterwards obtained by stronger pressure. A bulking-house, when filled, presents a remarkable sight, and with the long tiers of heads, set in salt and pointing outwards, bears some resemblance to a fairy's wine-binin which the precious juice would be stored, we suppose, in tiny silver flasks. The whole of the "take," however, is not put in bulk, a portion being kept for local consumption. The Cornishman never eats his pilchard fresh (a "fair maid" is its then designation); but he likes it salt; and boiled with new potatoes, it makes a savoury, though, we should think, a not very nutritious dish. Sometimes pilchard-pie is set before a guest ; and having tasted of it, we can affirm that for those who like paste with a spratty flavour, it is not so bad. We wonder the Cornishmen don't take a lesson from the fishers of Brittany, and pack up their pilchards in cases like sardines. Young pilchards cannot easily be distinguished from sardines, and are substituted for them on the Brittany coast.

In the fisheries at St. Ives and its neighbourhood the seine-net is used; at Newlyn, the drift-net is in favour. The disadvantage of seineing is, that it is limited by certain conditions - the net must touch ground, and the water must be tolerably smooth; whereas the drift-net may be fished in water of any depth, and in defiance of tides. We are inclined to think, however, that the fish are taken by the seine in better condition, as they certainly are in larger numbers. The mesh of the drift-net is large, and the pilchard gets its head into it, though its body cannot follow. Hence, when hanled up its appearance is provocative of laughter, for it is stuck full of "wriggling creatures caught by their gills,"-painful for the fish, certainly, but ridiculous in the eyes of a spectator. 
The uncertainty of seineing is very great; the quantity of pilchards shipped from St. Ives alone, for instance, has varied within the last quarter of a century from seven thousand to nearly thirty thousand hogsheads. In 1847, so large was the catch, that some of the seines had to be kept in the water a fortnight, from want of sufficient hands to take up the fish. As a matter of course, the price is also very variable: fresh fish, from two shillings a long hundred down as low as sixpence; fumadoes, or cured fish, from eighty-five shillings to thirty-five shillings a hogshead of fifty-two gallons, holding about three thousand fish.

The drifters do not confine themselves to the Cornish waters. Their well-formed boats may be found on the Irish coast and in St. George's Channel ; nay, they even push through the Caledonian Canal into the North Sea. It is the herring that takes them into these strange waters; but they are careful to return in time for the pilchards.

The scene when the drift-boats come ashore, has all the liveliness and something of the grotesqueness of a pantomime, though it is much more serious. We find it so graphically described by a contemporary writer (in the immortal Maga), that we cannot do better than transfer his description to our pages, unaltered :-

Not only is everybody busy, but every one is shouting or screaming (your Cornish are un peuple criard); the jowslers (hawkers), who have driven down from inland, cracking their whips and yelling out the highest they will give per hundred; the wives eager to learn what sort of take it has been; everybody, pitching his voice at that sing-song which so baffles the comprehension of the mono- 
toning Teuton. There is great fun and no fighting, though the fishermen occasionally turn sulky, and stand out resolutely for a certain price. Soon all the country round will smack of St. Ives. The "crystal clear" where you were wont to water your horse is surrounded by half-a-dozen women pulling off the pilchards' heads, and then dexterously scooping out the insides with their fingers. "I wish," says our authority, "they would understand that, put at once 'to pile,' the fish offal makes the best of manures-quite as good as the refuse salt which is so largely used-but that left to lie about, it loses its goodness, besides decidedly being ' matter in the wrong place.' It is a pretty sight," he adds, " to see a company of driftboats ranked like a miniature fleet in order of battle. A line of nets, each some twenty fathoms long, will stretch three-quarters of a mile. The chief danger to the gear is from the keels of passing vessels, which are therefore signalled off by burning a wisp of straw. For drifting, the sea must not be too clear; sometimes, if you look down, you can see the net through all its seven fathoms of depth, gleaming like a lattice-work of fire. At such times the fish are pretty sure to swerve aside. Two hogsheads per boat is a fair take, but a boat has sometimes taken up twenty hogsheads at one haul. The drifters always take their lines out with them, and find plenty of work in capturing the hake, and conger, and pollack, which are preying on the 'school,' even gnawing off the fish caught in the drift-meshes. Dog-fish, too, good for the lobster-pots, are sometimes caught in enormous numbers : they are so bold that you ean catch them with the hand as they run at the bait; but beware of the terrible hook with which their fins are armed." 
We don't know we can say much more about the pilchards. They lie in " bulk," or in store, as we should say, about four weeks, during which time they give up all the best of their oil. Then they are washed, and packed in hogsheads, and pressed again, so as to get rid of all the remaining oil and pickle. After which they are finally coopered up, and shipped to Italy or Spain. They are not smoked, though the Italians call them fumadoes; but, after all these processes, they are dry enough to be mistaken for smoked fish, and they taste not unlike the dried sprats which the Dutch send over to our markets.

We might say much about the pilchard-fishermen, for the Cornish population has characteristics of its own, reminding the traveller of the Celtic folk who inhabit the wild shores of the lochs and bays of Argyllshire. The dark eye, the thick eyebrow, the look of energy and determination, the lithe muscular frame, the rapid animated speech, all are contrasts to the leading traits of the slowmoving peasants of Devonshire or Dorsetshire. They are very hospitable, these Cornishmen; frank in their speech, respectful and yet independent in their manners ; and animated, most of them, by a strong religious feeling, which their fathers and grandfathers derived from the old and fervid Wesleyanism. The men, as a rule, are sober, and the women chaste; and the Cornish villages are seldom disturbed by riotous outbreaks.

We have already endeavoured to make the reader as wise as ourselves in reference to the true character of the SPRAT, which we must persist in considering a distinct species of the Clupeidx, and not the young of the herring. Sprats, which are really a nutritious and fine-flavoured 
fish, though sadly undervalued by our cooks and housewives, abound on the coasts of Norfolk, Suffolk, Essex, and Kent in the winter months, and are also very plentiful in the Firth of Forth, where they are known as garvies. The net used for taking them has smaller meshes than the herring-net. Drift-net fishing is practised, and also stow-boat fishing-

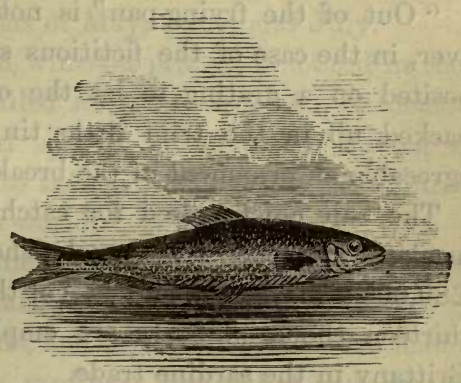

THE SPRAT. that is, a large bag-net is suspended from two horizontal beams beneath the boat, at an elevation of six or seven feet from the bottom, the fishermen being able to keep the mouth of the net always open by means of ropes from the ends of the upper beam. When the net is full, the ends are drawn together, and the booty hauled on board.

Fresh sprats find a ready sale in London, Edinburgh, and Glasgow ; and there is also a good demand for dried or smoked sprats. They do duty, too, as sardines, in the tin cases imported in such quantities from the west of France; and the kilkies brought from Riga, and other Baltic ports, are sprats cured with spices.

The sprat-fishery for sardine-making finds employment for a number of hands on the coast of Brittany. The process of curing them may be thus described :- After the fish have been well washed in sea-water, they are sprinkled with clean salt. The heads are then cut off, and the intestines removed; they are again rinsed in seawater, and hung up or laid out on willow branches or 
wire-work to dry and improve their colour. Finally, for a brief period they are placed in a pan of boiling oil.

"Out of the frying-pan" is not "into the fire," however, in the case of the fictitious sardines. They are deposited on a grating to let the oil drain off, and then packed up in the trim little tin cases which form so agreeable an ornament of the breakfast-table.

The bait chiefly used for catching sprats is cod and mackerel roe ; and the French fishermen, it is said, spend $£ 80,000$ a year in the purchase of this kind of bait. Fully thirteen thousand boats are employed on the coast of Brittany in the sardine trade.

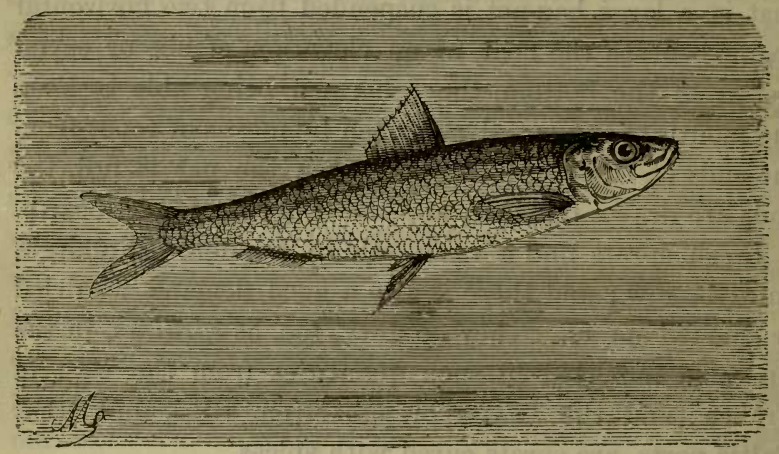

THE SARDINE.

The true SARDINE (Clupea sardina) is a fish of the same genus as the herring and the pilchard, but is smaller than either. It abounds in the Mediterranean; and sardines preserved in oil, after the fashion already described, are exported in large quantities from some of the French and Italian ports. Like its congeners, it moves towards the 
shore in immense shoals at the approach of the spawningseason; and the sardine-fishery on the coast of Provence takes place in the months of May, June, and July.

Sardines cured in red wine-a process practised in the south of France-are called sardines anchoisées, or anchovied sardines. Several species of Clupeidæ having a very close resemblance to this favourite species, are found in different parts of the world.

An important sardine-fishery exists on the coast of Brittany, and employs about 13,000 boats. But young herrings, young pilchards, and especially sprats, are made to do duty as genuine sardines; nor, when cured and served up in oil, can the difference be easily detected. The real sardine, however, closely resembles a sparling. though it is of fuller flavour. All along the coast from Nantes to Brest, including the magnificent sweep of the Bay of Douarnenez, the fishery extends, employing nearly the whole of the maritime population. The type of people in this part of Brittany is curiously Celtic ; and they have much more in common with the Welsh in speech and habits, as well as in physiognomy, than with the rest of Frenchmen. The men wear a kind of jacket, with a sash round the waist, and a hat with streamers to it that gives them the look of newly-enlisted recruits. The women's costume is picturesque in the extreme; their tall linen caps and embroidered muslin skirts rendering them peculiarly interesting to an artist's eye.

The Whitebait, the Anchovy, and the Shad are members of the great Clupeidæ family. Their fisheries are of no commercial importance, and, therefore, we can devote to them a few lines only. 
Of the Whitebait (Clupea alba), it seems to be by no means safe to say that it is either a distinct species or the

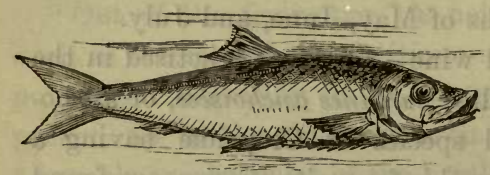

THE WHITEBAIT. young of the herring. Learned doctors have been found to argue on both sides. But this is clear-that it is a white-sided, greenbacked fish, found in the Thames, the Forth, the Humber, and other localities, and forced by fashion into a notoriety which, as an article of food, it does not deserve.

About the ANCHOvy (Engraulis encrasicolus), however, there can be no mistake. It is distinguished from the clupea by its more deeply cloven mouth, the greater width

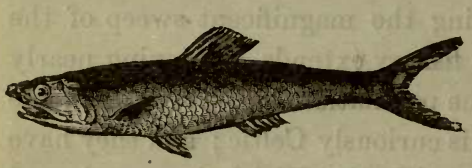

THE ANCHOVY. of its gill-openings, and its more numerous gill-rays. It is a fish of a rich and peculiar flarour, about as long as one's middle finger, with a sharp-pointed head, a deeply-forked tail, and large silvery scales which are readily removed. Though found in the British seas, or, at least, on the coast of Cornwall, and even ascending as far north as the Baltic and the shores of Greenland, it prefers the warmer waters of the Mediterranean, and the genial coasts of Spain, Portugal, and France. Here, in the months of May, June, and July, when this fish leaves the deeps and seeks the shallower waters, an extensive and profitable fishery is conducted. Night is the time for anchovy-fishing, and the fishes are drawn near the boats 
by the blaze of fires. They are cleaned, salted, and exported in small barrels.

Anchovy sauce, as a condiment, is very popular on our modern tables; and anchovies, it is said, were used by the Romans in the preparation of their celebrated garum, a seasoning of which they were strangely fond. Originally, this would seem to have been a shrimp sauce; but it was subsequently made of the intestines of anchovies, sarclines, sprats, or almost any fish, macerated in water, and saturated with salt. As soon as symptoms of putrefaction appeared, a little parsley and vinegar were added - and the sauce was complete. The Romans, however, were fond of " miscellaneous feeding," to judge from the following directions for preparing the accessories of a banquet, given in Horace's "Satires," ii. 4 :-

"Simplex e dulci constat olivo

Quod pingui miscere mero muriaque decebit,

Non alia quam qua Byzantia putuit orca.

Hoc ubi confusum sectis inferbuit herbis

Corycioque croco sparsum stetit, insuper addes

Pressa Venafranæ quod bacca remisit olivæ

Picenis cedunt pomis Tiburtia succo ;

Nam facie præstant. Venucula convenit ollis,

Rectius Albanam fumo duraveris uvam.

Hanc ego cum malis, ego faecem primus et allec, Primus et invenior piper album cum sale nigro

Incretum puris circumposuisse catillis."

[That is :-It is worth while to master thoroughly the qualities of compound sauce. The simple consists of sweet olive oil; which should be mixed with rich wine, and with the same pickle of which the Byzantine jar smells so strongly. ${ }^{*}$ When this has been made to boil with a mixture of chopped herbs, and has been allowed to cool, after Cilician saffron has been sprinkled over it, then do you add besides the oil of the pressed berry of the Venafrum olive. The fruit of Tibur is inferior in juice, but superior in appearance, to that of Picenum. The grape of Venucula is good for preserving in jars; the Alban is best when thoroughly smoked. On inquiry you will find that $I$ the first of all men placed round the table on clean dishes this kind of grape, together with apples, lees, and fish-pickle, white pepper sprinkled through a sieve, and black salt.]

* A pungent, malodorous pickle made from the tunny-fish. 
We turn to the SHad (Alausa), which differs from the clupea in having the upper jaw deeply notched. Other-

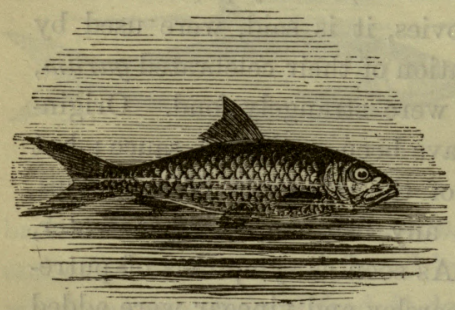

THE SHAD. wise, it closely resembles the herring in form and appearance, and on this account, and in allusion to its large size, the British species is known among Scottish fishermen by the name of the "King of the Herrings." The Common or Alice Shad (Alausa communis), which attains a length of two and even three feet, is found very abundantly in the Severn, and also on other parts of the British coast. It is a better flavoured fish than the Twaite Shad (Alausa fuita), which, however, is more plentiful, especially to the south of the Thames, and in the Thames itself below Blackwall. It seldom exceeds sixteen inches in length, and is marked by a row of dusky spots along each side of the body. Its fishing is prohibited after June, in order to allow it to deposit its spawn.

A large species of shad, which is much valued as an article of food, abounds in the Hudson, Delaware, Chesapeake, and other rivers of North America. 


\section{CHA P TER VII.}

\section{THE STURGEON.}

\footnotetext{
"Who has not learnt, fresh sturgeon and ham-pie Are no rewards for want and infamy?"-PoPE.
}

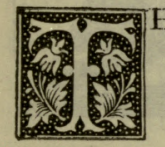

HOUGH the STURGeon, in its general form, resembles the Squalidæ, and in some respects is allied both to shark and ray, and though it is little inferior in size-the Great or Isinglass Sturgeon (Accipenser huso) attaining the length of twenty or twenty-five feet-yet it differs from them considerably in structure and habits. It has an elongated and slender body, tapering gradually towards the tail ; the snout is long and obtuse, and furnished beneath, at some distance from the end, with four long worm-shaped cirri ; its mouth, situated below and behind the muzzle, is small and toothless; and the upper jaw is formed by the palatal bones. Its pectoral fins are oval, and medium-sized; the dorsal are small, and placed very near the tail; the ventral and anal are likewise small, and nearly opposite the dorsal. The tail is slightly forked, the upper lobe extending far beyond the lower. As for the general colour of the sturgeon, it may be described as 


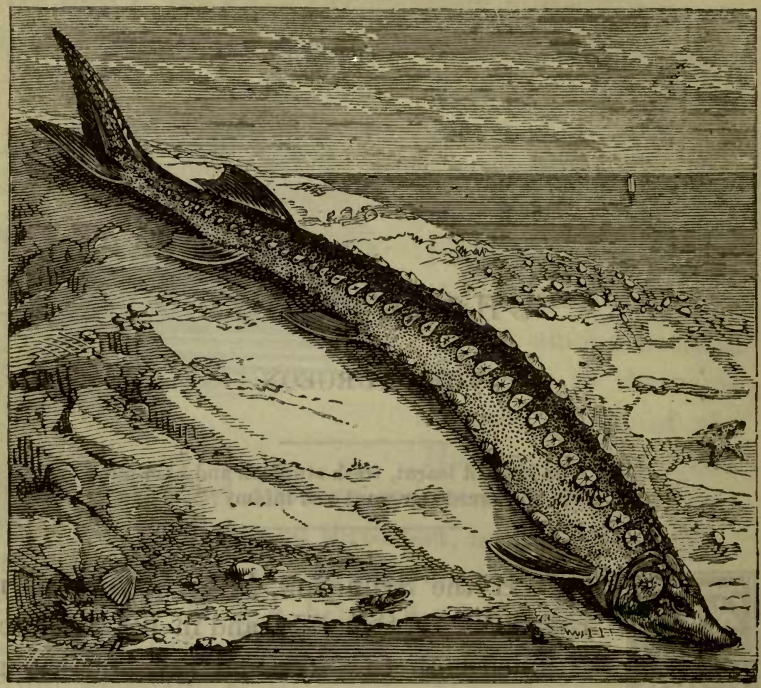

THE STURGEON.

ashy or sooty on the upper parts, and yellowish-white on the under; so that it can by no means claim attention on the score of brilliancy.

Notwithstanding its strength and size-and even the Common Sturgeon (Accipenser sturio) sometimes measures eighteen feet from snout to tail-it is dangerous only to those inhabitants of the waters which are unable to defend themselves: such as worms, for which it roots among the mud like a hog; herrings, mackerel, ducks and wild geese; and salmon, too, which, ascending the rivers at the same time as the sturgeon, are terribly thinned in numbers by the latter, - a fact which originated the old idea that the sturgeon was the "captain" or "leader of the salmon." 
Longitudinal rows of bony plates extending along its body equip it in a famous suit of "harness ;" and its head is as well protected as that of a "mailed knight." Like Hamlet's father, it is armed-

"At point exactly, cap-à-pie," -

from "head to foot;" and it is further covered throughout its whole length by five series of strong, large, osseous tubercles, rounded at the base, and terminated above by a keen curved point in a reversed direction. Its natatory bladder, which forms one of its claims to the epicure's regard, is of large size, and communicates with the esophagus through a considerable orifice.

There are at least four different species of sturgeon distinguished by zoologists; three of which, the three largest, frequent the Don, the Danube, and the other rivers which flow into the Black and Caspian Seas. The largest of these, occasionally found in the $\mathrm{Po}$, will weigh as much as three thousand pounds; and no power under that of a strong team of oxen can drag the monster from the river when taken. The common sturgeon is found in the Baltic and the streams of Northern Europe. It lives indifferently in salt water and fresh water, lakes, rivers, and seas. It may be caught in the Mediterranean or the Red Sea; and when spring returns to quicken the glad earth, it finds its way up all the great European rivers-the Volga, Po, Garonne, Loire, Rhine, Oder, Elbe, and even the secondary streams. Does not Ausonius describe the mighty fish cleaving with arrowy swiftness the calm waters of the "blue Moselle"? -

"Cum tranquillos moliris in amne meatus,

Te virides ripæ, te cærula turba natantum,

Te liquidæ mirantur aquæ, diffunditur alveo

Estus, et extremi procurrunt marine fluctus." 
See, stream and shore and azure shoals admire, As swift they breast the tide, And part the eddying waters, which recede To either grassy side.

Sturgeon were caught in the Moselle in 1758. In 1782 , two which were taken at Paris were transported to Versailles, and presented to Louis XVI. As late as 1800 a sturgeon flourished in the fish-ponds at Malmaison, which had been captured at Neuilly. These were common sturgeon, averaging six to eight feet in length. A fish of this size, taken in the Loire, was offered to Francis I. during his residence at Montargis.

Sturgeon, like salmon, enter the rivers for the purpose of depositing their spawn. Their fecundity is marvellous : in an individual weighing only one and a half hundredweight, 1,476,566 eggs have been counted. In oozy estuaries they thrust their cartilaginous snout into the mud, and find worms enough to satisfy an appetite which is never voracious. Sometimes, we are told, one of these fish will take possession of a particular locality, and continue in it for years, defying all efforts at its capture. One of these solitary recluses, says Badham, long established his quarters at the mouth of a small river on the Baian coast, and the sailors, do what they would, could never take it; its habit was to retire into the ground-floor of a submarine villa, and thus successfully elude pursuit.

Duly to estimate its commercial value, we must take several data into consideration; such as size, number, extended range, the estimation in which its flesh is held, and the important preparations made from its swimbladder and roe. As to its size, we have shown that the larger fish weigh as much as three thousand pounds, 
and attain a length of eighteen to twenty-four feet. The head alone sometimes yields a tun of oil. As to numbers, who can calculate the hordes which swarm in the Red Sea, the Black: Sea, and the Caspian, or annually ascend the principal rivers? In regard to range, they extend over a considerable portion of the globe. Then the sturgeon is the only creature eaten entire. "Beef and mutton require trimming and paring away superabundant fat, to say nothing of horns, hides, hoofs, and other uneatable appurtenances, reducing the Smithfield beast, when the cook has to deal with him, to greatly diminished proportions." But there is no waste about Accipenser sturio; it suffers scarcely any diminution in bulk: of its dainty carcass the whole is edible-flesh, blood, cartilage, ovaries, milt, liver, swim-bladder, skin, fin, tail, and spinal marrow. There are no bones; and the only parts not eaten are the osseous plates which encase, and the sinews which support, the processes of the back: and these last are made up into thongs by the Russian and Asiatic peasantry.

The flesh of the sturgeon is - very delicate, and is described as resembling veal when roasted. That of the male fish is the better flavoured, and it was regarded by the Greeks as a special dainty. The Romans paid the sturio a kind of worship; public officers, crowned with gay garlands and escorted by musicians, bore it, magnificently decorated, in grand procession along the crowded streets. Cicero recommends it as a more suitable gift to a sorrowing friend than any book full of the philosophy of Socrates. At this day, in China, it is reserved exclusively for the imperial table. In the Middle Ages, all the sturgeon eaught in English rivers belonged as of (502) 
right to the king. In France, the same privilege was bestowed by certain charters on the great lords. The Emperor of all the Russias similarly monopolized it, and supplied himself, and the crowned heads, his particular allies, with the white or finest caviare.

The sturgeon is still held in high estimation as an edible; but the eggs are more valued than the flesh. After they have been very carefully selected, they are washed, and kneaded up with salt and various condiments, to form red or black caviare, which is extensively used in Russia, Greece, Italy, and France. The finest caviare is made from the roe of the Accipenser ruthenus, or Sterlet, and is reserved for the Russian court. The preparation of caviare forms one of the staple trades of Astracan, and upwards of four hundred thousand pounds have been prepared in the Caspian fishery in a single year. The species which chiefly furnish it are the Osseter (Accipenser galdenstadtii), the Bielaga or Great Sturgeon, (Accipenser huso), and the Scherg or Scoruga (Accipenser stellatus). That it was in favour in England as early as the reign of Elizabeth, we know from Shakespeare's allusion: "It is caviare to the multitude." Isinglass is manufactured to a large extent from the swim-bladderas, indeed, its name indicates, being nothing less than a corruption of the German hausen-blasse, or sturgeon's bladder.

The sturgeon-fishery, according to ancient and modern writers, is conducted in many ways. When these fish appear in a river, it seems that you need only run along the banks, rending the air with your shouts, to frighten them into shallow water, where they necessarily become 
stranded. With strong cords and a yoke of oxen, you may then draw them ashore in safety.

On the Garonne, and other French rivers, the fishery begins in February, and lasts until July, August, or even September. A large net is dragged between a couple of boats, each manned by three or four men. As soon as a fish is caught, a rope is passed across its ears and round

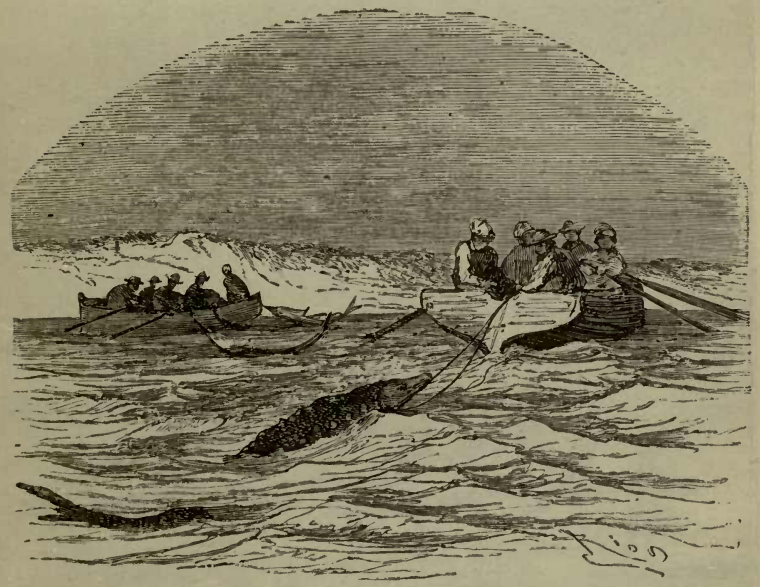

TOWING STURGEON.

its throat, and it is moored to one of the boats. This process continues until a sufficient number has been captured, when they are towed to Bordeaux and disposed of.

But the chief seat of the sturgeon-fishery is in Russia, where there are two seasons, a winter and a spring one. It begins in January, and is inaugurated with a grand ceremonial. The day being publicly notified, formal invitations are addressed to all whom it may concern. 
These, before dawn, assemble in the public place, and nominate a captain; who, prior to their departure, reviews the fishermen, and carefully examines the condition of their equipment. At sunrise a couple of cannonshots give the signal for starting, and the sledges dart away at full gallop, the one which first reaches the

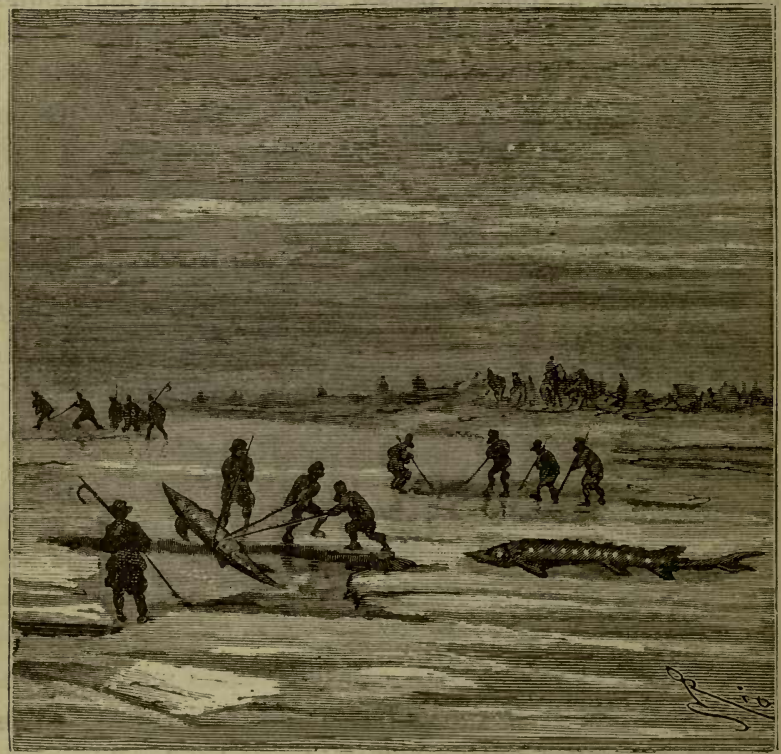

STURGEON-FISHING ON THE ICE.

river-bank being at liberty to select the best position. Quickly the ice-crust on the waters is broken with pickaxe and spade; each fisherman plunges his harpoon into the crevasse before him, stirs it to and fro, withdraws it as soon as he feels certain of a catch, and, with the assist- 


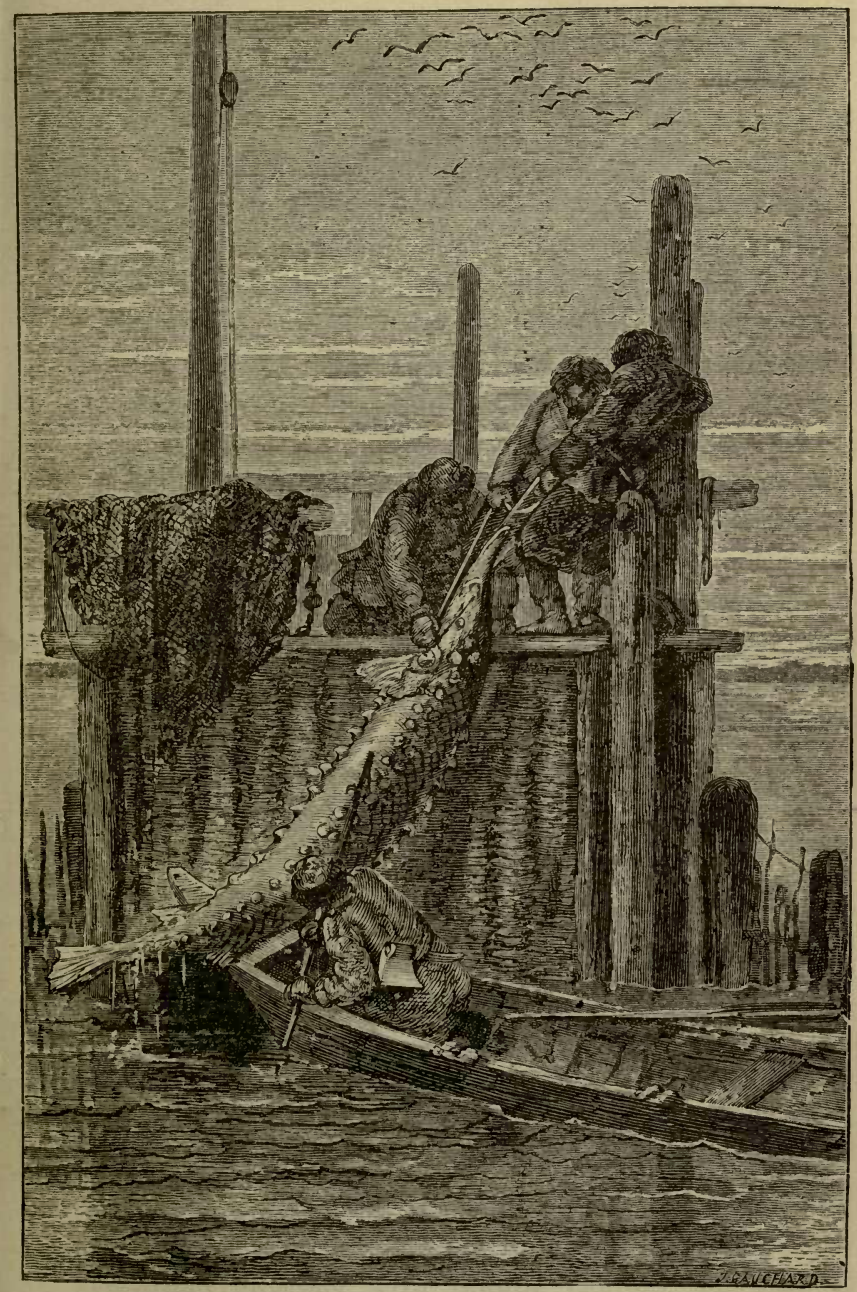

STURGEON-FISHING ON THE VOLGA. 


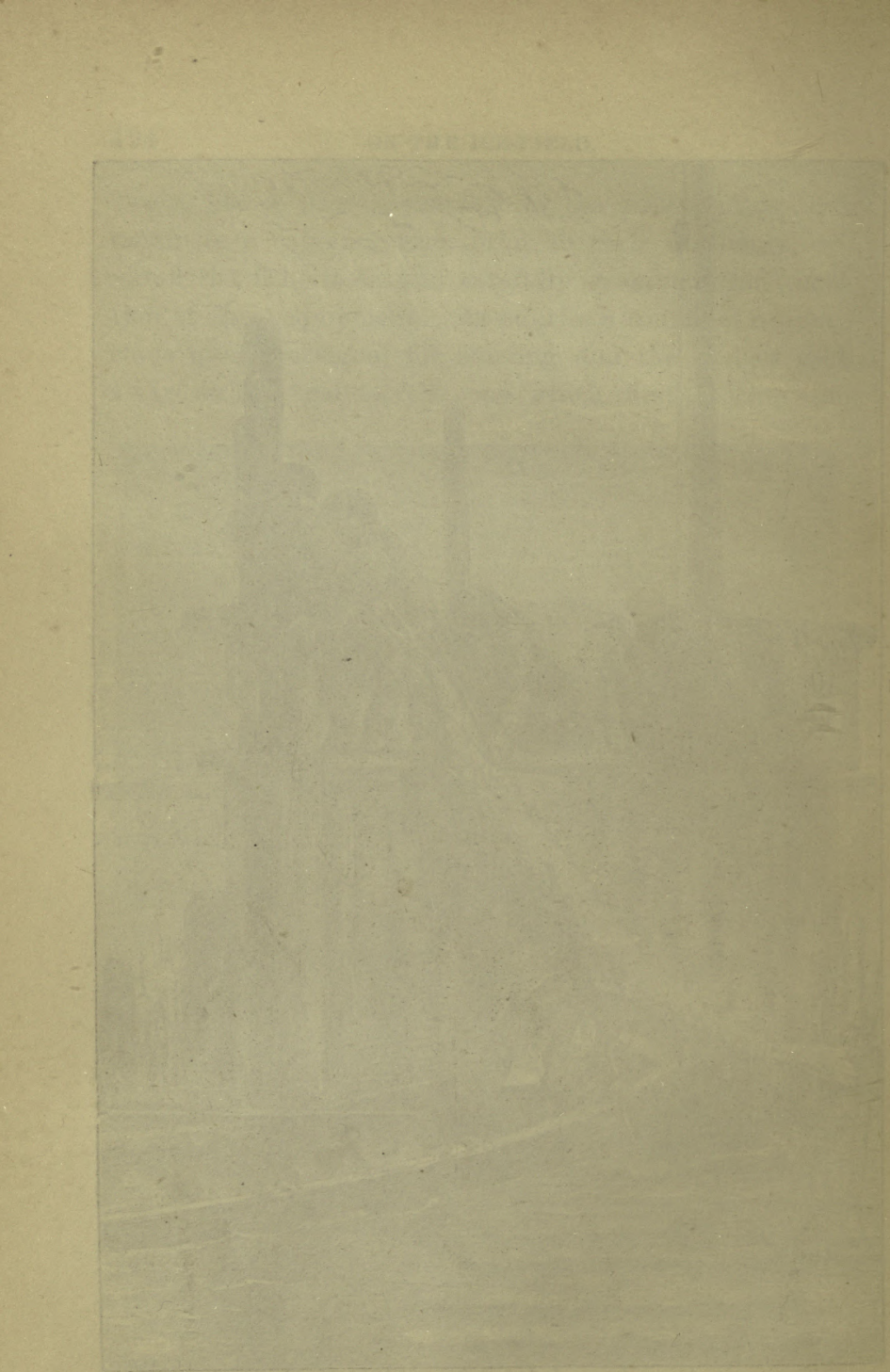

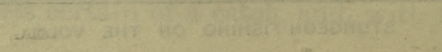


ance of stout tackle, brings his prey to the surface. A skilful harpooner will take from eight to ten fish in a day.

On the Volga they are caught in decoys. A weir, or embankment, is constructed with piles, in the centre of which is left an opening into a basin or compartment, enclosed with nets and osier-hurdles, and provided, like the madrague, with a movable bottom, which can be raised, when necessary, by men stationed upon the summit of the dyke for that purpose.

The sturgeon, swimming up the stream, are brought to a halt by the embankment. After awhile they find out the only gap or opening in it, and drift into the prison beyond, where they indicate their presence by unwittingly setting in motion a number of small floating buoys, secured by ropes. The look-out men immediately lower the hurdles behind their captives, and the fishers proceed to gather in their harvest. Some are taken immediately out of the water; others are drawn up the river by ropes fastened round the head; but much care and skill are necessary in thus harnessing the fish to avoid a blow from the tail, which would knock a man down, and break a limb or send him overboard.

It is said that a regularly equipped flotilla sails yearly in the rivers of Astracan to engage in this important fishery. It starts in the winter, when the sturgeon hide in the depths and hollows of the estuaries, hybernating sometimes alone, but more frequently sharing a common dormitory, where, it is said, they suck in sufficient supplies of isinglass from each other's bodies to keep them in good condition. The expedition proceeds with infinite caution, for fear of 
alarming the objects of the intended attack, and absolute silence is maintained on board the boats. When these have stolen to the winter quarters of the unsuspecting fish, the crews take in their canvas, and noiselessly lower their nets. The stupid creatures see the entangling mesh-work slowly descending, but in their utter simplicity do not move a fin. At length the net touches them, and they stir a little; but soon becoming used to its slight pressure, they drift lazily and indifferently towards the landing-place. When they get near the shallow water, the fishermen proceed to irritate them by dropping a plummet on the heads of the largest, whereupon, in a state of intense agitation, they rush together, plunge and rear like "high-mettled racers," and run themselves aground. There they lie at the mercy of their captors, who are nothing loath to secure the highly-valued prey. 


\section{CHAPTER VIII.}

\section{THE EEL-FISHERY.}

"Moth. I will praise an eel with the same praise. Armado. What, that an eel is ingenious? Moth. That an eel is quick."-SHAKESPEARE.

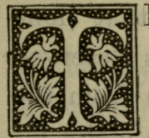

HE EEL is one of the fishes most extensively distributed over the surface of the globe. - It is found in the East and West Indies; it lives under the ice of Greenland; it penetrates into the interior of the Chinese Empire; it teems in the British rivers; it enjoys every temperate and tropical climate.

Its reputation is not less extensive than its habitat. From the most ancient times down to our own day it has figured on the tables of patrician and plebeian, prince and peasant, the opulent and the poor. Almost the only people who refuse to count it among their food-supplies are the Jews and Egyptians, Moslems and Greenlanders, and, to some extent, Scotchmen. With these few exceptions, the world generally, from the epoch of Aristotle to that of Darwin, has agreed in bearing unqualified testimony to the merits of this ubiquitous favourite; and amidst the caprices of fashion, the endless mutations of 
taste, and the continual revolutions of the culinary code, the eel has maintained a just celebrity.*

The Egyptians worshipped eels, and so did the Greeks, but in a different way. "Your idol is likewise my idol," exclaimed Antiphonus, a Greek epigrammatist, who flourished about 100 B.c.; " but I don't worship him in the same manner : you Egyptians reverence him as a deity, I adore him in a dish!" "The Egyptians," remarked another profane wit, "are right in esteeming eels above their other divinities; for the latter can be gained to one's side only by prayers and vows, while the former you secure for a few drachmæ." The best eels were eagerly sought after, and almost as many countries contended for -this distinction as cities for the honour of having given birth to Homer. The Macedonians asserted that none could equal theirs; Sicily protested that hers deserved the pre-eminence, especially those which came from the neighbourhood of Syracuse; Phrygia put in a claim for profit and laudation; so did the rivers Euclen and Eloris, and the Thracian Strymon; but it seems to have been admitted that the finest and fattest came from Bœotia. The Bootians were not unthankful for their good fortune. They crowned their eels for sacrifice, threw over them the usual salted cake, and offered up a devout prayer to the gods ; after which, we may suppose, the priests and their attendants enjoyed a glorious banquet.

If the finest eels came from Bœotia, the finest Bœotian eels came from Lake Copais ; they were sent in considerable quantities to Athens, where they found a ready sale. Pausanias says : + "The fish of this lake differ not in

* Badham, "Ancient and Modern Fish-Tattle," p. 369.

$\dagger$ Pausanias, bk. ix., c. 24. 
kind from those found elsewhere, but the eels are of large size, and very sweet." The lake is now, according to Colonel Mure, * a large yellow swamp, overgrown with sedges, reeds, and canes, through which the river Cephissus may be distinguished oozing its sluggish path for several miles. But it is still famous for its eels, which Leake describes as large, white, of delicate flavour, and light of digestion. +

The principal modern " eeleries" would seem to be the streams at Narbonne and Montpellier, and the Seine near Elbœuf, in France; the Elbe, where specimens weighing sixty pounds reward the industrious angler ; and Worken, in Prussia, which sends tens of thousands to England every year. In England we are all acquainted with

$$
\text { "The Kennet swift, for silver eels renowned ;" }
$$

while Ely, or Eel Island, Elmore on the Severn, and Ellesmere on the Mersey, owe their names to the quantity and quality of the eels found in their waters. The Cam produces good eels; and they are also to be taken, and when taken valued, in the streams of Norfolk and Lincolnshire. An old couplet says of two localities in the latter county :-

\footnotetext{
"Ankham eel and Witham pike In all England is none like."
}

The eels caught in the Thames and in the water-courses of Essex are never of large size, but they are tolerably good eating.

The most fantastic theories have been broached in reference to the reproduction of eels. One authority

* Mure, “Tour in Greece," i. 227.

† Leake, "Northern Greece," ii. 159. 
gravely affirms that they are engendered by mud. Another, that they spring from the hairs of a horse's tail, after they have been sufficiently soaked. A third protests that eels have no other parents than crabs. Pliny supposed that the old eels committed suicide by rubbing themselves against rocks, and that out of the pieces and particles thus detached a new brood issued. Van Helmont, a medieval philosopher, attributed them to the dews of a May morning; while others have conceived them to be developed from the various parasites which infest the gills and bodies of carp, cod, salmon, and similar fish.

The fact is, the birth of the eel is one of the mysteries of natural history. And notwithstanding the researches of naturalists, all we can safely say is that the eel is ovoviviparous, and that its young make their appearance with the genial spring. There is no doubt, however, about their fecundity; and wherever they take up their quarters, they soon accumulate in countless hosts. Spallanzani says that in the marshes of Comacchio nine hundred and ninety thousand were caught in a single year. In Jutland the fishermen sometimes capture nine to ten thousand at a single cast of the net. A French writer asserts that along the banks of the Lower Seine they are caught by the bucketful! In the ditches around Rouen they abound in such numbers, says Pouchet, that the children amuse themselves by catching the slippery creatures with the hand. We know of a fish-pond into which half-a-dozen were thrown to stock it, and in the following year we never laid our night-lines without securing a satisfactory harvest.

In spring the young eels ascend the rivers in countless 
bands, myriads upon myriads in a serried phalanx, which throws off immense detachments at every ditch and pool: this migration the French call la montée. In autumn they descend towards the sea; and you will find them swarming in thousands in the creeks and channels to which they are conducted by the barriers and embankments of the fishermen. They prefer to accomplish their migratory movements at night. Sometimes, when a failure of their food-supply, or other cause, induces them to change their quarters, they traverse a considerable extent of land to reach a suitable locality. Mr. Yarrell justly says that of this circumstance there can be no doubt. When grass meadows are wet from dew, he says, they travel during the night over the moist surface in search of frogs or their usual food. Some ponds continually produce eels - however desirous their owners may be to keep them out, from a knowledge of the havoc they commit among the spawn and fry of other fishes. It may happen that in other ponds they will refuse to stayon account, perhaps, of some obnoxious quality in the water; and though again and again introduced, they will leave the uncongenial locality during the night, and betake themselves elsewhere.

During the cold months of the year they remain imbedded in the mud; and large quantities are frequently taken by eel-spears in the soft soils, and harbours, and banks of rivers, from which the tide recedes and leaves the surface exposed for several hours every day. The sensitive fish, which are unable to endure any sudden depressions of temperature, and avoid all ice-cold waters, bury themselves, fully a foot deep or more, near the edge of the navigable channel, and generally near some of the 
many land-diains, the water of which continues to rum in its course over the mud into the channel during the whole time the tide is out. In Somersetshire, as Mr. Yarrell remarks, the people know how to find the holes in the river-banks in which the eels are hybernating, by the hoar-frost not lying over them as it does elsewhere, and they dig them out in heaps.

The eel seems to form a connecting link between the fish and serpent, and probably the abhorrence with which it is regarded by the Jews is due to its serpentine form.

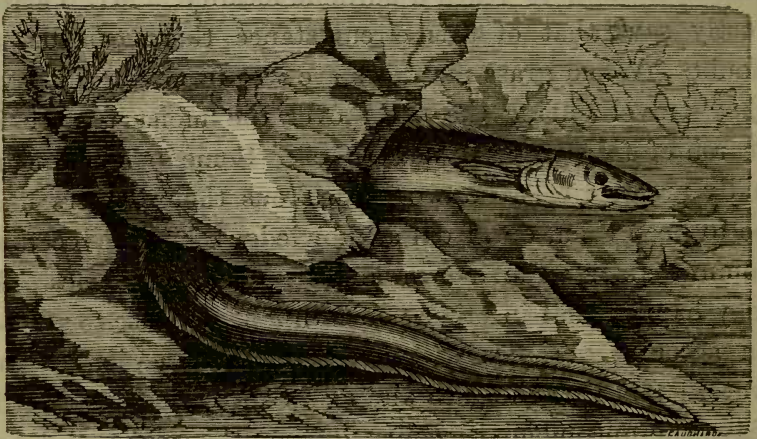

THE EEL.

It has no ventral fins, and its body is covered with a soft, thick, viscous skin, of which the scales are so minute as to be almost invisible, whilst they are sometimes wanting. It belongs to the family or order Murcenida, which some naturalists subdivide, according to their characteristics, into the families Synbranchida, Murcenida, Anguillida, Congerida, and Ophisurida. In all these the skeleton is without ribs, and the fin-rays are not articulated; two features distinguishing them from the Gymnotida, or 
electric eels, whose ribs encircle the body, and whose finrays are duly jointed. The gill-openings, in the eel, are remarkably small, and are placed far back, so that the duct from the air-chamber to the mouth is of considerable length. Thus the gills can retain their humidity for some time, and the eel remain out of water without suffering any inconvenience. Hence, too, its respiration is slow and feeble. This is a characteristic of the reptiles, to which, in form, the eel is closely allied, and is accompanied both in them and in the eel by an extraordinary tenacity of life,-a tenacity which has become proverbial. We need not believe, however, the story told by Gesner, of an Englishman who had seen an eel come nine times alive out of the trail of a raven, absolutely refusing to be digested ; but, when caught by a sturgeon, it has really been observed to retreat backwards in the same way. Its slipperiness has given rise to many a popular adage. The Latins said, "Anguilla est, elabitur ;" - $\mathrm{He}$ is an eel, and he is off! "As slippery as an eel," is a favourite comparison for a sly fellow not easily kept to the truth. And a Latin epigram likens life to this uncertain fish, which one moment you hold in your hand, and the next moment it is gone :-

\footnotetext{
"How mobile, fleet, and uncontrolled, Glides life's uncertain day!

Who clings to it but grasps an eel, That quicker slips away !"
}

The Murænidæ are marine fish; but the Anguillidæ or eels proper, though some of them occasionally pay a visit to the sea, are fresh-water fish. Their pectoral fins are of tolerable size, while their dorsal fins stretch down to and wholly encompass the tail. Groups of numerous 
longish scales, resembling very minute mesh-work, are sunken in the skin. There are three or four species found in British waters. The Sharp-nosed (Anguilla vulgaris, or acutirostris) is the most common. The Snig eel (Anguilla mediorostris) is best fitted for the table. Its cervical vertebræ are without the processes found in the first-named species and in the Broad-nosed eel (Anguilla latirostris).

The eel-fishery is conducted in various ways. Weirs and dykes are erected across streams, with baskets, or bucks, as they are called, fixed in them, to entrap the eels in the course of their passage. These bucks are of a considerable size, and shaped like a jar, in the mouth of which a funnel-shaped osier apparatus, constructed on the principle of a mouse-trap, is securely fitted. The eels readily force their way into the interior, but on attempting to return find the entrance closed against them. "Eel-pots" are also used. These are made like the bucks, but are not so strong or large. They are sunk, by means of stones, in the favourite "runs" of the eels, among the reeds or near the banks, and in this way scores are captured. They are also taken by "night-lines." The angler provides himself with a long stout line, to one end of which he fastens a heavy weight, and the other he secures to a post or stake on the border of the stream. At intervals of three or four feet he arms his line with hooks, baited with worms, minnows, or fragments of dead fish, and then he sinks it in the muddy bottom of the pond or stream. At early dawn he hauls in his line, and generally finds himself supplied with a good harvest. If left too long, however, the larger eels are apt to wriggle 
themselves off the hooks. "Sniggling" is another mode of eel-capture. Take a rod, or long stick, strongly curved at the top, and fasten a ring to its extremity; through this ring slip a piece of string, one end of which must be held tightly in your hand. To the other end, on some stout twine, attach a strong darning-needle, fastening it by the middle. For bait you secure a large lob-worm, through which you thrust your needle longitudinally, with an utter disregard of its feelings, taking care that only the twine shall emerge from the lob-worm's head. Having drawn your worm up to the ring of the rod, your preparations are complete; and fixing on some hole which you suspect to accommodate an eel, you thrust the point of your rod, and the living bait, into it. As soon as you think the worm has been swallowed, give a gentle twitch to the string; and the needle, which, inside the worm, has gone straight down the eel's throat, being tied by the middle, is twisted across the creature's gullet or stomach, and firmly hooks it. This process requires some skill and more patience; and, so far as our experience goes, is not very fruitful in satisfactory results.

Then there is "clod-fishing." You string a good-sized bunch or cluster of lob-worms to some stout worsted, and fasten the said bunch to the end of a cord, which is, in its turn, attached to a rod or pole. Where the eels are moving, you take up a convenient position, and dropping your clod into the water, allow it to sink to the bottom. The moment you feel "a bite," gently and smoothly, but quickly, draw up your bait. The eel or eels will be found to have so entangled its or their teeth in the worsted as to be unable to get free. This method is extensively practised in Holland. 


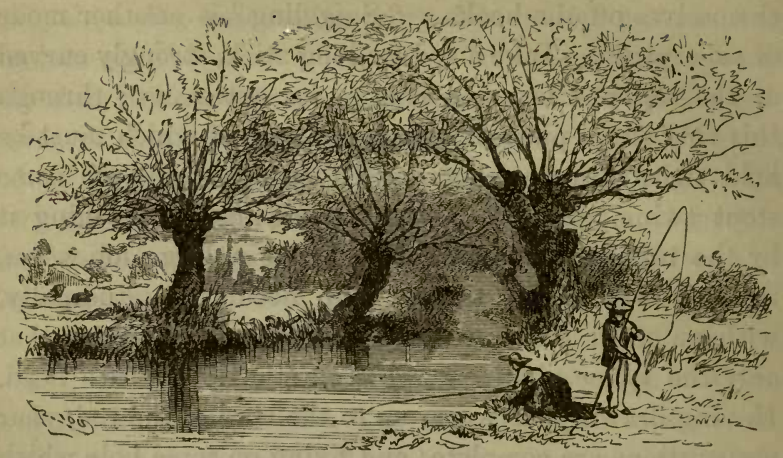

ANGLING FOR EELS.

At Comacchio, near Venice, an immense apparatus, the largest in existence, and constructed on principles which show a profound knowledge of the habits of these fish, provides for their capture on a gigantic scale.

The "lagoon" of Comacchio, lying about two miles distant from the Adriatic coast, measures one hundred and forty miles in circumference. It contains several islands, on one of which is situated the fortified town of Comacchio. The lagoon is divided into forty basins, or "fields," as they are locally called, by dykes, and each basin is connected with the Adriatic by a canal. Through these canals the fry of the sole, the mullet, and other fishes, but more particularly the eel, enter the lagoon, where they are fattened until they attain a marketable value.

The government of the lagoon is placed in the hands of the farmer-general, who rents the fisheries from the Italian Government. The men whom he employs are divided into brigades; and their business consists in the construction 
and repair of the dykes, in the management of the floodgates at the time of the arrival of the young fish, and the organization of the labyrinth during the fishing-season. This brigade numbers about three hundred men. For police purposes a brigade of one hundred and twenty is kept, and the general administration is carried on by a brigade of about one hundred. The islands sprinkled over the lagoon are termed "farms." Each is occupied by about twelve labourers, who live in barracks, under strict discipline, and obey the orders of a master, whose will, in his own little territory, is absolute, and who receives a salary of four scudi seventy-five baiocchi per month, with two pounds and a half of fish, or a corresponding allowance in money, per day. The labourers are paid a small fixed wage, and a commission on the produce of the farm. When old and infirm, they are supported at the expense of the community; and a similar charity is extended to their widows and orphans.

They are specially busy, these strange fisher-folk, - who live a life apart from the ordinary work-day world,-at the spring and autumn seasons; that is, when the young fry enter the basin, and when the adult eels are impelled by instinct to make their escape from them.

The canals are left open from the 2nd of April to the end of June; and during these three months the young eels spontaneously quit the waters of the Po and the Adriatic to enter the lagoon. The stormier the weather, the greater the influx. Of course, other young fish enter at the same time, and may be seen on the surface of the water, or at a very slight depth. The eels, on the contrary, keep close to the bottom, and do not show themselves; but the people of Comacchio have a means of as- 
certaining whether the montês is abundant or scanty, They eonstruet a number of faseines, or bundles of twigs, and sink them with a pole to the bottom of the basins, where they remain day and night. At intervals the men on duty raise them, shake them on the ground, and the eels which have entwined themselves among the boughs drop off । aecording to the number of these will be the magnitude of the shoal.

Having onee entered the basins, the eels make no attempt to quit them until they have reached maturity, Then the migratory fever attaeks them, and they strive to gain the sea. Their journeys are made only during the night, and before the meon rises, If the radianee of "the goddess of the night" surprises them during their passage, they halt immediately, and wait until the following night to resume their eourse.

The fishermen of Comaechio assert that any ordinary fire is suffieient to terwify the eels, and that they lnow this from experienes. Their praetiee is, to eonstruet with burdles a number of labyrinthine eompartments in the narrow reedy ehannels through whieh they leave; the fish easily pass into these elambers, but are unable to get out of them. As soen as a suflieient number have en. tered the trap, the flishermen kindle a fire at the mouth, and prevent any attempt on the part of others to go forward. Then they eolleot the eaptives with their nets.

Defore being sent to market, a large portion of the eela are eooked. This operation is eondueted in a large room eontaining sereral fireplaees ranged along one side of it. Caeh fireplaee measures about five feet square, and in front hang six or seven spits for impaling and roasting the eels, with a trough beneath to eateh the fat that drops 
from them. But before

- being roasted, they undergo an operation, which Bertram thus deseribes :- *

A workman seated before a bloek of wood, with a small hatehet in his hand, seizes the eels one by one, and dexter: ously amputates the head and tail, which are given to the poor, divides the body into a eertain number of pieces of equal length, and flings them into a basket at his side, Each piece at the same time is slightly notehed to aid the work of the next eperator, who deftly and rapidly places them on the spit. The smaller eels are not subjected to this process, but are simply notehed and put on the spit. The spits, when filled, are handed to the women in front of the fire, One of these maintains the

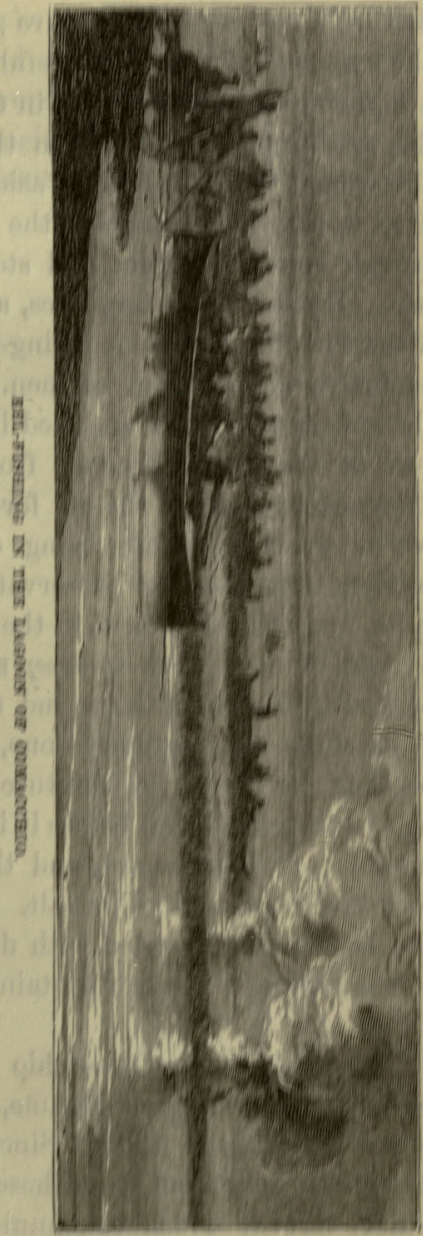

- Bertrain, "Harvest of the Bea," pp. 460, 461. 
fire at a proper temperature; the other superintends the roasting of the eels, carefully shifting the spits from a higher to a lower position in front of the fire, until the fish are properly done, when the spits are taken off by the woman who lays them aside for the next operation. This woman also attends to the grease that collects in the trough below the spits, and stores it in jars for future use. Besides these fireplaces, a number of furnaces are fitted with large circular frying-pans, which are under the exclusive management of men. All the fish for which the spit is unsuitable are fried in these pans, with a mixture of the grease dropped from the eels and olive-oil. They are exposed to the air for some time, even in very warm weather, before being cooked. This operation renders them fitter for preservation. The eels roasted on spits, and the fish cooked in the frying-pans, are placed in baskets of open work to dreep and cool. They are then packed in barrels of large and small sizes. The packing is carefully and regularly done, similar to the method of packing herrings. A mixture of vinegar and salt is poured into the barrel before it is closed up. The vinegar must be of the strongest, and the salt employed is gray rock-salt instead of white salt. Previous to exportation, the barrels are branded with different letters, according to the nature of the fish contained in them.

The fisheries at Comacchio date from a very early period. They did not assume, however, any degree of organization until 1229. Since that date, the waters have been dyked out from those of the Adriatic, and the canals formed which communicate with the Reno and Volano mouths of the Po, and the Adriatic. They now 
employ a population of about 6000 , and the average "take" may be estimated at $1,000,000$ lbs. yearly. When any "farm," or company of fishermen, captures $48,000 \mathrm{lbs}$. of fish in a single night, a grand festival is held, in which all the inhabitants of Comacchio participate. 


\section{CHAPTER IX.}

THE LOBSTER AND THE CRAB.

"If like a crab you could go backward."-SHAKESPEARE.

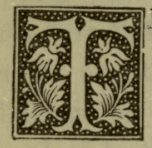

HE Lobster has been happily described as "a standing romance of the sea:" an animal whose clothing is a shell, which it casts away once a year in order that it may assume a larger suit; an animal whose flesh is found in its tail and legs, and its hair in the inside of its breast; whose stomach is in its head, and is changed annually for a new one, which begins its brief career by devouring its predecessor; an animal which carries its eggs within its body until they become fruitful, and then bears them outwardly under its tail; an animal which can throw off its legs when it finds them troublesome, and in a short time can replace them with others; and, finally, an animal whose quick, keen eyes are placed in a pair of movable horns.

The reader, if he had never seen a lobster, would probably conclude, from this description, that it was an altogether anomalous and abnormal creature, living a 


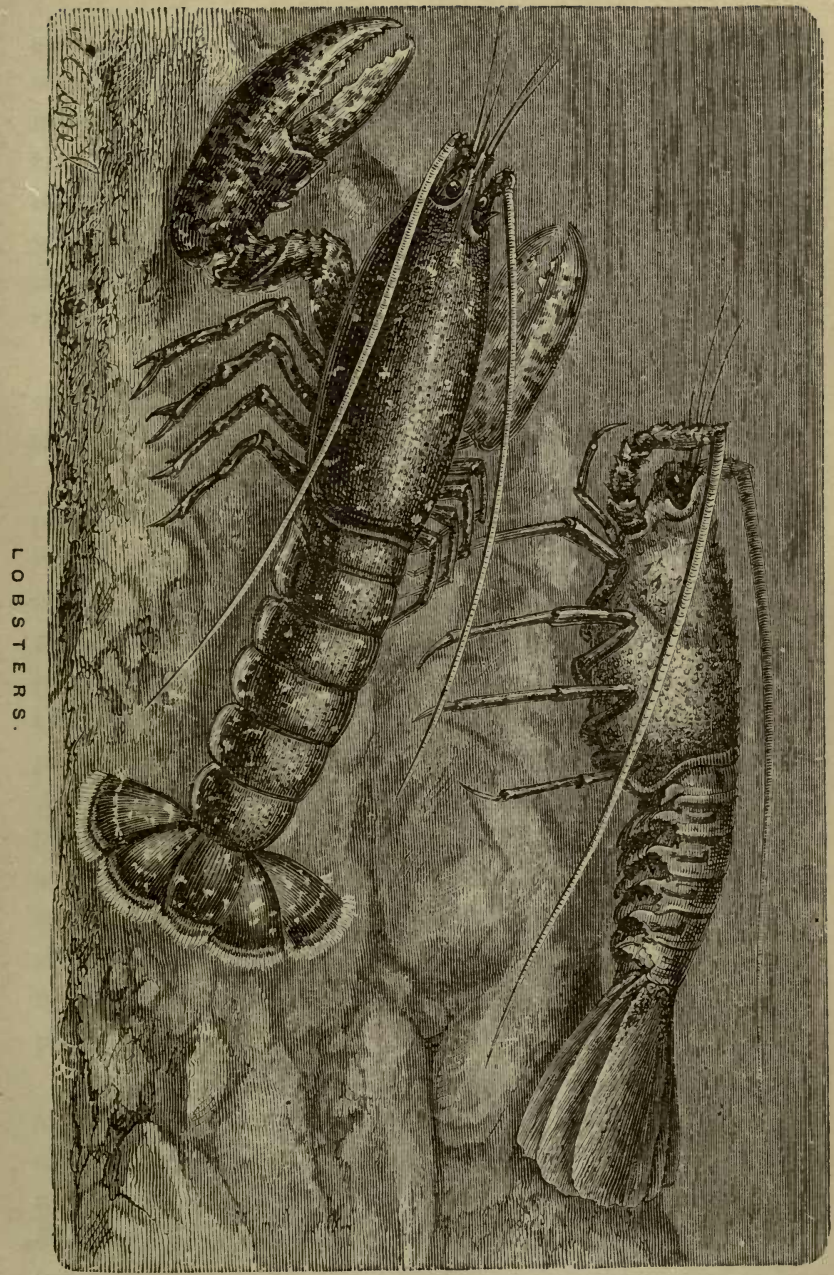




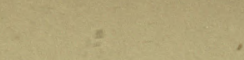


strange, wild life of its own, and belonging, indeed, to some singular world of monstrosities in which the ordinary laws of Nature had no control. But, on the contrary, it fills its proper place in the scale of animated life; its structure is admirably adapted to the conditions under which it performs the vital functions ; and in its organization the same great principles obtain as are apparent in the economy of all created beings.

The lobster is a crustaceous animal, belonging to the sub-order Macrura, or long-tailed Decapods. Its scientific name is Homarus vulgaris.

On examining it we see at once that its body is composed of two parts, popularly called the "head" and the "tail," the latter being jointed and flexible. The socalled "head" is really composed of both the head, strictly so termed, and the thorax (or "chest")- the two being wedded into a single mass which naturalists call the "cephalothorax." On the other hand, what is popularly called the "tail" is really the "abdomen." Along the lower surface of the body are disposed the feelers, claws, legs, and other appendages; and these, as well as the entire body, are enclosed in a complete suit of armour, a strong chitinous (or partly horny) shell, or ex-skeleton, while the cephalothorax is covered by a great cephalic shield or plate, termed the "carapace."

Each segment of the body is composed, in the main, of a convex upper plate, termed the "tergum," which is closed underneath by a flatter plate known as the "sternum;" the line where the two unite being extended, downwards and outwards, into a plate called the "plueron," or "pluera." 
The somites, or segments, may be described as follows, -beginning at the animal's posterior extremity :-

The last segment is called the "telson," and is without appendages. It forms the final articulation of the abdomen.

To the next segment, or last but one, is attached a pair of natatory appendages, the "swimmerets," each consisting of a basal joint which articulates with the sternum, and is called the "protopodite;" and of two diverging joints, the "exopodite" (which is the outer), and "endopodite" (which is the inner), attached to the former. These joints are considerably expanded, so as to form powerful paddles; and the outer one, or exopodite, is divided by a transversal joint.

The third segment carries a pair of "swimmerets" resembling those already described, except that they are much narrower, and that the exopodite is not divided.

In the succeeding segment the extremities of the limbs, or ambulatory appendages, are not simply pointed, but converted into nipping claws, or "chelæ."

The next segment carries a pair of chelate limbs, exactly like the preceding; and the next, or sixth, is furnished with appendages essentially similar in structure, but much larger, and constituting the "great claws."

The next two segments of the thorax, and the one in front of them, are provided each with a pair of modified limbs, which are termed " maxillipedes," or "foot-jaws." These are so modified as to serve as instruments of mastication.

The next two somites, or segments, carry appendages in the form of jaws, and are termed respectively the first and second pairs of "maxillæ." Each consists, as before, 
of protopodite, exopodite, endopodite, and the like; but the epipodite (or inner branch) of the first pair of maxillæ is rudimentary, while that of the second pair is large and shaped like a spoon. It is termed the "scaphognathite," and its function is to "cause a current of water to traverse the gill-chamber by constantly bailing water out of it."

To the next segment are appended the biting jaws, or "mandibles," each consisting of a large protopodite, and a small endopodite, termed the "palp" (or organ of touch), the exopodite remaining. undeveloyed.

The aperture of the mouth is situated between the bases of the mandibles, bounded behind by a forked process, called the "labium," or "metastoma," and in front by a single plate, the "labrum," or upper lip.

The next segment sustains the long antennæ, or feelers, each consisting of a short protopodite, and a long, jointed, and segmented endopodite, with an exopodite which is little more than rudimentary.

In front of the great antennæ we find the "antennules," or smaller antennæ, each composed of a protopodite and a segmented endopodite and exopodite, which are nearly of equal size. Finally, attached to the first segment of the head are the eyes, each borne upon an eyestalk formed by the protopodite. The gill-chamber consists of a great prolongation downwards of the "pluera" of the thoracic segments, and the gills are attached to the bases of the legs.

Such is the complex structure of the Common Lobster,* .which may fairly be regarded as a type of the higher Crustacea.

$$
\text { * Nicholson, "Manual of Zoology," pp. 205, } 206 .
$$


A few additional details are necessary, however, before the reader can present it to his mind's eye as it lives, moves, and has its being. From the enumeration given above he will have discovered that it possesses eight articulated appendages, which, in popular parlance, are called "legs;" and two great claws, which open like a pair of pincers, are singularly strong, very tenacious in their grasp, and serrated or toothed like a saw. These are its "arms." The tail portion of the animal consists of six joints, or segments, and, as it expands laterally, forms a powerful instrument of locomotion in the water. The head, which is very small, is placed between the two claws, and furnished with eye-stalks which can be projected or retracted at the animal's pleasure. The mouth, like an insect's, opens longitudinally, and contains two teeth for the comminution of its food; between them extends a fleshy protuberance shaped like a tongue. The colour of the shell of the living animal is a beautiful bluish-black, which is diversified, most fancifully, but agreeably, by paler spots and clouds.

As regards its digestive system, the alimentary canal is continued from the mouth in a straight line to the anus. The spinal marrow is lodged in the thorax. The stomach is globose, and contains, in the cardiac portion, a calcareous apparatus for triturating the food, popularly known as the "lady in the lobster." The liver is well developed, and consists of two lobes.

The sexes are invariably distinct. The ovary, or place where the spawn is generated, is situated near the tail ; and here is found a bright red substance, much appreciated by the lobster-eater: this consists of a large number of fry too small for exclusion. From the ovary proceed two 
effluent ducts opening at the base of one of the pairs of the thoracic legs. Through these passages the ova, destined for the future multiplication of the species, descend to be excluded and arranged under the tail.

The young in their larval state are very imperfect; nor is the form proper to the adult attained until after several moults, constituting a complete metamorphosis, though one effected by very gradual stages. In a few weeks, however, their shells acquire firmness and solidity, and become useful as offensive and defensive armour.

The most remarkable, and, so far as the creature itself is concerned, the most disagreeable incident in the lobster's life is its annual exuviations. Like the crab, it sheds its shelly covering every year. Previous to the change it seems to be sick, uneasy, languid. It ceases to harrow up the sand and prowl about for prey, and lies almost motionless and semi-torpid, as if dreading the impending trial. The new shell is developed in three or four days, if, during the period of its defencelessness, it has not fallen a prey to some one of its many enemies or of its own kind. The additional size which the animal gains at each occasion of "moulting" is really wonderful ; and not less wonderful is it to see the old coat cast aside, like a suit of worn-out clothes, while the creature, naked and soft, awaits, in a sheltered hole or corner, the growth of its new harness. It is difficult to understand, perhaps, how it contrives to draw the muscles of its claws out of their hard, shelly covering; but it would seem that during its sickly state the limb so contracts as to be capable of being withdrawn through the joints and narrow passages near the body. During the first year of its age it changes its shell every six weeks, in the second year 
every two months, and afterwards about once every three months, until, at some age as yet unknown, the moulting process ceases, because the animal ceases to grow.

The hen-lobster, during the period of exuviation, is guarded by the male; and should one male be taken away, another, before long, will be found in some mysterious manner to have replaced it. The lobster becomes reproductive, it is said, at the age of five years. It is found with eggs, or " in belly," to use the technical term, all the year round. The best season for this crustacean as an edible is from the middle of October till the beginning of May.

It was long disputed whether the lobster was able to replace a broken limb, or to throw off at its pleasure one which was so injured as to be useless; but that it possesses this twofold capacity is now a well-ascertained fact. We have frequently met with lobsters which have taken to themselves a new claw; it may almost always be detected by its comparative smallness.

Besides the ordinary lobster-the Homarus vulgariswhich is found on all the coasts of Great Britain, our markets are supplied with the Norwegian (Nephrops Norvegicus), which is distinguished by its kidney-shaped eyes and its pale, flesh colour. The American Lobster (Homarus Americanus) has very large claws. The Spiny Lobster (Palinurus vulgaris), which is often found on the southern coast, is better known, perhaps, as the Sea Crayfish. Its body is encrusted with a number of short spines. It has no claws or pincers, and its antennæ are of singular size. Some naturalists identify it with the karabos of the Greeks and the locusta of the Romans. 
The lobsters found in tropical seas are frequently of extraordinary dimensions, and beautifully coloured-as, for example, the Palinurus ornatus.

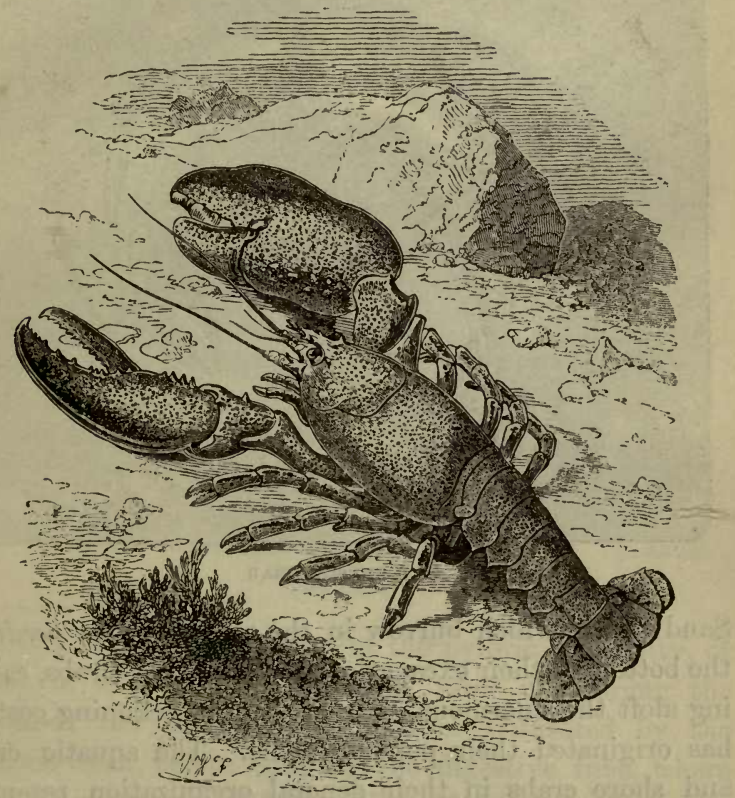

THE AMERICAN LOBSTER.

There are Crabs and-Crabs ; that is, Sea Crabs and Land Crabs. With the latter we need not concern our. selves, though some of the species are in high repute as table delicacies. The sea crabs are of many kinds : Painted Crabs, distinguished by the beautiful markings of their shells; Hermit Crabs, which roam about the sands and take possession of the deserted shells of univalves; 


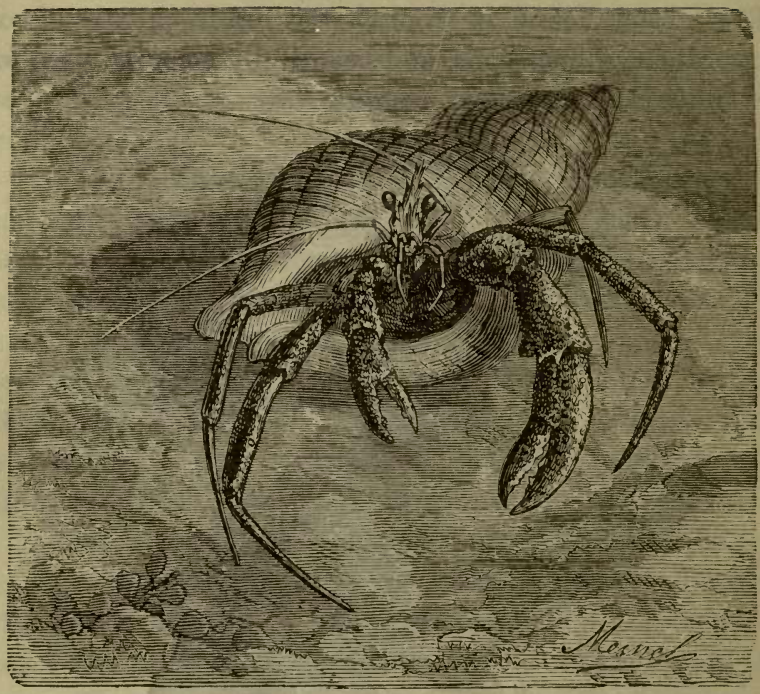

THE HERMIT CRAB.

Sand Crabs, which burrow in the sand, and lie perdu at the bottom of their excavations; and Calling Crabs, carrying aloft the enormous claw in whose beckoning gesture has originated their popular name. The aquatic crabs and shore crabs in their general organization resemble the crustaceans already described, and undergo the same process of " moulting," or exuviation. They are remarkable for their complex masticatory apparatus. The mouth is provided with fully eight pieces or pairs of jaws, which pass the food through an exceedingly short gullet into a membraneous stomach of considerable size. This stomach contains certain cartilaginous appendages, five in number, to which strong, grinding teeth are at 


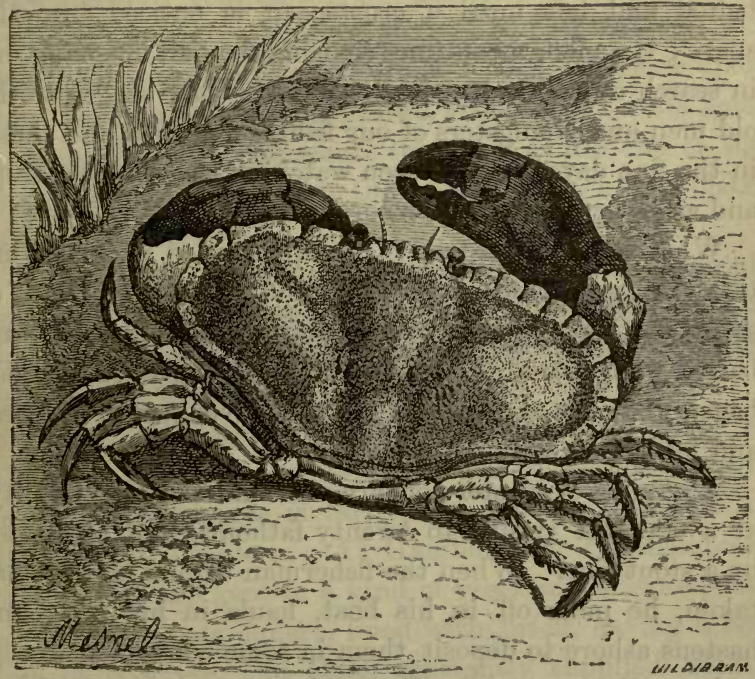

THE CRAB.

tached. As they are placed at the pyloric extremity, or outlet of the stomach, the food, after undergoing the action of the jaws, is re-chewed or triturated by the stomach-teeth, before entering the digestive tube, where it comes in contact with the biliary fluid of the liver.

The lobster and crab fishery can be conducted without much capital, and in the intervals of the fishermen's regular employment. The Scotch laird's advice to his son, says Bertram,* to " be always stickin' in the ither tree, it will be growin' when ye are sleepin'," holds good in lobster-fishing. The "pots," as they are called, may be

"Bertram, "Harvest of the Sea," p. 386. 
baited and left until a crustacean is enticed into the snare; the men, meantime, cruising for bait, or going out in search of haddock. Or the fishing may be left to the old men and youngsters of our fishing-villages; and these, in the fine days, may be seen watching their lobster-traps and crab-cages with praiseworthy vigilance.

What is a lobster-trap? In appearance it is not unlike "an overgrown rat-trap;" and it is constructed of stout netting fastened over a framework of wood, and baited with any kind of fish offal or strongly-scented garbage. For the crustaceans are the scavengers of the sea, and feed upon the foullest refuse.

A number of lobster-pots are sunk in a suitable locality, at a depth of twelve to twenty fathoms, and connected by a stout line. When the fisherman thinks his bait has taken, he pulls off in his boat, hauls in his pots, and hastens ashore to deposit them in some convenient receptacle until "wanted." The said receptacle is usually an old chest, perforated with many holes, so as to admit the water, and secured in a quiet corner of the beach. In such a receptacle the lobsters can live and ruminate, if crustaceans are given to rumination.

As for crabs, a line and a bit of raw meat will enable the amateur to make himself the lawful possessor of any number. They are caught in large quantities off the jetties and piers of our sea-ports, being attracted thither by the garbage which is thrown overboard from the fishing-smacks and homeward-bound vessels.

On the granite-bound coast of Scotland, says Mr. Bertram, the sport of crab-hunting may be enjoyed to perfection, and the wonders of the deep studied at the sames time. A long pole with a small crook at the end will 
draw the crab from its nest; or great fun may be enjoyed by tying during low-water a piece of bait to a string, and attaching to the other end a stone. The crab seizes upon this bait whenever the tide flows, and drags it to its hole, so that when the ebb recurs the stone at the end of the cord enables you to track the animal to its hiding-place, and pounce upon it.

Lobsters are collected and sent to London from all parts of the coast, being packed in sea-weed and sent in boxes by railway. At Thames Haven is a famous depôt for the Norwegian and Scotch lobsters. They arrive in welled vessels, and are kept in large store-boxes, as already described, until wanted. A considerable trade in these crustaceans is carried on between the Orkney Islands and Aberdeen. At Hamble, near Southampton, the lobsters are kept in a kind of reservoir or store-pond, about fifty yards square, lined with brick, having a bottom of concrete, and being constantly supplied with a lively current of sea-water. Here they may be kept as long as six weeks without suffering any injury, and forty thousand to fifty thousand can easily be accommodated. In the wooden boxes they live at such close quarters that their combative tendencies are easily excited; and to prevent them from mutilating each other, or repeating the experiment of the Kilkenny cats, the great claw is paralyzed by means of a wooden peg run through the lower joint. 


\section{CHAPTER X.}

THE SHRIMP AND THE PRAWN.

"Down on the shore, the sunny shore,

Where the salt smell cheers the land;

Where the tide moves bright under countless light, And the surge on the glittering strand."-ALLINGHAM.

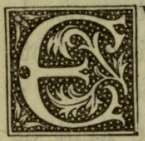

VERYBODY is familiar with the SHRIMP, both in its living condition, when it darts to and fro in the shallow waters, as if animated by some internal electricity, and as an edible, when, after boiling, it assumes a particularly agreeable flavour, and a not less agreeable colour.

How many millions of this crustacean are devoured at the breakfast-tables and in the tea-gardens of London alone, to say nothing of our English watering-places, where "tea and shrimps" meets the eye at every corner, or of our larger cities, into which it is now introduced by the extant facilities of railway communication from all parts of the British coast, we cannot pretend to calculate. Think of Greenwich, Gravesend, Margate, Ramsgate, where nearly all your excursionists are seen provided with a bag of "shrimps"; think of your sea-side resorts, and the legions caught and consumed by professional and 
amateur shrimp-fishers ; think of the gallons of "shrimp sauce" prepared by our British cooks; and own that the task of computation would defy even as expert an arithmetician as Cassio. In fact, he would be unable to obtain the data on which any accurate computation must necessarily be based. Enough to know that tens of thousands of gallons are consumed yearly; and that shrimp-fishing, therefore, deserves to be included amongst our staple industries. Yet it would seem to produce no very tempting return, the wholesale price of a gallon of shrimps not exceeding threepence or fourpence.

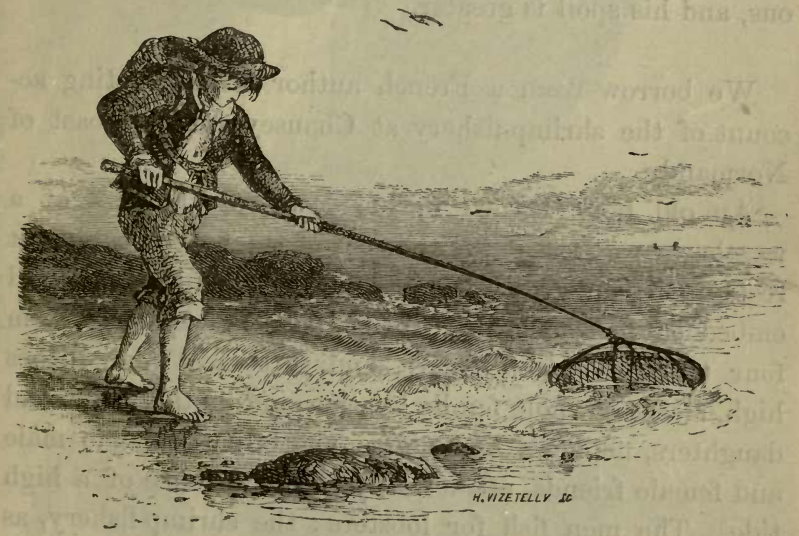

A YOUNG SHRIMPER.

"Shrimping," however, requires no very costly apparatus. The net is a simple and inexpensive affair, consisting of a framework of wood, to which is attached a kind of reticulated pouch or bag; and this the shrimper, by means of a long pole, drives before him, as he wades through the shallow water immediately inshore. No 
skill is necessary; an amateur, after an hour's practice, will catch as many of the agile and graceful crustaceans as a veteran fisherman. In fact, shrimping is pursued as a pastime at many of our watering-places. The Ramsgate holiday people make excursions for this purpose to Pegwell Bay; and having caught their shrimps, according to Mrs. Glasse's famous injunction, boil them, and eat them. The regular shrimper, however, does not confine himself to the shallow waters which bathe the sandy shore, but keeps a boat, and frequents the more distant sand-banks, where, of course, the shoals are more numerous, and his spoil is greater.

We borrow from a French author an interesting account of the shrimp-fishery at Chausey, on the coast of Normandy.

An old boat, turned upside down, at the foot of a weather-worn crag forms the roof of the fisher's cabin ; it rests upon four walls of stones rudely piled together, and embedded in clay for cement. Here, in a space of from four to twelve feet square, and three feet nine inches high, sleeps a whole family; father and mother, sons and daughters, nephews and nieces, and often too some male and female friends, attracted by the occurrence of a high tide. The men fish for lobsters; the shrimp-fishery, as less arduous, being abandoned to the women. Armed with their "putting-nets," and with petticoats looped up to the knees, and high Normandy caps covering their unkempt locks, they explore the windings of the sandy archipelago; groping under the rocks, and wading through the pools, and collecting, if they are industrious, as much as five to six pounds weight in a day. This fishery, how- 


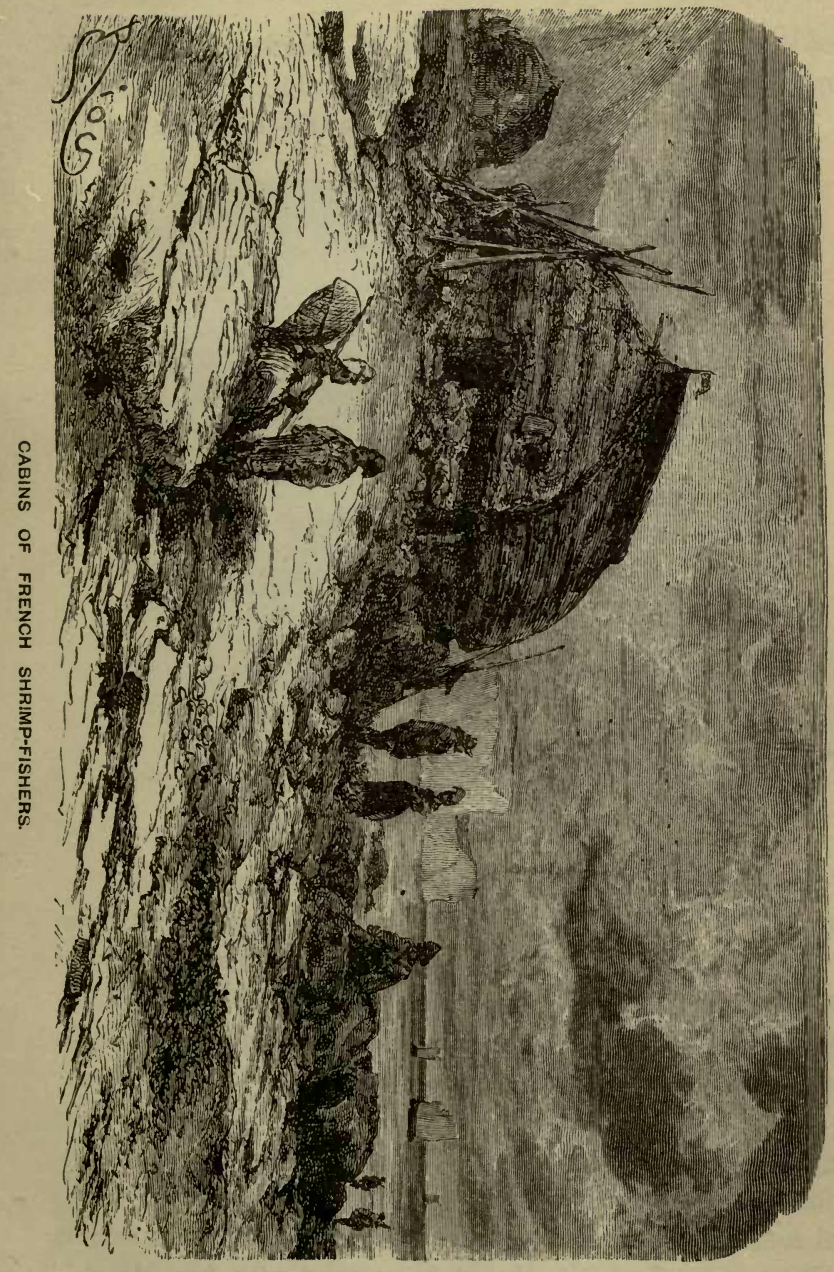



ever, can be carried on successfully only when the tides are tolerably high. The total product of the campaign will not exceed 480 to $750 \mathrm{lbs}$. each person.

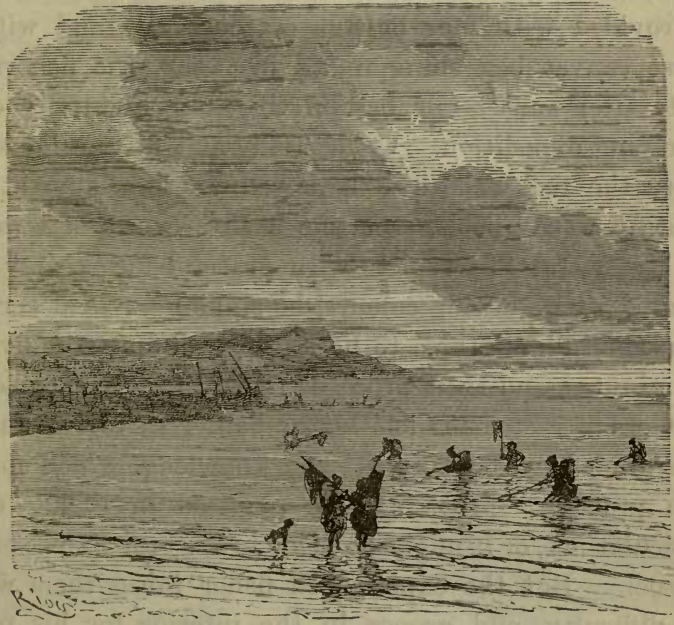

NORMAN WOMEN FISHING FOR SHRIMPS.

The putting-net_ "bouqueton," "truble," or " huxenau," as it is variously called-is made exactly after the fashion of the net in use among our English shrimp-fishers.

At Saint-Gilles-sur-Vic, in the department of La Vendée, the process adopted is very different. Here the net employed-locally termed a "ret" (from the Latin rete ?) - has no handle, and the opening is circular. It may be likened to one of the old-fashioned night-caps with which our forefathers disguised themselves, and forms a pocket or pouch, twenty to twenty-four inches in length, and fifty to sixty inches in circumference at the 
mouth, suspended by the framework which keeps it open to a cord, and ballasted by a stone or lump of lead. Across the opening is carried a line, baited with fragments of crabs or heads of sardines.

Provided with four or five of these rets, and with a coarse canvas bag slung round his neck, the fisherman starts after sunset-or better still, after nightfall-on a shrimping expedition. On arriving at a favourable spot, where the rocky shore is hollowed out in a labyrinth of beautiful weedy pools, each one a little world of strange and wonderful life, replete with graceful forms, and illuminated with glowing colours, he sinks his rets at certain intervals; allows them to lie untouched for some five or ten minutes, and then proceeds to capture the crustacean prowlers attracted to them by the bait. In this operation he is guided by the dexterity and knowledge which spring from practice. Much care is required in lifting each particular net, or it might be made to disgorge its prisoners too soon. But the experienced fisher raises them without difficulty, and gropes in the interior for his prey, which he transfers to his capacious bag, lining it with sea-weed to keep them alive.

Having filled his bag, or the tide having ebbed, he wends his way homeward, and prepares his shrimps for delivery to the wholesale dealers. Over a lively fire he places an iron pot, filled with fresh water, and as soon as the water boils, pours in his stock of fish, adding about one pound of salt for every nine pounds of shrimps. After they have boiled for five minutes, he takes them out, spreads them on a table, and sprinkles them with salt water. This process deepens the beautiful rose-red tint which is so much admired by connoisseurs. 
Those fishermen who have boats put out to sea, and on arriving at a suitable distance from the shore drop anchor, and proceed to lower their nets all around them; hauling them in as soon as they think they are tolerably well filled.

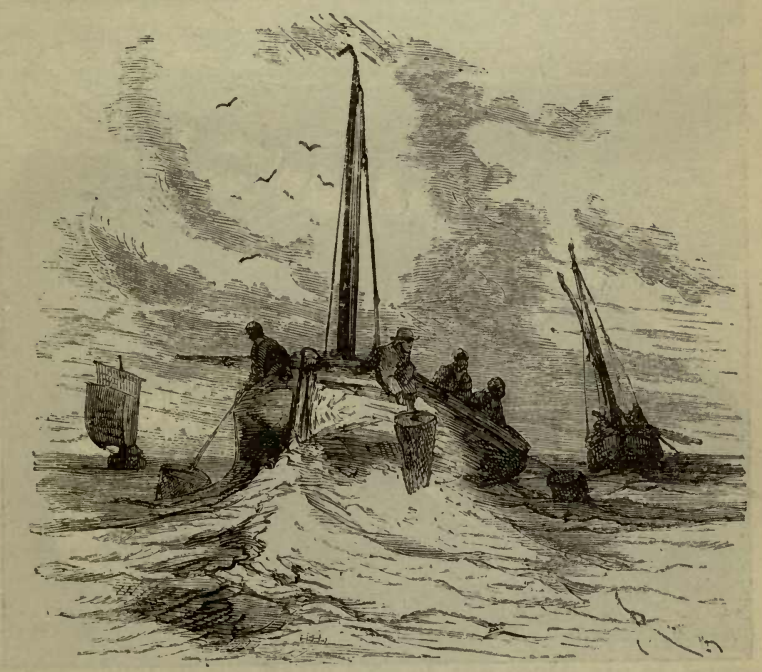

SHRIMP-FISHING OUT AT SEA.

Prawns are taken in a very similar manner; only, in some localities, the fishermen make use of osier-baskets, or " pots," like those employed in catching lobsters-and the nets are usually longer.

The Shrimp (Crangon vulgaris) is a genus of crustaceans of the order Decapoda, the sub-order Macroura, and the family Crangonidce, allied to lobsters, cray-fish, and prawns. 
It is so well known, that to describe it would be as superfluous as to paint the lily; but shortness of its beak should be noticed as distinguishing it easily from the prawn. It is a delicate, almost transparent creature; endowed with such a wonderful vivacity of motion, that

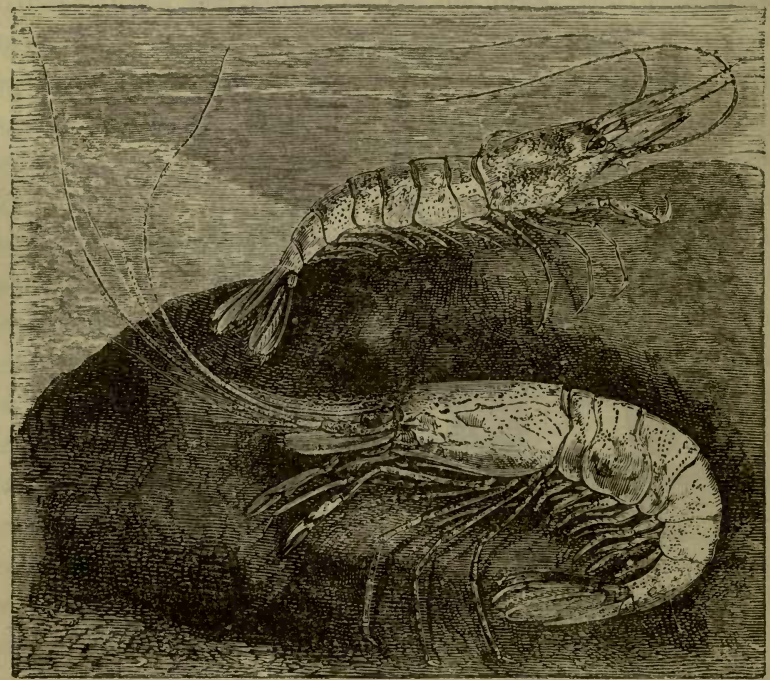

SHRIMPY.

its leaps and turns in the crystal rock-pool almost defy observation. When alarmed, it buries itself in the sand by a peculiar effort of the tail-fin. In length it varies from two to three inches. There are several species; the banded, the spinous, the two-spined, the three-spined ; but all are fit for the table.

The Prawn (Palamon serratus) belongs to the same 
order and sub-order as the shrimp, but to a distinct family, the Palcemonidac; and is characterized by the long serrated beak which projects from its carapace. It attains a length of from three to four inches, and though not so plentiful as the shrimp, is common on our coasts. It is seldom found, however, in the rock-pools. As an edible, it is more highly esteemed

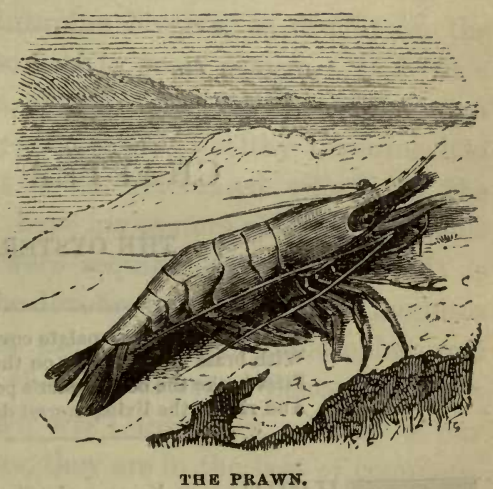
than the shrimp, but is not so universally popular. There are numerous species, all of them very active and very voracious, and all remarkable for the number of times they change their skin; an operation which practice does not seem to render easier, for, apparently, the work of exuviation is always accompanied with much distress. Prawns found in the warm seas of the south are of large size, and often of brilliant colouring; as, for instance, the Stenopus hispidus. Their habits are sufficiently curious to justify greater attention being paid to them than they have yet received. 


\section{CHAPTER XI.}

THE OYSTER.

\footnotetext{
"The man had sure a palate covered o'er With brass or steel, that on the rocky shore First broke the oozy oyster's pearly coat, And risked the living morsel down his throat."
}

HERE can be no doubt that the Oyster was the favourite shell-fish of the epicures of ancient Greece and Rome. The Greeks procured it from Pelorus, Abydos, and Polarea; the Romans, from Brindisi, the Lucrine Lake, Brittany, and the shores of Britain. We are inclined to agree with Dr. Doran, that the latter were hardly worthy of the delicacy, seeing that they abused it by mincing it up with mussels and sea-hedgehogs, stewing the whole with pinealmonds and pungent seasonings, and devouring the heterogeneous compound scalding. O dura Romanorum ilia! Their digestive powers must have almost approached those of an ostrich in efficiency. Other Romans, however, were wise enough to eat them raw, - a slave opening them at the table as fast as his master could devour them; and the larger the fish, the more the "senatus populusque Romanus" appreciated them. Not only were 
they relished as a provocative before the feast, but, during the feast, whenever the appetite began to flag. The Bordeaux oyster would seem to have been in favour with the emperors; but the Rutupine bivalve, as caught on the coast of Kent, was also held in great esteem. It is to a Roman, Sergius Orata, that we owe the great invention of an oyster breeding-pond. The wealthy Lucullus had the sea-water brought to his celebrated villa from the Campanian coast, and kept his oysters alive in capacious reservoirs until they were required for the table. It is said of Vitellius that he devoured these delicious molluses all day long. Cicero, the orator and philosopher and statesman, swallowed them by dozens; Seneca was not less partial to them; nor was Calisthenes. If any of our readers are oyster-eaters, they are in the best of company.

Oyster-enthusiasts have not been wanting in later times. Louis XI. annually entertained the learned doctors of the Sorbonne at an oyster-banquet. Shakespeare, who alludes, with fine poetic sympathy, to "an oyster crossed in love," and Cervantes, the creator of "Don Quixote," loved oysters : so did Helvetius, Raynal, Voltaire, Rousseau, Danton, Diderot, Robespierre, Dugald Stewart, Hume, Lord Jeffrey, Pope, Swift, Thomson, Professor Wilson. Bentley, most erudite of scholars, could never pass an oyster-shop; the temptation always enticed him into it. Napoleon, before a great battle, cleared his perceptions and strengthened his judgment by partaking of the justlycelebrated bivalve; and now-a-days our wits, however inferior in some respects to their predecessors, are fully their equals in the matter of oyster-suppers. They have, however, a great difficulty to contend with: oystersuppers now-a-days are costly banquets ! 
Who does not remember the numerous highly-appreciative allusions to the oyster in Wilson's " Noctes Ambrosianæ"? For instance :-

"The Ettrick Shepherd (loquitur). As sure's death, there's the oysters! $O$ man, Awmrose [Ambrose, the landlord], but you've the pleasantest face o' ony man o' a' my acquaintance! Here's ane as braid as a mushroom. This is Saturday nicht, and they've a' gotten their bairds shaved. There's a wee ane awa' doon my wrang throat ; but, deil a fears, it'll find its way into the stomach.

"Tickler. They are, in truth, precious powldowdies."*

Take a second example :-

" Hech, sirs! but the month of September's the month after my ain heart, and worthy ony ither twa in the year - comin' upon you, as it does, after May, June, July, and August, wi' its $r$ and eisters. $\mathrm{Na}$, that brodd beats a'-ilka shell as wide's my loof, ilka fish like a shot-star, and the tottle of the whole sooming in its ain saut-sea liccor, aneuch to create an appeteet in the palate of a skeleton!" †

And again :-

" I never, at ony time o' the year, hae recourse to the cruet till after the lang hunder; and in September, after four months' fast frae the creturs, I can easily devour them by theirsels just in their ain liccor, on till anither fifty ; and then, to be sure, just when I am beginning to be a wee stawed [surfeited], I apply first the pepper to a squad; and then, after a score or twa in that way, some dizzin and a half wi' vinegar; and finish aff, like you, wi' a wheen to the mustard, till the brodd [board] is naething

* Wilson, "Noctes Ambrosianæ," i. 272.

† Ibid., ii. 98 . 
but shells......There's really no end in nature to the eatin' of eisters."*

According to an old proverb, "Whoever eats oysters on St. James's-day [July 25] will never want money." A recent writer, in explanation of the saying, affirms that it is customary in London-which we doubt-to begin eating oysters on St. James's-day, when they are necessarily somewhat dearer than afterwards; so that the proverb may be understood as a jocular encouragement to a little piece of extravagance and self-indulgence. We are more inclined to regard it as ironical : the epicure who can purchase oysters so long before the oyster-season begins, must needs be a man whose resources will raise him above want!

In connection with oysters and St. James's-day, we have the old association of the apostle with pilgrims' shells ; the scallop-shells which the "palmers" wore in their eaps when bound on a pilgrimage to the shrine of St. James at Compostella. So says the old ballad :-

\footnotetext{
"And how should I know your true love

From many an other one?

$\mathrm{Oh}$, by his scallop-shell and hat,

And by his sandal-shoon."
}

A custom in London, now rapidly dying out, makes this relation more evident. In the course of the few days following upon the introduction of oysters for the season, the children of the humbler classes employ themselves diligently in collecting the shells which have been cast out from taverns and fish-shops; and these they pile up in various rude devices. By the time that old St. Jarnes'sday [August 5th] comes round, these little structures

* Wilson, "Noctes Ambrosianæ," ii. 107, 108. 
are all arranged in fantastic order, with bits of candle in the interior, to illuminate them at night ; and their architects sally forth to greet each passer-by with the supplicatory salutation, "Please, remember the grotto." It may not be doubted that we have here a relic of the old days of pilgrimages and saints, which has survived the changes of upwards of three hundred years.

Buttes, in his "Dyet's Dry Dinner," published in 1599 , says : "It is unseasonable and unwholesome in all months that have not an $r$ in their names, to eat an oister." And modern physiological research seems to have proved that oysters should not be eaten from May to August, inclusive. In the latter month, however, they always reappear in the London markets.

According to an old adage, "He was a bold man who first ate an oyster." How the discovery was made of the edible qualities of this now famous mollusc, is thus pleasantly told by Mr. Bertram :- *

Once upon a time, he says, a man of melancholy mood was walking by the shores of a picturesque estuary, and listening to the murmur of the "sad sea-waves"-or, as Mr. Disraeli would say, of the "melancholy main"-when he espied a very old and ugly oyster-shell, all coated over with parasites and weeds. Its appearance was so unprepossessing that he kicked it aside with his foot; whereupon the mollusc, astonished at receiving such rude treatment on its own domain, gaped wide with indignation, preparatory to closing its bivalve still more closely. Seeing the beautiful cream-coloured layers that shone within the shelly covering, and fancying that the interior

\footnotetext{
* Bertram, " Harvest of the Sea," pp. 342, 343.
} 
of the shell itself was probably curious or beautiful, he lifted up the aged "native" for further examination, inserting his finger and thumb within the valves. The irate mollusc, thinking, no doubt, that this was intended as a further insult, snapped its nacreous portcullis close down upon his finger, causing him considerable pain. After relieving his wounded digit, our inquisitive gentleman very naturally put it in his mouth. "Delightful !" he exclaimed, opening wide his eyes; "what is this?" And again he sucked his finger. Then flashed upon him the great truth that he had discovered a new pleasurehad, in fact, opened up to his fellows a source of immeasurable delight. He proceeded at once to realize the thought. With a stone he opened the oyster's threshold, and warily ventured on a piece of the mollusc itself. "Delicious !" he exclaimed; and there and then, with no other condiment than its own juice, without the usual accompaniment, as we now take it, of "foaming brown stout" or "pale Chablis" to wash it down - and, sooth to say, it requires neither-did that solitary, nameless man indulge in the first oyster-banquet!

Scientifically speaking, the oyster (Ostroea edulis) is an acephalous mollusc; so called, because it has no distinct head, and having no head, can have no brain,- though, singular to tell, it rejoices in a beard.

Having no head, it has no organ of sight, no organ of hearing, no organ of smell. Nor has it any organ of locomotion. It is, therefore, an animal of the simplest organization; one might almost say, merely the outline or rudiments of an animal. However, it has a large and expansible mouth; a stomach like a pouch or pocket, 
with very thin sides; intestines; a good-sized liver, in the substance of which the said stomach and intestines are enclosed; branchiæ; a heart, possessing both auricle and ventricle, and surrounding the rectum, on which two great vessels abut, and from which an aortic trunk issues, divided into three branches-one for the mouth, another for the supply of the liver and digestive organs, and a third for the remainder of the body.

The blood of the oyster is colourless. The molluse adheres to the two valves of its shell by means of a strong muscle (the "adductor") situated near the middle of its body.

But though the organization of the oyster is apparently imperfect, it is complete so far as it goes, and possesses at least the indication of organs which, in beings of a more complex type, serve a loftier purpose, and point out the beginnings of Nature, enabling the thoughtful observer to understand her onward course, from the simplest outlines of animal life to the admirable human machine.

We have spoken of the "mouth" of the oyster; this is a kind of trunk or snout, with lips remarkable for tenuity; it lacks both jaws and teeth. The lungs or gills are foliated coverings extended over the surface of the body, so as to protect the air necessary to the animal's existence from the action of the water. These lamelliform gills are provided with membraneous plates, which act as capillary funnels, open at the furthest extremities. The circulating vessels open into muscular cavities, which play the part of the heart. There is no "foot," locomotion being accomplished by the alternate opening and closure of the shells. The animal secures its food by means of its beard, which acts somewhat after the manner of a rake. 
As everybody knows, the oyster is a marine mollusc. It lives close to the shore, and in comparatively shallow water; attaching itself to the rock, to one of its own kind, or to any object calculated to afford it the support it requires. Here its sole exercise would seem to consist in opening and closing its valves; its only pleasure in eat-

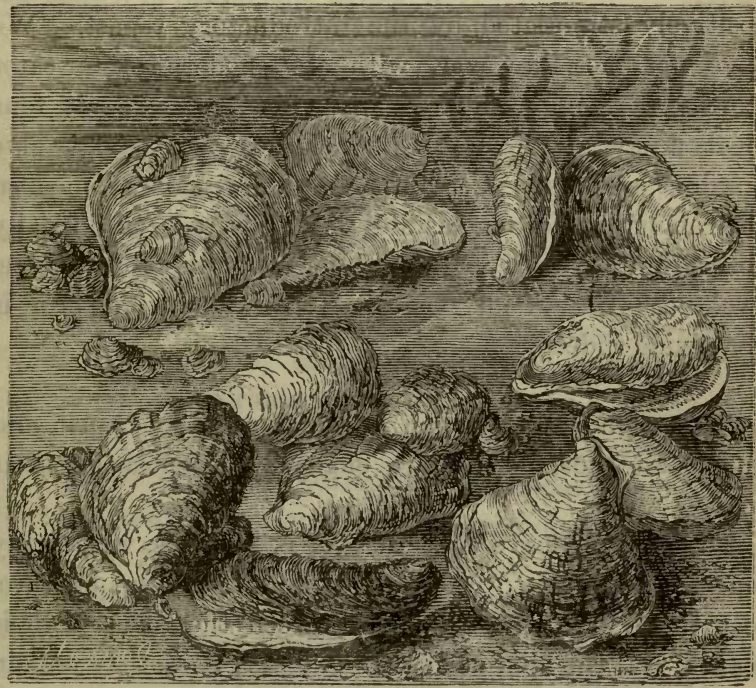

A GROUP OF OYSTERS.

ing. Its food is brought within its reach, to some extent, by the motion of the waves, and is formed of animal matter held suspended in the water. Though emphatically a marine mollusc, yet M. Beudant proved, by experiments made in 1816, that it may be trained to live in freshwater streams. 
The oyster, as food, is wholesome, light, and easily digested. An eminent French writer has characterized it as pre-eminently adapted for dyspeptics, from its peculiar success in nourishing and healing a feeble or irritated stomach. Persons may eat considerable quantities, and not only not suffer any inconvenient effects, but enjoy their dinner afterwards, as if their appetite had been positively stimulated by the introductory repast. We have not met, however, with any modern oyster-eater worthy of being compared with Vitellius, who ate four meals a day, and devoured at each meal, it is said, twelve hundred oysters! Certainly, in the annals of modern gastronomy a Doctor Gastaldi is celebrated for his daily absorption of thirty to forty dozen; but the interval between the Italian physician and the Roman emperor is very wide indeed.

Oysters begin to sicken about the end of April, and during the hot months are engaged in depositing their spawn.

They do not leave their ova, as is the case with many marine creatures, to be hatched independently; but protect them for several weeks between the folds of their mantle and the laminæ of their lungs. Here they remain surrounded by a mucous matter which assists their development; this matter, with its accumulated ova, gradually losing its fluidity, and changing successively to a light shade of yellow, gray, brown, and violet; the lastnamed indicating that the embryonic condition of the ova is nearly at an end. Then comes the happy moment of release; and nothing, says a French authority, is more curious than the spectacle of a bank of oysters at the 
spawning-season. Each adult individual sheds its own cloud of progeny. A living dust is, as it were, exhaled from the crowded oyster-bank, disturbing the water, and communicating to it a dense foggy appearance; and this dust gradually spreads abroad, until it is scattered far away from its focus of production. Unless the "spat," as the spawn is technically called, encounters some solid body to which it can adhere, it inevitably falls a victim to the voracity of the numerous enemies which prey upon it. The state of the weather is also an important consideration, as a cold day will kill the spat.

The quantity of spawn produced by a single oyster is not very accurately known. Some authorities count by millions; others estimate the season's product at five or six hundred thousand. Mr. Bertram says that he has examined oyster-spawn, taken direct from the oyster, under a powerful microscope; he describes it as a liquid of some little consistency, in which the young oysters, like the points of a hair, swim actively about, in great numbers, as many as a thousand being distinguishable in a very minute globule of spat. There can be no doubt, therefore, of the fecundity of this wonderful hermaphrodite, but it is much modified by variations of temperature. If the breeding-season be not mild and genial, the fall of spat is only partial.

On finally taking leave of the parent shell, the young oyster is provided with a locomotive apparatus; a kind of pad or cushion, surrounded by vibratory ciliæ, and set in motion by certain

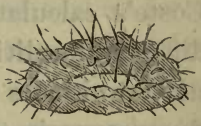

YOUNG OYSTER. powerful muscles. Hence it is able to swim about freely in search of a resting-place; and this once found,--a 
shelly bottom is best,- the pad disappears. But it is a mistake to suppose that the adult individual is incapable of progress. Diquemarc says that it can transport itself from place to place by the simple process of absorbing sea-water and ejecting it violently from between its valves. And thus it defends itself against its enemies among the minor crustacea; particularly the smaller crabs, which endeavour to enter its shell when the valves are partly open. There is reason to suppose, moreover, that our favourite molluse is not altogether so dull and inert as the earlier naturalists represented it. Oysters exposed, says Diquemarc, to the daily ebb and flow of the tide, seem aware that they are likely to be exposed to dryness at certain recurring periods, and consequently retain a supply of water in their shells to serve their need when the tide is out. This is true, however, of those oysters only which are found close in-shore.

The longevity of the oyster is another point on which our information is not very exact; but many authorities allow it a "span" of twelve years. The young oyster, at the end of three days, measures three lines in diameter; at the end of a month it is as big as a pea ; in six months it is as large as a half-crown. In three years the best oysters are large enough for sale. Such, at least, is M. Coste's calculation; but the rate of growth varies in different localities. The oyster on the Yellette bank does not acquire its full proportions in a shorter period than five years ; in the bay of Cancale it comes to maturity in eighteen months.

There are several oyster-farms in the Thames-all conducted on much the same principles. That at Queens- 
borough, in the Isle of Sheppey, is famous for producing the Milton oysters, which are of good size and excellent flavour. The Faversham Company is reputed to be the most ancient in the Thames. There are many beds belonging to private gentlemen. Of these Mr. Allston is the largest owner; and he employs from forty to fifty vesselssome being merely dredging vessels of eight or ten tons, and others, smacks of thirty, forty, or fifty tons, which carry young oysters, for breeding purposes, from Ireland and the Channel Islands.

The largest and most fertile are those of Whitstable. They belong to a kind of joint-stock company of fishermen,-into which there is, however, no other way of entrance but by birth, since none but the "free dredgermen" of the town can hold shares. When a proprietor dies, his interest in the company dies with him; but his widow, if he leaves one, obtains a pension. The public and private oyster-beds at Whitstable employ upwards of three thousand hands, and their returns have been estimated at from $£ 100,000$ to $£ 120,000$ per annum. The affairs of the company are regulated by twelve directors, who are known as "the jury." The area occupied by the "layings" measures fully a mile and a half square, and from their long-continued prosperity have received the name of the "happy fishing-grounds."

The business of the company is to feed oysters for the London and other markets; therefore they do not breed them. They buy the spat or brood in various quarters, and then lay it down in their grounds to grow and fatten. Sometimes, it is true, the company's own oysters produce a spat; namely, when the spawn, or "flotsom," as the dredgers call it, emitted from their own beds chances to 
fall upon their own grounds ; and then the company profit largely, as they are enabled to save purchases of brood to the extent of what has fallen. But this falling of the spat is, to a great degree, accidental. No rule can be laid down whether the oysters will spawn in any particular year, or where the spawn may be carried. Of late, however, the artificial contrivances in use in France and elsewhere for saving the spawn have been introduced at Whitstable, and it seems probable that oystercultivation will be conducted there on the most approved principles.

The system of management adopted by the Thames companies is very simple. Take, for example, the Colne Fishery Company. This is superintended by a jury of twelve, appointed by a functionary called the waterbailiff; whose appointment, by the way, is in the hands of the corporation of Colchester. At the beginning of the season the jurors hold a meeting, take stock of the oysters in hand, and then agree upon the prices at which sales may be made during the season. They also settle the price to be paid to the dredgermen for lifting them, which is so much per wash - the name of a local measure. The company's foreman apportions to the dredgers their daily stint; which, of course, varies with the demand, and ranges from three to twelve wash. The time occupied in the work seldom exceeds a couple of hours, and the remainder of the day is at the man's own disposal. Further, many of these dredgers are good divers, and thus they secure double employment. The wages of the professional dredgers are very good; from three to six shillings per wash. They pay one-fourth of what they earn for their boat, and divide the rest among the crew. 
Of late years there has been a tendency to rise in the dredgers' wages, as in the wages of all other operatives.

In the Firth of Forth the organization is very defective; and though the firth has been rightly described as "one great oyster-bed," the supply of oysters is far below the demand, and what ought to be an important industry seems in a fair way of perishing. From Inch (island) Muckra to Cockenzie, the oyster-beds extend over a length of twenty miles, and range from one mile to three miles in breadth. The bivalves are of excellent quality ; particularly those called Pandores, which are obtained off Prestonpans. It is said that their fine flavour is owing to the refuse water which escapes from the neighbouring salt-pans. The beds producing them are now greatly neglected. From inquiries made quite recently, we cannot find that any system of cultivation is pursued, or that they are under any careful or enlightened management. Large quantities of the brood are sent southwards to supply the oyster-beds in the estuary of the Thames.

We agree with a writer in the Cornhill Magazine, that "the wholesale spoliation now going on at the oyster-beds of the Firth of Forth is greatly to be regretted, although we think it is destined to work its own cure, for the beds once thoroughly exhausted from the over-dredging which is now going on-and it is so great that the oysters consumed in Edinburgh will soon have to be brought from London-will in all probability be given over to persons to restock on the plan now so popular on the Continent, and the fishermen be very properly deprived of the chance of ever again despoiling them." This was written ten years ago, but as yet no improvement has been effected. The Firth of Forth seems to have been "intenrled by 
nature," says an enthusiast, for the laying down of oyster-farms : every inch of the bottom of that estuary might be lined thick with oysters from Alloa to North Berwick, and a thousand oyster-farmers carry on a highly remunerative business.

Turning to Ireland, we find that its people are beginning to recognize the resources of their seaboard, and that numerous applications have been made of late years for the formation of oyster-beds on various parts of the coast. The result has been that some six thousand to seven thousand acres have been granted by the Fishery Commissioners to several persons for the purposes of oysterfarming. The authority to whom we have already been indebted remarks, in reference to the Irish oyster-fisheries, as a curious fact, that although the Irish "natives" had at one time a very bad reputation, all the great banks have been cleaned out by over-fishing. Thus, the celebrated Carlingford beds, the beds of Sligo, and the banks of Clare, have been exhausted, owing to the culpable ignorance of the fishers, who have yearly reaped without sowing, and yet continued to expect an abundant harvest! On the famous Tralee beds it is declared to be difficult to find a shell; while some of the remaining beds have been nearly exhausted by the transportation of the young oysters to the English banks. It is recorded, as the opinion of a distinguished Thames oyster-farmer, who has carefully surveyed the Irish coast, that it contains many excellent spots for the laying down of oyster-beds, and that a considerable commerce might be carried on, if not in oysters for consumption, at any rate in brood for the Thames oyster companies.

From what we have said, the reader will understand 


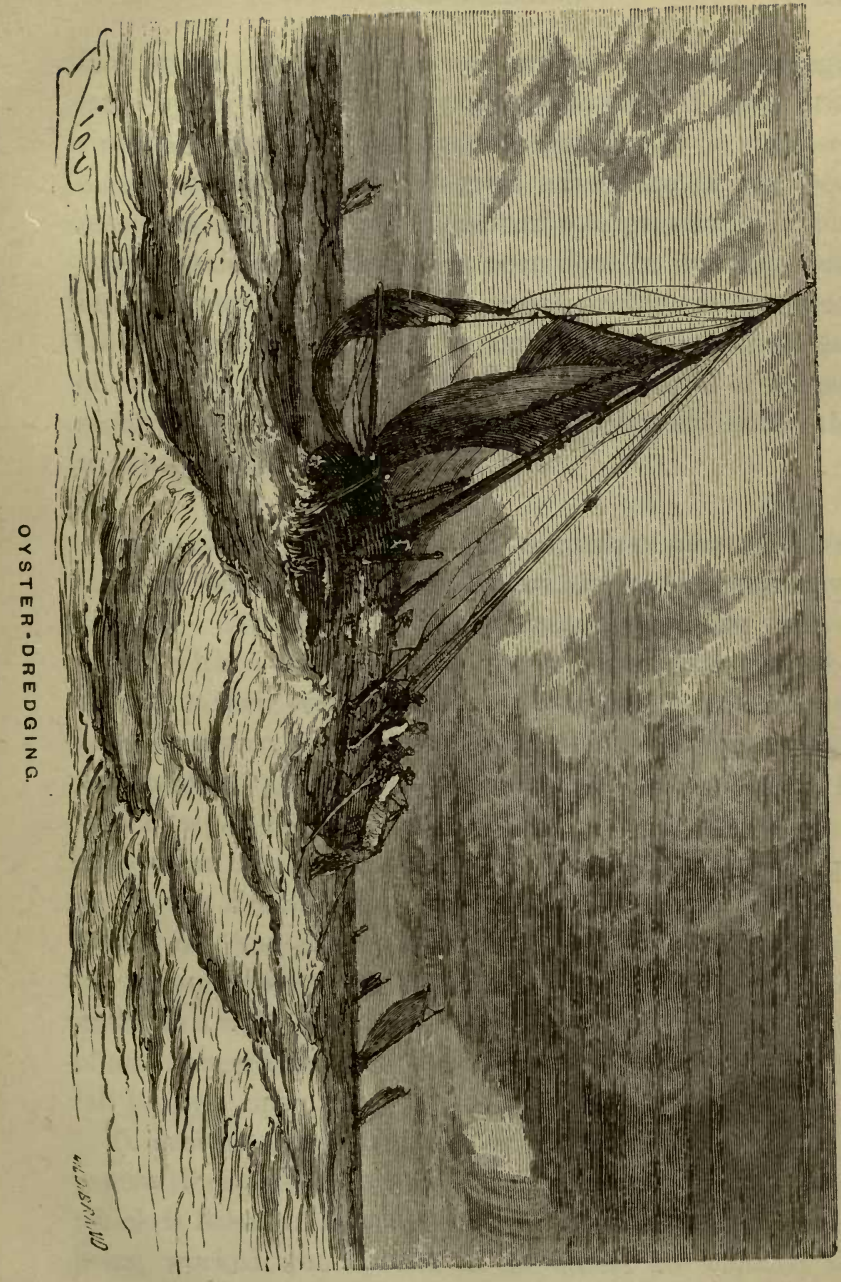



that oyster-farming is an industry which must be regulated by certain fixed principles; but that, if these principles are observed, the supply of oysters may be increased almost indefinitely, to the great advantage of our foodresources, and the direct benefit of a large portion of our coast population. Much has been done in this direction, but even now a deplorable ignorance prevails on a subject which is really of national importance; and people appear oblivious of the evident truth that the treasures of the sea require to be as carefully and intelligently utilized as the treasures of the land!

We now come to the various methods of oyster-fishing. In some localities this is conducted after a very primitive fashion. At Majorca divers descend into the water, armed with a hammer, and detach the molluses, one by one, from their resting-places. Obviously, such a process is adapted only for places where oyster consumption does not exist on a large scale, and where human labour is very cheap. In England and France, as in the United States, the oyster-fishery is carried on by dredying: the dredge (or drague) being a kind of iron rake, equipped with a net, and attached to the stern of the fishing-boat by a long tow-rope. The oyster-smack presses forward under full sail ; the dredge harries and sweeps the bank of molluses, which, as they are torn from the rocky bottom, fall into the open net.

To prevent an " oyster-bed" from being exhausted, it is generally divided into a certain number of zones, each of which is fished in due succession; and thus, while one is being worked, the oysters in the others are enabled to multiply, and grow to a proper size. Fishing is illegal (502) 
during the months of May, June, July, and August, when the bivalve is depositing its spawn.

When first removed from their habitat, oysters, however, do not possess in their highest perfection the properties which are so much esteemed by oyster-eaters; and to render them fatter, more tender, and more savoury, they are deposited, before being sent to market, in "parks" of from three to four feet deep, the bottom of which consists of sand or pebbles, with gently sloping sides, and communicating with the sea by means of a channel or trench which is easily shut or opened. In some "parks" the water is renewed every tide : in others, only once or twice a month. The celebrated oyster-parks at Marennes, Tréport, Etretat, Fécamp, and Dunkirk, belong to the former category; those at Havre and Dieppe to the latter.

The period during which the bivalves undergo the fattening process varies from a few days to a month. Under certain conditions, they acquire a greenish colouring, as well as that piquant flavour to which the epicure is so partial.

A French authority-M. Valmont de Bomare-apparently supposing that oysters feed upon grass, enunciated the hypothesis that the colour of the "green oyster" can be produced only in "parks" freely surrounded by vegetation; an hypothesis which it is quite unnecessary to examine with any degree of seriousness. Another French writer-M. Gaillon-attributes it to a microscopic animalcule, the Vibrio ostearius, on which the mollusc feeds; but it has been proved that the vibrio is not normally green, and becomes so only under the same conditions as the oyster. Bory de St. Vincent thought it arose from 
the "green matter" of Priestley, which may be detected in all water exposed to the action of light.

Some authorities have sought for the cause in the confervoe and relvoe which multiply so rapidly in those "parks" where the supply of water is not frequently renewed; others think that the colouring principle belongs to the soil.

The most likely explanation seems to be that which M. Coste, the distinguished pisciculturist, has put forward. $\mathrm{He}$ is of opinion that the green oyster owes its peculiar tint and characteristic flavour to a "disease of the liver." Such is also the belief of M. Valenciennes; according to whom, the immediate cause of the discoloration is a peculiar animal substance, due to a particular condition of the oyster.

The largely increased demand for this favourite mollusc, and the gradual exhaustion of many of the best oyster-banks, have led to the adoption of artificial means of increasing the supply.

The art, or science, of oyster-culture was introduced, as we have seen, by a wealthy Roman, named Sergius Orata, who in his time was famed for his epicurean tastes, and attained the curious title of "master of luxury." He was something more, however, than a gourmand, for Cicero speaks of him as "ditissimus, amœnissimus, deliciosissimus." It is said of him that he patriotically asserted the superiority of the shell-fish bred in the Lucrine Lake; though, under the empire, they were less valued than those imported from Britain. He owed his surname, Orata, or Aurata, either to his fondness for gold-fish (Auratoe pisces), or to his halit of wearing two very large gold rings. 
From the artificial oyster-beds which this ingenious and refined gentleman laid down at Baiæ, he derived a considerable revenue. He had his enemies, however, and was brought to trial on a charge of having appropriated the public waters of the Lucrine Lake to his own private behoof. He obtained an acquittal ; and we are told that his advocate, L. Cassius, in the course of his pleading, observed, that the revenue officers who had interfered with his client were greatly mistaken if they thought he would be deprived of his cherished molluses, when driven from the Lacus Lucrinus ; rather than endure such a loss, his client would breed them on the roofs of his houses!

We wish he had essayed the experiment, and succeeded in it; for then, perhaps, every householder might now be growing his own stock of oysters for private consumption.

One of the earliest seats of oyster-culture is Lake Fusaro, in the south of Italy; it is the Avernus, the lake of gloom and desolation, which Virgil has described in such exaggerated language. It is a black-looking sheet of water, occupying the crater of an extinct volcano, the steep and rugged sides of which, rising precipitously around it, invest it with a strikingly sombre character. It was probably this circumstance, associated with the sulphurcous and mephitic odours which pervade the neighbourhood, that induced the Greeks to conceive of it as the entrance to the infernal regions and the scene of the visit of Odysseus to the lower world. It measures about three miles in circumference, and is situated between the Lucrine Lake and the ruins of the ancient city of Cumæ. A canal, from eight to ten feet in breadth, and four to five 
feet in depth, connects it with the sea. It is now called the Foce di Fusaro.

The reader will have understood, from our remarks on the oyster's mode of reproduction, the importance that its ova or spat should be deposited on some solid object. This principle was kept in view when Lake Fusaro was converted into an "oyster-farm."

Upon the bed of the lake, and along its margin, small pyramidal piles of stones have been erected, on which are

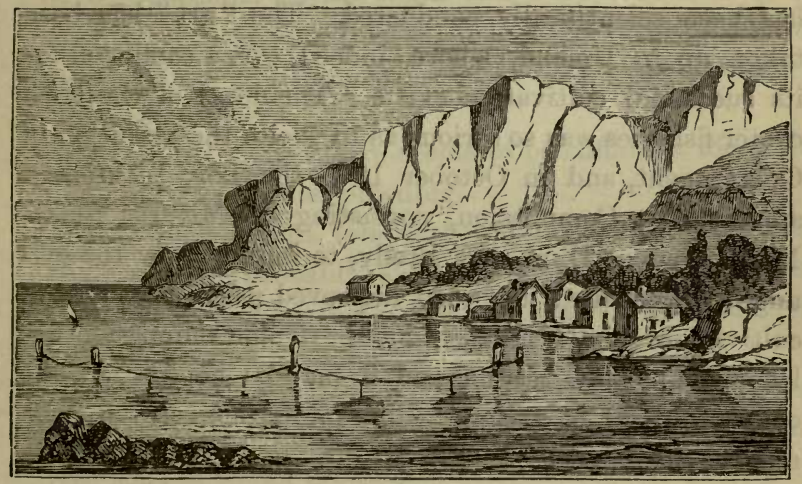

CHAIN OF SUSPENDED FAGOTS.

deposited the young oysters imported from the neighbouring Gulf of Otranto. Each heap is surrounded by a ring of piles, driven in close to one another, and rising slightly above the surface of the water. Other piles are set in long rows, and bound together by ropes, to which fagots of young wood hang suspended. In the spawning-season, which begins early in May, the oysters on the artificial rockeries shed the thousands of spat carefully incubated 
in the laminæ of their lungs and the folds of their mantle. The suspended fagots arrest the floating ova before they can be carried away by the waves, and they are thus able to develop themselves under suitable conditions of light, sustenance, temperature, and safety. When the fishingseason arrives, the piles and fagots surrounding the beds are removed, and the oysters fit for market are duly gathered.

Oyster-farms have been established in England for many years, but it is only of late that oyster-breeding has been scientifically conducted. The "art" has been taken up in Ireland, where, indeed, every condition for its successful cultivation exists. The decay of the Irish oyster-fisheries was so serious as to excite the attention of Government, and in October 1868 the Lord-Lieutenant appointed a Commission, consisting of Messrs. Blake, M.P., Francis, Hart, and Brady, to inquire how the evil might be remedied, and what improved methods of oystercultivation should be introduced. This Commission has led to important results, and it may be hoped that the oyster-fisheries of Ireland will rapidly increase in commercial importance.

The report of the Commissioners, we may add, contains much useful matter, and treats of some collateral questions which deserve the reader's attention.*

For instance, they dwell on the preference given in France to the green oysters, which leads to the importation on a large scale of the Essex oysters. Oysters with green beards, they say, do not owe their colour to copper, but to their peculiar feeding, and they suggest that the diatomaceæ are probably the cause. They point out that

* Report of the Commission, \&c. (Dublin, 1870). 
the warm temperature of the surface of the sea on the Irish coast particularly adapts it for oyster-breeding; and the following conclusions are put forward in a paper by Professor Hennessy :-

" 1 . The temperature of the sea on the coast of Ireland varies within narrower limits than on the coast of Great Britain; or, in other words, it is more equable throughout the year, and also during the summer season, when oyster-breeding takes place.

" 2. The temperature of the sea at noon on the Irish coast, especially on the south and west coasts during the months of June and July, is, upon the whole, higher than on the coast of Great Britain, and less than on the west coast of France.

" 3 . This temperature seems to be sufficient for the requirements of oyster-breeding.

" 4 . The highest temperature of the seas surrounding Ireland, and probably also of those surrounding Great Britain, is during the month of August, and the least during the month of February."

The Commissioners also publish some conclusions arrived at by Professor Sullivan in reference to the composition of the soils of oyster-grounds :-

" 1 . That the influence of the soil upon the breeding and growth of oysters is complicated by-temperature, especially during the spawning-season; sudden alternations of heat and cold, due to currents; alternations of depth of water, especially as regards whether the maximum of sun heat and light concords with low water during the spawning-season; velocity of tide, angle of inclination of shore, \&c.

" 2 . That the soil of oyster-grounds may be made up 
of materials of any of the great classes of rocks, arenaceous, argillaceous, or calcareous, provided they contain-

" 3 . More or less of a fine, flocculent, highly hydrated silt, rich in organic matter, which indicates that diatomaceæ, rhizopoda, infusoria, and other minute ereatures abound. •

"4. That the character and abundance of such small organisms in a locality seems to be the true test of a successful oyster-ground.

“5. And, lastly, that although oysters do undoubtedly assimilate copper from water where mine-water containing traces of that metal flows into the sea in the neighbourhood of the oyster-beds, the copper is chiefly, if not exclusively, confined to the body of the oyster, and does not appear to reach the mantle or beard ; that the so-called green oysters of Essex, Marennes, and other places, on the other hand, are green-bearded, and contain no copper, nor can the most minute trace of copper be detected in the soil of the oyster-grounds where such green-bearded oysters are produced."

The ratio of oyster-growth, an important consideration in connection with oyster-farms, is thus estimated by a very accurate and judicious writer :- *

While in the spat state, a bushel measure will contain 25,000 oysters. The spawn, when two years old, is called brood, and while in this condition a bushel-measure will hold 5500. In the next stage of growth, oysters are called ware; and it takes about 2000 of them to fill the bushel. In the final stage a bushel contains about 1500

\footnotetext{
* Bertram, "Harvest of the Sea," pp. 367, 368.
} 
oysters. Very large sums have occasionally been paid by the Whitstable Company for brood with which to stock their grounds, and great quantities are collected from the Essex side. There a number of people gain a sufficient livelihood by gathering oyster-brood on the public foreshores, and disposing of it to persons who have private nurseries, or "oyster-layings," as they are locally called.

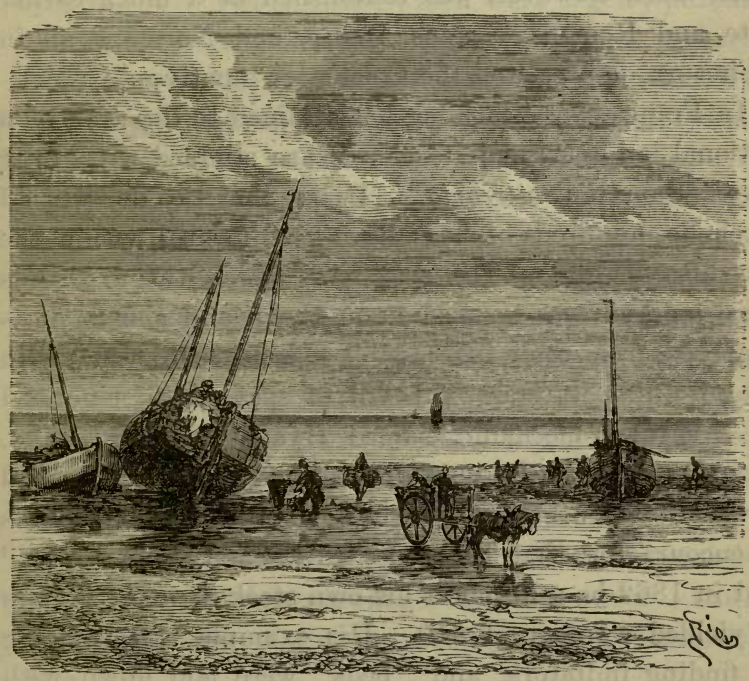

UNLOADING THE OYSTER-SMACKS.

Large quantities of spat are yielded by the grounds of Pont; a fine open space of water, sixteen miles long by three broad, free to all comers. Here about one hundred and fifty boats, each manned by three or four men, are constantly employed in obtaining young oysters, which they sell to the neighbouring oyster-farmers, although it 
is certain that the brood thus obtained must have floated out of beds belonging to the purchasers.

Extensive oyster-grounds occupy the numerous shallow creeks and channels of the estuary of the Colne, which, as early as Drayton's time, was celebrated for its bivalves :-

" Think you our oysters here unworthy of your praise? Pure Walfleet, which do still the daintiest palates please."

Their fame, however, was established at a much earlier date, and Romans, Saxons, Danes, and Normans, all in their turn, appreciated the Colchester " natives."

In France oyster-farming has attained to the rank of a national industry, and its shores are studded with fully seven thousand ostrearia. Upon the Ile de Ré, off Rochelle, hundreds of beds have been formed within the last fifteen years. The spat with which the first beds were stocked was washed upon the island shores, it is supposed, from some inaccessible natural scalp situated in the adjoining waters. This fall of spat was first noticed by a shrewd mechanic, named Hyacinthe Boeuf, who, about 1858, formed a small "park" within which he laid down a few bushels of growing oysters. The result was so encouraging that he proceeded to enlarge his "park," and in 1862 he sold out of his own stock as many oysters as yielded a return of $£ 40$. His example was not long in finding imitators, and "beds" were laid down with such rapidity, and prospered to such an extent, that in six years a stock of oysters was accumulated, valued at upwards of $£ 100,000$.

Near the Ile de Ré exists a remarkable mussel-farm, where the culture of that popular bivalve has been successfully carried on for upwards of seven centuries. The artificial system of growing mussels was accidentally dis- 
covered by a shipwrecked Irishman named Walton. To supply himself with food, he made a net to capture seabirds, and to fix his instrument of capture securely, he planted stout stakes or posts in the mud of the fore-shore. In a short time he found that large quantities of mussels, torn by the tidal action from some natural bed, had adhered to the net fixtures. These in due course matured into fine-flavoured animals, which were eagerly purchased by connoisseurs. On this hint the French fishermen acted; rows of strong stakes were planted in the Bay of Aiguillon, which, when interlaced by boughs and branches, supplied the spat with an excellent resting-place. Thus sprang up a regular system of mussel cultivation, which appear's to have suggested to M. Coste, the pisciculturist, some of those ideas of oyster-culture which he was developing with much industry almost about the same time that Hyacinthe Boeuf began his successful experiment. The reports which M. Coste addressed to the Imperial Government led to its adoption of the oyster-farms as a source of national wealth, well deserving of State aid and encouragement.

The most carefully constructed are those established under the imperial patronage, in the basin of Arcachon, a sheltered arm of the sea, about thirty-five miles from Bordeaux.

Arcachon, now a fashionable bathing resort, was, a few years ago, a small fishing village, celebrated for its abundant supply of naturally-bred oysters. As the scalps, or beds, were of great extent, it was supposed they could never be exhausted, and thousands of bushels of capital oysters were annually sent to all parts of France, as well as to foreign countries. After these beds had been ex- 
hausted by over-dredging, Professor Coste took a survey of the basin, and superintended its conversion into a gigantic oyster-farm, predicting that the five thousand acres of ground in the basin, which were suitable for the growth of oysters, would, after time had been allowed for their proper development, yield an annual revenue of $£ 380,000$, - an estimate which has been more than realized.

There are three Government oyster-beds in the basin of Arcachon; these are Lahillon, Grand Ces, and Crastorbe.* The first-named was laid down on the most inappropriate soil, in order to demonstrate the pursuit of oyster-growing under difficulties. Its soil was a mere slime, totally unsuitable for the molluse; the enemies of the animal were superabundant; moreover, the growth of many kinds of marine plants was luxurious. To promote oyster-culture under conditions so unfavourable, so that the enterprise should be remunerative, was a task worthy of the enthusiasm of M. Coste. The first thing to be done was to clear away the slime at such times as the ground was left dry by the ebbing tide. The vegetable growth was also removed, and the site, consisting of about nine acres, was divided by earthen boundaries into thirty-four squares, each of which was planted with from nine thousand to thirty thousand oysters. All kinds of spat collectors were then introduced; some consisting of bundles of twigs, others of tiles covered with a thick coat of cement, and the principal being a wooden structure formed of planks, to which fagots of branches were attached. At one time the Lahillon nursery contained

" Our description is founded on an article on "French Oyster-Fisheries" in Once a Week for September 1868, pp. 232-234. 
four hundred artificial spat collectors, in addition to the natural "culch," or bottom. Oyster-hives were constructed,- -that is, a series of boxes of wood, containing perforated drawers filled with natural bottom, or culch, so that when the parent oysters emitted their spawn it could not escape. The tile system has proved very successful, and as many as three hundred oysters have been stripped off a single tile. The advantage of having tiles coated with cement is obvious; as soon as the shells have grown to the size of a sixpence or a shilling, the cement is peeled off with the shells adhering to it -and the tile being re-covered with cement, can again be used. It is stated that as many as ten thousand young oysters may be retained in the space of a cubic yard.

Of the other Government beds in the Arcachon basin, that of Crastorbe occupies thirty acres, while Grand Ces contains twenty-five. All kinds of collecting apparatus are laid down here just before the spawning-seasonthat is, from the middle of June to the end of July; and these are protected from mud and sea-weed by fences of various kinds. The oysters, which are all carefully selected for spawning purposes, are then placed in and around the various "collectors." When a spawn has been obtained, the oysters are allowed to develop for a few months, after which they are gathered from off the apparatus and set aside to grow in the various departments of the "park;" the appareils, being then taken to pieces, are cleaned and laid aside till again wanted-the best kinds, of course, receiving the preference.

The grand secret, says our authority, of successful oyster-culture is constant work. It is by unremitting labour that the dredgers at Whitstable and Essex have 
brought the natives - that is, the bred oyster-to perfection. They constantly dredge and re-dredge their layings, separating and classifying the oysters upon each occasion, changing them to different parts of the ground, and throwing aside all kinds of enemies and dead shells. Most of the beds are laid bare by the ebbing tide, and then the overseers and keepers, who live in floating houses or miniature arks, turn out to work upon the farm until the tide comes in again. To each man engaged are allotted his particular duties; one superintends the spat collectors, another gathers in the infant oysters, a third distributes them over the different "parks." Then some have it in charge to maintain a constant warfare against the mud, which is the deadliest enemy of the young molluse; others to collect and remove the seaweed; others to assort the stock, and divide it into batches for market or for the greening and fattening "claire."

We need only add that oysters are found "all round the world;" and some parts of the American continent, as the Racoon Banks off Florida and Georgia, and the New York district, are specially famous for their production. Virginia possesses an area of about $1,680,000$ acres of oyster-beds, containing about $784,000,000$ bushels. There is no fear that the American stock of this highly-appreciated molluse will be speedily exhausted. 


\section{CHAPTER XII.}

PEARLS, AND MOTHER-OF-PEARL.

\section{"Orient pearls at random strung."}

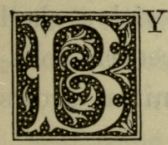

$\mathrm{Y}$ a natural transition we pass from Oysters to Pearls, these beautiful jewels having been long associated with the popular molluses in the popular mind. Pearls, as well as motherof-pearl, are the product of certain molluses, fresh-water and marine, such as the pearl-oyster, the pearl-mussel, the haliotides, and the patellæ. The finest, however, are those obtained from the so-called pearl-oyster, - the Avicula, or Meleagrina margaritifera.

This molluse, like the oyster proper, is a bivalve, and a lamellibranchiate molluse of the family Aviculidce. It owes its generic name, Avicula - from avis, a bird-to the peculiarity that, in certain species, the animal, when its valves are open, presents a vague resemblance to a bird with outstretched wings. Hence it has sometimes received the poetical appellation of "the swallow." It is usually found congregated in great numbers, attached to submarine rocks at a considerable depth in all tropical waters. Pliny affirms that the finest pearls are found in 
the Indian Ocean; and his statement still holds good. The avicula abounds, for example, off the shores of Ceylon, accumulating in banks of several miles in extent. It is very plentiful, also, in the Persian Gulf. Of late years a large number have been drawn from the Arabian Gulf, being popularly known as Red Sea jewels. Amerigo Vespuccio, who unwittingly deprived Columbus of the honour of giving his name to the New World, records that they were abundant in the regions he visited in the course of his second voyage. The pearl-oysters are found, in fact, at Panama in South America, St. Margarita in the West Indies, the Coromandel Coast, the Sooloo Islands, the Bahrein Islands, and the Mediterranean.

The avicula is of an oblique, oval form, with a shell longitudinally ribbed, and marked by concentric foliations which gradually disappear as the animal grows older. There are about twenty species.

Most of the molluses, as our readers will remember, are provided with a fluid secretion which they use to line the interior of their shells, and to coat the otherwise rugged material with a smooth, lustrous surface. This is not only a matter of beauty but of usefulness, since it saves the soft, tender body of the animal from injurious friction. The secretion is laid in semi-transparent films of great tenuity, which, as a whole, are remarkable for their iridescence, and in some species acquire a sufficient thickness to be wrought and moulded by human skill. The material itself, in its hardened state, is called nacre, or " mother-of-pearl."

Now the pearl which is so highly prized as an ornament of rank and beauty is nothing more than a spherical or rounded fragment of nacre. But whereas the nacre is 
a natural product, and an integral portion of the shell, the pearl is the result of accident ; and while in one mollusc you may find fifty, sixty, or seventy of these beautiful gems, in another of the same species and the same variety you may not find above one or two. And why? Because the pearl is the result of the avicula's effort to remedy an injury it has sustained by some fracture of its shell or by the intrusion of some foreign body.

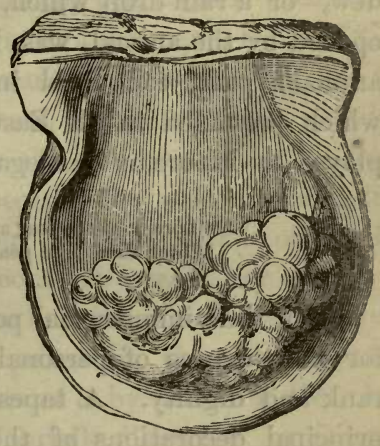

PEARL-OYSTER.

If an avicula be wounded in any part of its substance, -if some perforating animal work through its shell, or some hard, angular body, such as a grain of sand, force its way between the valves, - the mollusc, unable to remove the cause of offence, proceeds to cover it with its secretion. This is deposited in thin films, one upon the other, and overlying each other withont the slightest pretence to regularity; and as the animal grows, so does the secreted nacre, or pearl, increase in size and iridescence.

The Chinese have turned to advantage this exquisite arrangement of Nature. They keep a species of freshwater mussel, the Unio Hyria, in tanks; and between the shell and mantle of the molluse they introduce either small leaden shot or tiny spherical fragments of motherof-pearl. In due time they are regularly coated with the nacreous secretion, and assume the appearance of pearls naturally produced.

(502) 
Such is the actual origin of the product which Pliny and Dioscorides supposed to be "a drop of congealed dew," or a rain-drop which, falling into the shells when opened by the animal, was, by some strange effort on the animal's part, converted into a pearl. This opinion, which prevailed in all Eastern countries, has been employed by Moore as an elegant simile :-

\footnotetext{
"And precious the tear as that rain from the sky, Which turns into pearls as it falls in the sea."
}

From time immemorial pearls have been highly valued for the purpose of personal adornment, or as a sign of rank and dignity. A tapestry of pearls was one of the principal decorations of the magnificent hall in which Ahasuerus received his ambassadors and held his councils. In very early days the princes of the East enriched with pearls their garments, their weapons, and their household ornaments; and the same custom still prevails. We read that Tavernier sold to the Shah of Persia, for the sum of 2,700,000 francs, a pearl which he had bought at Catifa. They are frequently mentioned in the New Testament. Our Lord, in Matthew xiii. 45, 46, likens the kingdom of heaven to "a merchant man, seeking goodly pearls." Another allusion occurs in Matthew vii. 6. That they were commonly worn by women, we learn from 1 Timothy ii. 9 and Revelation xvii. 4 ; and the value placed upon them may be inferred from the circumstance that the seer of Patmos, in his Apocalyptic vision, conceived of the twelve gates of the heavenly Jerusalem as twelve pearls.

Both by the Greeks and Romans they were regarded with singular appreciation. Julius Cæsar offered to Ser- 
vilia, the mother of Brutus, an "Orient pearl" valued at more than a million of our English sovereigns. Pliny calculates the worth of the famous pearl which Cleopatra swallowed in her costly draught at a sum equal to $£ 80,729$. Of course, no such amounts could now be realized. It is recorded that Pompey possessed a cabinet lined entirely with lustrous pearls. Pliny also informs us that he had seen Lollia Paulina, who became the wife of Caligula, decorate her beauty with four millions' worth of pearls and emeralds ; they shone about her tresses, her ears, her neck, her shoulders, and her fingers. In medieval days they were not less highly prized by the chivalry and beauty of England and France: by Edward IV., by Catherine de Medicis, and Gabrielle d'Estrées; by Queen Elizabeth, Sir Walter Raleigh, the Earl of Leicester, and even by the ungainly James I. In our English poetry allusions to their bright soft lustre are innumerable. In Shakespeare's T'wo Gentlemen of Verona, occurs a fancifully elegant comparison :-

\section{"A sea of melting pearl, which some call tears."}

And in Much Ado About Nothing we read that Hero's wedding-dress of "cloth of gold" was "set with pearls." Milton includes among the treasures of "the gorgeous East," " barbaric pearl and gold ;" and pictures beneath the mysterious stairs which led up to the gate of heaven, "a sea of liquid pearl." In Eden, the "crispëd brooks" went on their winding way, -

" Rolling on Orient pearl and sands of gold."

The poet tells us that in the smooth Severn stream,-

"The water-nymphs that in the bottom play Hold up their pearlëd wrists." 
So, too, Tennyson's Mermaid combs her hair under the sea,-

\author{
"In a golden curl \\ With a comb of pearl."
}

And the same poet, when describing the beauty of the "sweetest lady of the time," in his ballad of good Haroun Alraschid, speaks of

"A brow of pearl

Tressed with redolent ebony."

Among the largest pearls ever known was one presented to Philip II. of Spain in 1579. It was equal in size to a pigeon's egg, was shaped like a pear, and came from Panama. Its value was estimated at 100,000 francs, or nearly $£ 4000$; equal, at the present value of money, to $£ 50,000$. "Among the number of pearls yearly offered to the King of Spain," says a writer of the last century, "this prince put aside the most beautiful, and employed them in the divine service." We may judge of the quantity he thus employed, from a vestment worn by the image of Our Lady of Guadaloupe, all the white ground of which was wholly pearls ; the red and green embroidery being made up of rubies and emeralds. Well may the chronicler exclaim: "There is not in the world any other sovereign but the King of the Indies who could exhibit so great a magnificence in his devotion."

A collection of four hundred and eight pearls, valued at $£ 20,000$, formed part of the ancient regalia of the French crown. We read of a single pearl, belonging to Sir Thomas Gresham, which was estimated to be worth $£ 15,000$. The story runs that he reduced it to powder, and drank it in a glass of wine to the health of Queen Elizabeth, in order to eclipse the Spanish ambassador, 
with whom he had wagered to give a more costly banquet than the Spaniard could.

An extraordinary pearl belonged to the late Mr. Hope of Deepdene. It measured two inches in length, four in circumference, and weighed eighteen hundred grains.

Great regularity of shape (oval, pyriform, or circular), a beautiful "water," or a vivid white tint, with brilliant gleams like those of an opal-what jewellers call a bel orient - and a considerable size, are the qualities which give value to a pearl. And when these are found combined, the ocean-jewel may fairly challenge comparison with topaz or emerald. Its serious defect is its liability, from some unknown cause, to a sudden loss of colour.

It is said that the lustrousness of the pearl is greatly increased if a pigeon is made to swallow it. Redi asserts that he proved by experiments the efficacy of this apparently absurd device. At the same time, he warns us that the jewel should not remain too long in the bird's digestive tube, as in twenty-four hours it loses one-third of its weight.

This method is adopted in Ceylon, where, according to the Asiatic Journal, the chicken to which the pearl has been entrusted for improvement is killed at the expiry of a minute or two. The friction which it undergoes in the bird's stomach, and, we suppose, the action of the gastric juices, are held to account for a result which, we think, might be obtained by some less barbarous process.

The pearl-fishery now demands our attention.

In Ceylon, the principal locality is a bank about twenty miles in length, ten or twelve miles from shore, off the villages of Condatchy and Aripo. The season begins 
early in February, and lasts about three months. To prevent the young pearl-oysters from being destroyed, the bank is divided into several sections, one of which is worked every year. The Singalese believe that the avicula attains maturity in seven years, after which it expels from its valves the pearls which prove inconvenient through their numbers.

The boats licensed by the Ceylon Government to carry on the fishery are open, and vary in size from ten to fifteen tons burden. At ten o'clock every evening a gun fires : it is the signal for them to put out to sea; and immediately the dusky-winged flotilla makes for the Government vessel, moored on the bank, which answers the double purpose of a guard and light ship. Each bark carries a crew of about twenty men, of whom ten are rowers and ten are divers. The latter, under the direction of an adapanaar, are chiefly Tamils and Moors from Colung, the Malabar coast, and Manaar.

They are now divided into two gangs, five men in each; one remaining on board the boats to rest, while the others descend. For several days previously they have prepared themselves by feeding on the most nutritious food, and rubbing their body with oil. They also take care to secure a talisman, consisting of three leaves of the wild medlar, covered with strange characters ; this, they believe, is an effectual safeguard against the monsters of the deep.

Each diver is provided with a small net, or basket, slung round his neck, to receive the products of his labour; and of a diving-stone, of about thirty pounds weight, fastened to the end of a stout rope, which is of sufficient length to reach the bottom. Placing his foot in the loop attached to the stone, and filling his lungs with air by a 
deep inspiration, he gives the signal, and is rapidly lowered to grope among the "dark unfathomed caves" of ocean for "many a gem of purest ray serene." Immediately he fills his net or basket with oysters, pulls at the rope, and is straightway hauled up to the light of day. The process is necessarily rapid, for the best divers, according to

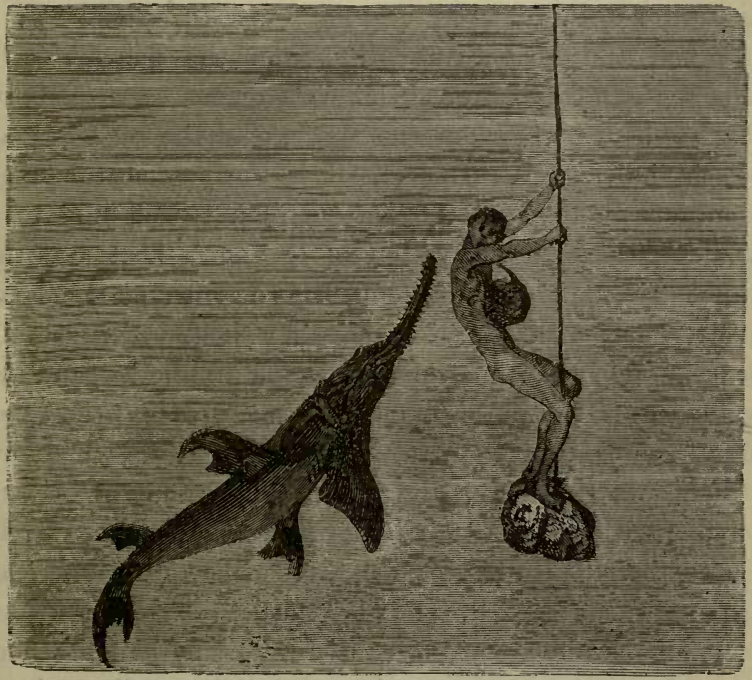

PEAIR-DIVER ATTACKED BY A SAW-FISH.

Lieutenant Wellstead, cannot remain under water longer than sixty or eighty seconds. The greatest depth to which they descend is thirteen fathoms, and the usual depth about nine.

Their work is not without its dangers. Not infrequently the diver is attacked by shark or saw-fish, in 
which event a terrible struggle takes place; and unless he is promptly hauled to the surface by his companions, it does not always end to the diver's advantage. He suffers also from the pressure of the water, which frequently forces the blood to his ears, nose, and mouth; and so terrible is the exhaustion, that a pearl-diver's career is invariably a brief one, and prematurely terminated by disease or death.

When the boats, returning from the fishery, have landed their cargoes of shells, each owner carries off his share, which he piles on the shore, that the oysters may perish and putrefy. In India it is the custom to spread them out on mats at the bottom of a trench, and then abandon them to the action of the sun's heat and the atmosphere. It is not long before putrefaction commences. Then a search is made for those which contain pearls ; the animal matter is collected and boiled, and the water carefully strained, so as to recover any pearls which may have escaped the first inspection. Those which are attached to the valves, the "clippers," as they are called, remove with pincers or hammers, and they are used only for setting. The others, which are usually quite spherical, are polished, drilled, and threaded. They are first sorted, however, according to their sizes, by passing them through a series of copper sieves of different dimensions. In stringing them, the natives make use of bodkins of various magnitudes, and are careful to distinguish which is the best side of each pearl, so as to bring that side forward in the chaplet.

In this delicate and minute work the Indians and Chinese excel ; and in one day a man will pierce six hundred large, or half that number of small, pearls. The 

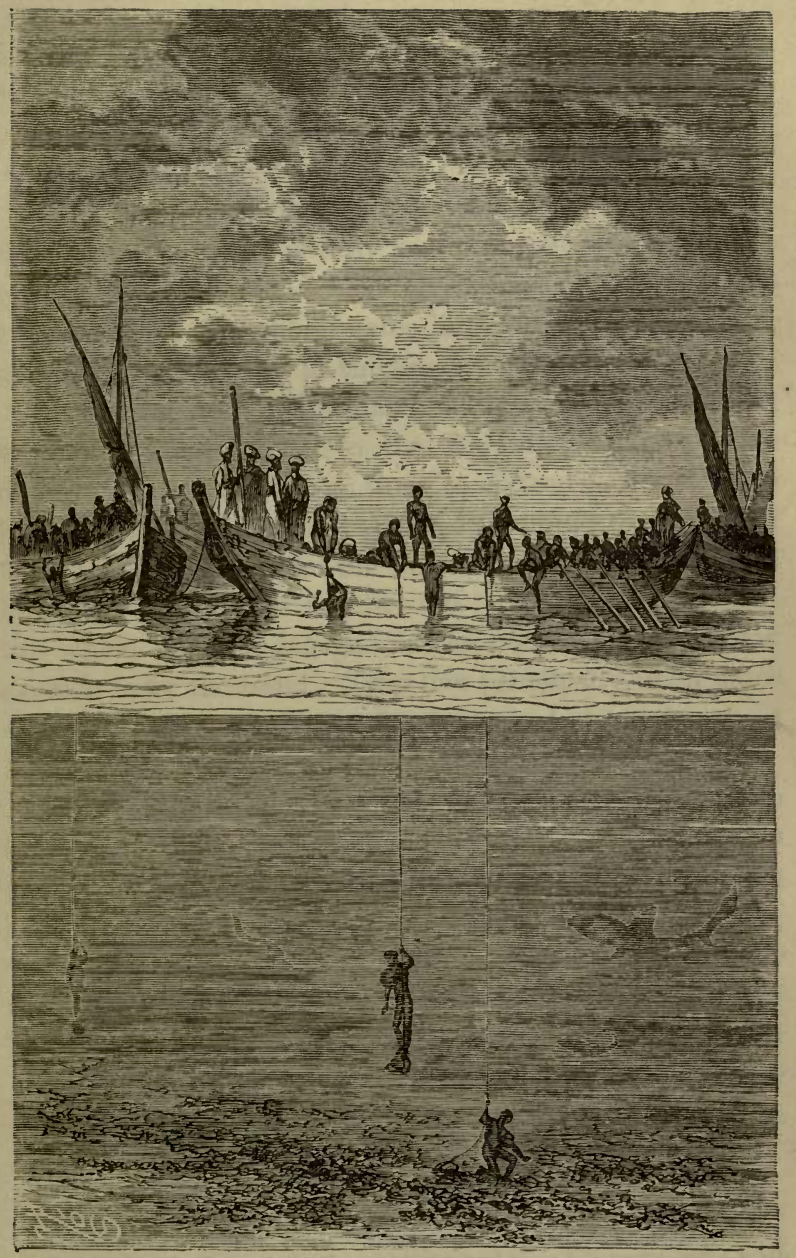

PEARL-FISHING IN THE INDIAN SEAS. 


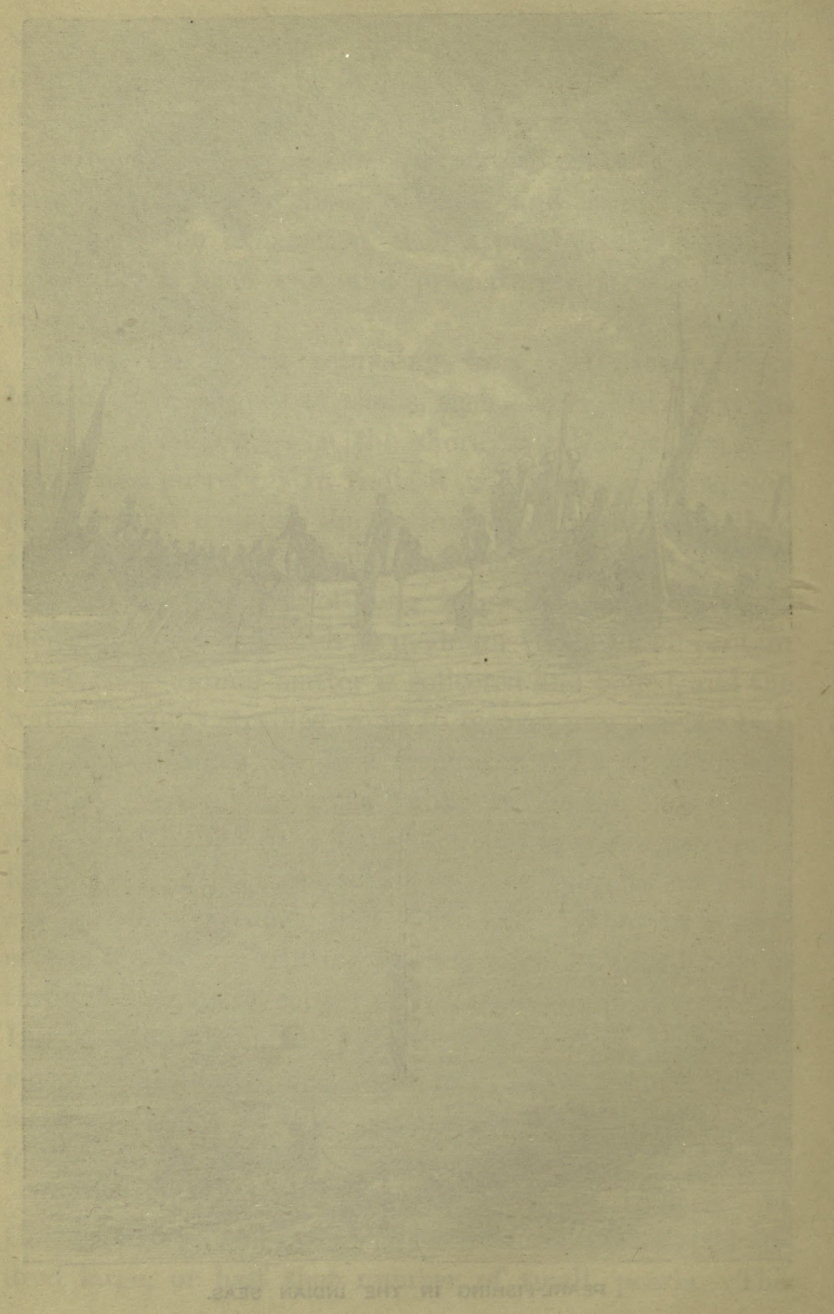


medium and smaller sized pearls are threaded on white or blue silk; the different threads are fastened together by a knot of blue ribbon, and they are sold in "masses" of so many threads.

As no use is made of the oyster-shells, and as the pearlfishery at Condatchy is fully two thousand years old, the reader will understand that an immense bank has accumulated on the shore, extending for many miles, and averaging several feet in thickness.*

A very fine bed of aviculas occurs in the Persian Gulf, stretching from Sharja to the Biddulph Islands. The depth of water varies from three to sixteen fathoms. The island of Bahrein despatches three thousand five hundred boats to this fishery, and the shores of the gulf about eight hundred. The crows number ten to fourteen hands, and the whole number engaged in the course of the season exceeds forty thousand. They live principally upon dates and fish. They receive no fixed wages, but one-fourth of the product, which is estimated at $£ 400,000$ a year.

The traffic in Oriental pearls finds its principal outlets in Persia, India, Indo-China, and China. Considerable quantities also are imported into Europe. The rough and irregularly shaped pearls are sold in Russia and Italy, where few women, even of the lowest classes, think their attire complete without a pearl necklace. $t$ As for globular or pyriform pearls of tolerable size, they are purchased by jewellers of every country. Seed-pearls-that is, the very smallest-are largely sold in Spain, to be employed in

* Sir Emerson Tennent, “Natural History of Ceylon,” p. 373.

$\dagger$ "Towards twilight the girls put on their better dresses, and comb their glossy raven hair, heaping it up in great solid braids, and, hanging two long golden earrings in their ears and necklaces round their full necks, come forth conquering and to conquer."-W. W. Story, "Roba di Roma," i. 180. 
ecclesiastical decoration; in the East, they are used in embroidering garments.

In the Roman period, our British pearls, found in the fresh-water mussel (Unio margaritifera), attained a considerable celebrity, and were much esteemed by the patrician ladies of Rome. These pearls, however, are usually small and discoloured, and specimens equal to those of the pearl-oyster are not always forthcoming. Of late years the British pearl-fishery has been revived in the Scotch rivers, under the direction of Mr. Moritz Unger of Edinburgh, and with much success. Large quantities of the elegant pink-hued jewels have been purchased by the Queen and the ex-Empress of the French, and "Scotch pearls" are popular among the wealthier classes for purposes of personal adornment. They are found chiefly in the rivers Tay, Doon, Don, Teith, Forth, Ythan, Spey, Ugie, and Earn. In the smaller of these rivers the mussel-beds have been exhausted by over-fishing; but in the Tay and the Doon the labour of the fisher is still fairly rewarded.

It has been truly said that the mode of fishing is "primitive in its simplicity." No apprenticeship is required to it ; there is no outlay for fishing apparatus ; there is no need of skill; and men, women, and children engage in it on equal terms. The most tedious part of the work is preliminary; namely, to search the river-bed until a collection of the unionidæ is discovered. The numbers at any single point are never considerable; but once discovered, the fisher wades in among them, armed with a large stick, one end of which has a simple slit in it made by a knife. This stick he thrusts down among the shells, and brings 
them up firmly wedged in the slit. He tosses the shells ashore, and continues his labours until he has collected a large heap. Then he proceeds to open them, either with a knife or a sharpened shell ; finding, it is calculated, a pearl in every fortieth shell, and one pearl in a dozen being of a kind to bring a profit. The musse's taken from a rocky or shingly bed are more productive of pearls than those derived from the sand.

Excellent river-pearls, known as "Bohemian," are proeured from the rivers Moldau and Wottowa. A freshwater pearl-fishery is also carried on in Bavaria ; and, on a small scale, in some of the Welsh rivers and in the north of Ireland.

The avicula is not the only molluse which yields pearls. The Bay of Tamblegam, near Trincomalé, is the seat of a fishery, where the shell producing the pearl is the thin transparent oyster, Placuna placenta, whose clear white shells are used in China and elsewhere as a substitute for window-glass. Its diminutive pearls are exported to the Indian coast to be calcined for lime, which the wealthy natives affect to chew with their betel. The quantity of shells taken yearly exceeds six millions.

The Ceylon fisheries occasionally fail through overfishing, or the migration of the aviculæ in search of food to some other quarter ; ${ }^{*}$ and it has been proposed to adopt

* Stewart's "Pearl-Fisheries of Ceylon," p. 27. After an interval of ten years the fishery was revived in 1873 . The Ceylon Observer, writing of it, says : - "This last pearl-fishery is the first that has taken place for ten years, the oysters having during that period mysteriously disappeared; and though for three years an English savant was employed at a salary of $\$ 1000$ a year, he proved unable to account for their conspicuous absence. Perhaps out of compliment to him they have returned to their old spot; at any rate, the take this year (1873) has reached the important number of one million of oysters, producing to the Government the respectable sum of $£ 10,000$. The 
M. Coste's system of oyster-farming, and establish beds in suitable localities, so as to guard against the loss of a very important staple of commercial industry.

oysters generally have been found to be too young to yield good pearls; and this being the case, we wonder that they were not at once returned to their native element, as landing useless ones is certainly a most suicidal policy. The way in which we are told that a Tamil coolie found one pearl worth £150, leads us to suppose that the narrator did not place the least reliance in the rumour which he thought it his duty to record; indeed, what follows will show our readers that no such result was at all probable. The fishing-ground is distant about twelve miles from Silawatorre, and as many as two hundred boats are engaged in the fishery. These are divided into two fleets, distinguished by blue and red flags; and they are engaged for twelve days, this being the limit assigned for the pearl-diving. On the sound of the gun at midnight the boats weigh their anchors, and on their arrival another gun gives them the signal that they are to set to work. There are twenty-three hands to each boat, and one-quarter of the 'take' is their share, the remaining three-quarters falling to the rapacious maw of the Government. On this last occasion very great assistance was afforded to the natives by an English diver clad in a proper diving-dress, who was able to stay under water for an hour, and is reported to have walked a mile at a time, and to have indicated to the super-aqueous confraternity where they could descend with the great. est advantage." 


\section{CHAPTER XIII.}

THE MUSSEL.

" Ecce inter virides jactatur mytilus algas."-A NTHotogra.

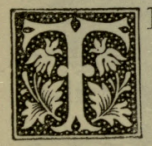

HE Mussec is a well-known lamellibranchiate molluse, belonging to the family Mytilida: a family which includes the Sea Mussel, Mytilus; the Pond Mussel, Anodontu; the Mulete, or Painter's Mussel, Pina cardium; and some other genera. As the Mytilus is the object of an extensive fishery, it requires and deserves description.

Like the oyster, which it resembles in its general organization, the mussel is an acephalous mollusc and a bivalve. Unlike the oyster, it attaches itself to its resting-place by an apparatus of threads, called the byssus, which is secreted by a special gland. In shape it differs greatly from the more popular mollusc, for it is longitudinal, with a regular equivalve, and comparatively smooth shell, pointed at the base, and of a bluish-black colour. The hinge is without teeth, but the uniting ligament is located in a deep furrow.

The animal enclosed in this oblong equivalvular case is elongate, and oval, with the lobes of its pallium (or 
"mantle") simple or fringed; the said pallium, which secretes the shell, being simply an expansion of the dorsal integument. It does not possess a distinct, differentiated head; and the mouth is just situated at what may be called the anterior extremity of the body. It opens into a gullet, and the gullet into a stomach consisting of a

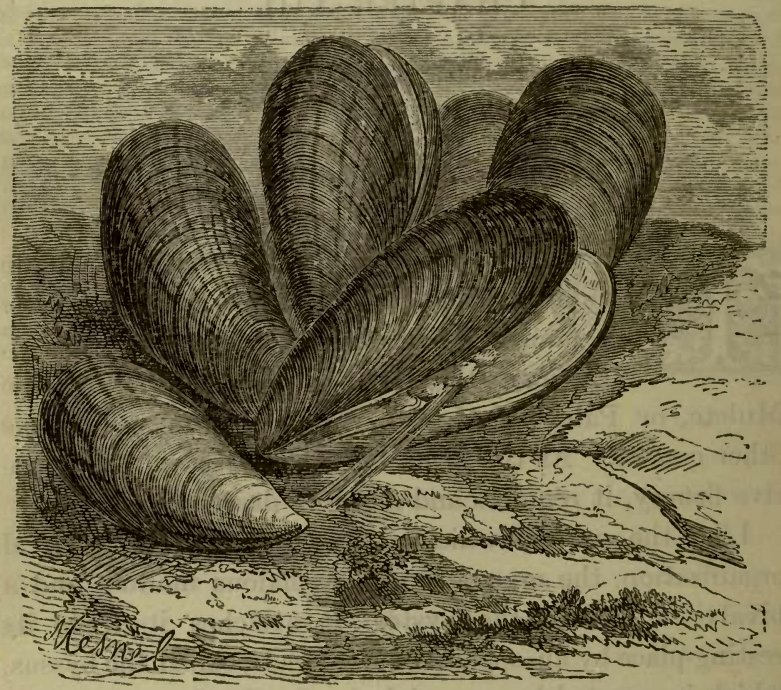

MUSSELS.

thin, white, opaline membrane. The liver is large and well-developed; the respiratory organs consist of two lamelliform gills, placed on each side of the body.

A remarkable organ of the mussel is its foot-which is small, and when not in motion semi-lunar, but capable of elongation until it resembles a kind of conical tongue, 
with a longitudinal furrow on either side. It is subsidiary to a special gland; the gland which, as we have already said, secretes the tuft of silky threads known as the " byssus."

It is difficult to imagine what the mussel would do without its byssus. It constitutes its special advantage over the oyster; for while the latter is unable to accomplish any long or rapid journey, or any continuous motion, the mussel is free to move about at all times and in all directions. Attaching its byssus to some fixed object, it draws upon it as upon a cable, and is gently carried forward. But not only does the byssus act as a locomotor, it is also an anchor, and when the animal is moored by it to rock or pile, it defies the violence of the strongest currents. Moreover, it ean in this way suspend itself to the face of a perpendicular crag, and keep its shell to some extent above the surface of the water; to which cause the comparative smoothness of its shell is probably owing.

The mussel seems able to cling to any surface, however slippery. Put one or two into your aquarium, reader, and you will soon find them securely anchored to the glass; so securely, that to remove the shells you must rend or sever the threads of the byssus, and these are about a hundred and fifty in number! It is a curious fact that, to bind together the loose stones of the Cherbourg breakwater, the French sowed, or planted, tons of mussels, thus depending on the tenacious and adherent properties of the byssus.

In almost all the seas of the world the mussel is to be found, and on the English and Scotch coasts it is one of the "common objects of the shore." It is used as an 
edible-though the cook needs to be careful in dealing with so dangerous a mollusc - and by the fisher-folk for bait. You may see the fisherman, and his wife and bairns, all engaged in the early part of the day groping among the weedy stones and rocks for the provision which he must take with him when he sails his boat at nightfall. Mussels are even purchased for bait, and the supply, not infrequently, is less than the demand. It is surprising no one in our islands has yet taken to musselculture, at any rate not on a large scale. They manage these things better in France. In the Bay of Aiguillon an immense mytilicultural farm exists, and has existed for nearly six centuries, - though not, of course, on its present scale.

Strange to say, the mussel-farm we speak of was established by the Irishman, Walton, to whom we have already referred, under the following curious circumstances :-

In 1236 an Irish bark was wrecked in the Bay of Aiguillon, a few miles from Rochelle. All the crew appear to have perished, but the neighbouring fishermen saved the life of the master, a man named Walton. Those were days in which men had a hard struggle for existence, and on the barren shore of the Aunis, Walton was compelled to support himself as best he could. At first, he lived principally upon the sea-fowl which, in countless flocks, frequented the neighbouring marshes. Growing dexterous through incessant practice, he in-. vented a species of net,-a "night-net," as he called it, -measuring, it is said, three or four hundred yards in length by three yards in breadth. This immense stretch of mesh-work he disposed horizontally, like a screen, along 
the beautiful waters of the bay, retaining it in its position by piles driven into the "oozy bed." In the darkness the wild fowl, as they floated with the ripple, came in contact with Walton's "engine," and entangled themselves in its meshes.

The bay, however, was exceedingly shallow, and, near the shore, was navigated with difficulty. Something ot lighter draught than the clumsy French boats was needed. Walton's ingenuity again came to his assistance, and he succeeded in devising a flat-bottomed, square-sided craft,

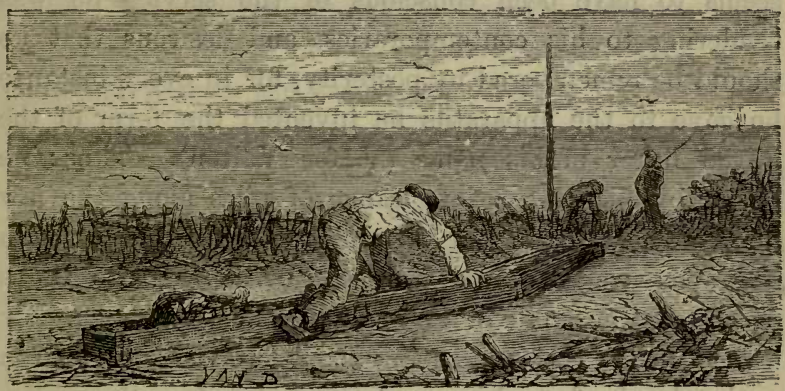

PUNT USED BY MUSSEL-BREEDER.

resembling our modern punts. It had a wooden frame, nine feet long by three feet broad and deep, the fore-part of which sloped into the water, like a prow, at a slight angle. To propel the boat, the puntsman, for we cannot call him the "rower," knelt on his left knee, bending forward, with one hand on each side, and used his right leg as a punting pole.

In his punt-trajects Walton observed that the bay abounded with mussels, and he observed also that these were most plentiful on that part of the retaining posts of 
his net which were a little above the mud. Further, he noted that these grew fatter, and were better flavoured, than their mud-embedded congeners. On this hint he acted. He began a system of mussel-culture, and teaching it to the fishermen of Aiguillon, he founded a new and profitable industry. So well-adapted was that system to its object, that it has flourished down to the present time with scarcely any modification.

M. Coste, the great French authority on this subject, very justly remarks that Walton, in developing his idea, seems to have been conscious of the service he was rendering to his contemporaries, and desirous that he should be remembered by posterity, for in every instance he gave to the apparatus he invented the form of the initial letter of his name ( $\mathrm{V}$ for Valton). Thus: he began by planting a long range of piles along the low marshy shore, each pair forming the letter $V$, of which the apex was towards the sea, while the two limbs diverged at an angle of $45^{\circ}$. The posts were kept nearly a yard apart; each measuring about twelve feet in length - that is, six feet above and six feet below the watersurface-and all were bound together with hurdles of intertwisted branches. The two rows of hurdles formed what is now called the bouchot. To the unaccustomed eye the appearance is that of a number of fences, or basket-work palisades, arranged in the form of acute triangles.

The bouchot is now-a-days constructed in exactly the same manner; but there are so many planted in the little creek that it looks as if all the sheep-farms of the country had been deprived of their hurdles! We believe they count up to 500 ; that each is from 200 to 250 yards 
long, and six feet high; that the piles number fully 230,000 ; and that the fascines supported by them are no fewer than 125,000. The space thus covered extends about five miles, from the headland of St. Clemens to the mouth of the Marans river.

The bouchotier, following the example of Walton, traverses the muddy expanse of the bay at low water, in a punt, and with the wonderful topographical knowledge born of experience, glides in and out of the labyrinth of hurdles, without making a mistake, even in the darkest night. He readily finds out his own establishment, and then attends to the proper condition of his crop, or repairs and renews the wave-worn hurdles. The furrows ploughed in the mud by the labouring canoe might, when hardened in the summer sun, render his farming a laborious task, but for the assistance of a small crustacean, which swarms in the mussel-fields towards the beginning of May, and in hunting after its prey, the annelids, completely effaces the ruggednesses and inequalities of the muddy soil. This crustacean suddenly vanishes, about the end of October, in a single night.

Mussel-culture is the prevailing occupation of the inhabitants of Esnandes, Chavron, and Marsilly.

Sometimes a bouchotier owns several bouchots, and is quite a man of substance; sometimes he has but a share in a bouchot, which he cultivates in common with others, receiving his due proportion of the profit. The bouchots are arranged in four divisions, according to their place in the bay, and are distinguished accordingly as bouchots du bas or d'aval, bouchots batard, bouchots milieu, and bouchots d'avant.

The bouchots du bas are those nearest the sea. They 
are uncovered only during spring-tides, and instead of being formed, like the others, of basket or wattle work, consist simply of a row of piles, planted about nine feet apart, and in what seems the best position for catching and preserving the nuissain, or mussel-spat, which is afterwards transplanted, as we shall see, to the musselfarms further in-shore.

We owe to M. Coste a lively description of the industry supported by this interesting culture.

In order, he says, to supply the distant markets, the bouchotiers bring ashore their cargoes of mussels, which the women carry into the neighbouring caves or grottoes ; there they are cleaned, and packed in hampers or baskets, which are conveyed in carts or on the backs of packhorses, by night, to Rochelle, Rochefort, Angoulême, Poitiers, Tours, Angers, and Saumur. Ninety carts and one hundred and forty horses make annually upwards of thirty-three thousand journeys to these and other towns. Moreover, forty or fifty boats come from Bordeaux, the isles of Ré and Oléron, and the sands of Olonne-accomplishing in all some seven hundred and fifty voyages per annum, and distributing the rich harvest of Aiguillon at places inaccessible to the horse and cart of the villagers.

A well-equipped bouchot supplies every year, according to the length of its wings, from four hundred to five hundred charges. A charge weighs upwards of $300 \mathrm{lbs}$., and sells for about four shillings. A single bouchot, therefore, produces a harvest equal in weight to 130,000 or 140,000 lbs., equal in value to $£ 100$; and at this estimate the whole bay will yield a gross yearly revenue of $£ 480,000$. These figures afford some idea of the alimentary wealth of the sea-shore ; and both in England 
and Scotland there are numerous parts of the coast where mytiliculture could be pursued with no less advantage. Meantime, as M. Coste remarks, the Bay of Aiguillon remains as a memorial of what may be accomplished by the efforts of a single individual.

The various processes of the "cultivation" are these:Towards the end of April the seed (semence) which, during the two preceding months, has become attached to the piles of the bouchot $d u$ bas, attains to the size of a grain of flax, and is then designated the nuissain. By July it has grown as large as a bean, and receiving the name of cenouvelain, is ready to be transplanted to the less comfortable pastures of the bouchot batard. The bouchotier proceeds to remove it, during low water, by means of a hook fixed to the end of a pole, and in his punt conveys it across the mud to the fences of the bouchot batard, where, enclosed in bags of old net, it is placed in all the intervals along the palisades until the different hurdles are fully covered. This operation is called la batrisse. The bags are large enough to admit of the development of the young mussels; and, moreover, the action of the water and the atmosphere soon rots them, and they fall away, leaving the bivalves attached to the sides of the bouchot.

In due time the mussels grow so large as to touch one another, and the fences at a distance seem long lines of blackness; then the mytiliculturist thins the mass, just as a gardener thins an overcrowded bed of turnips or carrots. The thinned-out mussels are transplanted to the empty or partially-covered hurdles of the bouchot milieu, which at neap-tides is left exposed by the water. In 
this second transplantation no nets are used, the large size of the mussels rendering them unnecessary.

In the bouchot milieu the mussels remain for about a twelvemonth, after which they pass a short time in the buchot d'avant; there they are so near the shore that, when fully ready for the market, they can easily be gathered by the hand. They are in the best condition from July to January. During the spawning-season, from February to April, they lose their flavour, and acquire a toughness which is anything but agreeable.

Certain localities are famous for the special quality of their mussels, and they would seem to be of superior excellence when found in tidal estuaries. This will probably be due to the nature of their food. A very large and fine species, the Mytilus choros, is found at Chiloe.

Fresh-water mussels, though allied to the Mytilidæ, form a different family. They have a much larger foot, which, except when the animal is very young, does not produce a byssus. Though some of the species are European, most are American, where they abound in the lakes and rivers, and generally live embedded in mud.

It is supposed they feed upon animalcules, and upon decomposed animal and vegetable matter. In many the epidermis is very brilliantly coloured, while the inside of the valves is coated with a beautiful iridescent nacre.

On the south and east coasts of England are found two species; while the Cineo (Alasmodon) margaritifera or Meya margaritifera, which inhabits the streams of Wales and Scotland, is celebrated for the pearls it produces.

Of the British pearl-fisheries, however, we have spoken in the preceding chapter. 


\section{CHAPTER XIV.}

THE HOLOTHURIA, TREPANG, OR SEA-CUCUMBER.

"What hidest thou in thy treasure-caves and cells,

Thou hollow-sounding and mysterious main?"-Mrs. HeMaNs.

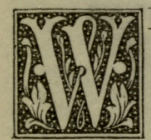

E do not suppose that many of our readers will have seen a "sea-cucumber;" we are certain they will not have partaken of one as "an article of diet." Yet in many parts of the world it forms a recognized and valued "dish;" and as it is the object of a not inconsiderable fishery, it will rightly figure in these pages.

"Sea-cucumber" is the popular appellation for a member of the great class Echinodermata (literally, spinyskinned), which zoologists have christened HoLothuria.

It has an elongated, vermiform, or sometimes slugshaped body, enclosed in a coriaceous skin, frequently containing calcareous granules or spicules. While some specimens attain a length of three feet, others do not exceed a few inches; and while some are opaque, others are semi-transparent. The digestive tube extends from one end of the fleshy body to the other; the mouth being 
placed at the bottom of a kind of funnel, and surrounded by a fairy-like ring of feathery tentacles. Iocomotion is effected by means of tube-feet, which, when present, are distributed over the body in five rows; or by the alternate extension and contraction of the body, as in the worm. The intestine is long and convoluted, and opens into a terminal dilatation, termed the "cloaca," which serves both as an anus and as an aperture for the admission of sea-water to the respiratory tubes.

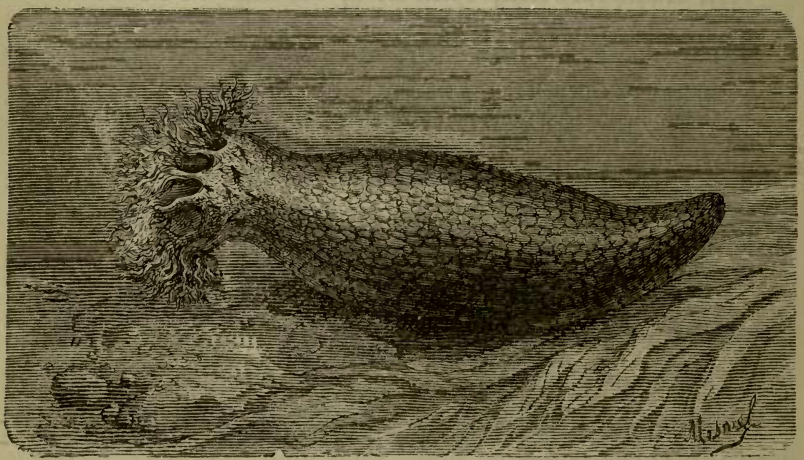

THE HOLOTHURIA.

Many of the holothurias possess so remarkable a degreo of contractility, that, if injured or irritated, they can eject the whole of their internal organs.

They are found in nearly every sea; often at great depths, but not infrequently in shallow water. As we have said, in some parts of the world it is esteemed a valuable article of food. The Neapolitans consume it largely; but it is in China that it obtains the most extensive reputation. The famous "trepang" is neither 


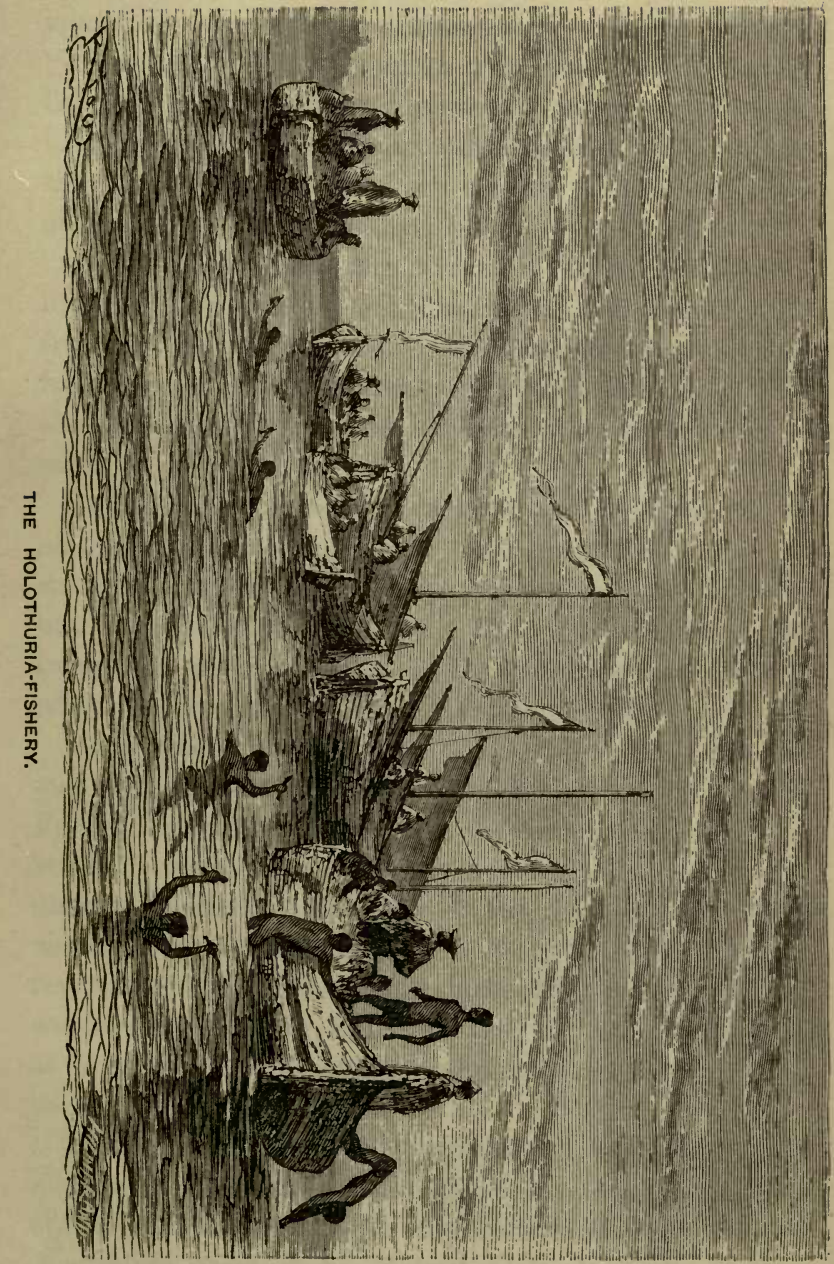



more nor less than "sea-cucumber." In the so-called "Celestial Empire" it forms the staple of a thriving fishery and an extensive commerce ; and we are told that long before New Holland was discovered by Europeans, the Malays visited its shores to fish for the holothurias abounding in the Australian waters.

Dumont d'Urville, the French voyager, furnishes an interesting description of this curious fishery. The two frigates under his command, the Astrolabe and the Zelee, had dropped anchor in Raffles Bay; and there, on an islet, the scientific officers of the expedition erected an observatory.

In his shore rambles, Dumont d'Urville frequently noticed, at numerous points, ranges of low walls, constructed of dry stones, and arranged in a semicircular form, but joining one another. He had vainly framed conjectures as to the possible use of these strange constructions, when a company of Malay fishermen arrived.

Four prahus, carrying the Dutch flag, entered the bay, and took up their positions at a cable's length from the French observatory. Their crews then proceeded to land several large cast-iron caldrons, not less than three feet in diameter, and these they raised upon the low stone dykes we have spoken of, which turned out to be intended for furnaces or fireplaces. Some sheds of bamboo were afterwards run up; four bundles being set into the ground at the corners of a square, and a rude roof rested upon them.

The owners of the prahus explained to the French commodore that, setting out from Macassar towards the close of October, they fished for the holothurias all along the Australian coast, from Melville Island to the Gulf of 
Carpentaria, until driven away by the easterly winds; that on their homeward voyage they would revisit every point of the coast, anchoring in those bays and creeks which give promise of a successful fishery.

Such a crowd of men, busily labouring at the construction of their sheds and laboratories, gave to Raffles Bay an unusual aspect, which soon excited the curiosity of the savage inhabitants of the mainland. They hastened to it from every quarter; most of them reaching the island by swimming, or by fording the comparatively shallow channel which separated it from the mainland. There was but a single canoe, and even that was made of the bark of a tree, and loosely put together. It was unable to carry more than three persons.

By nightfall the Malays had completed their preparations ; and a few remaining to guard the articles conveyed ashore, the others returned to their prahus.

One of these was visited by Dumont d'Urville. The keel, he says, seemed solidly built, and the lines of the boat were not without a certain gracefulness. In the stowage, however, the greatest disorder seemed to prevail.

Each prahu was provided with a couple of rudders, one at either end, which could be readily lifted if the boat ran aground. There were two masts ; shrouds there were none, but the masts could be easily lowered on deck by means of a hinge. The anchors were of wood, the cables of rattan, or gomoton. The crew numbered about six and thirty; and to each prahu were attached five or six skiffs or canoes.

On the following day, these canoes were spread all over 
the bay, and the fishery began. For success in it the main requisite seemed to be that the men should be good divers, and that they should have a keen eye to detect the holothurias, which are caught by hand, at the bottom of the water. The best time for fishing is noon, for the higher the sun above the horizon, the more easily can the

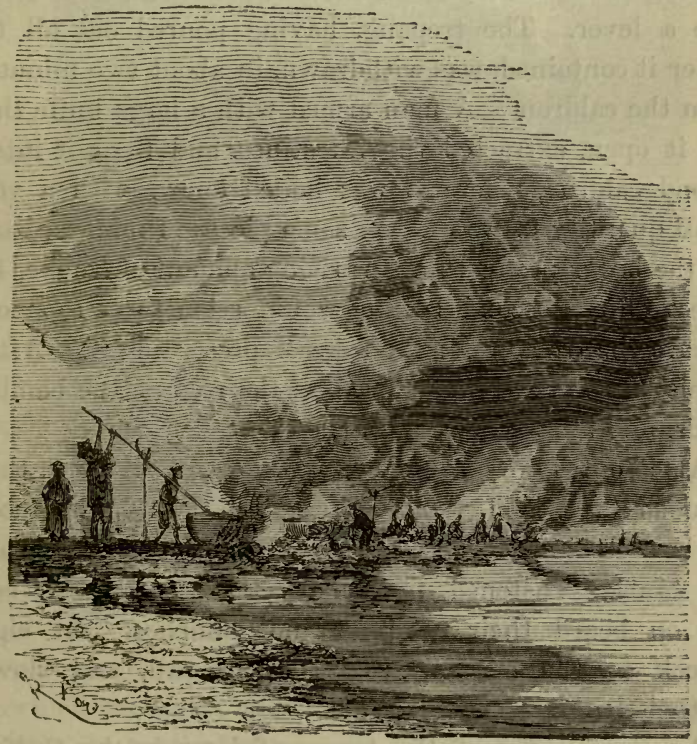

BOILING THE TKKPANG.

divers discover their prey. The burning orb poured its fiery arrows upon their heads, apparently without inconveniencing them. Each man, on rising to the surface, would have one or two sea-cucumbers in his hands, which he cast into the nearest canoe, and immediately dived 
again. When the boats were sufficiently loaded, they returned to the shore, and others took their places.

The cargo of sea-cucumbers, or sea-slugs, as some authorities call them, being conveyed ashore, the fish were forthwith cast into a caldron of boiling sea-water, and kept constantly stirred, by means of a long pole moving on a forked branch fixed in the earth, so as to act like a lever. The trepang, having poured out all the water it contained, was withdrawn, in about two minutes, from the caldron. A man armed with a large knife then cut it open, extracted the intestines, and flung it into a second caldron, where it was boiled anew, with a very small quantity of water, and some pieces of mimosa bark. As the latter produced a surprising amount of smoke, the object of the second boiling would seem to be to smoke or cure the trepang for the sake of preserving it. Afterwards, the trepang was placed on the roof of the bamboo sheds, and allowed to dry in the sun.

At about two o'clock the divers ceased from their arduous task, and went ashore. In two hours more, the processes of boiling and curing were completed, and the Malays hastened to embark their store, and convey on board their caldrons and bamboos. At eight o'clock in the evening they hoisted sail, and slowly quitted the bay.

Another centre of the trepang-fishery is the Gulf of Manaar, on the coast of Ceylon. After being dried, the trepang is exported to China. There is also a considerable export from Manilla. But Macassar would seem to be the great depôt, upwards of 8000 hundredweight of bêche-de-mer, or trepang, being annually sold to the Chinese merchants, at prices varying, according to kind 
and quality, from two to twenty guineas per hundredweight. The Chinese use it for thickening their soups.

The largest European species is the Holothuria pendosa,

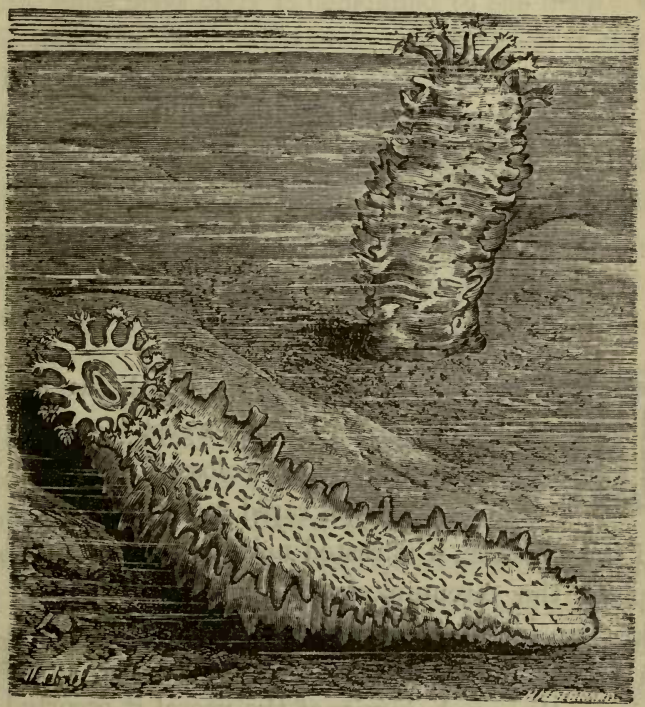

THE HOLOTHURIA PENDOSA.

- which measures about twelve inches in length, but, unlike its tropical congeners, is of a dull and unpleasing appearance. 


\title{
CHAPTER XV.
}

\author{
THE SHARK.
}

"A blue shark is hanging within the blue ocean."--SHEr.tey.

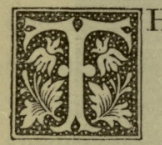

HIRTY-THREE feet in length (we are referring, of course, to the largest members of the terrible Squalidæ); colossal muscular force; such a power of rapid motion that it is calculated the creature, if it rested neither day nor night, could complete the circumnavigation of the globe in thirty weeks; so entire an insensibility to fatigue that it has been known to follow a ship from Europe to America, making a thousand circuits of the vessel it escorted ; jaws of such dimensions, that, when wide open, their circumference is nearly equal to one-third of the animal's whole length; triangular teeth, sharp and trenchant, and increasing in number with the animal's age ; a skin impervious to musket-balls; a voracity which seems insatiable, and an audacity which nothing intimidates; the ferocity of the tiger in union with the strength of the cachalot;such is the SHark, the terror of the marine world, the most formidable monster of ocean ! 
It is found in every sea, except in the icy waters of the Pole. It undertakes the pursuit of a ship, and continues it with unfailing perseverance, waiting and watching until, perchance, some unfortunate mariner falls overboard, or some dead body is consigned to the deep; waiting and watching with a patience which makes it the seaman's horror-and specially faithful, it has been remarked, to its self-imposed mission during the fury of a storm, for its instinct, perhaps, leads it to count upon the wreck of the labouring vessel. Even the tumult of a sea-fight has no terror for it: alas, it knows that in the hour of battle man is working for the shark!

That ocean-pirate, as Badham expressively calls it, whose atrocities, though perpetrated, are not written, in water, and which, "overwhelmed with cruelty," yet "comes to no misfortune like other fish;" whose eyes swell with fatness, and which does even as it lusts ; raging horribly everywhere like a wild beast !

From the writings of the ancients, we know that it was regarded by them with at least as much dread and abhorrence as it is by ourselves. At first, when natural history was an undeveloped science, the different species were not generally distinguished; but as the knowledge of men broadened, and their research extended to the inhabitants of the waters, it was shown beyond all doubt that, though they agreed in voracity and destructiveness, they differed in structural character. There is a curious passage in Pliny, descriptive of a species which would seem to be identical with the "tope" of the English, the Squalus milandra of the French, and the Samiola of the Italians. It abounds in the Mediterranean as well as in the Indian Seas, and in both regions is much dreaded by seamen, and bathers, 
and divers. Here is Pliny's account of it, as translated, quaintly enough, by Philemon Holland :-

"The dyvers that use to plunge down into the sea are annoyed very much with a number of sea-hounds (Caniculoe) that come about them......Much ado they have, and hard hold with these hound-fishes, for they lay at their bellies and loines, at their heeles, and snap at everie part of their bodies that they can perceive to be white. The onely way and remedie is to make head directly affront them, and to begin with them first, and so to terrifie them; for they are not so terrible to a man as they are afraid of him againe. Thus within the deepe they be indifferently even matched; but when the dyvers mount up and rise againe, above water, then there is some odds betweene, and the man hath the disadvantage, and is in the most daunger, by reason that whiles he laboureth to get out of the water he faileth of meanes to encounter with the beast against the stream and sourges of the water, and therefore his only recource is to have helpe and aid from his fellowes in the ship; for having a cord tied at one end about his shoulders, he straineth it with his left hand to give signe of what daunger he is in, while he maintaineth fight with the right, by taking into it his puncheon with a sharp point, and so at the other end they draw him to them; and they need otherwise to pull and hale him but softly : marry, when he is neere once to the ship, unless they give him a sodaine jerke, and snatch him up quickly, they may be sure to see him worried and devoured before their face; yea, and when he is at the point to be plucked up, and even now ready to go aboard, he is many times caught away out of his fellowes hands, if he bestir himself not the better, and put his own good 
will to the helpe of them within the ship, by plucking up his legges and gathering his body nimbly togither, round as it were in a ball. Well may some from shipboard proke at the dogges aforesaid with forkes; others thrust at them with stout speares and such-like weapons, and all never the neare; so crafty and cautious is this foule beast, to get under the very belly of the bark, and so feed upon their comrade in safetie."

We in England, who rarely see a shark except in a museum, and when it can no longer do us any injury, can hardly estimate the intensity of the hatred with which the monster is pursued by the inhabitants of less secure shores. The Malayans regard the killing of a shark as a noble deed, and the killer as a man who has deserved well of the country; and even the Italians, who are chiefly acquainted with the samiola, certainly not the most dangerous of the race, pour out upon the Squalidæ the full torrents of their wrath. In Mr. Badham's entertaining pages, we find a graphic and amusing sketch of the scene in the fish-market of Palermo, when, on one occasion, some seamen brought ashore a tope which they had captured in their tunny-nets.* The mangled corpse was surrounded by an excited and admiring throng. The men who had secured the monster, well content with the results of their night's toil, smoked the pipes of peace, and told to all who cared to listen the oft-told tale of the surprising capture. Women, of course, mingled largely in the crowd ; all, with outstretched fingers, pointing at the harmless monster, gesticulating and screaming "Bruto!" "Scelerato!" "Nerone dei pesci!" with other customary

* Badham, “Ancient and Modern Fish-Tattle," pp. 42צ, 423. 
names of abuse for a shark in Sicily ; everybody was exclaiming, everybody exulting over its destruction. "Eccolo, Bippo; we have him at last, you see," remarked one of the crew to a boatswain who had just entered the market. "Buono giome a lei! Good day to you! I make you my bow, sir," said the other, gravely doffing his red worsted cap to the fish. "We are all happy to welcome you on shore, signor; after this, I fancy, you will not again intrude into the chamber of death (la camera della morte),* and make a hole for the tunny to slip through our fingers-eh? No, my lads; now we really have him, and you may mend your nets in security." "Pu Bacco and St. Anthony!" exclaimed a third; "will you tell me, sir, where you have put the flannel drawers you snatched from my felucca, as they were drying on Sunday last, in less than five minutes after Giuseppe's legs were out of them?" "Cune maledetto! (accursed hound!) where's my brother's hand, which you snapped off as he was washing it over the side of his boat, not a week ago?" "Caro lei! did you happen to bolt down Padre Giacomo's poodle, which disappeared so suddenly the day before yesterday, as he was swimming ashore with his master's stick?" "Risponde, Risponde!-answer, answer!" shouted twenty eager voices at once. "Gentlemen," said the master boatman and proprietor of the canesea, "we shall get more out of him by looking into him than by asking such questions as these," - and forthwith proceeded to cut him up.

In Ceylon the terror inspired by the Squalidæ has induced the growth of a singular superstition. Before the 
natives venture into the water, they resort to the aid of a shark-charmer, whose exorcism is supposed to be an effectual protection.*

But we must now say a few words on the general character and organization of the sharks.

As Professor Owen says, + not only are they the most voracious, but they are the most active and vigorous of fishes. Like the birds of prey, they soar, as it were, in the upper regions of their atmosphere, and without any assistance from a modified respiratory apparatus, and though devoid of an air-bladder, they contrive to maintain themselves near the surface of the sea solely by the action of their large muscular fins.

With this mode and sphere of life, to adapt still further the language of our great British naturalist, the gristly skeleton admirably harmonizes; and we can trace welldefined modifications of the digestive and other systems of the shark by which its body is rendered as light, and the space encroaching on the muscular system as small, as might be compatible with those actions. Moreover, lightness, toughness, and elasticity are the qualities of the skeleton most essential to the shark; to yield to the contraction of the lateral inflectors and aid in the recoil are the functions which the spine has mainly to perform in the act of locomotion, and to these functions its alternating elastic balls of fluid, and semi-ossified biconcave vertebræ, most admirably adapt it. Had its entire skeleton been consolidated and loaded with earthy matter, the consequent burden would have been wholly at variance

* Sir Emerson Tennent, “Natural History of Ceylon," p. 578.

† Professor Owen, "Hunterian Lectures," vol. ii., lecture 6. 
with the office the shark is appointed to discharge in the economy of the great deep.

A very curious feature in the organization of the oceanmonster is its eye, though its structure is founded on simple principles when compared with that of other animals. We know that most fishes have round, prominent, and as it were sleepless eyes; eyes which never close, either in sleep or at the approach of danger. But in the sharks, at least in the majority, the exposed surface is rendered oval by means of an arrangement of the skin above and below the globe, which, when the fish is in any way imperilled, closes over the eye, in much the same manner as the eyelids of birds. The globe itself is supplied with muscles to regulate its actions, and its sphere of action is further extended by means of a contrivance which furnishes a remarkable instance of the adaptation of an already existing mechanism to a new use. On examining the cavity in which the eye of the shark revolves, we find that the globe, which is the immediate seat of the power of vision, is lighted from the bottom, on which in other animals besides those of this great family it rolls, and is placed on a small platform or plane formed by the top of a small pillar, whose base is fixed on the osseous circle of the common ocular cavity; or, in more scientific language, the pillar we speak of, which inclines slightly forward in order that it may be accommodated to the direction in which objects are usually viewed, is an extension or modification of the orbitary process of the "sphenoid bone."

We have alluded to the enormous dimensions of the mouth of the shark. It is armed with from three to six rows of compressed, sharp-edged, triangular, and serraterl 
teeth ; these, which form a crushing apparatus of great power, are movable at the will of the animal; they. are usually laid down and directed backwards, but are raised when the shark prepares to seize its prey.

The skin of the shark, in most species, is exceedingly rough, and covered with numerous little osseous tubercles; that of some species yields the substance known as shagreen.

The males are distinguished from the females in a way very unlike any that is observable in other families of fishes; that is, they are endowed with jointed organs, attached to the body close to the ventral fins.* These are popularly known by the name of "claspers." The females possess no milt or roe, such as we find in the bony or osseous fishes. They have, however, a something equivalent, which is often found studded with eggs in various stages of growth; and as the eggs escape from their primitive station, they descend to their proper receptacle, and there remain until their final development. Most of the sharks hatch their young within themselves, though without any adhesion to the organ in which they lie.

Among the Squalidæ belonging to, or found in, British waters, we may particularize the Neuse Hound or Catfish (Scyllium stellaris); the Rough Hound, or Lesser Spotted Dogfish (Squale roussette); the Black-mouthed or Eyed Dogfish (Scyllium melanostomum); the Six-gilled or Gray Shark (Hexanchus griscus); the White Shark (Squalus carcharias); Blue Shark (Carcharias glaucus); the Thrasher (Squalus vulpes); the Basking Shark, or

* Couch, "British Fishes" (edit. 1862), p. 9. 
Sunfish (Squalus maximus, Yarrell); Cetorhinus maximus, Gray); the Greenland Shark (Segnuus borealis); and the Spinous Shark (Echinorhinus spinosus, Yarrell). A few notes upon these remarkable species, so remarkably named, may prove acceptable to the reader.

Let us begin with the Blue Shark, which visits our coasts in summer and leaves them at the approach of winter-being attracted, apparently, by the pilchards and herrings. It is held in great abhorrence by the Cornish fishermen, on account of the injury it does to their nets. Like its congeners, it has a rapacious appetite, and has been known to leap out of the water to seize upon a piece of beef hanging on the quarter of a ship. Our bathers, however, have no cause for alarm, since it seldom approaches very near the land or enters harbours. It pursues its prey by sight rather than by scent; yet it has a strong objection to things malodorous, and our fishermen declare it can be driven away by pouring bilge-water into the sea in its immediate vicinity.

The average size of the blue shark, so far as our knowledge of captures on the southern coast extends, will be six or seven feet; but Couch says he has heard of specimens upwards of fourteen feet in length. Our own impression is that those large fish very rarely enter British waters. It is by no means inelegant in aspect : the body is round and slender, tapering towards the tail; the colour of the upper part a bluish-green, or greenish-blue; that of the under, white. The pectoral fins are large and long; the ventrals, small. The head is rather large in proportion to the body, with a very long and pointed snout. The tail is deeply bilobate. 
The blue shark is found in almost all parts of the globe. As it abounds in the Mediterranean, it was known to the ancients; and Oppian records some illustrative particulars of its remarkable love for its offspring, which our sailors agree in accrediting, but our scientific naturalists disbelieve. Here is the passage :-*
"Aye the blue sharks, secure from chasing foes, Within their widened mouths their young enclose. Beneath the circling arch they fearless hide, Though bulky forms drive on the rising tide.... Of all oviparous kinds that throng the seas, The fond blue sharks in tender care surpass.... They rear their fondlings, like some careful nurse, Observe their motions and restrain their course, Eye every wave, and show the doubtful way, Teach where to hunt, and where to find their prey. When big with secret guilt the waters heave, They in their mouths their sheltered young receive. But when the waves at their own leisure roll, And no fierce robber drives the scattered shoal, Again the parent's pointed jaws comprest, By force expel them from their pleasing nest."

We own ourselves as incredulous as the naturalists, and from a fact so dubious turn to one about which there can be no difficulty, - the creature's greediness. It will eat pilchards, tunny, herring, mackerel, conger, gurnard, dogfish, and never knows when to cry, "Hold, enough!" Its tenacity of life is another remarkable characteristic. An individual was caught with a line,- - the usual mode of eatching this fish,-its liver was cut out, and the bowels left hanging from the body, in which state it was again thrown into the sea. But it continued near the boat of its captors and executioners ; and not long afterwards pursued, and attempted to devour, a mackerel that had escaped from the net. Mr. Couch relates an instance when a fish had been thrown overboard, after the head

$$
\text { * Oppian, "Halieuties," bk. i. }
$$


had been severed from the body; yet for a couple of hours it continued to swim in various directions.

When taken into the boat a large shark may still prove a formidable enemy, from the violent blows it is able to deal with its tail. But this danger may be guarded against by an immediate amputation of the offending member.

Owing to its well-known destructive character, fishermen are always eager to shorten the race of this fish; and, consequently, many hundreds are caught in the course of a season. It is, however, of very little value, and yields no other result than a littlo indifferent oil from the liver, while the body is used for manure.

We pass on to the terrible Carcharias, or White Shark, which occasionally wanders into the British Channel, but finds a more congenial habitat in the warm waters of the tropics.

We are not sure but that it should be regarded as the most formidable of the inhabitants of the deep; for in none besides are the powers of destruction so equally combined with a thirst for carnage. With its enormous jaws it usually snaps in twain any object of considerable size before swallowing it; but if it finds a difficulty in doing this, it hesitates not to pass into the stomach even what is of enormous bulk: and the formation of its jaws and throat is well adapted for such an operation. Ruysel asserts that the whole body of a man, and even of a man in armour, has been found in the stomach of a white shark; ${ }^{*}$ and Captain King records the capture of a monster which could have swallowed a man with the

* Couch, "Natural History of British Fishes," i., p. 27 . 
greatest ease.* Blumenbach reports that an entire horse has been removed from this strange sepulchre; and Captain Basil Hall speaks of one in which, besides sundries, he found the skin of a buffalo, which, a short time before, had been thrown overboard from his ship.

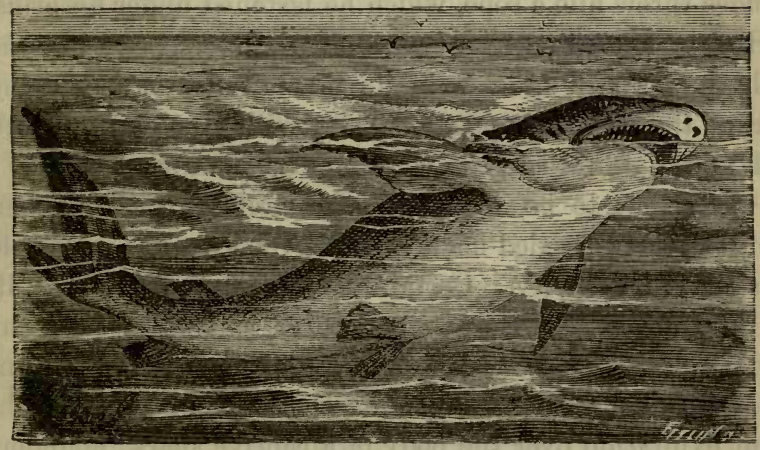

THE WHITE SHARK.

It is of this ferocious species that the following stories are told.

One day, in the North Sea, a sailor lowered himself into the water for the purpose of swimming to a neighbouring vessel, on board of which was an old comrade whom he had not seen for many years. On his way he was encountered by a shark, which, before the eyes of all the awe-struck crew, made a fierce attack upon the unfortunate swimmer. At the first snap of his jaws he carried off a leg, at the second an arm, at the third a shoulder. By dint of great exertions the seamen succeeded in rescuing from the shark their comrade's mutiCaptain King, " Narrative of an Expedition in Australia." 
lated body; but as it was lifeless, they were soon compelled to abandon it to the monster, which ceased not to hover in the immediate vicinity of the vessel.

At Antibes a sailor was bathing near the ship to which he belonged, when, underneath him, he suddenly discovered a shark. He uttered a piercing cry. His comrades threw him a rope, which he fastened under his arms. He was hauled on board with all possible speed ; but the shark was still quicker in its movements, and springing from the water, snapped off a leg with a precision which the most skilful surgeon could not have surpassed.

It is not to be wondered at, therefore, if the seamen pursue their dreaded enemy with a vengeance as insatiable as its own voracity. Certainly, says Captain Basil Hall, I have never seen the savage part of our nature peep out more clearly than when a whole ship's company, captain, officers, and young gentlemen inclusive, shout in triumphant exultation over the body of a captive shark, floundering in impotent rage on the poop or forecastle. The capture always affords high and peculiar sport, for it is one in which every person on board sympathizes, and to a certain extent takes a share. Like a fox-chase, continues Captain Basil Hall, it is ever new, and draws within its vortex every description of person. The lunarian, busy taking distances, crams his sextant hastily into its case ; the computer, working out his longitude, shoves his books on one side; the marine officer abandons his eternal flute; the doctor starts from his nap; the purser resigns the Complete Book; and every man and boy, however engaged, rushes on deck to see the villain die. Even the monkey, if there be one on board, takes a vehement interest in the whole progress of this 
wild scene. "I remember once observing Jacko," says the captain," "running backwards and forwards along the after-part of the poop hammock-netting, grinning, screaming, and chattering at such a rate, that, as it was nearly calm, he was heard all over the decks.

"'What's the matter with you, Master Mona?' said the quarter-master. Jacko replied not, but merely stretching his head over the railing, stared with his eyes almost bursting from his head, and by the intensity of his grin bared his teeth and gums nearly from ear to ear.

"The sharp curved dorsal fin of a huge shark was now seen rising about six inches above the water, and cutting the glazed surface of the sea by as fine a line as if a sickle had been drawn along.

" ' Messenger, run to the cook for a piece of pork,' cried the captain, taking command with as much glee as if it had been an enemy's cruiser he was about to engage.

" 'Where's your hook, quarter-master?'

" ' Here, sir, here !' cried the fellow, feeling the point, and declaring it as sharp as any lady's needle, and in the next instant piercing with it a huge junk of rusty pork, weighing four or five pounds ; for nothing, scarcely, is too large or two high in flavour for the stomach of a shark."

The hook used on these occasions is generally about as thick as one's little finger, has a curvature about as large as that of a man's hand when half-closed, and measures from six to eight inches in length, with a formidable barb. To this potent grappling-hook three or four feet of chain are attached, a precaution which is

* Captain Basil Hall, "Fragments of Voyages and Travels," Second Series, i, 266-270. 
absolutely necessary; for a voracious shark will sometimos take the bait so deep into its stomach, that, but for the chain, it would snap the rope by which the hook is held as easily as Samson burst the withes of the Philistines !

A good strong line being made fast to the chain, the bait is cast into the ship's wake. The shark is generally hungry; but in the few cases where its appetite is indifferent, it sails slowly up to the bait, smells at it, and turns it over and over with its muzzle. It then sheers off to the right or left, as if it apprehended mischief, but soon returns, to enjoy the "delicious" flavour of the damaged pork.

During these proceedings, the whole after-part of the ship is so clustered with heads that not one inch of spare room is visible. The rigging, the mizzen-top, and even the gaff, the hammock-nettings and the quarters, almost down to the counter, are thronged with breathless spectators, speaking in whispers, if they venture to speak at all, or can find leisure for anything but fixing their gaze on the monster, who as yet is free to roam the ocean, but who, they trust, will soon be in their power.

It is supposed by seamen that the shark must perforce turn on its back before it can bite anything; and, generally speaking, it does so turn before it takes the bait. But this arises from two circumstances: one of them accidental, and belonging to the particular occasion; the other due to the peculiar conformation and position of its mouth. When a bait is towed astern of a ship that has any motion through the water at all, it is necessarily brought to the surface, or nearly so. This, of course, compels the shark to bite at it from beneath; and as its mouth is placed under its chin (so to speak), it must turn 
nearly on its back before it can seize the floating dainty in which the fatal hook is concealed. Even if it does not turn completely round, it is forced to "slue" itself so far as to show some portion of its white belly. And no sooner does the white skin flash on the sight of the expectant crew than a subdued cry of satisfaction may be heard, like a distant ripple. No one speaks, however, for fear of alarming the shark.

Sometimes, just as the bait is flung over the stern, the monster leaps at it with an eagerness which takes its body partially out of the water. This, however, is rare. On such occasions it gorges the bait, hook, and a foot or two of the chain, without mastication and without hesitation, and darts off with its treacherous prize with such prodigious velocity and force, that it makes the rope crack again as soon as the whole coil is drawn out. Generally it sets to work more leisurely, and seems rather to suck in the bait than to bite at it. Much dexterity is required in the hand which holds the line at this moment; for a bungler is apt to be too precipitate, and to jerk away the hook before it has got far enough down the shark's maw. Our greedy friend, indeed, is never disposed to part with aught which once has passed its formidable batteries of teeth ; but the hook, by an abrupt twist of the line, may fix itself in a part of the jaw so weak as to give way in the violent struggle which always ensues.

The secret of expert shark-fishing is, to let the voracious monster gulp down the huge mess of pork, and then to give the rope a-violent pull; by which means the barbed point, quitting the edge of the bait, buries itself in the coats of the victim's throat or stomach. As the shark does not submit patiently to such an operation, it (502) 
is not well with any person whose foot happens to be accidentally on the coil of the rope, for, when the hook is first fixed, it spins out "like the log-line of a ship going twelve knots."

The suddenness of the jerk with which the monster is brought up when it has reached the length of its tether often turns it quite over on the surface of the water.

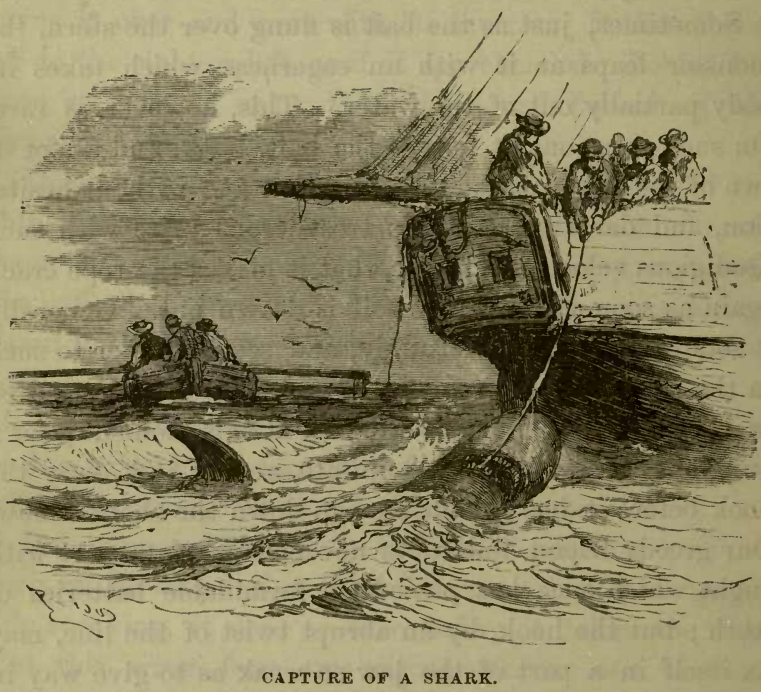

Then commence the loud cheers, so long, and with so much difficulty suppressed! A steady pull is insufficient to carry away the line, but it sometimes happens that the violent struggles of the shark, when too speedily drawn up, snap either the rope or the hook, and so it gets off, to digest the remainder as best it can. Accordingly, it is con- 
sidered good practice to "play" it a little, with its mouth at the surface, till it becomes somewhat exhausted. Captain Hall writes, that during this operation one would almost fancy the enraged animal was conscious of the abuse showered down upon it; for, while it turns and twists and flings itself about, its eye glares upwards with a ferocity of purpose which makes the blood tingle in a swimmer's reins, as he thinks of the hour when it may be his turn to writhe under the tender mercies of his sworn foe!

When the shark is hauled on board, the first operation always is to deprive it of its tail; after which it is cut open, and the contents of its capacious interior are submitted to public inspection. Of the multifariousness of these contents we have already given the reader an idea, and we need dwell no longer on details which are, to say the least, unsavoury.

The shark, to Europeans generally, is a very useless prize. They do not care for its flesh, and it has no conmercial value. It is true that Athenæus, the old Greek writer, has penned an eulogium upon it; but his eulogium does not improve its quality. It is hard and leathery, except in the case of very young individuals. This does not prevent the negroes from feeding upon it. They remedy the hardness by keeping it from eight to ten days, until it begins to smell badly; it is then as tender as anybody could wish. It is also eaten by the coast population of the Mediterranean, but only when they have no other choice. The sole endurable portion is, it is said, the belly; which, after lying in pickle for fourand-twenty hours, is boiled in water and eaten with oil. Among the Icelanders the fat of the shark is used instead of pig's fat; they eat it with their stock-fish. 
Of the skin, which is very hard, shoes and harness are made, and the Greenlanders also construct canoes. The Norwegians eat the eggs of the female, and cut up the flesh to feed their cattle. The liver, which is of great size, yields a quantity of oil adapted for illuminating purposes, but far inferior in quality to that afforded by the whale.

So great is the audacity of the carcharias, that it will fling itself upon the whales which the hunters have in tow, and even upon those which are being cut up by the side of the vessel. It is not without difficulty that the best-armed men can keep it at a distance. It nearly always, says a writer, accomplishes a surprising amount of destruction before it loses its hold, and will damage as much as fifteen quintals of fat before it beats a retreat.

Generally it lives upon fish, upon tunny and cod especially, and upon seals. In default of larger prey, it is content with cuttle-fish and other molluses; and when everything else fails, it eats shark.

It has been rightly asserted that the shark would depopulate the seas, but for the difficulty it experiences in seizing its prey. This difficulty is due, as we have shown, to the position of its mouth, which is situated some ten to twelve inches behind the extremity of the muzzle. Hence it results that the animal pushes before it the object it wishes to bite. It guards against this inconvenience by throwing itself a little on one side; but while it turns, quick as may be its movements, the prey has sometimes an opportunity of escape. When the prey is a negro, the latter seizes this moment to invert their respective parts; profiting by the short interval, he dives underneath the shark, and rips open its belly. According 
to Dixon, the natives of the Sandwich Islands swim fearlessly in the midst of the sharks. Is this because they are skilful in eluding their attacks, or because the latter have learned to fear them?

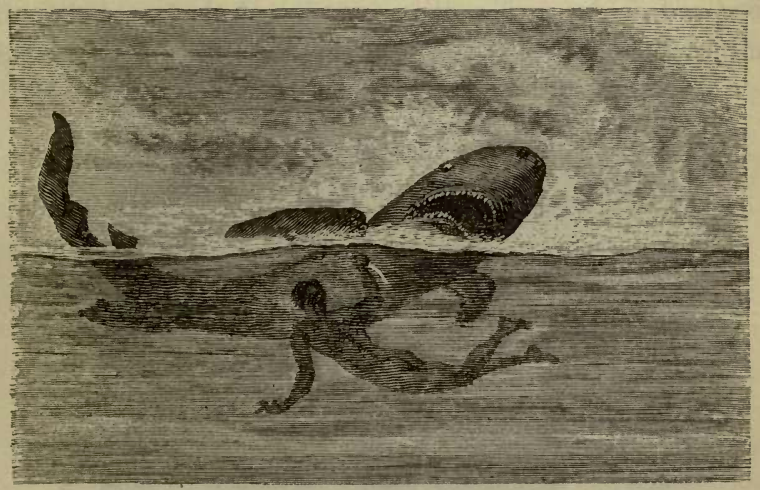

THE SHALK AND THE NEGRO.

Of the Gray or Six-gilled Shark, which sometimes attains a length of eleven feet, we have nothing particular to relate; nor need we linger long over the Black-mouthed Dog-fish, which is common enough in the Mediterranean, but rare in British waters. In allusion to the singular blackness of its jaws, the Italians expressively name it Boccc d'Inferno, or Hell's-mouth. The Neuse Hound is better known to English fishermen as the Cat-fish. Like the Rough Hound, it is a ground shark; so called because it seeks its prey near the bottom. It feeds on the crustacea chiefly, but may be caught by almost any tempting bait. The young are not hatched within the body, as is the case with the sharks proper; but are separately enclosed in curious leathery pouches, about three inches long, which 
may sometimes be found attached to a stalk of flexible coral or tuft of sea-weed.

A well-known genus of Squalidæ is the Thrasher, or, as it is occasionally called, the Fox-Shark or Sea-Fox ; a

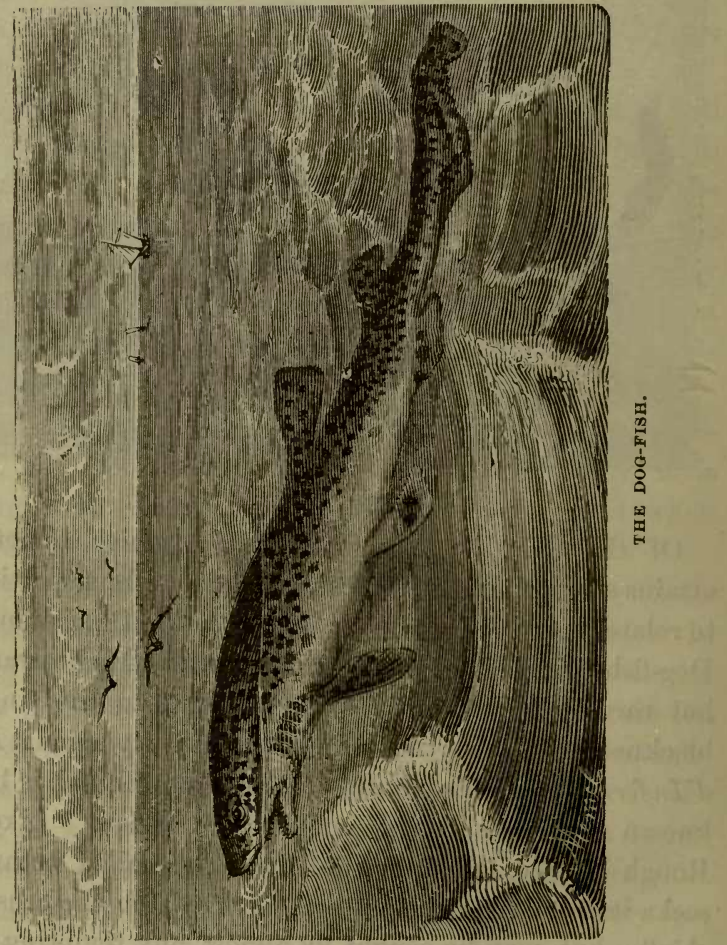

vulpine designation due to a supposed resemblance between its tail and that of a fox. It was well known to the ancients, who, building upon the vulpine analogy of structure, 
endowed it with a foxy character, and attributed to it a peculiar astuteness. Its more familiar appellation of the thrasher was given by modern sailors, and alludes to the manner in which it manifests its remarkable antipathy to the whale. It lashes the sea with a fury which has been known to put to hasty flight a bevy of gambolling dolphins;

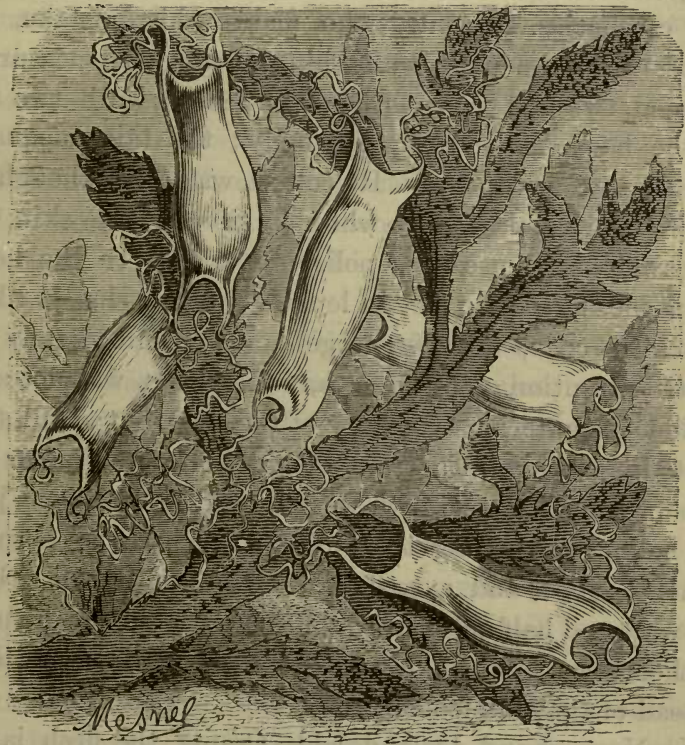

EGGS OF THE CAT-FISH

and instances are recorded where a sword-fish on the one hand, and a thrasher on the other, have persecuted a large whale even to the death, - though the terror of the ocean-mammal is difficult to explain. The thrasher possesses no weapon of offence except its teeth, and these 
could not harm the whale. Equally unintelligible is the cause of the thrasher's hereditary antipathy.

Of the Toper, it seems very needful to record that its flesh is freely eaten for food by the French and Italians.

Passing over the Picked Dog and Spurious Shark, we come to the Greenland Shark (Scymnus, or Squalus borealis), which was formerly confused with the more formidable carcharias. Crantz, who makes this mistake, describes a specimen which he himself saw, ${ }^{*}$ as measuring between two and three fathoms in length, with two fins on the back, and six on the belly; the tail unequally divided into two parts. Its colour was gray, though in the water it appeared as white as silver. The skin was very rough, and used for polishing wood. In the head, which measured two feet in length, and was shaped like a truncated cone, the two large nostrils immediately attracted attention. The mouth, a foot wide, was not situated at the anterior extremity of the head, but a full span on its under side, in a transverse direction. Five or six rows of small pointed teeth were ranged in the upper jaw ; the nether containing two rows of fifty-two large teeth, rather hooked, and extremely sharp; half of them bent one way, and half another, so that they resembled a doubletoothed saw, - and the Greenlanders formerly used them instead of that implement.

In Norway and Iceland, adds Crantz, the flesh is cut into rashers, and dried in the air ; but the Greenlanders do not much esteem it, and eat it only when it is dry and semi-putrid.

Dr. Scoresby furnishes a very interesting description of the animal. Its length he estimates at from twelve

* Crantz. "History of Greenland," i., pp. 93, 94. 
to fourteen, and its girth at from six to eight feet. Its colour is ashen gray; it has two spiracles, and five gillopenings. It is a formidable foe to the Greenland whale, pursuing it when alive, and preying upon it when dead. In the former case it bites fragments out of its flesh; in the latter, it feasts greedily upon the blubber, and so rapaciously enjoys its banquet that not even the presence of man, or a blow from a harpoon, will drive it away. In the absence of other food it has been known to attack man.

The Basking Shark,* the last but one of the tribe to which we shall direct the reader's attention, is popularly known as the Sun-fish, + and in the Orkney Islands as the "Hoe-mother."

It attains the length of thirty feet and upwards. Formerly, it was ranked among the whales; on account, perhaps, of its comparative amenity and peacefulness of disposition, and its love of basking in the sunshine on the surface of the waters. It makes its appearance in the Firth of Clyde, and along the western coast, about the end of April or beginning of May; generally in pairs, or in small shoals of seven or eight. Its tail is very large. The colour of the upper part of the body is a dull lead; of the belly, white; the skin on the back is granulated, like shagreen. In the interior of the mouth, towards the throat, is a substance resembling whalebone.

A regular fishery is carried on for taking the sun-fish, on account of the large quantity of oil (as much as nine to

\footnotetext{
* Now very generally classified as Selachias maximus.

+ The reader will remember that it is not to be confounded with the Orthagoriscus mola, which is also called the sun-fish.
} 
twelve barrels) obtained from its liver. The process is as follows :-**

If the end of April is hot, the sun-fish are certain to show above the water, and remain on the Clew bank till the end of May. They are found there in great numbers, and their large dorsal fin may be seen at a great distance, as it rises three or four feet out of the water, while they lie motionless on the surface basking in the sun. At this time they are easily approached, and struck with a harpoon; the boat employed for this purpose approaches the fish with a man in the bow ready to harpoon it; the line attached to the harpoon is two hundred fathoms long, and is coiled up in the bow ; a man stands by with a hatchet ready to cut it, should it become entangled in running out. When the fish feels the iron, he dives with a sudden rush, carrying out from seventy to a hundred and fifty or two hundred fathoms of line; and reaching the bottom, it rolls and rubs itself to get rid of the harpoon.

The fishermen allow it an hour to waste its strength in these fruitless efforts before they begin to haul in the harpoon line. They coil up the slack of it again, in preparation for another rush, and in this way play with the huge creature, sometimes for eight or nine hours, before they can bring it to the surface. When it at last rises, they strike it with two or three more harpoons; and on these being fixed, they are in a position to haul it alongside with the harpoon lines. Then they stretch the fish fore and aft along the vessel's side, and get a rope round its head, and a hawser round its tail ; after which they deal two deep cuts, one on each side of the tail, with

\footnotetext{
* Brabazon, cit. by Conch. "British Fishes," i. 62, 63.
} 
a hatchet. In its agony, and its efforts to free itself, it works its tail so hard, as to snap the bone across where the cuts were made; they then cut "flesh holes" in the body of the fish on both sides, large enough to receive a good-sized rope; and by reeving ropes through these holes, and hauling tight on the side of the fish next the vessel, they succeed in turning it over on its back. Next they split down the stomach, take out the liver, which is the only part they use for oil, and let the rest of the fish go adrift. There is no blubber between the skin and the flesh, as in the whale; but the oil extracted from the liver is as fine as the finest spermaceti. The liver is generally two tons in weight, and yields from six to eight barrels of oil.

These fish are of great power in the water, and if harpooned in the shoulder are very hard to kill, often running away with the whole of the harpoon line. Experienced harpooneers, therefore, are careful to strike them in the body near the dorsal fin, rather low down, where it will go through the intestines, or near the vertebræ towards the tail. They must be struck both with caution and dexterity, as they will stave in the boat with a single blow of their huge tail if it veers within their reach.

The fishermen on the coast cherish a superstition that the fish will leave the coast if the bodies of those captured are brought ashore.

This is the largest of the sharks, and of all true fishes; so that, partly from its immense size, and partly from its habits, it was anciently included among the Cetacea. Pennant, among the moderns, was the first to distinguish its true affinities. 
The last of this family which seems to require mention is the curious Zygaena, or Hammer-head, sometimes called the Balance-fish. The Greeks named it Zygaena, or the "balance," in allusion to the shape of its head. Oppian refers to it as, -

"The monstrous balance-fish of hideous shape,"

and gives it the palm over the lion for powers of destructiveness :-

"But what! the lion? sharper weapons arm
The balance-fish, and keener furies warm"

Alian also dilates very fancifully on the dangers to which mariners are exposed from it. Certainly, it is illlooking enough to justify this unpleasant reputation; but, in reality, the limited size of its mouth prevents it from committing such havoc as is committed by the white or blue shark.

In shape it may be compared to the letter $\mathrm{T}$, - the down-stroke representing the body, and the horizontal bar its singular transverse head; at the opposite ends of which two very prominent yellow eyes are situated, commanding from their position a very considerable field of vision. When the creature is irritated, these jaundiced eyeballs suddenly change to blood-red, and staring in their orbits, roll and glare in a very horrible manner.

Beneath the head, and near its point of junction with the body, lies the semicircular mouth, which is furnished on each jaw with three or four rows of large teeth, pointed and barbed on both sides.

The most common species in our seas is long and slender in the body, which is gray; the head is blackish. It usually attains the length of eleven or twelve feet, weighing occasionally nearly five hundred pounds. 
The hammer-head is a native of the Mediterranean and Indian seas, and very rarely makes its appearance in British waters. It is described as scarcely less voracious and formidable than the dreaded carcharias, and some authorities assert that it is equally partial to human flesh. On the other hand, it frequents the shores of the islands of the South Pacific, without exciting any terror

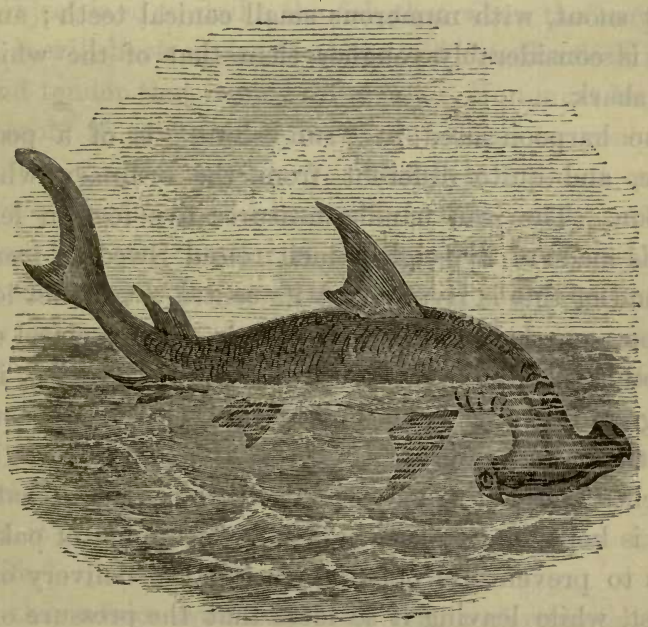

THE HAMMER-HEADED SHARK.

among their inhabitants, who bathe and swim in complete disregard of its supposed anthropophagic propensities. It may be that the Polynesians trust to their skill in swimming to elude its attacks; but, on the whole, we are inclined to think that, so far as man is concerned, it is the least formidable, as it is certainly the most hideous, of all the Squalidx. 
Many of our readers will be surprised to learn that sharks are frequent visitors on the west coast of Ireland, and that shark-fishing, or, as it is there called, "sunfishing," is sometimes adopted as an agreeable though exciting pursuit. The species of Squalidx found in western waters we have already described as the "basking-shark," which attains a great size, but does not generally exhibit a ferocious character. It has a short blunt snout, with numerous small conical teeth; and its skin is considerably rougher than that of the white or blue shark.

The harpoon used in "sun-fishing" is of a peculiar shape, and quite different from the ordinary whaler's weapon. The iron handle measures five feet in length, and is made of five-eighth inch round Swedish iron; to the end of this is rivetted, at its centre, a two-foot length of iron; one half is flat, and ends in a sharp chisel edge ; the other grooved, so that, in the striking position, it lies along and partly around the handle; the end curves slightly outward, presenting the appearance of a semidetached chip cut from a bar by the stroke of a hatchet. This is kept in its place by a soft "grummet of oakum," so as to prevent its opening during the delivery of the thrust, while leaving it so loose that the pressure of the skin, when the harpoon passes through, forces it over the shoulder, and leaves the harpoon blade free. Consequently, when the fish pulls and the backward pressure comes against the inside of the curved end, it opens about nine inches; a shoulder on the handle preventing it from expanding further.

Such is the description given by a writer who has had some experience of "sun-fishing;" rather a wild and ad- 
venturous experience, as the following condensed nurrative will show.*

The writer was chosen to act as harpooneer, and received from his friend, the owner and skipper of the yacht in which he was "hunting the shark," elaborate directions as to the proper mode of using it.

"Remember," he said, "the fish has but one bone, the backbone, which is about twelve inches thick. The great object is so to strike the fish that when the harpoon opens, it will hook under the bone; if not, the flesh is so soft and tender that it may draw out. You must be perfectly cool; if you cannot be so, be as cool as you can; remember, there is no hurry. The fish does not care a straw for the boat, which is not half his size. About two feet beneath the dorsal fin you will see a whitish streak along his side; strike him there, and downwards ; always remembering to keep the curved end upwards, that it may open round the bone. You must try to calculate this. When you strike, do it with a will; the instant you feel him plunge from you, seize the hatchet, and hold it poised over the rope that will then be flying out; if it kinks [that is, if it gets entangled], cut it for your life."

All this advice was excellent, but, unfortunately, in the moment of action it was not easily remembered. A fish was discovered, the boat got within forty yards of it; nearer and nearer; twenty yards, fifteen yards, ten! The amateur harpooneer was overcome with excitement. Grasping the handle firmly, he raised his harpoon on high; he saw, as through a mist, a huge brown mass before him, more like a rock than a fish. He forgot his 
friend's directions in the rush and whirl of his sensations, and would probably have missed the brute; but just as they closed up with him, his triangular black fin, which he generally carries above the water,* suddenly disappeared, and the boat swept over the spot where he had been. Down below, some eight or ten feet, the monster could be seen descending; such a monster! more than double the size of the boat. Quickly and dexterously the boat was brought round, and, lo and behold, the shark rose once more to the surface, at a distance of about one hundred yards. Onward dashed the hunters, and by this time the harpooneer had regained his composure, and was prepared to do his duty. Just as the boat arrived within three feet of the large fish, the iron went quivering into his flesh, and was soon buried over five feet, right up to the socket. With a tremendous plunge he disappeared. Whirr went the rope through the notch; and the harpooneer, seizing a hatchet, stood by, prepared to cut it if necessary. The notch soon began to smoke, but water was poured upon it from time to time. The fish was struck in about fifty fathoms of water, and went straight down to the bottom to roll himself for some time. As soon as the rope had ceased to pay out, skipper, harpooneer, and crew took off their caps and indulged in a triumphant shout; oars were laid in; two men were placed at the rope; rations were served out, and all was prepared for the struggle which would speedily begin, and would last, perhaps, some seven or eight hours.

In about twenty minutes they were moving to the north-west at the rate of five knots an hour. The rope was fast in the strong hands of a couple of men, who

* Hence he is sometimes called the sail-fish. 
watched the course taken by the shark, and indicated to the steersman the way in which he should steer. After a second hour four men grappled at the rope, and commenced to pull against the fish, taking in rope whenever they could. Three hours passed, and the contest grew earnest; every man in the boat, sitting one behind the other, held on the rope, and sought to weary out the wounded monster. As the boat sunk in the trough of the sea, the slack was hauled in, and carefully coiled by the last man. On its rising to the next wave, "Hold on all !" was the word, and the reluctant shark was lifted a few feet. The same process was repeated at every dip and rise until many fathoms had been taken in, when the fish suddenly went away with a rush, the rope whirling through the men's hands as though they were the hands of infants. The rush was not checked until upwards of a hundred fathoms had run out, then the laborious process of hauling in was recommenced.

A laborious process, indeed! For at times the mighty fish made a fresh start, and away went the rope through the bleeding hands of the weary fishers! Again it was gathered up, coil after coil ; and so the work went on, while further and further out to sea the good boat was carried, and the hours passed rapidly by, and darkness came down upon the waters. At length, a second harpoon was got ready. The weather was lowering, and the sea ran high. Evidently the fish must be killed at once, or the fishers would have to cut their gear and run to the nearest shore for shelter. So the rope was hauled in fathom by fathom, till but ten or twelve fathoms stretched between the pursuers and their quarry. Nearer and nearer came the fish; the harpooneer stood in (502) 
the bow with weapon poised, and when the huge fin once more showed on the surface, drove it in lustily, until the iron was completely buried.

Like a flash of lightning away sped the shark, apparently as fresh as at first. Like a flash of lightning sped the rope, and the men looked round upon one another with faces of dismay. Suddenly the speed slackened, and all closed in their grasp upon the rope. The fish had stopped! With hearts full of hope, the men applied themselves to their task. Again the harpoon handles emerged above the water, and four men got out their oars to keep the boat stern away while the death-struggle was being fought. When all was ready, they hauled up the prey until his back touched the stern; then they remorselessly plunged into him pike and sword, and hewed at him with hatchet, until the sea was purple with his blood; while in his agonies, and in his fruitless attempts at vengeance, he lashed the water into clouds of spray with his ponderous tail.

At last he died, and cheers of triumph signalled the success of the hunters. Truly, it was "royal sport." And the crew, while they grasped each other's hands, and the boat, anchored to the heaving monster now so powerless, rose gaily to the rolling waves, showed by their joyflushed faces "how glorious is the delight of those who feel that they have had men's work to do and have done it well."

The next task was to pull up to the yacht-for the adventure we have been describing took place with the yacht's boat-and as the sea was angry, no little danger was incurred. The men, however, with the skipper and harpooneer, got safely on board; and then began to dis- 
pose of their prey. It was a "tremendous job" to haul up the twenty feet of the head-part of the fish that hung downwards from the dorsal fin; but at length they managed to pass a chain cable over the head, and made the noose fast by passing it under the gills, of which there are five on each side. "With sail reduced to close-reefed mainsail and storm-jib," says the historian of the enterprise, "we struggled through the night. It blew more than half a gale; the sea ran literally higher than our mast, and sometimes threatened to poop us, as the enormous mass that we towed astern held us almost stationary. Although we were going dead before the wind, we did not make more than three knots an hour; and morning had already dawned ere, wearied beyond expression, we glided once more into harbour, with our prize in tow."

When the fish was towed ashore and measured, it proved to be no less than forty-two feet in length, and eighteen feet in girth.

On the whole, we think the authority to whom we owe the preceding particulars is justified in asserting that " the west coast of Ireland offers a glorious sport, as far superior to any other afforded by the British Isles as is fox-hunting to pigeon-slaughter;"--but then the sport is adapted only for strong nerves and resolute hearts! 


\title{
CHAPTER XVI.
}

\author{
THE TURTLE.
}

\footnotetext{
"Here the young turtle, crawling from his shell, Steals to the deep wherein his parents dwell ; Chipped by the beam, a nursling of the day, But hatched for ocean by the fostering ray."-Byros.
}

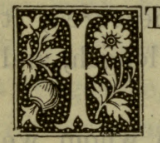

T was a great loss to the epicures of Rome that they knew nothing of the Turtle! How an Apicius, a Crassus, an Asinius Pollo, or a Sergius Orata would have revelled in all the luxuries of calipash and calipee! What oceans of turtlesoup would have flooded their banquets! The Shah of Persia rejoiced, it is said, that he had visited England, because the visit had made him acquainted with the merits of this famous dish. We may be sure that they would have been as fully appreciated by the Roman gourmands, and that they would have cultivated the turtle as assiduously as they cultivated the muræna, the mullet, and the oyster. It was not, however, until European enterprise had discovered and colonized the West Indies that the value of the turtle became known to our cooks.

The first glance at one of these reptiles-for the Cheloniadae belong to the class Reptilia, and not the class 
Pisces-would give the observer no more conception of its possible edible qualities than the first glance at an oyster; and we may suggest to our readers as a question for their grave consideration, Who first invented turtle-soup ? The marine tortoises, or turtles, are ungainly in the extreme, and apparently consist of little more than a small head, four flippers, and a strong oval shield of bone, coated externally by hard, horny plates, and known as a carapace. There is nothing in them to please the eye, agreeable as they may be to the taste! They have no legs, but fin-like paddles, which are useful for swimming but not for walking. The fore limbs are much longer than the hind limbs. The toes are not all furnished with nails; in some species, indeed, there is but one in each foot, though in others there are two. They are aquatic in their habits, only visiting the shore for the purpose of depositing their eggs, which they stow away in holes scraped in the warm moist sand with their hind feet. Their fecundity is considerable; for they lay several times in a year, and as many as one hundred and fifty to two hundred eggs at a time. Their too rapid increase, however, is prevented by the number of their enemies; for man is not singular in his partiality for turtles' eggs.

These eggs are hatched by the heat of the sun, and the young turtles, which never receive any parental attention, as soon as they struggle into life disembarrass themselves of their sandy covering, and make their way to the water. On land their gait, we may add, is singularly awkward and ungraceful ; but in their natural element they move with swiftness and comparative facility.

Their diet varies according to their species. Some feed upon crustaceans, molluses, and fishes, and the strength 
of their jaws enables them to crack the hardest shell with much ease ; others live wholly upon sea-weed and aquatic plants. The flesh of the carnivorous Chelonians is much less esteemed than that of the vegetarian species.

The turtle most valued for culinary purposes is the Green or Edible Turtle (Chelonia mydas) of the West

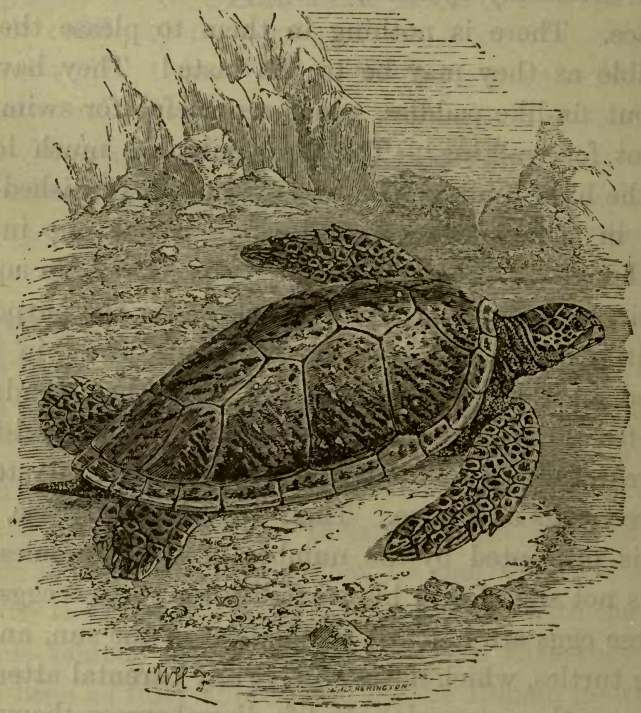

THE GREEN OR EDIBLE TURTLE.

Indies. It receives its distinguishing name from its fat, which is of a green colour. In Jamaica the markets are as freely supplied with turtle as ours are with butchermeat, and Scott, in his "Tom Cringle's Log," has several allusions to its abundance as well as its excellence. The 


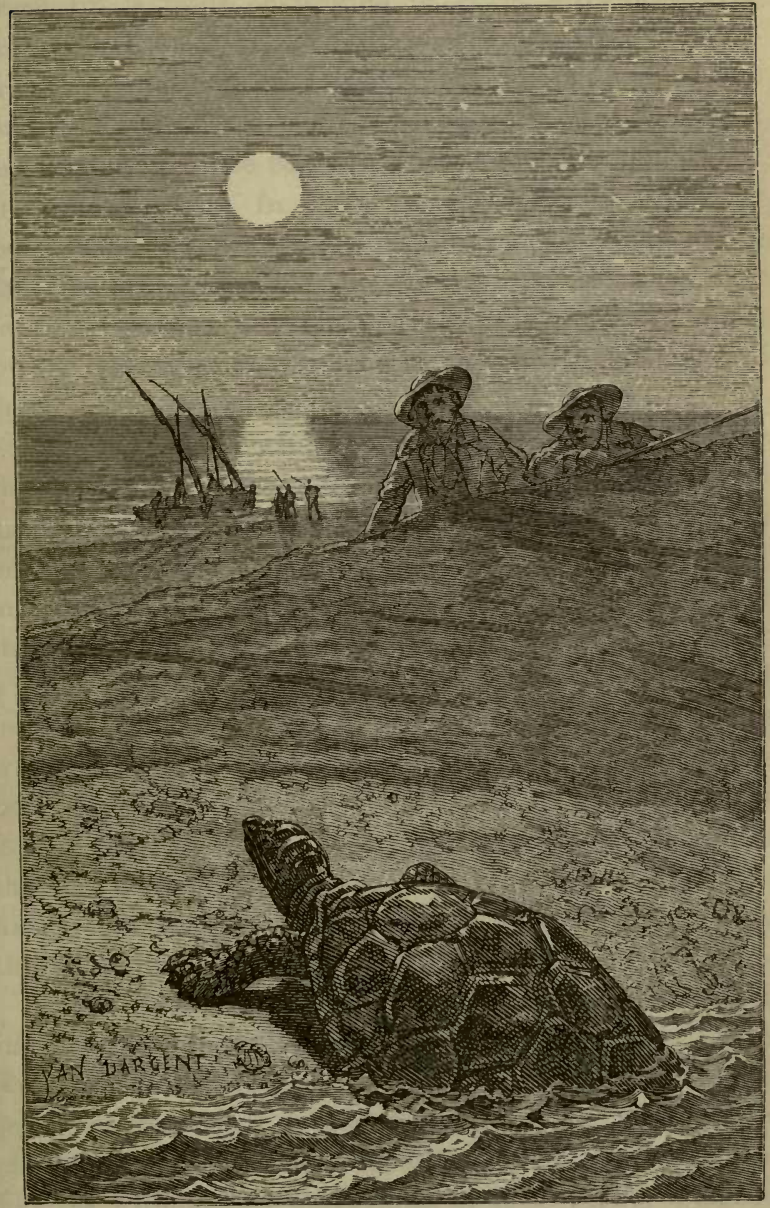

TURTLE-CATCHING IN THE WEST INDIES. 

green turtle feeds on a kind of grass, growing at the bottom of the sea, which is appropriately named "turtlegrass." According to Catesby, the inhabitants of the Bahamas are very expert in turtle-catching. In April, they set off in little boats to Cuba, and other neighbouring islands, where, in the evening, especially when the moon is up, they watch the reptiles on their journeys to and from the nests, and dexterously turn them on their backs, in which position they are utterly helpless. Some are so large that it requires three men to turn one of them.

But the mode in which they are generally taken in the Bahamas is by striking them with a small iron peg, two inches long, fixed in a socket, at the end of a staff twelve inches in length. Two men usually set out for this work in a little light boat or canoe; one to row and gently steer the boat, while the other stands at the end of it with his weapon. The turtles are sometimes discovered by their swimming with the head and back out of the water, but they are more frequently found lying at the bottom, a fathom or more deep. If a turtle perceives it is discovered, it starts up to effect its escape; the men in the boat pursuing it endeavour to keep sight of it, often losing the track, but recovering it again when the prey thrusts its nose out of the water to breathe.

Green turtles abound in the Gallapagos Islands, which, indeed, owe their name to this very abundance. They were noticed there by the sea-rover Dampier, who conjectured, from their extraordinary numbers, that five or six hundred men might subsist upon them for several months without any other kind of food. They weighed one hundred and fifty to two hundred pounds each, and 
their flesh was of great delicacy. Four species were found here: green turtle, loggerhead, trunk-turtle, and hawksbill.*

Mr. Darwin describes the method of catching them adopted in this part of the world. The water in the creeks and lagoons is so clear and shallow, that although at first a turtle quickly dives out of sight, yet, in a canoe or boat under sail, the pursuers, after no very long chase, come up to it. A man standing ready in the bows

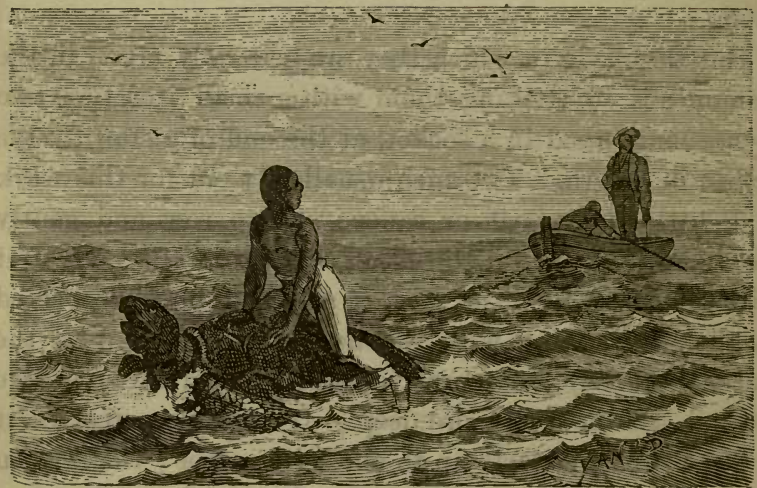

NUVEL MUUE UH CATCHING TURTLE.

at this moment dashes through the water upon the turtle's back; then, clinging with both hands by the shell of the neck, he is carried away till the animal becomes exhausted, and is secured. It is quite an interesting chase to see the little boats thus doubling about, and the men dashing into the water, endeavouring to secure their prey. $t$

* Dampier.

† Darwin, " Journal of a Naturalist," 
Some interesting details respecting turtles and turtlecatching at the Isle of Ascension are given by Sir J. E. Alexander, and though they have been frequently quoted, they are sufficiently fresh and important to justify us in reproducing them here. Two large basins are formed on the shore, to which the sea obtains entrance through a breakwater of large stones. Here they are kept until required for exportation; and between the ponds a wooden framework is erected on which they are slaughtered, "by suspending them by the hind flippers, and then cutting their throats,"-in more porcorum. As many as three hundred of these creatures, of four and five hundred pounds weight each, may be seen here at one time; "a sight to set an alderman mad with delight."

In the hot months of January, February, March, and April, the females land at night; and waddling over the sands in the various bays of the island far above highwater mark,- - for by a pole in the ponds it is shown that the tide rises only two feet,- they scrape up, by alternate scoops of their flippers, a hole deep enough to cover their bodies. Into this they get, "sighing heavily," and deposit from one hundred and fifty to two hundred eggs; cover them up; leave them to the sun to hatch; and then waddle again towards the sea. Two stout hands are, meanwhile, on the look-out, watching the movements of the unfortunate turtle; and running up to her after the completion of her task, one seizes a fore flipper, and dexterously shoves it under her belly, to serve as a purchase; while the other, avoiding a stroke which might lame him, cants the turtle over on her back, where she lies helpless. From fifteen to thirty were thus 
turned in a single night; but, of late years, the supply has been less abundant.

According to Sir James, no ships' crews are ever allowed to turn turtle, which has been converted into a Government monopoly; and two pounds ten shillings is the fixed price for each. Strange to say, from the time that the young turtles, the size of a dollar, are observed scuttling down to the water, they are never seen again until they are four or five hundred pounds weight; and how long they take to attain this great size, and where they spend the intermediate time, is as yet a mystery.

The turtles are kept in the ponds for a year and upwards without a morsel of food of any kind.

The edible turtle of the East Indies is the Chelonia virgata. It is found on all the coasts of Ceylon, and sells for a few shillings or a few pence, according to its size and the extent of the supply and demand. In the Gulf of Manaar some very large specimens, frequently measuring three or four feet in length, are met with. Sir Emerson Tennent records that on one occasion, as he rode along the sea-shore, he saw a man in charge of some sheep, resting under the shade of a turtle shell, which he had erected upon sticks to protect him from the sun!*-thus almost verifying the statement of Elian, that in the seas off Ceylon there are tortoises of such a size, that several persons might find ample shelter beneath a single shell!

The same authority notes that a very repulsive spectacle is exhibited in the markets of Jaffna by the mode in which the flesh of the turtle is sold piece-meal, whilst the animal is still alive, by the families of the

* Sir Emerson Tennent, "Natural History of Ceylon,” p. 293. 
Tamil fishermen. The creatures are to be seen in the market-place undergoing a most frightful mutilation; the plastron and its integuments having been previously removed, and the animal thrown on its back, so as to display all the motions of the heart, viscera, and lungs. A broad knife, from twelve to eighteen inches in length, is first inserted at the left side, and the women, who are generally the operators, introduce one hand to scoop out the blood, which oozes slowly.

Next the blade is passed round until the lower shell is detached and placed on one side, and the internal organs exposed in full action. A customer, as he applies, is served with whatever part he selects, which is cut off and sold by weight. Each of the fins is thus successively removed, with portions of the fat and flesh-the contortions of the animal bearing witness to the agony it suffers. And in this state it is allowed to lie for hours, writhing in the sun, the heart and head being usually the last pieces chosen; and, till the head is cut off, it would seem from the snapping of the mouth, and the opening and closing of the eyes, that life is still present, though the shell has been nearly divested of its contents.

The tortoise-shell of commerce, which forms the staple of so considerable an industry, is obtained from the Hawksbill or Imbricated Turtle (Chelonia imbricata), a native of the Asiatic and American seas, and occasionally found in the Mediterranean. It derives one of its characteristic names from the manner in which its scales overlap each other at their extremities, like tiles on the roof of a building; and the other from the narrowness and curvature of its beak, resembling the bill of a hawk. Its shell 
is not unlike a heart in shape; each of the middle row of scales on the back has an acute form at the tip, and a ridge or carina down the middle. Its fore limbs are longer than in the rest of the tribe, and it is said that

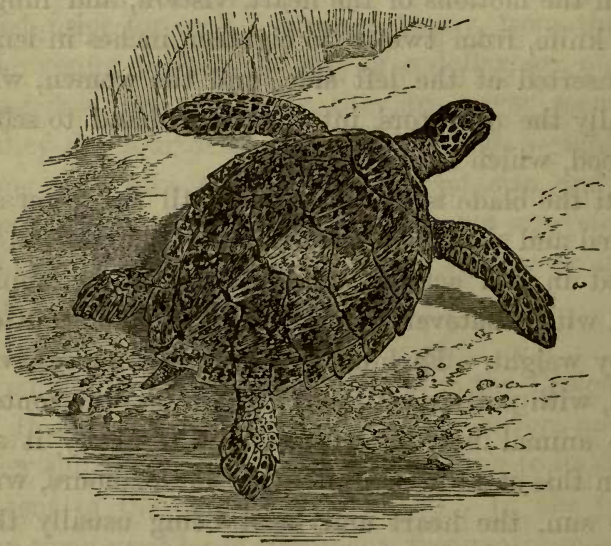

THE HAWKSBILL TURTLE.

the animal, when turned or laid on its back, is able, through their assistance, to recover its former position, which no other of the Cheloniadæ can do. Its general length is about three feet, though in Indian waters specimens have been found measuring fully twice that size.

Tortoise-shell is afforded by the lamellæ, or plates, of its shell. There are thirteen dorsal, while the marginal row consists of twenty-five smaller pieces. They are transparent, and richly variegated with whitish, yellowish, reddish, and dark brown shades and wavy cloud-like streaks.

This species, says Sir Emerson Tennent, was formerly taken in great numbers in the neighbourhood of Ham- 
bungtotte during the season when they came to deposit their eggs. Hence arose the trade in tortoise-shell at Point de Galle, where the Moors still manufacture it into articles of ornament; but the shell they employ is almost entirely imported from the Maldives.

If the shell is taken from the animal after the latter's death and decomposition, its colour becomes clouded and milky. Hence the natives adopt the barbarous expedient of seizing the turtles when they come ashore to lay their eggs, and suspending them over fires until heat frees the plates on the dorsal shield from the bone of the carapace, after which the cerature is permitted to escape to the water. In illustration of the irresistible force of instinct at the period of breeding, Sir Emerson Tennent mentions that the identical tortoise is believed to return repeatedly to the same spot, though at each visit she is subjected to a renewal of this torture. In 1826, Mr. Bennett records, that a hawksbill was captured near Hambungtotte, with a ring attached to one of its fins which had been placed there by a Dutch officer thirty years before, in order to establish the fact of these periodical visits to the same beach.

We are told that at Celebes, which exports the finest tortoise-shell to China, the natives kill the turtle by blows on the head, and immerse the shell in boiling water to detach the plates. It is the unskilful only who resort to dry heat; a process which frequently destroys, or injures the shell.

An authority already quoted records a curious and interesting illustration of instinct in the turtle, when about to deposit her eggs. As if conscious that to go and return by the same line across the sandy beach would en- 
able her enemies to trace out her nest, she adopts the expedient of curving her course, so as to regain the sea by a different track. Then, after depositing the eggs, and burying them about eighteen inches deep, she carefully smooths over the surface to render the precise spot indiscernible. But the Singhalese neutralize her device by sounding her line of march with a rod until they come upon the hidden treasure.

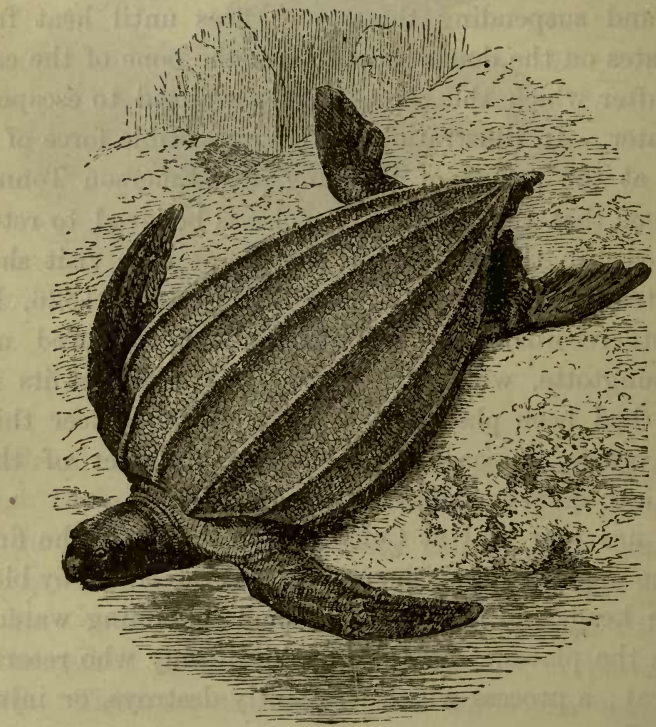

THE CORIACEUUS TUR'LE.

The peculiarity of the Coriaceous Turtle (Sphargis coriacea) is its outer coat or covering, which consists of a substance resembling stout coarse leather, obscurely 
marked by a number of pentagonal and sub-hexagonal lineations, like a geometric pattern. Further: along the entire length of this leathery shield are carried five prominent tuberculated ridges, in addition to those which border the sides. The colour is a dusky brown, but the under part of the animal is of a paler hue. This species belongs to the Mediterranean, but is found occasionally on the coasts of Africa and South America.

The largest as well as the most voracious of the thalassites, or sea-turtles, is the Loggerhead (Caouana olivacea), but it can hardly be said to possess any commercial value. It is distinguished by having fifteen, instead of thirteen, dorsal plates.

The quantity of tortoise-shell imported into Great Britain annually is about sixteen tons, of the value of about $£ 25,000$.

Turtles are very plentiful among the Polynesian archipelago, and the inhabitants make fish-hooks of their shell. At the Samoas are found two species, the hawksbill and the green. Of the shell of the former the natives manufacture finger-rings, as well as fish-hooks, and neck and ear ornaments; it also forms an article of export. The turtle was formerly considered by the Raratongans and Tahitians as most sacred. A part of every one caught was solemnly offered to the gods, and the remainder, being cooked with "sacred fire," was set aside as a special repast for the king and his principal chiefs. Prior to the introduction of Christianity into these islands, it is supposed that no woman ever tasted this aldermanic luxury.*

* Williams, “Narrative of Missionary Enterprises," pp. 501, 502. 


\section{CHAPTER XVII.}

THE WHALE : AND THE WHALE-FISHERY.

"Where the whale tumbles in the foamy deeps."

I.-NATURAL HISTORY OF THE WHALE.

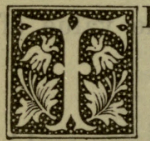

HE WHALE is the leviathan of the animal world ; the Anak, or, poetically speaking, the Titan of the seas. Among the monsters of the deep he reigns supreme in size and strength ; and were he not gifted with a gentle, and even a timorous disposition, he might commit unchecked the most formidable ravages. Formerly, he was included among the fishes; and before zoology was developed as a science, it was not unnatural that men should adopt such a classification for a creature shaped like a fish, and dwelling in the ocean-waters. But his organization and habits are now better understood; and as he is a warmblooded animal, with a twofold circulation of the blood,that is, to and from the heart, - as he breathes the atmospheric air, as the female is viviparous and suckles her young, the whale is rightly placed among the mammals. The anatomist can show you that he has a respiratory 
system, like that of the horse or lion; that like other mammals, he has a pulmonic circulation. Yet in common parlance it is still customary to speak of the whale as a fish, and of the whale-fishery. No doubt the general outline of his body, as we have said, is " fish-like ;" but consider the modified character of his limbs, his horizontal flattened caudal fin or tail, the tough leathery skin or hide, the solid and expansive bones of the face, the peculiar structure of the skull, the development of the vertebral column, and the formation of the ribs, and you will see that he is truly and actually a mammal, a mammal adapted to an ocean-life.

Adapted to an ocean-life? yes, and adapted in a most ingenious and interesting manner. A close examination of details, however, would carry us into the domains of comparative anatomy, and we must content ourselves here with indicating only a few of the more important.

In the first place, then, let us direct the reader's attention to the ocean-giant's "extremities." At a cursory glance, he will see little or no resemblance between the human arm and the "flipper" or "swimming paddle;" but if he saw the osseous structure, the skeleton, the points of coincidence would immediately become apparent. We may say of them that they are like, and yet unlike; the same organ, but modified to a different end.

Next, we have to remember that the whale is an aquatic, or rather pelagic mammal, seeking the "unfathomable depths" of ocean, and consequently required to endure an extraordinary pressure. How has it been fitted for this purpose?

Partly by its shape, which is that of a cylinder ; partly by the arrangement and solidity of its bones, and partly 
by the nature of its integuments. These are threefold :-

1. The epidermis, scarf-skin, or outermost skin, which is remarkable for its smoothness, and is covered also with a mucous oily fluid exuding from the whole substance, and completely protecting it from injury by the water.

2. The intermediate skin, or rete mucosum, to which is due the variety of colouring in the various races of man; it answers the same purpose in the whale tribe.

3. The true skin, or blubber of the animal, which contains its fluid oil, and consists of a mass of fibres crossing and intercrossing each other in every direction.

An eminent naturalist observes that it is interesting to see how, in the works of nature, an apparently trivial alteration often effects the most wonderful change. It is so with respect to this true skin. A layer of fat or blubber, even had it been double in thickness to that usually found in the Cetacea, would not have resisted the pressure of the superincumbent ocean-waters; but the requisite density and power of resistance have been obtained by the modification of the skin into a firm and elastic substance, like caoutchouc, not less than eight and sometimes fifteen inches in thickness.

This firm elastic wrapper, or "blanket," as it has been called, is an indifferent conductor of caloric (or heat). It retains the animal warmth, while it excludes the atmospheric cold. Hence it is in this respect admirably adapted as a protection for a warm-blooded animal exposed to the severest cold in the deepest recesses of icy seas.

The bulk and quantity of this integument is enormous. Sometimes it weighs as much as thirty hundredweight, so that you would naturally suppose it sufficient to overwhelm 
the animal ; but as its specific gravity is actually less than that of the ocean-waters, instead of being a burden and an incumbrance, it is a help,-it buoys up the whale's colossal bulk, renders it relatively lighter, and largely increases its activity.

We proceed to some other characteristics of the whale.

Its flesh is described as more nearly resembling that of beasts than of fish ; it is firm, solid, somewhat coarse, and in flavour not unlike indifferent beef. The osseous structure also reminds the anatomist of a terrestrial quadruped. The milk of the female is very rich; like cow's milk to which cream has been added.

A remarkable circumstance connected with the vital economy of the whales, is the long period during which they can suspend the respiratory function. In the mammals generally the inhalations succeed each other with great rapidity, and the interval between each is never more than a few moments. Man, even when at rest, breathes every three seconds; but the Cetacea can suspend their inhalations, or, in more popular language, "hold their breath," for an hour or even two hours, and thus are enabled to remain under water for a considerable period without inconvenience.

All fishes separate the air from the water by means of their gills; but the whale, having the respiratory apparatus of the mammal, must draw his supply of air from the atmosphere, and hence must frequently come to the surface to breathe. He has, however, no nostrils properly so called, and seldom opens his mouth in free air. How, then, does he manage to breathe? By tubes opening nearly on the crown of the head, called spiracles or blow- 
holes.* In man and other mammals the mouth and nostrils are connected inwardly with a pouch or bag, known as the pharynx, in which both the windpipe and gullet originate; the former, and anterior, opening from it through an aperture called the glottis; this is covered by a valve, the epiglottis, which usually stands erect, but on the passage of any article turns down like a lid, and gives free ingress to our food.

In the Cetacea the air-currents pass out of or into the lungs through the spiracles; but as the mouth is at the same time usually filled with water, it is obvious that some contrivance is necessary to prevent the water from rushing, along with the air in the air-tubes, into the lungs, and producing suffocation. Here we meet with another example of the ingenious adaptation of a mammal to an aquatic life. The epiglottis, or valve, is no longer a simple valve, generally kept open ; but in some species of the Cetacea it is the anterior rim of the rima, or slit, and in others it encloses the base of the pharynx, and assists in forming a projecting tube or air-duct. The lower extremity of this air-duct is provided with a circular aperture, surrounded by a strong muscle, which unites both the windpipe and the air-duct. These intersect the fauces, or "swallow," dividing it into two passages, one for air, and the other for water.

A naturalist observes, that the whole of this singular mechanism is peculiar to the Cetacea. The other mammals, when feeding, are in a medium which, through their respiratory organs, becomes the great vital agent; but the Cetacea obtain their nutriment always under

\footnotetext{
* There are two of these apertures in the. whale, or Balanida family; but one only in the other Cetacea.
} 
water, which, if it found its way to their lungs, would prove as injurious to them as to man. Yet, by a slight alteration in the cartilages at the top of the windpipe, and in the direction of the air-tube, their feeding in the deep ocean is made as safe for them as that of other mammals in the balmy breeze.

The tail, or caudal fin, is the most important appendage, and the chief motive agent of this mightiest of all animals that swim the ocean-stream. In most fishes the tail rises vertically, but, as we have said, in the whale it is flat and horizontal; not more than four or five feet in length, but fully twenty feet in breadth. It consists of two beds or layers of muscles, connected with an extensive layer which surrounds the body, and enclosed by a thin coat of blubber. Of its enormous force many examples might be adduced. With a single stroke it can hurl a large boat, fully manned, into the air. Small boats are but as straws before it. Here is an experience recorded by Captain Markham. With three companions, he was in pursuit of a whale. They pulled close alongside the monster, which received three harpoons in its body. The wounds maddened it, and one of the hunters loaded his gun and fired. Captain Markham swept his boat round as speedily as possible, but failed to get clear of the brute's tail, which it had thrown up out of the water on receiving the coritents of the gun; descending with terrific violence, it caught the gunwale of the boat, and knocked the captain over the stern. "Before coming to the surface," he says, "I imagined the dingy had been smashed to pieces, which would have been rather a bad case for us, as the other boats were some way off, and 
also fast to the fish; and no loose boat being near us, and the temperature of the water only a few degrees above freezing-point, I don't think that I for one would have kept up long, accoutred as I was in a heavy monkeyjacket and sea-boots. However, on rising to the surface I had the satisfaction of seeing the dingy a couple of boat-lengths off, and the doctor (who had taken to the water, imagining that the tail was coming right down upon us) and myself were soon hauled in, none the worse for our ducking. If the boat had been one foot nearer the fish it would most assuredly have been dashed to pieces, and we should all have been killed before having time to jump overboard."

It is said of the whale that he sometimes places his huge body in a perpendicular position, with his head downwards; then, rearing his tail aloft, he beats the water with inconceivable violence. On such occasions the sea is white with foam; vapours seem to darken the air ; and at a distance of several miles the sound of its repeated blows is like the roar of a far-off tempest. At other times he makes an immense bound, raising his whole body above the surface,-a spectacle which may excite the admiration of the veteran whaler, but to the inexperienced is certainly a source of terror.

The whale possesses the power of giving utterance to strange wild cries, likened by some authorities to the bellowing of bulls. But he has no voice; and there can be little doubt but that these sounds are produced by the blowing apparatus. The spiracles are often described, as vaguely as incorrectly, as if they were fountains throwing up water to the height of forty or fifty feet; but Dr. 
Scoresby has shown that they emit vapour only, except when the vehement breathing or blowing takes place beneath the surface, and in that case a considerable quantity of water is hurled into the air. As often, says Mr. Wilson, as the whale opens his enormous jaws, his mouth of course immediately fills with water; but only the fish,

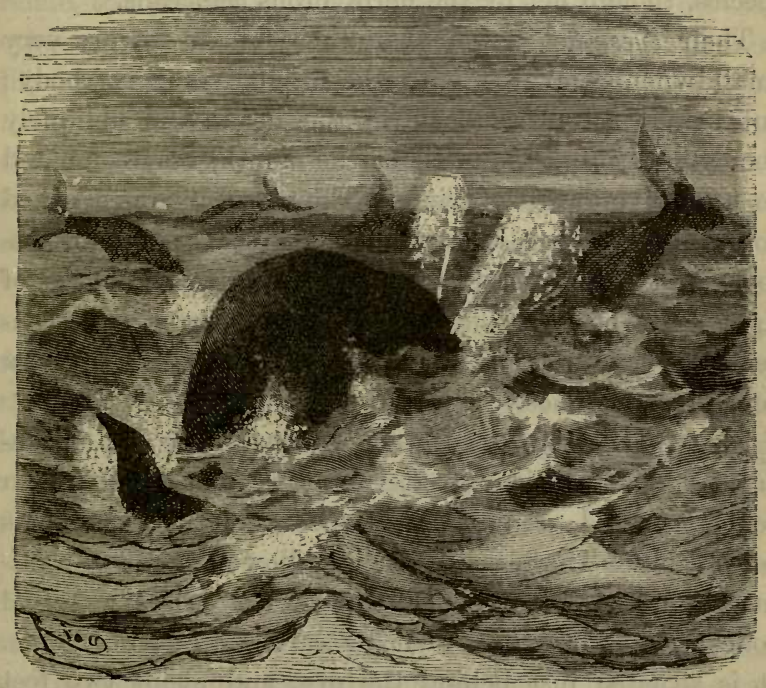

WHALES SPORTING.

fuci, or small marine animals which chiefly compose the cetacean's food, are actually swallowed. "The water itself is partly regurgitated and partly made to pass upwards, and, by a peculiar and very admirable mechanism, is thrown out by the blow-holes. When the animal breathes on the surface, a moist vapour, mixed with mucus, is exhaled; but no water is thrown up unless 
the expiration is made beneath the waves, or the creature itself is either in a sportive mood or under the influence of rage and terror."

-With respect to the senses of the whale, it may be said that that of smell seems to be enjoyed by most of the species, though not by the herbivorous cetaceans.

Their eyes, not larger than those of an ox, are very small when compared with the animal's bulk of body; but being placed far back in the head, and obliquely above and behind the angle of the mouth, they command an extensive range of view. The visual axis is directed obliquely downwards, so as to assist the animal in discovering the food floating beneath him ; and the power of sight must be acute, inasmuch as he recognizes his congeners, when under the surface and in clear water, at a very great distance.

The whale's organ of hearing is marked by some peculiarities. There is no external ear; but on the skin being removed, a diminutive opening into the skull is perceptible. The internal ear is hollowed out of a particular bone which forms no part of the ordinary cranial bones, but is attached to it by cartilaginous ligaments. It is situated just behind the eye, and about two feet deep, and is not large enough to admit of the introduction of a man's little finger. What is known as the "Eustachian tube" opens high up into those air-ducts which, as we have explained, answer to the nose. Through this channel it is that the animal must have the sounds transmitted on the waves of air, and with this channel must be connected the cavities in which, according to some authorities, the olfactory nerves are situated. 
With some slight exaggeration, it may be said that the whale hears by the nose and smells by the ear.

\section{II.-CHARACTER OF THE WHALE.}

As in all other tribes, so among the whales, the different genera differ greatly in their habits and disposition. Some, too, possess a higher intellectual organization than others, excel in courage, powers of endurance, or amiability of character. But to all the species one faculty seems to be common, and that is their mutual affection, whether as regards the mother and her young, the cub and its parent, or the several members of the same family or shoal. The female watches over her nurslings, or "suckers," as they are called, with vigilant affection; and the whalers, therefore, frequently strike them, not for their own value, but in order to bring the mothers to their defence. Captain Markham was told that a whale, having a young one in company, will, when struck, invariably kill it if she gets a chance. And he relates the following adventure :-

He was out in a boat, acting as steerer, when he saw " a heavy blast" some distance ahead, accompanied by a small one, signs which his harpooneer interpreted to mean a "monstrous big fish with its sucker." With another boat in company, away they went in chase. Judging, from the course she took, where she would rise for breathing purposes, they lay on their oars, and waited for her. The plan proved successful, for the whale rose close to " Harky Hunter," who, pulling quietly up, delivered his harpoon; all yeliing at the top of their voices, "A fall, a fall !" But though so easily struck, she was not so easily killed, but proved a difficult and troublesome cus- 
tomer. After about three-quarters of an hour's hard pulling, chasing her first in one direction and then in another, until the men were so weary as nearly to drop at their oars, they succeeded in closing up, and giving her another harpoon; immediately on receipt of which she flew off at a terrific rate, towing the two boats fully six knots an hour, and drawing out the line with such velocity that the bows of the boat were enveloped in the smoke caused by the friction.

"We had a very near shave," says Captain Markham, "one time, of being taken down altogether. The fish having stopped to blow for a few minutes, the line, which from the extreme friction had burned a deep scar round the bollard (or block on which it runs), cooled, and adhered to the wood. The fish suddenly took it into her head to go straight down; the line would not render, the bows of the boat were dragged under water, and the water came rushing in over the harpooneer. This saved us; for the water, lubricating the line, allowed it to render, and the boat righted, though not before a large quantity of water had been shipped. We should, indeed, have been placed in a most dangerous and unpleasant predicament; for, had the line not rendered, nothing could have saved the boat from being taken down, and our chance of escape would have been very small."

About five o'clock other boats came to their assistance, when five more harpoons were buried in the monster's flesh, and several lances plunged in, but all apparently to no avail, - she would not die. Three rockets were also fired into her huge bulk. Eventually the ship came up, and took the lines from one of the boats on board; yet, mirabile dictu! the fish actually towed the 
ship and seven boats at the rate of three miles an hour, "incarnadining" the water with her blood. However, her struggles gradually grew less furious : loss of blood, and the immense efforts she had made to escape, necessarily caused great exhaustion; and at nine o'clock a boat was able to overtake her, and, firing a rocket, succeeded in dealing the death-blow with a lance, whereupon she expired, amidst the cheers of all hands.

The little "sucker," adds Captain Markham, that had accompanied the "big fish," was seen for about half an hour, coming up to blow every time its mother rose for the same purpose, and then suddenly disappearing after the mother had given some unusually violent convulsion with her tail and fins. Here was another illustration of the fact that a whale, having a young one in her company, will, when struck, invariably kill it if she has the opportunity.

Whether this be a proof of affection, some of our readers may be inclined to doubt. But of the general "philoprogenitiveness" of the whale the evidence is abundant, and it is admitted by all our travellers and naturalists. There are well-authenticated instances on record, though we may not be able to accept in its entirety the incident described by Waller in his "Battle of the Summer Islands." In a well-known passage of this poem he represents two whales, a mother and her young one, as adrift in the shallow waters of the coast :-

\footnotetext{
"Two mighty whales! which swelling seas had tost, And left them prisoners on the rocky coast: One as a mountain vast, and with her came A cub, not much inferior to his dam.

Here in a pool, among the rocks engaged, They roared, like lions caught in toils, and raged."
} 
The islanders, discovering the stranded monsters, hasten to make prize of them :-

"They man their boats, and all their young men arm With whatsoever may the monsters harm; Pikes, halberts, spits, and darts that wound so far, The tools of peace and instruments of war.....

The boat which on the first assault did go Strook with a harping-iron the younger foe; Who, when he felt his side so rudely gored, Loud as the sea that nourished him he roared. The bigger whale like some huge carrack lay, Which wanteth sea-room with her foes to play: slowly she swims, and when provoked she would Advance her tail, her head salutes the mud: The shallow water doth her force infringe, And renders vain her tail's impetuous swinge: The shining steel her tender sides receive, And there, like bees, they all their weapons leave.

This sees the cub, and does himself oppose Betwixt his cumbered mother and her foes: With desp'rate courage he receives her wounds, And men and boats his active tail confounds; Their forces joined, the seas with billows fill, And make a tempest though the winds be still."

The "sucker" now returns to the channel through which she and his mother entered the ocean-pool; but the tide having ebbed, the latter is unable to effect her escape :-

"She by the rocks compelled to stay behind, Is by the vastness of her bulk confined,They shout for joy! and now on her alone Their fury falls, and all their darts are thrown; Their fixëd javelins in her sides she wears, And on her back a grove of pikes appears. Roaring, she tears the air with such a noise As well resembled the conspiring voice Of routed armies when the field is won, To reach the ears of her escaping son."

And now, if we may believe the poet, takes place a miracle of filial devotion !-

"He, though a league removëd from the foc, Hastes to her aid:The men, amazëd, blush to see the seed of monsters human piety exceed. 
Well proves this kindness what the Grecian sung, That Love's bright mother* from the ocean sprung. Their courage droops, and hopeless now, they wish For composition with the unconquered fish;

So she their weapons would restore again,

Through rocks they'd hew her passage to the main."

The fishers attacked them with volleys of musketry, but to no successful purpose ; and they were on the point of sending to the fort for artillery, when the whales were delivered by the flowing tide, which carried them out into the deep waters. Thus the combatants

\section{"Parted with exchange of harms ;}

Much blood the monsters lost, and they their arms." +

Of the conjugal affection of the whale, the following example is related. Two which were swimming in company, and proved to be male and female, were attacked by a whaler. On her companion being wounded, the other exhibited the greatest uneasiness; swam gallantly up to the whaling boat, and with one stroke of her gigantic caudal fin killed three men, and hurled them into the sea. To the last the two kept in close neighbourhood; and when the male was killed, the female gave utterance to her grief in terrible cries.

The mother-whale's affection for her young is frequently turned to good account by the hunters. They strike the "sucker" as a means of bringing the mother to its assistance; and she seldom fails to come up beside it, encourage it to swim off, and take it under her protecting fin,seldom deserting it so long as life remains. It is then, says Scoresby, very dangerous to approach her. She loses all thought for her own safety in anxiety for the

* Venus Aphrodite.

† Edmund Waller, "Battle of the Summer Islands," cantos ii. and iii. 
preservation of her cub ; dashing furiously to and fro, and not fearing to rise in the very midst of the attacking boats. Except, however, when the mother is called upon to defend her young, the male is generally more active and dangerous than the female.

\section{III.-DIFFERENT SPECIES OF CETACEA.}

The great family of the Cetacea is divided into two tribes: the Ordinary and the Herbivorous Cetacea. The former, including the whales, is, as we have seen, wholly aquatic in its habits, and lives in the open sea ; the latter, including the dugong and manatee, is found only in the estuaries of great rivers, or the shallow waters of the shore, and feeds upon the vegetable growth of these localities.

It is to the former, which is the more numerous and varied tribe, that we shall limit our attention.

The principal species is the Greenland or Right Whale, an inhabitant of the polar waters, and the staple of an important commerce. He is sought in preference to any other species, because he yields the most oil; and, from the comparative slowness of his movements and timidity of his nature, is captured with the greatest ease.

In some of the old books we meet with the most wonderful stories of this species; but Dr. Scoresby has proved that the Greenland whale seldom exceeds sixty feet in length, and never seventy. His greatest girth is just behind the swimming fins, and near the middle of the body, whence it gradually tapers in a conical form towards the tail, and still more gradually towards the head, which is of extraordinary bulk, forming nearly one-third of the 


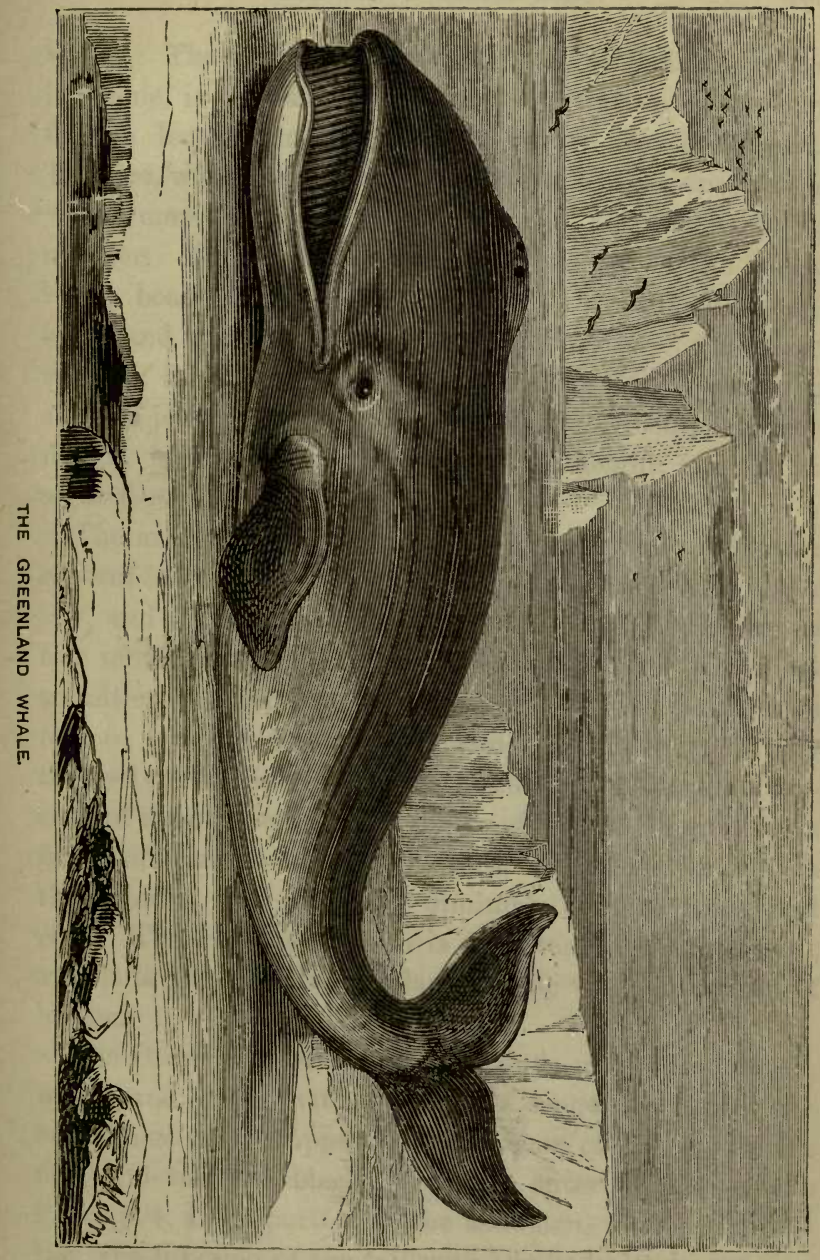



whole. The under part of the head, as defined by the jaw-bone, is flat, and measures from sixteen to twenty feet in length, and from ten to twelve feet in breadth. The lips, which are of proportionate thickness, enclose the "cavernous recesses" of the mouth in a remarkable manner. The upper jaw curves inwardly at the edges, like a boat turned upside down, so as to shut in the anterior and upper parts of this "fearful cavity ;" fearful, in truth, if it be capable, as some writers assert, of receiving a ship's jolly-boat, fully manned-being fifteen or sixteen feet in length, ten or twelve feet in height, and six or eight feet in width.

The mouth has no teeth, but is lined by two extensive rows of baleen, or " whale-bone," suspended from the upper jaw, and curved longitudinally, so as to give the roof of the mouth an arched form. Between their lower extremities they enclose the tongue, which is fixed from root to tip, and incapable of being protruded; and they themselves are covered by the nether lip. Each row consists of about two hundred plates of baleen, resembling a frame of saws in a saw-mill; these plates are longest in the middle, and gradually diminish both in front and rear. Their average length is from ten to fourteen feet; and it is estimated that a large whale will yield a ton of baleen.

The Greenland whale, like Milton's monks, is "black, white, and gray," with, however, a tinge of yellow : the back, most of the upper jaw, and part of the lower, the fins, and tail, are black; the lips, anterior part of the lower jaw, and a portion of the abdomen, white ; the eyelids, the junction of the tail with the body, and a portion of the "axilla" of the fins, are gray. The older the 
animal, the more white and gray are present in his colouring ; and some individuals are completely piebald.

The most valuable part of the animal is the "blubber," which lies in a kind of wrapper all round his monstrous body, from eight to fifteen inches in thickness. In some old whales it is said to resemble the substance of salmon, but in the younger it is yellowish white. The lower jaw, except the two bones, consists almost wholly of blubber. The oil is retained in minute cellules. Four tons of blubber yield three tons of oil.

Notwithstanding the great size of the Greenland whale, and his apparently unwieldy form, his motions are not deficient in rapidity. If disturbed when lying prone on the surface of the sea, like Milton's Satan, "supine upon the flood," he will sink, in five or six seconds, beyond the reach of his human antagonists. Dr. Scoresby has observed a whale descending, after he had harpooned him, to the depth of four hundred yards, at the rate of seven or eight miles an hour. The usual velocity of these animals, however, when on their passage from one situation to another, seldom exceeds four miles an hour; but they are capable, for the space of a few minutes, of darting through the water with the swiftness of a frigate under full sail, and of rising with such rapidity as to spring sheer out of the water.

The Greenland whale usually remains at the surface for about two minutes to inhale a fresh supply of air ; and during this interval he "blows" eight or nine times. He remains underneath for five, ten, or even twenty minutes, frequently sinking to the depth of about a mile. In "blowing" the whale makes a noise which may be compared to the roar of artillery. The vapour discharged 
A "MILD-MANNERED MONSTER."

rises to the height of several yards, and at a distance resembles a puff of white smoke. He blows strongest, densest, and loudest when in a panic of terror, or when appearing on the surface after being a long time below.

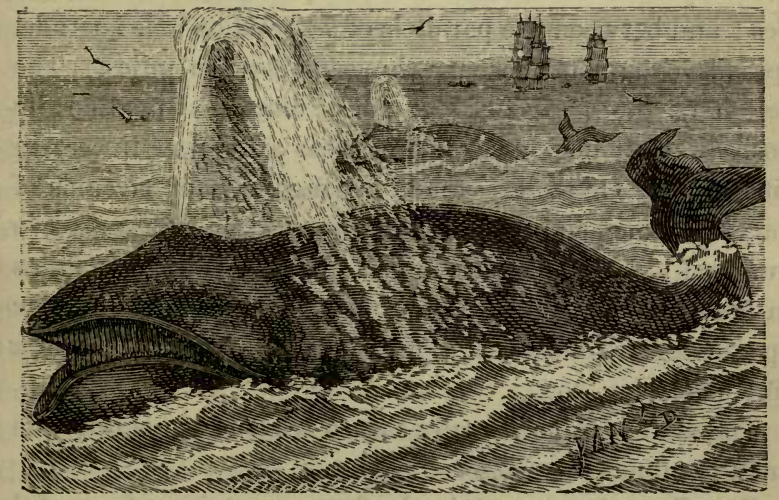

GREENLAND WHALES BLOWING.

When we reflect on the immense size and colossal strength of the whale, we are tempted to think that no marine animal can possibly escape his voracious jaws, and that he must be as truly the scourge of the seas as is the tiger of the jungle. But, apart from the fact that he is of a gentle and even pacific disposition, he has no teeth, and is wholly unable, therefore, to live by carnage. $\mathrm{He}$ can neither prey on his own kind, nor on the larger fishes. Even if he could capture and masticate, he could not swallow them; for his throat is so small that he is unable to dispose of a morsel which an ox could swallow easily. It has been forcibly remarked that his well-provided pasture-grounds exhibit, to the contemplation of the curious, 
a characteristically wonderful manifestation of Divine beneficence and wisdom. A considerable area of the regions inhabited by the Greenland whale is occupied by what seamen call "green water." According to Dr. Scoresby it forms almost a fourth part of the Greenland Sea; and between the parallels of $74^{\circ}$ and $80^{\circ} \mathrm{N}$. latitude, spreads over some twenty thousand square miles. The action of the great polar currents somewhat modifies its position ; but it is always found year after year in certain situations. Often it extends in long belts or streams of varying dimensions; from one hundred and forty to two hundred miles in length, and five to thirty or forty miles in breadth. It is usually an olive-green, and of peculiar opaqueness; sometimes a grass-green, or green with a tint of black.

The reader will naturally ask to what cause is due this very peculiar colouring.

Dr. Scoresby ascertained, from a series of careful analyses, that the green water region is, in reality, a world of animalcules; most of them invisible to the naked eye, and belonging chiefly to a species of Medusadoe; the medusæ being well known to sea-side visitors under the popular name of "sea-blubber" or "jelly," a soft gelatinous substance frequently found lying on the shore, and exhibiting no other indication of life than to shrink and contract when touched.

The medusadæe are globular, transparent, and from onetwentieth to one-thirtieth of an inch in diameter. To convey any exact or definite idea of their number is almost impossible. Scoresby estimates that two square miles of sea contain 23,888,000,000,000,000; but these are figures which carry no actual meaning to the imagina- 
tion. We know that they represent something formidable, and that is all. It may assist the reader, however, in his attempt to realize them, if we add that eighty thousand persons must have begun counting at the creation of the world, to complete the enumeration by the middle of the present century.

The whale, however, does not feed upon these animalcules, but on the shrimps and minute crabs, the lobsters and sea-snails, which find in them their nutriment. When he is feeding, he swims with considerable swiftness below the surface, his jaws being widely extended. Consequently, a continuous stream of water flows into his mouth, carrying along with it large quantities of animal life. The water escapes again at the sides, but the food is entangled in and sifted through the baleen, which, owing to its compact arrangement, and the thick internal fringe, does not suffer even the minutest particle to be lost.

We have already spoken of the maternal affection of the whale. The following anecdote relates to one of the numerous species we are now describing :-

One of the harpooneers of a Greenland whaling-ship had struck a cub, with the view of enticing her mother within reach. Presently she arose in the neighbourhood of the "fast boat," and seizing the young one, dragged about six hundred feet of line out of the boat with remarkable force and swiftness. Again she came to the surface, darted furiously to and fro, frequently stopped short, or suddenly changed her direction, and gave every possible indication of extreme agony. For a considerable time she continued to act in this way, though hotly pursued by the boats ; and inspired with courage and resolu- 
tion by her affection for her young, seemed wholly insensible to the perils that environed her. One of the boats at length approached near enough to deliver a harpoon at her; it struck, but did not penetrate. A second harpoon was flung, and this too failed to attach itself; but a third was more successful, and entered the flesh. Still she made no effort to escape, allowing the other boats to gather round her; so that in a few minutes three more harpoons were fastened, and in the course of an hour she was slain. There is something very pitiful, as Dr. Scoresby remarks, in the destruction of a whale, when thus exhibiting a degree of affectionate regard for its offspring which would do honour to the superior intelligence of human beings; yet the object of the adventure, the value of the prize, and the joy of the capture, cannot be sacrificed to compassionate sentiments.

The principal products of the Greenland whale are its oil, its whalebone, and its skin. These, together, form an important commercial staple; but other portions are utilized by the peoples which inhabit the arctic islands.

Thus, its flesh is esteemed by some a choice article of food. The Eskimos eat the flesh and fat and drink the oil with an almost disgusting avidity. Captain Hall draws some strange pictures of the voracity with which they pounce upon the carrion. It is said that not a few of the tribes carry with them in their migrations bladders filled with whale-oil, to which they resort as a toper does to his bottle,-with equal relish, but with infinitely less injury to their constitutions. Both adults and children eat the skin of the whale uncooked, and infants suck it, 


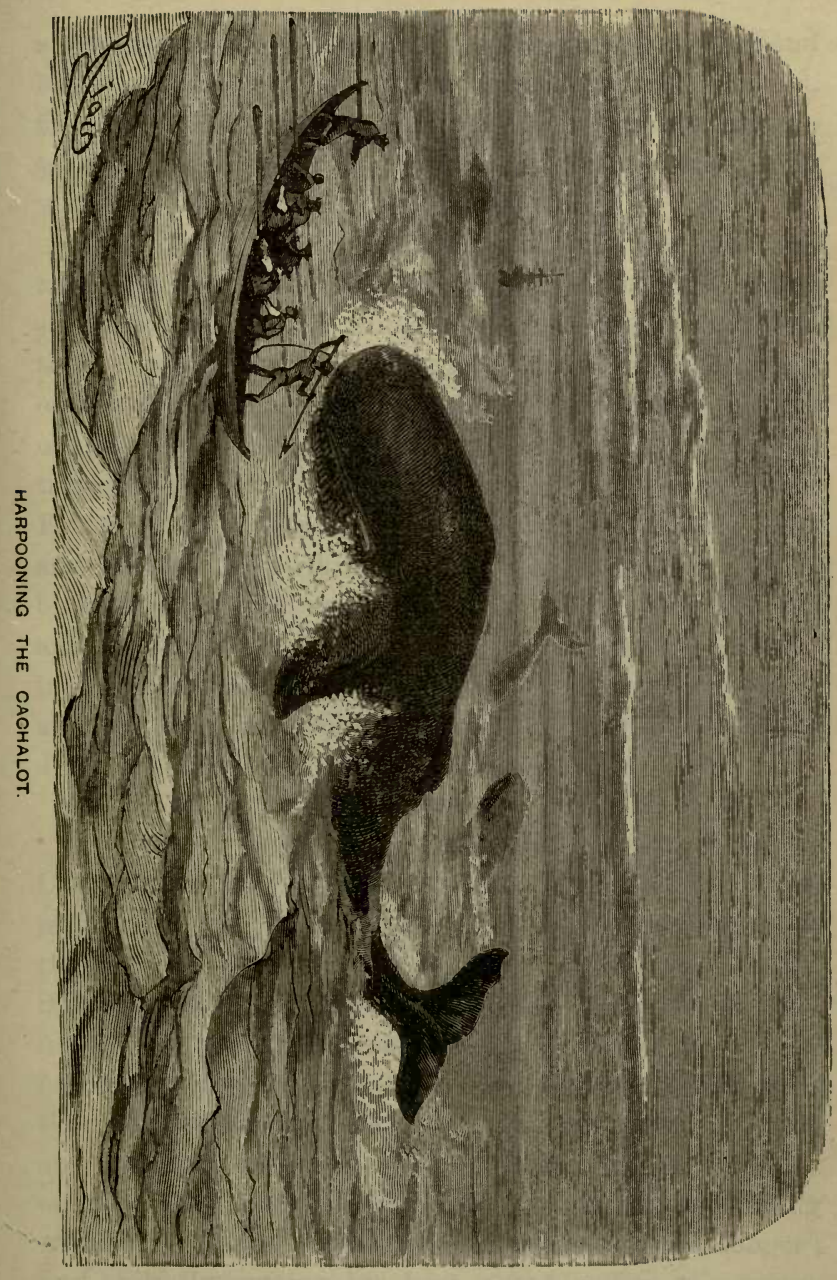




\section{,}
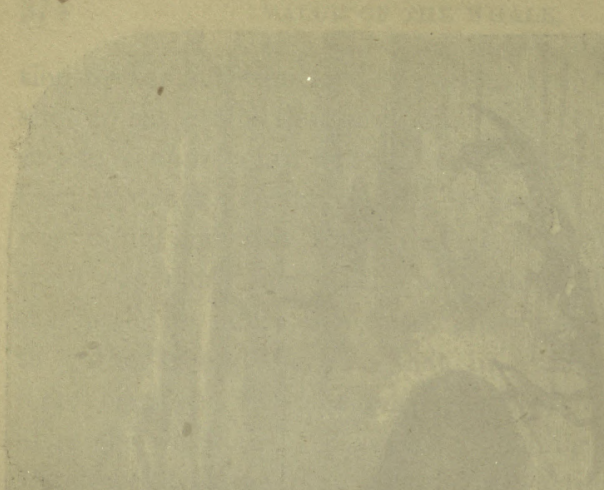

10. 
apparently with delight. The blubber, when pickled and boiled, is described as not an unsavoury dish; the tail, first parboiled and afterwards fried, is not only not unsaroury but even agreeable; and the flesh of the young whale has been compared to veal.

The inferior products of the whale, we may add, are turned to good account in regions where Nature has been so thrifty of her good things that man cannot afford to throw aside the veriest trifle as waste. The membranes of the abdomen are used for the upper articles of clothing; and the peritoneum, in particular, being thin and transparent, serves instead of glass in the windows of the Eskimo huts. The bones are converted into harpoons and spears, for striking the seal or darting at oceanbirds, and are also employed in the framework of tents and the construction of boats; the sinews are divided into filaments, and used as thread, with which they sew, and sew very dexterously, the different articles of their dress.

In the waters of the great Southern Ocean lives the Cachalot or Sperm Whale, which is the terror of all marine animals, and deserves his title of "The Tyrant of the Seas." In strength immense, in appetite insatiable, if he encounters an enemy he rushes to the attack, and never desists until he conquers or is conquered. When he receives the whale-hunter's harpoon, he rushes towards the boat, raises his head, opens his tremendous mouth, and seems intent upon crushing in his mighty jaws his enemies, their weapons and implements, and everything within his reach. But the hunter knows the danger; and skilfully putting his boat about, suffers the ocean- 
monster to rush past in headlong fury, and watches a favourable opportunity for driving his spear into his flank. Wounded and panting with rage, he opens his jaws afresh with an ominous sound and snap which make the listener shudder. Who, indeed, can help a momentary

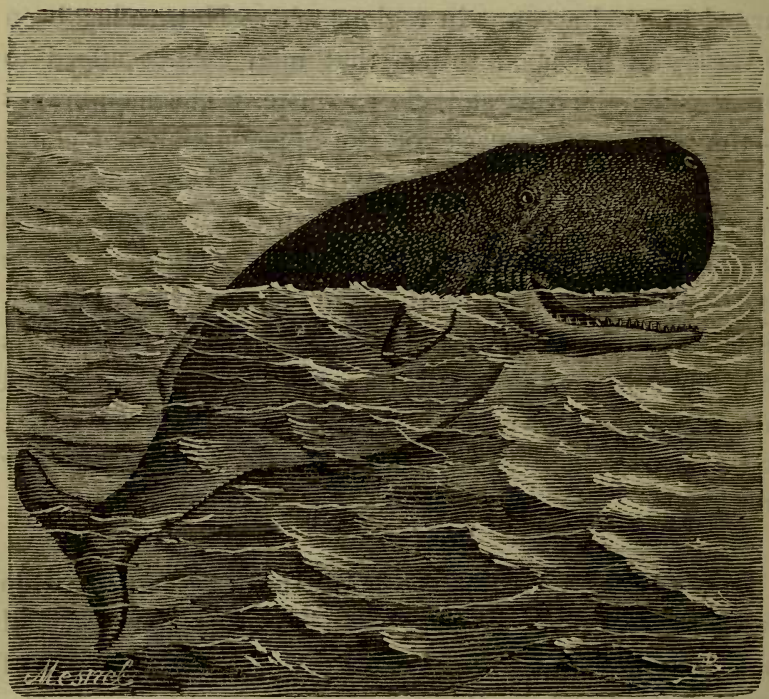

THE CACHALOT.

alarm at the thought of falling a victim to his horrid rage? It is asserted that a cachalot can sink a goodly vessel by rushing against her sides, and some authorities pretend that he can crush a boat between his jaws.

The head of the cachalot occupies more than a half of the total length of his body. There is something very remarkable about its structure; all the upper part of the 
face and skull has the form of a vast oval basin, the edges of which, seven feet high in the posterior part, decrease towards the anterior, until they wholly disappear. This great cavity is principally formed by the jaw-bones ; it is arched over with a kind of fibro-cartilaginous roof, and divided into two compartments or stories by a membraneous partition. Both compartments are filled with adipocere, or, as it is popularly called, spermaceti (the blanc de baleine of the French); a kind of oil which, as it cools, congeals, and as it congeals turns white. The cavities of which we have been speaking communicate with canals which are similarly full of adipocere, distributing it over different parts of the body, and intermingling it in the tissue under the skin. However, the chief supply is found in the cephalic reservoir, which fills, we are told, as fast as it is emptied; and twenty-four barrels, each containing one hundred and twenty-four pints, have been obtained from a cachalot measuring sixty-four feet in length.

But it is not only spermaceti which the huge cachalot furnishes ; it also yields oil, though in less quantity than the Greenland whale, the layer of fat surrounding the body being inferior in thickness. And yet again, a third substance far more valuable than either oil or spermaceti; namely, the precious ambergris, which is found in lumps, each weighing from two to thirty pounds, floating in the sea, or wave-drifted on the neighbouring shore.

The origin of ambergris was long regarded as enveloped in mystery. Some supposed it to be a mixture of wax and honey, modified by the action of the sun and the salt water. Owing to this very mystery, it was formerly held in high 
repute. It entered into the composition of various perfumes, and was also employed as a drug. The Moslems who performed the Mecca pilgrimage offered it at the shrine of their prophet as a sweet-smelling savour. By some of the African peoples it is valued as a seasoning for food. This incense, this medicament, this perfume is now known, however, to be neither more nor less than the excrement of the sick cachalot. When the animal is captured in a diseased condition, the ambergris is found lying hardened in its cœcum, and as much as one hundred to one hundred and twenty pounds will be obtained from a single individual.

The cachalot or sperm whale feeds principally upon molluses ; but it is said that he will hunt the largest fish, even sharks, and, among the mammals, both porpoises and seals. Carcasses of seals upwards of ten feet long have been found in the stomach of these monsters. With open mouth they snap at their prey, plunge their fifty teeth into its body, and bring their jaws together with such force as to snap it in twain.

The course of the cachalot is always direct and steadfast, like that of an arrow. Generally he faces the wind, and he moves with remarkable swiftness, attaining to twelve and even fifteen knots an hour. His jets or "blowings" occur at intervals of less than a minute, and are repeated fifteen, twenty, and even thirty times. As he remains for a considerable period on the surface of the water, so he lingers long in the depths; and, therefore, when the fisher descries his puffs of vapour, he should be alert to launch his boats, or his hoped-for prey may disappear. 
IV. - THE WHALE-FISHERY.

The whale-fishery is chiefly carried on by the British, the Americans, and the French. In the northern waters British ships are most numerous; and these "hail" chiefly from the ports of Hull and Whitby, Peterhead, Dundee, and Aberdeen. Formerly, sailing-vessels were employed; but screw-steamers have now come into use, and are far more effective, being better able to force their way through the drift-ice, or against a contrary wind.

They usually put to sea about the beginning of May, and after passing Cape Farewell, the extreme southern point of Greenland, occupy two or three weeks in what is called the south-west fishing, in the neighbourhood of Frobisher Strait, to the northward of the coast of Labrador. Afterwards the whalers keep up the east side of Davis Strait and Baffin Sea to Melville Bay, which is notorious in the annals of arctic navigation as the scene of disastrous wrecks. The ice-floes congregate here in great numbers, and the passage through them is always difficult and often dangerous. But, supposing it successfully accomplished, the whaler makes for the fishing-ground at the entrance of Lancaster Sound or off Pond Inlet. Here he remains until July, and then he strikes up Lancaster Sound as far as Prince Regent Inlet. In August and September the whales are followed as far as the Gulf of Cumberland, until the approach of winter, with its thick darkness and its snow-storms, warns the whaler that he must retrace his steps. He reaches home about the beginning of November.

The whaling-ships are stoutly built, doubled and fortified by thick planking and iron bolts both externally and 
internally. Angle-irons on each side of the stem are so placed as to protect the fore-foot from injury by the driving ice, while they also act as rams or spurs, assisting it to break through the smaller and thinner floes.

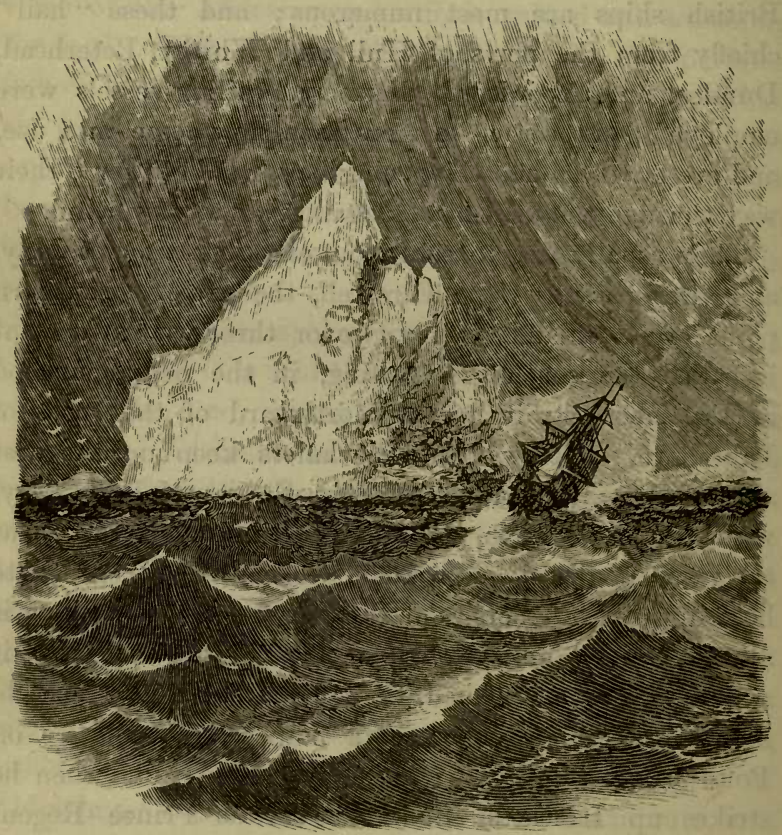

IN MELVILLE BAY.

The average length is about 150 feet, the extreme breadth 30 feet. The tonnage varies from 300 to 450 ; the engines have a horse-power of 50 to 70 ; and each vessel carries 6 to 8 boats. The numerical strength of the crew depends on the number of boats; the object being that 
when all the boats are despatched, fully manned, in pursuit of the "fish," two or three hands may be left on board to work the ship. A full complement is fifty-four officers and men, including captain (or master), mate, second mate, doctor, engineer, "speksioneer," two harpooneers, two loose harpooneers, six boat-steerers, eight line-managers, ten able seamen, and so on. Both the mate and second mate act as harpooneers when required. The "speksioneer." is the officer who superintends the cutting up of the whale. The word is derived from the Dutch spek, or "blubber."

In order, says Captain Markham,* that all the men on board may take an interest in, and use their utmost exertions for, the furtherance of a successful issue to the voyage, each individual, according to his rank, receives a percentage on the amount of cargo brought home, their regular wages being small. Moreover, a bonus is paid to every man in the boat that captures the first whale; the barpooneer receiving $10 \mathrm{~s}$. if he gets fast with the gunharpoon, 10s. 6d. if with the hand-harpoon, and $21 \mathrm{~s}$. if with both, while his mates receive $2 \mathrm{~s}$. $6 \mathrm{~d}$. each. This is termed "sticking-money," or "fast-boat money." The master is usually rewarded with $£ 1$ for every payable fish struck by a harpooneer, and $£ 3$ if it be struck by a loose harpooneer; the latter being a kind of embryo or apprentice harpooneer, who, if he discharges his duties satisfactorily for a couple of years, is promoted to be a full harpooneer.

"The duties of a whaler's crew," says our authority, "are allotted according to the abilities and qualifications which the men possess as fishermen. Thus the har-

* Markham, "A Whaling Cruise to Baffin's Bay," pp. 12, 13. 


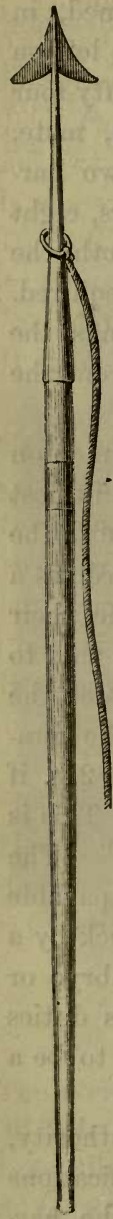

HAN DIARPOON

pooneers attend to the coursing of the ship during their watch on deck; the two mates and the speksioneer (who are also harpooneers) are in charge of the watch; the boat-steerers attend to the ropes on the forecastle ; the linemanagers to those round the mainmast, and also to the cleanliness of the ship between decks; the boatswain, who is also a boat-steerer, is held responsible for all work aloft; the skeeman [the officer who superintends the 'stowing away' of the blubber in the tanks], who is the head lineman and also a boat-steerer, is responsible for everything between decks. The remainder are the foremast hands, who make themselves generally useful when required...... When all boats are away from the ship, there remain on board the captain, doctor, engineer, ship-keeper, cook, and steward. Fach boat has a crew of six men, five rowers and one to steer. No ruddens are fitted to the boats; a steer oar, in consequence of the rapidity with which, by its means, a boat may be swept round, being invariably used. The harpooneer is in charge of the boat, and pulls the bow oar. It is his duty to strike the fish. The line-manager pulls the stroke oar, and it is his province, with the boat-steerer, to see the lines coiled away clear, and to attend them when running out, after a fish has been struck."

The weapons with which man goes forth to hunt the ocean-monster are the hand-harpoon and the harpoon-gun. The latter is constructed 
on the principle of a cross-bow ; and being fixed on a swivel in the bows of the boat, can easily be moved from side to side, depressed or elevated by the harpooneer. The harpoons are made of the softest Swedish iron, which is more pliable than English; therefore they readily bend without snapping, when any pressure is brought to bear on them.

With these preliminary remarks, we proceed to clescribe the pursuit and capture of " a fish."

The look-out man, who is stationed in a crow's

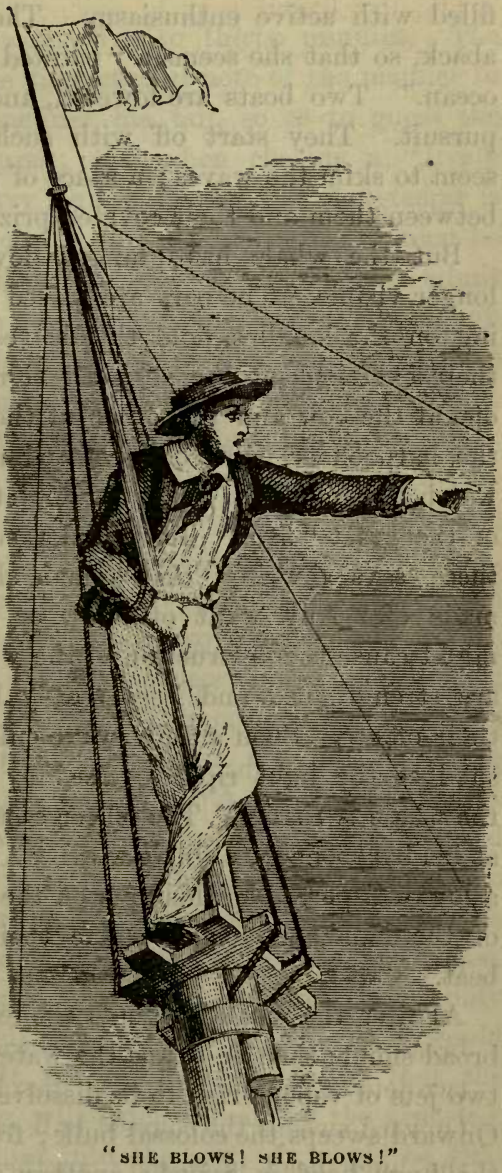
nest triced up to the mainmast-head, cries, "She blows! she blows!" and at the welcome signal the whole crew are 
filled with active enthusiasm. The ship lays her sails aback, so that she seems a "painted ship upon a painted ocean." Two boats are lowered, and sent in immediate pursuit. They start off with such velocity that they seem to skim the waves; a space of one or two miles lies between them and their coveted prize......

But the whale has plunged downwards, and is no longer visible. The oars are raised; and the men, resting on the handles, hold themselves prepared to renew their exertions at the slightest signal. Standing erect, one at the bow and the other at the stern, the mate and the harpooneer, with outstretched neck and fixed gaze, watch the surface of the water to detect the reappearance of the great "fish." It is under such circumstances as these, says a writer, that a man shows the stuff he is made of. Any want of skill, or deficiency in nerve, might cause the destruction of the whole crew; and they are strengthened and kept steady by the steadiness of their officer. Soon an oily wave enlarges in a circle, and subdues the light ripples raised by the passing breeze; the whale is rising! The officer casts a significant glance at his harpooneer; a single word, "Attention!" uttered in a low whisper, keeps his men on the alert, and at a wave of the hand, the oars resume their rapid but regular beat.

At first the whale presents the extremity of his black broad snout; then he skims the water with his vents, and two jets of vapour rise, to be dissolved in the atmosphere. Onward sweeps the colossal bulk; from minute to minute the huge head is raised; another spout escapes; after the seventh or eighth he gradually bares the long ridge of his colossal back, balances the enormous tail, and then 
plunges anew for twenty-five to thirty minutes. The fisher must therefore take careful note of the manner in which the animal inclines his tail, so as to guess the direction of his course; and when chasing a "lively whale" amongst heavy ice the duty of the boat-steerer is both arduous and.onerous. At times the boats must be forced between two floes, just wide enough apart to admit her passage ; in such a case she has to be sculled through by the steerer, and the continuous work of carrying the boat round the numerous pieces of ice is most laborious. Now the men must throw all their force into a long pull, a strong pull, and a pull all together; now they scarcely move their oars-; at times they drift with the current; always vigilant, always ready, always composed and calm.

They lie on their oars, at length, and wait for the whale to rise. In a minute or two he once more comes to the surface, and the harpooneer, quick as thought, discharges his fatal weapon. It shoots through the air, pierces the fat, and fixes its barb in the huge quivering side. A joyous shout goes up, "A fall! a fall!" A second harpoon follows; the line unrolling from the reel with inconceivable velocity. Already upwards of two hundred fathoms are beneath the waves, and yet the panic-stricken animal continues his downward course. With so much violence is the line uncoiled, that if only a fragment of a shell impeded the movement it would capsize the boat. It not infrequently occurs that the rope, when uncoiling, will catch a man by the arm, leg, or body, and drag him into the sea. It would be difficult, then, to give the reader an idea of the absolute coolness and tranquillity with which every manœuvre must be executed. The true whaler, however, is insensible to 
fear; he braves death with ready heroism, though not with imprudence. When the animal rises after his first plunge, the "line-manager" slowly pulls upon the line, and the boat draws towards the monster, cautiously, without haste, and yet with sufficient quickness. How many difficulties must be conquered, and sometimes how long a delay must be endured, before another harpoon can be thrown! Yet it is not one, but ten, perhaps twenty, which may be needed to ensure death; while, if a mortal wound be not inflicted in the first quarter of an hour, the whale recovers from his alarm, regains his senses, and takes to flight. Then comes the breathless, rapid chase. The boat springs forward like an arrow, darting between the waves as between two walls of vapour. In vain the wounded monster would escape his relentless pursuers; he rises to the surface, he sinks, again he rises, and every time he shows his gigantic bulk the harpooneers drive in their lances to the depth of six or seven feet. The water all around is dyed a deep dark crimson; even the neighbouring ice is stained with the same ensanguined hue. These vigorous and deadly blows no animal can long survive; and after a brief struggle, and one last convulsive heaving of his enormous tail, the ocean-leviathan, yielding to the superior force and skill of his enemies, turns slowly over on his back, and expires, amidst their shouts.

The experiences of those who go down to the icy seas in quest of their monsters are often of a most romantic character. The perils they encounter are so numerous, that gentlemen who live at home at ease may reasonably wonder at the love of adventure and the desire of gain 


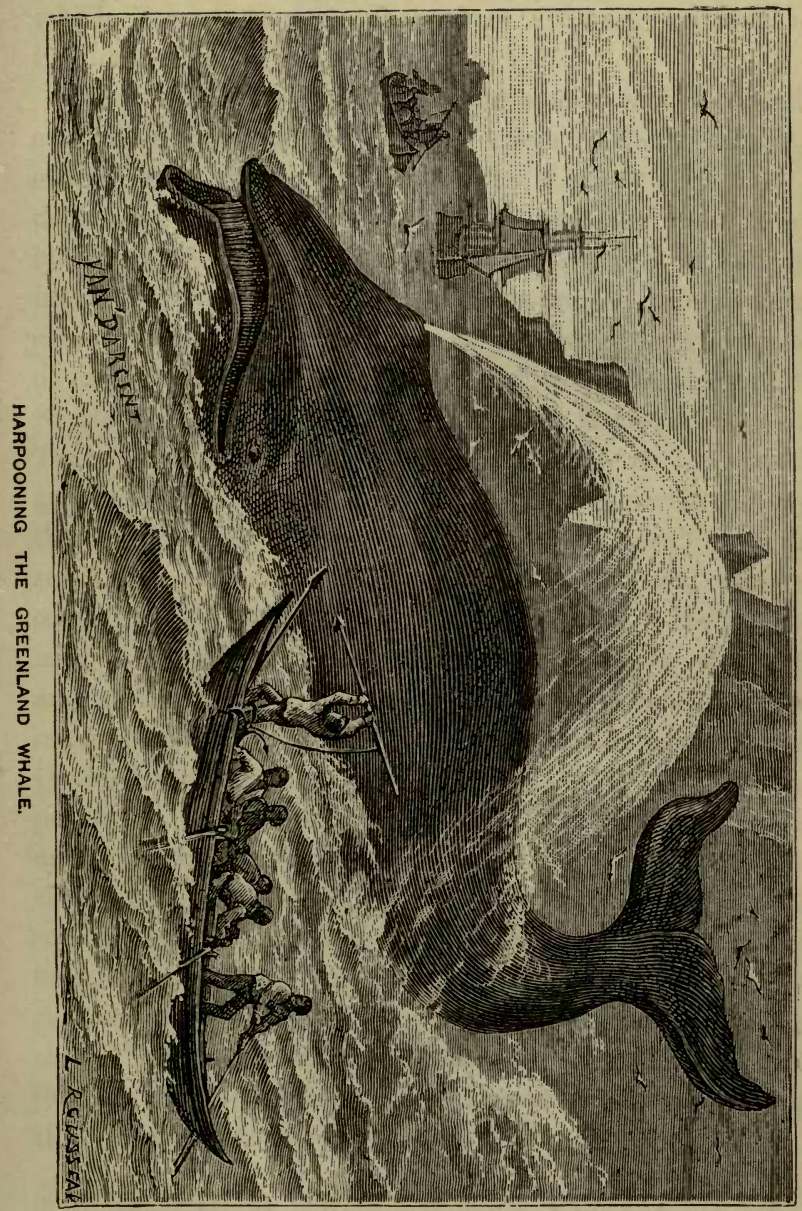


which induces men to face them. Thus, we read of incidents such as the following :- *

The whaling-vessel was running under reefed topsails and foresail at the rate of ten knots an hour before a strong south wind, snow falling in a heavy drift, and a dense fog everywhere prevailing. All the crew were busily employed in getting the boats in-board, and securing them from the heavy and white-crested billows that came rolling up on every side, as if eager to overtake and devour the puny craft that seemed to mock their rage. Suddenly a tremendous iceberg loomed through the mist. To have struck it would have been ruin to the vessel, and death to her gallant crew. "Hard-a-port," shouted the look-out on the forecastle; "Hard-a-port," rang in stentorian tones along the deck ; "Hard-a-port," was reechoed by the ready and vigilant helmsman. He was no less quick to act than to answer, and in a moment, amidst the roaring of the wind, and the creaking of the masts, and the rattling of the cordage, the obedient vessel swung round, and, as she did so, the eddy and current produced by the floating ice-mountain nearly threw her upon her beam-ends to windward. Happily she righted; and as the wind again filled her sails, her lee yard-arms actually scraped the frozen surface of a lofty, precipitous berg, breaking off small fragments, which fell in a shower of ice upon her decks. In another moment she had forged ahead, and-was saved! Her crew could just see the enemy they had so narrowly escaped drifting slowly away into the darkness.

To Captain Markham we are indebted for another

* Markham, "A Whaling Cruise," p. 75. 
illustration of the dangers which beset the arctic whaler.

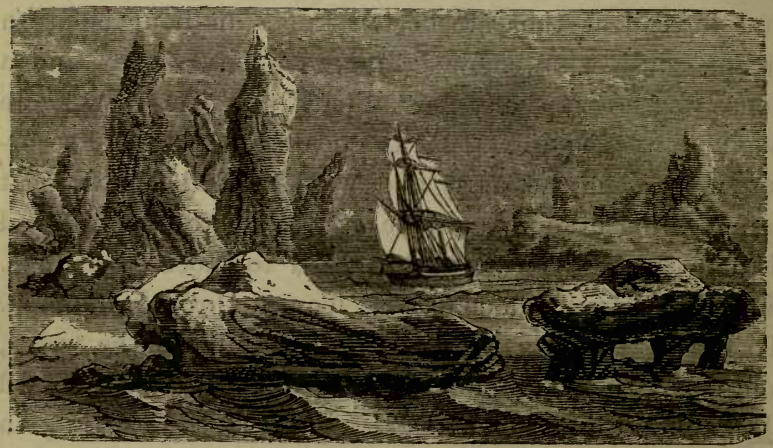

A MONG THE ICE.

A whale had been struck, on the east side of Baffin Sea, but the line having broken, had succeeded in effecting his escape, carrying with him, however, as memorials of his past adventure a couple of harpoons embedded in his flesh. Strange to relate, the same fish was fallen in with, a few days later, by the same ship, on the west side of the bay. The boats were immediately sent in pursuit. When the foremost got up with the expected prize, the harpooneer fired and "got fast," and was in the act of delivering the hand-harpoon, when the fish, with a mighty effort, dealt the boat a crashing blow with his formidable and ponderous tail, shivering it into a mass of broken timbers, and precipitating the crew into the water.

The unfortunate harpooneer was seen no more; his body having probably been entangled by the line, and 
carried down. The remainder of the crew, with the exception of one man, were picked up by the other boats; the man we speak of had succeeded in swimming to a

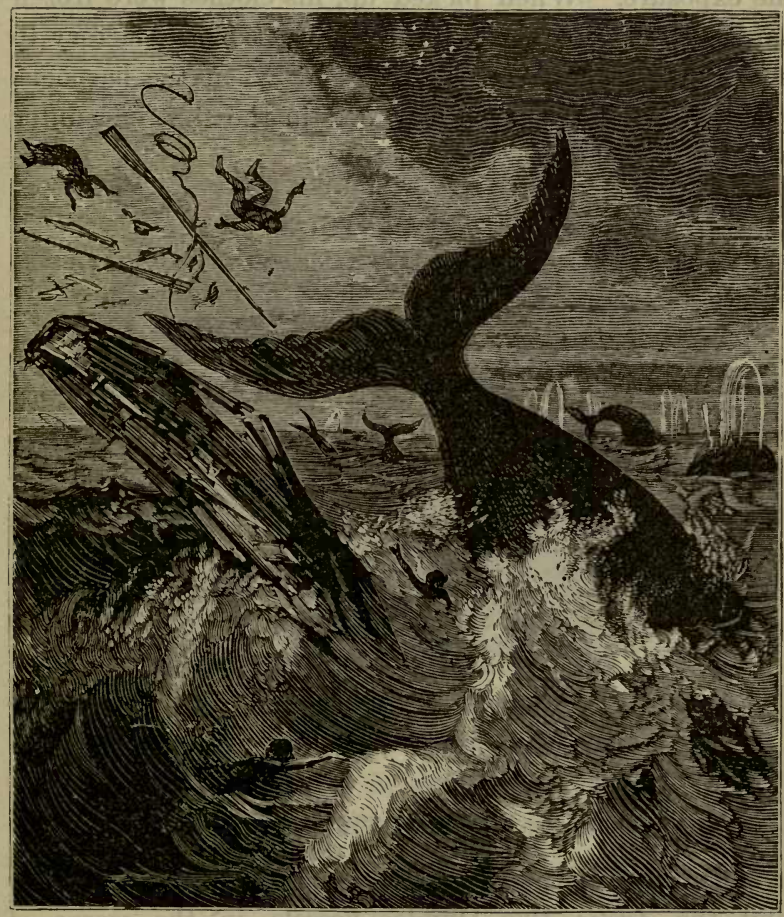

WHALE CAPSIZING A BOAT.

piece of ice, but, owing to the numbness and exhaustion produced by excessive cold, had been unable to raise himself upon it. And there he must have perished, had not one of his mates, mistaking him for a seal, pointed 
him out to his companions. Immediately he was taken on board; and restoratives were administered to him; but it was some time before he recovered from the effects of the exposure. When picked up, his clothes were frozen hard on his body. As for the whale, it is satisfactory to know that he was eventually killed, when the harpoons with which he had been wounded in the first encounter were recovered.

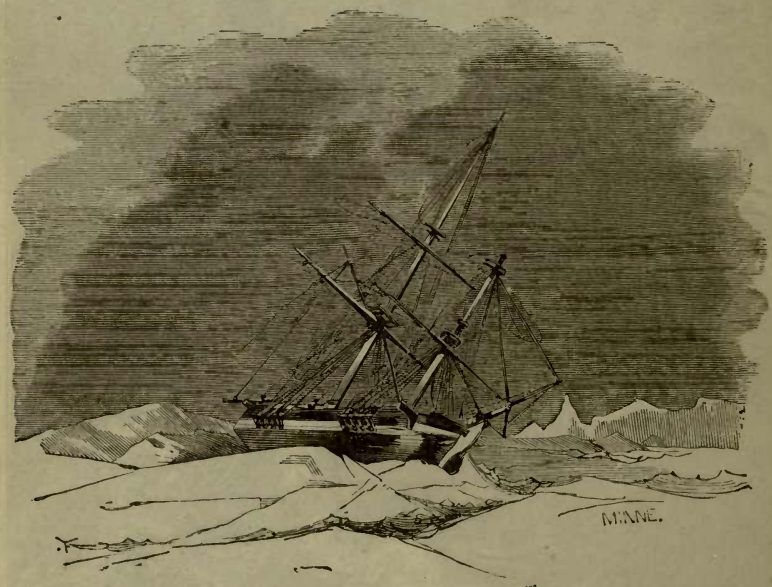

CAUGHT IN THE ICE.

Sometimes the whaling-ship - as in the case of the Tay and the Arctic, two Dundee vessels, in the season of 1874-is caught in the ice; and all the efforts of her crew to extricate her proving fruitless, they are compelled to take to their boats, until rescued by some more fortunate vessel, or they make their way over the ice-fields to the nearest settlement. 
But let us suppose that no such accidents occur, and that the whaler's crew have caught their first great " fish." The question naturally arises, What will they do with it?

The first thing is to cut a hole through each fin, and fasten on a rope; and the tail being caught up to the bows of the boat, the whale is brought to the port-side of the whaling-vessel, and there secured. This is done as follows :-

The fish is always brought alongside with the tail forward abreast of the fore-chains; it is then secured by means of a tackle from the fore-rigging, which is hooked to a strap round the small end of the tail (where it is united to the back of the fish), and by a stout rope, which is called the " rump rope." A similar purchase is hooked from the main-rigging to a strap rove through a hole cut in the extremity of the under jaw; and this is called the "nose tackle." Let it be understood, however, that the whale is on its back. Its right fin is now secured by a chain or rope to the upper deck; and, next, between the fore and main masts is fixed a stout wire rope, called the "blubber guy," with four large single blocks strapped on to it, to carry the tackles used in hoisting on board the large layers of blubber, some between one and two tons in weight, as they are cut off. An apparatus at the mainmast-head turns the fish over as it is being "flinched."

These preparations completed, the crew are "turned up," and each man receives a glass of grog before setting to work. Two "mollie boats," as they are called, attend upon those engaged in cutting up, and are manned by a couple of hands, euphoniously termed "mollie boys." The captain superintends the whole course of operations, 
standing in the main-rigging; the mate, in the gangway, repeating his orders, if necessary.

Under the direction of the speksioneer, the seven harpooneers take their stand upon the whale, and with their blubber spades and knives separate the blubber from the carcass in long strips, which are hoisted on board by means of the "blubber guy." Each harpooneer, to prevent him from slipping, wears iron spikes, or "spurs," attached to his boots.

Operations always commence at the belly of the whale; and when this has been completely stripped of blubber, the fish is "canted," or "tilted," and the blubber from the opposite side is similarly removed. Next, the whalebone is detached; the lips are then hoisted in; and so the process of "flinching" is continued, until all that is valuable of the dead monster has been carefully got on board. The tail being separated from the carcass, or "kreng," as it is called, the latter goes down to the depths with a heavy plunge, amidst loud shouts of triumph.

Meanwhile, the large pieces of blubber, as they are hoisted on deck, are cut up by the boat-steerers into pieces about two feet square. These are seized by the line-managers, armed with "pickics" or "pick-haaks," and lowered into the hold, where they are received by the skeeman, and stowed away for the nonce. The whalebone, on the other hand, is split up, by means of large iron wedges, into portions, each containing from nine to sixteen blades; and these are subdivided into smaller pieces of three or four blades. The whale's tail is cut up into blocks, which answer a useful purpose in the further process of " making-orfi," yet to be described. 
A fair average-sized fish, measuring between forty and fifty feet in length, yields about thirteen tons of oil, and, including the whalebone, is worth about $£ 800$.

We now come to the "making-off." This operation is reserved for a quiet day, in order that, when once begun, it may not be interrupted until completed.

The blubber being again hoisted on deck, is seized by a couple of men on each side, who, with their pickics, drag it to a couple of harpooneers, also on each side, by whom it is cleansed of all kinds of refuse, and cut up into pieces of about twelve or sixteen pounds weight. These men are called "krengers." The blubber is then thrown forward to the remaining harpooneers, who are stationed on each side of the deck near a "clash," or iron stanchion, about three feet high, with five iron spikes on the top.

Each harpooneer, or "skinner," as he is called while engaged in "making-off," has an assistant, or "clasher," who picks up the pieces of blubber having skin on with a pair of clash-hooks, and places them on the top of the clash. With a long knife the skinner dexterously removes the skin, and the blubber is then deposited in a heap called the " bank," directly in front of the "spek trough,"-that is, a large oblong trough, about eighteen feet in length, and two feet in width and breadth, which stands immediately above one of the hatchways. In the middle of this trough a hole, about a foot square, is fitted with a long canvas shoot or hose, called a "lull," which opens into the tank intended for the reception of the blubber. The lid of the trough, turned back, and supported by props, forms a capital table, about three feet high, on which are placed the blocks cut from the whale's tail. Behind these blocks 
are stationed the boat-steerers, armed with choppers ; and very vigorously and dexterously do they chop up into small pieces the large lumps of blubber which have passed through the skinners' hands. Then they throw the pieces into the spek trough, whence they pass down the lull, and finally disappear in the tanks.

We can well believe what Captain Markham tells us, that this work makes the ship in a greasier and filthier state than even the operation of "flinching;" and though he tells us that there is nothing absolutely repugnant or disgusting in witnessing the process, we think it is one which inexperienced eyes would certainly dislike. "The upper deck," he says, "during the time the work is at its height, presents a most animated and busy scene. Forward, standing in a line across the forecastle behind their blocks, are the boat-steerers, with their continual and ceaseless chopping; in front of them are men busily employed with pickics, transferring the blubber (which has rather the appearance of huge lumps of cheese) from the deck to the spek trough; whilst on each side are the skinners, with their assistants, engaged in their individual labours. All is life and activity, every one in a good humour, and working with that cheerfulness and energy which are the result of a contented and happy disposition."

The whale-skin is sometimes thrown overboard ; sometimes preserved for distribution among the Eskimos, who relish it as an article of food. It is said to be an excellent anti-scorbutic.

As we have said, the Greenland whale is the species generally pursued by the whaler; but the Balsena physalis, 
-or "sulphur bottom," as the whalers call it,-is sometimes hunted. This is truly the "king of fishes," or of ocean-mammals, his average length being one hundred feet. He is not so easy or tranquil in his movements as the Greenland whale, and when wounded, breaks into such a tempest of rage that approach to him becomes exceedingly dangerous. His flight, after being struck by the harpoon, is very rapid, and so long sustained that to tire him out is very difficult, and generally impossible.

The whale-fishery at Vadsö, a sea-port of Arctic Norway, presents some features of special interest.

Vadsö is one of the numerous islands which stud the broad bosom of the Varanger Fjord, the eastermost of the great inlets on the coast of northern Europe which the influence of the Gulf Stream keeps free of ice throughout the year. It forms a great salt-water channel, which a succession of promontories and the Island of Vadsö lock in like a mountain-lake. The island is green with firwoods, and though within the Arctic Circle, has little of the true arctic character.

Its principal or only town, Vadsö, is a scattered multitude of houses, between and beyond which extend acres upon acres of low wooden scaffolding, the object of which is not very clear to the observer at the first glance. But examining it more closely, he sees that it consists of a repetition of wooden framework, upon which, at a height of about six feet from the ground, are laid horizontal wooden bars or poles, and to these wooden bars are suspended pairs of split cod-fish for the purpose of drying. Their number is legion, and if he be wise he will make no attempt to count them. Under and around the frames 
the ground is thickly covered with cods' heads, also drying. These, when in proper condition, will be ground into a white meal-like powder, and, under the name of " fish guano," exported for manure.

Fish guano, cod-liver oil, and dried cod-fish are not, however, the only commercial resources of Vadsö, or we should not have introduced it in these pages. It has of late years risen into importance in connection with the whale-fishery. An enterprising Norwegian, M. Sven Foyn, has improved on the murderous methods suggested by Thiercelin and Devisme, and invented some projectiles of peculiarly deadly power, solely for use against the monster of the deep. The bow of his vessels is equipped with small swivel-guns, from which is fired a compound projectile, consisting of a harpoon with hinged barbs or flukes. These, while the harpoon is on its deadly course, lie snugly down by the side of the harpoon shaft; but when it has entered the flesh of the whale, and the shaft is drawn backwards, they open out, piercing the flesh sideways and obliquely, until checked by the stop of the hinge. Thus they obtain a firm hold, and effectually prevent the withdrawal of the barb. Nor is this all. The harpoon is also furnished with explosive shells, so designed as to burst within the hapless leviathan's "too solid flesh," and destroy him almost instantaneously. A towing cable is then attached to his ample nose, and his huge slate-coloured carcass is triumphantly towed into Vadsö harbour.

"I have just returned," says a writer in a contemporar: journal, "from a rowing excursion round a dead whale, which at a distance looks like one of the low rounded island-rocks that abound in the harbour; and, indeed, might be mistaken for one, were it not for a curious flat 
angular peak that stands above the water a few yards beyond. This is one lobe of the dead creature's tail. The island is his back. His head, with huge open mouth, which appears large enough to swallow himself, is lying deep under water. The nose-cable is already attached to a windlass on shore, fixed at the top of a sloping wooden
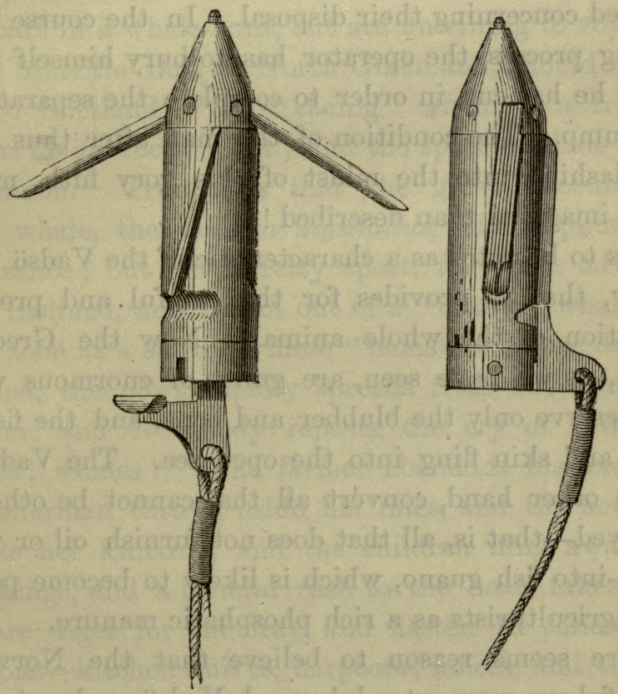

GUN-HARPOON.

landing-place or whale-pier. On this huge slab the remains of a whale brought in some time ago are still lying; a loathsome mountain of pinkish beefy flesh, into the midst of which half-a-dozen of hideously blood-stained men are chopping and hacking with great hatchets and long-handled, big-bladed weapons, like inverted scythes or 
large bill-hooks. Some are peeling off the blubber that surrounds the whole carcass, and serves during the life of the animal to protect its warm blood from the deadly chilling of the arctic water. Others are hacking at the already peeled portion of the flesh-mountain, and thus detaching great slabs that slide down the sloping whale-pier into the sea, to float and stink until further orders are received concerning their disposal. In the course of this carving process, the operator has to bury himself in the chasm he has cut, in order to complete the separation of each lump. The condition of the man after thus diving and slashing into the midst of this gory filth, may be better imagined than described!"

It is to be noted as a characteristic of the Vadsö whalefishery, that it provides for the careful and profitable utilization of the whole animal. Now the Greenland fishers, as we have seen, are guilty of enormous waste; they reserve only the blubber and bone, and the fish, entrails, and skin fling into the open sea. The Vadsöites, on the other hand, convert all that cannot be otherwise employed-that is, all that does not furnish oil or whalebone-into fish guano, which is likely to become popular with agriculturists as a rich phosphatic manure.

There seems reason to believe that the Norwegian whale-fishery may extend beyond Vadsö, and enter-into competition with that of Greenland; always provided the harpoon-guns, with their formidable projectiles, do not exterminate the whales. But it is to be hoped that a prescient legislation will enact a "close time" for the oceanmonsters, and prescribe certain limits to the whalers in their usual cruises. It would be a serious disaster if this important fishery were destroyed by an imprudent greed 
of gain. Not only is it valuable on account of its products, which human ingenuity has utilized for so many purposes; but as the nursery of a race of skilful and hardy seamen, in whom the old Norse blood, with its love of adventure, its indefatigable courage, and its unconquerable resolve, seems to flow uncorrupted.

Those of our readers who feel an irresistible desire to take part in a whale-hunt, but are unwilling to voyage so far as Melville Bay or North Greenland, should make a trip to Shetland. The "caaing" whale is a frequent visitor to its rocky coast; and the spotted whale is not uncommon. True it is that the great Greenland or right whale, the Balcena mysticetus, seldom puts in an appearance; but very pretty sport, for those adventurously inclined, may be got out of a "caaing" whale.

As soon as a shoal of these "monsters of the deep" is descried, the news rapidly spreads from one hamlet to another, and everybody repeats the cry of "Whales! whales! whales!" The farmer abandons his oxen, and the fisherman throws aside his lines, and the housewife deserts her knitting, and the children fling away their playthings, and a general rush to the boats takes place. All are eager for the fray, and hasten to collect their weapons-kitchen-knives, harpoons, lances, and the like. The principal personage of the crowd takes the command, marshals his flotilla into something like order, and leads the way out to sea.

On approaching the enemy, the boats creep slowly round them, making every possible effort to interpose between the whales and the open sea. When successful in this manœuvre, they begin to close in upon the pack, and force it towards some shallow and sandy bay. Dur- 
ing these operations the strictest silence is maintained; but if, happily, the whales should enter the chosen inlet, their pursuers come to close quarters with triumphant shouts. Then the mêlée grows fierce. The poor whales, sensible of the increasing shallowness of the water, turn round and make for the open sea. Then how the excited crews scream, and shout, and howl! And how the no less excited whales dive and reappear, and rush to and fro! Sometimes the pack, headed by their " bull," break through the cordon of boats, and effect their escape ; but generally they are driven into the toils by incessant thrust of harpoon and spear, and rattling volleys of stones. As soon as the whales are stranded, the men jump from their boats, and with whatever implement they have at hand stab them to the heart. The "dying flurry" then sets in ; and, amid the exultant cries of the victors, the huge animals struggle terribly, lashing the water furiously with their tails, spouting up columns of mingled blood and water, and even uttering dolorous sounds. Meantime the "multitudinous sea," becomes "incarnadined" with blood.

The work of death accomplished, "flinching" is the next operation, and one in which the Shetlanders display remarkable dexterity; but as we have described it in all its details, it is needless to dwell further upon it. The dead whales having been flinched and decapitated, their blubber is next put up to public anction. It generally realizes from $£ 10$ to $£ 15$ a ton, and the heads from 8 s. to 12s. each. The "kreng," or flesh, is usually left on the beach to pollute the atmosphere all around, until devoured by birds of prey, or washed away by the sea. Occasionally more economical considerations 
prevail, and it is converted into a rich and fertilizing manure.

Our chapter on the whale will fitly conclude with a few stories of adventure and peril connected with the fishery.

A writer in the Quarterly Review is responsible for the facts embodied in the following narrative :-

A "school" of young bull-whales making their appearance close to a whaling-ship in the North Pacific, the captain ordered the mate to lower his boat, while he did the same with his own, in order to hasten in pursuit of them. The two boats were quickly in the water; and their crews plied the oar with such good will that they soon drew near the whales. Unfortunately the latter took the alarm, and before the harpoon could be delivered with any chance of success, took to flight in different directions. One, however, after making several turns, came right towards the captain's boat, which waited silently for his approach, without moving an oar; so that the young bull passed close beside it, and received the blow of the harpoon some distance behind his hump.

For a few seconds it appeared terror-stricken; then recovering itself suddenly, darted off like the wind, and spun the boat so quickly round, that when the pressure came upon the line she was nearly capsized. But away they flew to windward, at the rate of twelve or fifteen miles an hour, right against a head sea, which dashed against and over the bows of the boat with so much fury that at times she seemed to be cutting a path through it, with a high bank of foaming surf on either side.

The second mate, observing the course taken by the whale and boat, contrived to waylay them; and on their 
coming near, flung out a "short warp," which was duly caught and made fast, so that the two boats were soon being towed at nearly the same rate as the captain's boat had been before.

The men on board the whaling-ship, who had been watching this headlong chase with great anxiety, now saw the captain dart his lance at the whale as it almost flew along; but the blow seemed to have been ineffectual-at least, it did not check the speed of the whale; and in a very short time all disappeared together, being at too great a distance to be visible to the naked eye from the deck. The officer in charge ran aloft, and with his glass could just discern three dark specks on the rippled surface of the ocean. But soon these, too, could no longer be traced, and he ordered the ship, therefore, to beat up in the direction which they had apparently taken.

"It was now," says an eye-witness of all that occurred, " within half an hour of sunset, and there was every appearance of the coming on of an ugly night ; indeed, the wind began to freshen every moment. I remained aloft," he continues, "until I saw the sun dip, angry and red, below the troubled horizon, and was just about to descend, when I was dreadfully shocked at hearing the loud cry of 'a man overboard' from all upon deck. I looked astern, and saw with horror one of our men grappling with the waves, and calling loudly for help. The ship was soon brought round, but in doing so she unavoidably passed a long way from the poor fellow, who still supported himself by beating the water with his hands, although he was quite unacquainted with the art of swimming. Several oars were thrown overboard the moment after he fell, but lie could not reach them, though they were near him; 
and directly the ship brought up, a Sandwich .Islander, who formed one of the crew, leaped overboard, and swam toward him, while at the same time the people on deck were lowering a spare boat, which is always kept for such emergencies."

The Polynesian struck out bravely at first, but when he was at some distance from the ship, being unable to see the man of whom he was in search, he was suddenly seized with an appalling sense of loneliness, and in his terror returned to the boat. The men again plied their oars, and the boat swept with tremendous speed through the rolling waves ; but, unfortunately, was half a minute too late to save the unfortunate castaway. To the last he struggled against his fate; but the foam of a broken sea roared over his head, and he disappeared for ever. The boat was rowed round and round the fatal spot, in the hope he might rise again to the surface, but in vain; and when night closed over the scene, her sorrowing crew pulled back sadly and slowly to the ship.

The moment the ill-fated seaman sank, a large bird of the albatross kind came along on labouring pinions, and alighted on the water at the very spot where he was last seen. It was almost as if he had scented a victim from afar; however, he was too late.

It was quite dark by the time the boat was got on board, and the wind blew in heavy squalls. A general feeling of depression spread through the crew, for they had lost one of their best men. Moreover, the captain, the second mate, and ten experienced seamen were missing; and who could say whether they would ever be seen again? The gloomy weather seemed to answer to and sympathize with the sombre thoughts that overshadowed 
every mind. However, the ship still made all sail to windward, under a press of canvas which made every mast reel and quiver; and every twenty minutes she was put about, in order that as wide an extent of ocean might be surveyed as possible. Lights were burned; and a large vessel, flaming with oil and ravelled rope, was lowered over the stern-rail as a beacon for the missing boats.

But though every eye was engaged in searching for them, no vestige could be discovered; and when half-past nine o'clock came, all on board gave them up as lost. Few there were among that anxious crew who did not think of home that night; few whose hearts did not turn towards the bright fireside and genial roof-tree of their youth, or who would not cheerfully have given up all they possessed to see them once more. But in the darkest hour light often shines forth suddenly on the stricken human soul. And even so, in the moment of their despair, a man from the mast-head gave the welcome intelligence that he could see a light ahead of the ship. All eagerly gazed in that direction, and in a few minutes could perceive it plainly. Before long they were close up with it, and, to their exceeding joy, found their captain and all their comrades in the boats, lying to leeward of the dead whale, whose bulk in some measure sheltered them from the violence of the sea.

After securing the whale alongside, all came on board, and were received, it is needless to say, as men who had been rescued from the grave.

The following narrative is also recorded as authentic; its pathos cannot fail to move the reader :- 
On an August evening, many years ago, Captain Warrens, the master of a Greenland whale-ship, found himself becalmed among an immense number of huge icebergs, in about seventy-seven degrees of north latitude. On one side, and within a mile of his vessel, these were of colossal height, and closely wedged together, like an array of giants; while behind them appeared an almost endless succession of snowy peaks, showing that the ocean in that direction was completely barred against the adventurous mariner. No wonder, then, that our captain felt dissatisfied with his situation; but owing to the dead calm which prevailed he could not move in one direction or the other. His vessel lay as motionless as

\section{"A painted ship \\ Upon a painted ocean ;"}

and all he could do was to maintain a strict watch, knowing that he was safe so long as the bergs continued in their respective places. About midnight, however, the wind suddenly rose to a gale, and dense showers of snow descended, while a succession of thundering, grinding, and crashing noises showed only too clearly that the ice was in motion.

The vessel experienced violent shocks every moment, for the haziness of the atmosphere prevented those on board from discovering in what direction lay the open water, or whether there were any at all on either side of them. The night was spent in tacking as often as any sign of danger was observed. . In the morning the storm abated, and Captain Warrens found to his great joy that his vessel had sustained no serious injury. He remarked with surprise that the close barrier of icebergs had been broken up by the fury of the storm, and that in one 
place an open water-way wound its course among them as far as the eye could discern.

It was two miles beyond the entrance of this canal that a ship made her appearance about noon, looking, in the misty distance, very much like a phantom vessel, and attracting the captain's attention from the strange manner in which her sails were disposed, and the dismantled aspect of her yards and rigging. She was observed to drift before the wind for a few furlongs, and then grounding upon a low field of ice, remained immovable. Captain Warren's curiosity was strangely excited. Whence came this mysterious vessel? What was her errand? Could she be navigated by human hands? The captain leaped into his boat with several seamen, and hastily rowed towards her.

As he drew near, he noticed that her hull was waveworn and weather-beaten; and that not a soul appeared on the deck, which was covered with snow to a considerable depth. He hailed her repeatedly; but no reply was made. Previous to stepping on board, an open porthole near the main-chains caught his eye, and, looking, he could just discern the figure of a man reclining in a chair, with writing materials on a table before him, but in the faint glimmering light he could not see very distinctly. So with some of his men he went upon deck, and having uncovered the hatchway, which he found - closed, descended into the cabin.

Captain Warrens was a.brave man, and accustomed to face danger, but he could not contemplate without emotion the strange spectacle before him. Its inmate retained his former position, and seemed utterly indifferent to the presence of strangers. And well he might be; 
for he was dead! He had a pen in his rigid hand, and before him a log-book, in which the last sentence ran as follows :-

"November 11th.-We have now been enclosed in the ice seventeen days. The fire went out yesterday, and our master has been trying ever since to kindle it again, without success. His wife died this morning. There is no relief."

Without uttering a word, Captain Warrens and his seamen hastened from the spot.

Arriving at the principal cabin, their attention was attracted by the dead body of a female reclining on a bed, as if enjoying a calm, untroubled sleep. All the freshness of life still remained on her countenance, and it was only the contraction of the limbs that showed her form was inanimate. Seated on the floor was a man in the very prime of life, holding a steel in one hand and a flint in the other, as if in the act of striking fire upon some tinder which lay beside him. He too was dead. And the dead bodies of several sailors were found lying in their respective berths, while that of a boy was crouched at the bottom of the gangway stairs.

Neither provisions nor fuel could anywhere be discovered; but Captain Warrens was prevented, by the superstitious prejudices of his followers, - for seamen are the most superstitious of all human beings, perhaps because they come so constantly into contact with the mysterious forces and weird influences of Nature,--from inspecting the vessel as closely as he could have wished. He contented himself, therefore, with carrying away her log-book; and returning to his ship, immediately steered to the southward, leaving behind him a "romance of the 
seas," which, for its strange icy horror, could not be surpassed by the most inventive imagination. What might not be made out of it by a poet's pen! What better subject could be desired than that lonely ship, with its dead crew, moving silently through the icy seas, and carrying such a burden of unutterable woe!

On returning to England, Captain Warrens made the necessary inquiries respecting the owner of the vessel and her destination; ascertained the names of her crew ; and discovered that she must have been "frozen in" fully thirteen years before he had encountered her among the polar ice.

A remarkable illustration of the immense strength of the whale was afforded by the fate of the American whaler Essex, which stands almost alone in the annals of whaling adventure.

Late in the "fall of the year," when in lat. $40^{\circ}$ of the South Pacific, she fell in with a "school" of sperm whales, and immediately manned three boats and despatched them in pursuit. The mate's boat was struck by one of the leviathans, so that he was compelled to return to the ship to repair the damage sustained. While this was being done, a sperm whale, estimated to measure fully eighty-five feet, "rose" about twenty yards from the ship on her weather-bow. He was going at the rate of about three knots an hour, and the ship at nearly the same speed, when he struck the bows of the latter just forward of her chains.

So great was the force of the collision, that the ship quivered with it like a leaf. The whale dived under her, just grazing her keel, and then reappeared at about the 
distance of a ship's length, lashing the sea with his huge tail in mingled rage and agony. That he had suffered from the collision was evident; but in a few minutes he seemed to recover himself, and started with great swiftness directly across the vessel's course to windward. Meantime, the men on board the Essex discovered, to their horror, that she was gradually settling down forward, and the pumps were immediately rigged. While working at them, the cry arose:- " Heaven have mercy on us! he comes again !"

The whale, when about one hundred yards from the ship, had suddenly turned, and, as if intent on vengeance, was making for her with double his former speed, his trăck being clearly marked by a line of foam. Rushing head on, he struck her again at the bow, which was driven in by the tremendous blow. Then the whale again dived and disappeared ; and the ill-fated vessel foundered in ten minutes from the first collision.

The crew took to their boats, and after enduring very severe hardships, reached the low shores of Ducies Island on the 20th of August. It was a bare and dismal sandbank, but contained a spring of fresh water, and was frequented by numbers of wild-fowl. On this barren spot three of the men preferred to remain, rather than once more tempt the cruelty of ocean. The remainder, in three boats, started, on the 27 th of December, for the island of Juan Fernandez, distant two thousand miles. Of these, the mate's boat, with three survivors, was picked up by the Indian of London, ninety-three days from the date of the catastrophe. The captain's boat fell in with an American merchant vessel on the 23rd of February, having no more than two men living, and 
these had saved their lives only by having recourse to an expedient at which humanity stands aghast. The third boat was never heard of, nor have any tidings of the three castaways on Ducies Island reached civilized men.

We might multiply almost indefinitely these painful narratives. Nor are they without value; inasmuch as they bear a strong though indirect testimony to the courage, endurance, and seamanship of the adventurous men who, season after season, prosecute an enterprise beset by so many forms of peril. It seemed to the old Latin poet that the hero who first committed himself and his bark to the mercies of the waves must have been armed in a triple panoply of resolution; what would he have said of the gallant spirits who yearly dare the dangers of the whalefishery, and penetrate into the ice-bound straits and inlets of the Polar world?

Our next anecdote is derived from the record of an American whaler.

Early one morning, while cruising in the North Pacific, he caught sight of a whale, and immediately despatched a couple of boats in pursuit. They overtook the "monster," delivered their harpoons, and having "made fast," were rapidly towed by their struggling victim out of sight of the ship. Meantime, another whale made its appearance within a few yards of the vessel. The captain had but one boat on board, but he could not brook the idea of losing a goodly prize. He ordered it to be lowered and manned, and leaving the ship in charge of one seaman and two boys, took the direction of it himself, and started in chase of the whale. 
After a vigorous pull, he came up with it, and the harpooneer soon got in his fatal weapon. The wounded animal at first took a headlong course, which carried her assailants a distance of fifteen miles from their vessel. Then she dived perpendicularly into the ocean-depths. Rising after a few minutes, she bore down upon the boat with open cavernous jaws; but the captain steering skilfully, she missed her aim, and again she dived.

She rose a second time, and repeated her manœuvre of attack; but the captain was on his guard, and steered his boat out of danger. The third time he was less fortunate. The infuriated whale came up under the boat with tremendous violence, and striking it in the centre of the keel, hurled it fully fifteen feet into the air! Fragments of planks, and oars, and sailing gear were quickly strewn over the surface of the waters, and among them the captain and crew struggled bravely for their lives. The whale had finally disappeared; and each man clung with the energy of desperation to the pieces of the shattered boat. Their situation was most terrible. They were fifteen miles from the ship, and out of sight to any one on her deck; but were it otherwise, the vessel could not be put about by the few hands so imprudently left on board of her. As for the other boats, it was impossible to say what had become of them. Even to the most sanguine all hope of safety seemed gone; and when their strength gave way, nothing was left for them but a watery grave.

It was noon. How slowly passed the hours may be conceived by those who have known the long, lingering agony of suspense,- -have watched, perhaps, by the bedside of some beloved one, and waited with sickening (502) 
dread for the issue of the struggle between life and death! The shadow of twilight at last began to creep over the waters, and still the unfortunate mariners, worn, weary, and almost spent, clung to the spar or plank which was their only chance of safety. "Oh, how fervently I prayed," said one of them afterwards, "that God would interpose to save our lives! I thought of my wife, of my children, of my prayerless life, of the awful account $I$ had to render at the bar of God for grieving the Spirit, neglecting the Saviour, and absenting myself from his sacraments. All the horrors of the dreadful death which threatened me were forgotten in the thought that I was about to render up an account before the bar of God for years of ingratitude and disobedience."

Now came still evening on. The last rays of the sunset had disappeared below the horizon, and the darkness of the coming night was already at hand. Just as all hope seemed vanishing, they descried in the dim distance one of the whaling boats returning to the ship. It was so far off, however, that the chances of attracting the attention of her crew were very meagre. In their despair they raised a loud simultaneous shout; but it was drowned by the many voices of the winds and waves. The boat continued on her path. A second shout; but this too proved ineffectual. What could be done? The darkness was growing deeper; the boat was rapidly passing into the gloom. They raised yet another shout-or rather shriek - a cry of desperation and suffering, which rose above the swell of the billows, and was borne to the ears of their comrades! They rested on their oars. Another shout! The boat turned towards them; oars 
were strenuously plied; it drew nearer and nearer; and they were saved!

Dr. Scoresby relates a melancholy incident which happened to one of his crew while he was in command of the whaling-ship Baffin. He had sighted a whale, and despatched his boats in pursuit. After an absence of some hours, which had greatly alarmed him, he saw them returning; and on their coming within hail, his anxiety induced him to inquire if anything had happened. "A bad misfortune has befallen us," replied the officer in charge of the first boat; "we have lost Carr!" Scoresby was exceedingly shocked by intelligence for which he was wholly unprepared ; and some time elapsed before he felt able to listen to the details of the accident which had deprived him of a good seaman.

As far as could be ascertained from the confused accounts of the crew of Carr's boat, the circumstances were as follow :-

The two boats that had been so long absent had, at the outset, separated from their companions, and, allured by the chase of a whale and the fineness of the weather, had proceeded until they were far out of sight of the ship. Their hot pursuit led them into the midst of a vast "school." So numerous, indeed, was the assemblage that the "blowing" was incessant; and the men believed that fully a hundred "monsters" were gathered there together. The whalers were puzzled by the embarras de richesses before them! They feared lest they should alarm them without striking any, and for awhile rested on their oars, waiting for a favourable opportunity to deliver the attack. At length a whale rose so near the boat of which 
William Carr was harpooneer that he ventured to pull towards it, though it is never a good or prudent plan to meet a whale, and generally proves unsuccessful. However, they encountered the huge creature, and Carr contrived to harpoon it. The boat and the whale sweeping past each other with great rapidity after the stroke, the line was jerked out of its place, and, instead of running out at the stern, was thrown over the gunwale, where its pressure so overweighted the boat that the side sank below the water, and she began to fill. In this emergency the harpooneer, a man of great strength and activity, seized the bight of the line, and, in order to relieve the boat, made an effort to restore it to its place; but, through some strange and unaccountable mishap, a turn of the line flew over his arm, dragged him overboard instantly, and he sank-to rise no more!

The accident was so terribly sudden that only one man, who was watching the harpooneer's movements at the time, was aware of what had happened; so that when the boat righted, which, though full of water, it did immediately, all the crew, alarmed by an exclamation of the man who had seen him launched overboard, simultaneously inquired, Where was Carr? It is surely impossible to conceive of a death more awfully sudden and unexpected! "The murderous bullet," says Scoresby, "when it makes its way through the air with a velocity that renders it invisible, and seems not to require a moment for its flight, rarely produces so instantaneous destruction. The velocity of the whale on its first descent is usually (as I have proved by experiment) about eight or nine miles per hour, or thirteen to fifteen feet per second. Now, as this unfortunate man was occupied in adjusting the line at the 
very water's edge, when it must have been perfectly tight, in consequence of the obstruction to its running out of the boat, the interval between the fastening of the line about him and his disappearance could not have exceeded the third part of a second of time; for in one second only he must have been dragged to the depth of ten or twelve feet! The accident was, indeed, so instantaneous that he had not time for the least exclamation; and the person who witnessed his extraordinary removal observed, that it was so exceedingly quick, that although his eye was upon him at the instant, he could scarcely distinguish the object as it disappeared."

To Dr. Scoresby we are indebted also for our final illustration of the dangers to which the whaler is constantly exposed. Yet there is such a fascination in the life, that a supply of good and steady seamen is never wanting. Whether at Hull or Dundee, at Peterhead or Lerwick, the whaling-ship finds no difficulty in making up her complement. It cannot be the attraction of gain, for the payment, though liberal, is not excessive, and assuredly cannot be set in the opposite scale against the hardships and dangers to which the Arctic navigator is compelled to accustom himself. We are inclined to believe that the glittering field of ice, the snow-burdened shore, the drifting berg, and the lonely creeks and inlets of the Polar Ocean, exercise a wonderful influence upon the adventurous spirit. Whoever has once entered within the charmed circle of the Arctic regions seems never at rest until he can return thither. Their strange and marvellous scenes haunt him apparently by day and night, and his thoughts turn as steadfastly towards the North as the soul of a devout Moslem towards Mecca! And it is a 
fancy of ours, judging from personal observation, that the whaler is always graver, more reserved, and less excitable than other "sons of the sea;" and such may well be the ease in men who spend so much of their lives in Arctic solitudes, and are so constantly brought face to face with death. To none can the simple but earnest words of Scoresby's prayer, written specially for the use of the crew of a whaling-ship, come with greater force: "Grant us, we beseech thee, O God, a continuance of thy favour; preserve us, while we trace the treacherous deep, from every evil-from rocks and shoals ; from fire and tempest; from sea and ice; from distress and accident; and from every danger, seen and unseen, known and unknown."

The catastrophe we are about to relate occurred on the homeward voyage of the Baffin.

She had been overtaken by a violent storm, but no water had yet been shipped, though the tremendous sea that was running beat with all its fury on the vessel's quarter or beam, being in a direction of all others the most dangerous. A fital wave, however, at length struck the quarter with tremendous violence, and throwing up a vast weight of water, carried along with it, in its passage across the deck, one of the harpooneers, or principal officers, who, in concert with several others, was employed on the weather-rail, endeavouring to secure one of the boats hanging over the side,-carried him quite over the heads of his companions, and swept him into the sea! Most of the crew being under water at the same time, his loss was not known until he was discovered just passing under the vessel's stern, but out of reach, and lying apparently insensible upon the waves. He was seen only for a few seconds, and then disappeared for ever! 
Some minutes elapsed before the identity of the missing individual could be ascertained. Every one was greatly distressed, and each, in his anxious exclamation, revealed his anxiety for his friend. "It is Shields Jack," one ex- claimed. "No," replied a voice of pathetic self-congratulation; "I am here." "It is Jack O'Neill," exclaimed another; "ay, poor fellow, it must be Jack O'Neill!" But a dripping, stupor-stricken sailor, clinging by the weather-rail, stepped forward suddenly, and answered, "No; I am here." After a pause of suspense, a voice added, "It is Chambers." "Oh, it must be Sam Chambers," cried another; and none contradicted the assertion, for, in truth, it was the unfortunate seaman so named who had thus suddenly and awfully perished.

But here we must stop, not, indeed, from want of material, for the annals of the whale-fishery are full of these distressing incidents, but from want of space. Moreover, the reader may be disposed to think that of such sombre narratives he has already had enough.

\section{V.-THE HERBIVOROUS CETACEA.}

From these monstrous Cetacea we turn to a group presenting a certain likeness to them in form and organization, but differing in their habits, and distinguished by the absence of spiracles, or blow-holes, and by the position of the nostrils, not on the upper part of the head, but at the extremity of the proboscis. These are the Herbivorous Cetacea of our naturalists ; the "tritons" and "sirens," it is said, of ancient mythologists ; and the "mermen" and "mermaidens" of modern fable-makers.

The reader is probably familiar with the legends that in course of ages have clustered round the sirens and 
the mermaids; legends descriptive of their wonderful beauty, on which it was ruin for man to look, and of their exquisite singing, to which it was death for man to listen. The sirens, it was said, lingered among the rocks and caves of the wild sea-shore, and on the approach of a vessel, raised immediately their choral song, which had such a power in its melody, that the mariner, in spite of himself, was drawn towards the singers, and thus knowingly steered his vessel into the jaws of destruction. Homer tells us that Odysseus saved his own life and the lives of his crew only by an ingenious stratagem. He caused his men to stop their ears with wax, and then directed them to bind him firmly to the ship's mast; so that though he heard the wild and wailing music, which they could not hear, he was unable to yield to its temptation. The classic myth descended to the medieval poets, and, combined with some rude fancies of the Norse, developed into the well-known story of the Men and Maidens of the Sea, the mermaids and mermen, who occupy so large a space in our modern poetry. Of these it was said that they lived a charmed life in the restless waters; and the beautiful mermaids were described as sleeking their long golden tresses in the ocean brine, or sporting gracefully on the sunlit waves. Tennyson has embodied the popular conception in one of his most graceful lyrics :-

"I would be a mermaid fair;

I would sing to myself the whole of the day ;

With a comb of pearl I would comb my hair,

And still as I combed I would sing and say,

'Who is it loves me? Who loves not me?'

I would comb my hair till my ringlets would fall

Low adown, low adown,

From under my starry sea-bud crown,

Low adown and around,

And I should look like a fountain of gold 
Springing alone,

With a shrill inner sound, Over the throne

In the midst of the hall;

Till that great sea-snake under the sea

From his coiled sleeps in the central deeps

Would slowly trail himself sevenfold

Round the hall where I sate, and look in at the gate

With his large calm eyes for the love of me.

And all the mermen under the sea

Would feel their immortality

Die in their hearts for the love of me."

It is difficult to believe, though such is asserted to be the case, that poetical figures like these could have been suggested by the somewhat ungraceful outline and inexpressive countenance of the Herbivorous Cetacea. To the ordinary observer, at all events, the resemblance is not apparent. And considering the fact that the Herbivorous Cetacea frequent the mouths of the tropical rivers, while the ancient navigators knew but little of the western and southern waters, we may reasonably doubt whether they had anything to do with the ancient fable of the sirens. We do not see why the plastic and prolific imagination which peopled the fountains with Naiads and the groves with Oreads, should not, unassisted, have created the singing-nymphs of ocean, whose music mingled artfully with the murmur of the whispering waves.

The Herbivorous Cetacea (order Sirenia) include the Manatee, so named on account of the resemblance of its fin to the human hand, and the Dugong; often spoken of collectively as "sea-cows," and forming the zoological family of the Manatidce. Like the whales, they possess a powerful caudal fin, which is placed horizontally. The anterior limbs are modified into flippers or swimmingpaddles, and the posterior are wholly wanting. The snout is fleshy and well developed; the thick upper lip usually 


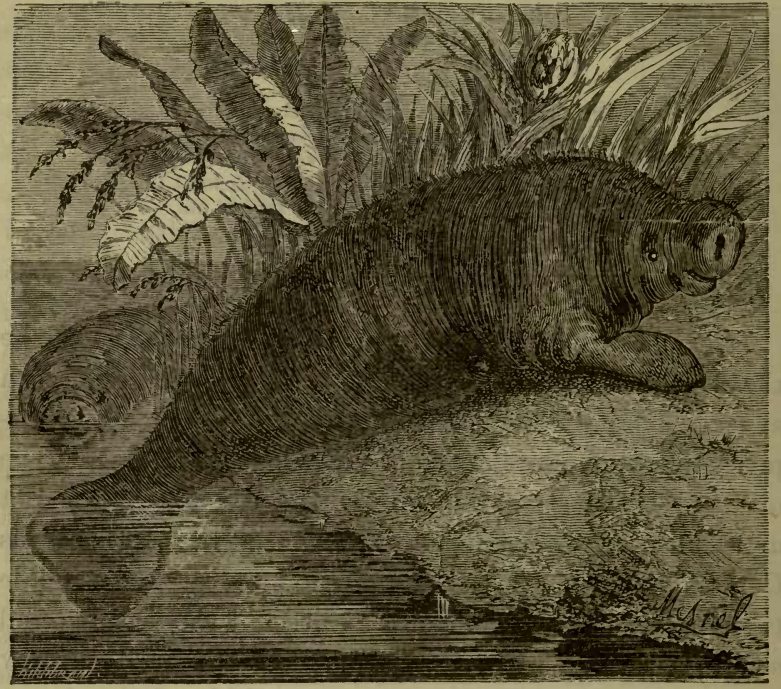

THE MANATEE.

carries a moustache. The skin is covered with fleshy bristles. The head is not so huge or disproportioned as in the true whales, and is much more distinctly defined.

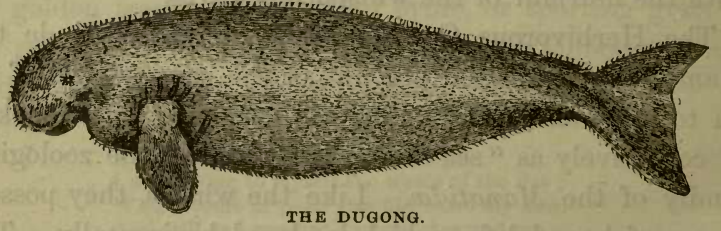

The anterior limbs of the manatee, which is found in the Gulf of Mexico, and on the east coast of Africa, are furnished with nails to the four outer digits. 
The anterior limbs of the dugong, which frequents the shores of the Indian Ocean, are nail-less.

The manatee sometimes attains the length of twenty feet; but neither the manatee nor the dugong often exceeds ten to twelve feet. They agree exactly in their habits, living upon aquatic plants, sea-weed, and the usual littoral vegetation. Their flesh is edible. 


\section{CHAPTER XVIII.}

THE SEAL : AND THE SEAL-FISHERY.

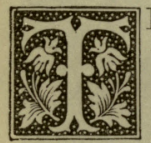

HE seals and walruses are now included among the Carnivora, and form a section which zoologists call Pinnigrada or Pinnipedia. This section is subdivided into the two wellknown families of the Seals (Phocidce) and Walruses (Trichecida).

Almost everybody, we imagine, is familiar with the SEAL, and can call up to "the mind's eye" a distinct picture of its semi-quadrupedal, semi-piscine body. Horace, in an often-quoted passage, imputes it as a fault to the painter if he should delineate the figure of a beautiful woman as terminating in a fish's tail, -

\section{"Ut turpiter atrum}

Desinat in piscem mulier formosa superne."

But Nature, in creating the seal, has come very near to incurring the poet's censure. The fore part of its body is that of a mammal, the hind part that of a fish, except that it resembles the quadrupeds in the possession of two posterior limbs. These, however, are placed far back, their axis being nearly coincident with that of the body. As they are partly included in the general integument, their position renders them efficacious in facilitating the 
animal's motions in the water. The tips of the toes are equipped with strong claws, and the toes are united together by a membrane, so that the feet form powerful swimming-paddles.

It must be owned that the physiognomy of the seal is peculiar; the peculiarity being due to the short snout, the orbits without eyebrows, and the rounded conformation of the large skull. The general expression, however, is characterized by mildness and intelligence. The ears are small, and mostly indicated only by small apertures, which the animal has the power of closing when beneath the surface. The large eyes are on a level with the head; their pupil resembles that of the domestic cat, which contracts in a full light, but dilates and grows circular in the darkness. The dental system varies, but there are always present three kinds of teeth, and the canines are long and pointed. The tip of the large fleshy tongue is slightly indented. On either side of the mouth project long bristling hairs, like moustaches, which communicate with nerves of considerable magnitude. The nostrils are placed near the extremity of the snout, each presenting two longitudinal apertures which form almost a right angle. Usually they are closed, and it would appear that the animal opens them only when it needs to exhale the air from the lungs, and to inhale fresh atmospheric air. The usefulness of this contrivance to an animal remaining long under water is very evident. Moreover, it enjoys an extraordinary faculty of suspending the respiratory function for intervals of half a minute or more, while at each inhalation it takes into its lungs a very considerable quantity of air.

With regard to the "senses" of the seal, it may be 
said that its power of vision is superior to that of the whale, and it is able to distinguish objects at some distance.

Its hearing must necessarily be imperfect, because it possesses no external organ to collect and transmit sounds. It is probably deficient in sense of smell ; and as for taste, there is so little variety in its food, for it lives chiefly upon fish, that it can but seldom, and only to a slight extent, be called into requisition. It is instinct, we suspect, rather than taste, which confines the animal almost exclusively to one kind of fish. At least, in captivity, it will refuse all fish to which it has not been accustomed. We may admit, however, that this apparent fastidiousness may be the result of habit.

It will be seen, then, that, from our human point of view, the organization of the seal is defective, and that the senses are but partly developed. Yet, as a writer remarks, it is able to derive from its limited sensations a result much superior to that obtained by many animals of an apparently more favourable organization. For it is endowed with a large and vigorous brain; a brain rich in circumvolutions; a brain which, in not a few individuals, is even proportionately more voluminous than it is in man. Hence, it has been found possible to tame the seal; to accustom it to the sound of the human voice; and to teach it the performance of various devices. A "pelforming seal" is by no means an infrequent exlibition in our great cities. Numerous experiments have shown that the animal is capable of the emotions of gratitude and attachment; and when captured young, and humanely treated, it will exhibit a dog-like affection for its owner. 
The seals compose a very numerous family, and species are found in almost every sea beyond the limits of the Tropics. It is in the waters of the Arctic and Antarctic regions, however, that they specially abound. On the shores and ice-fields of the north they may still be encountered in large herds. For two-thirds of the year the locality they inhabit is shrouded in gloom,-in the gioom of mist and fog, of rain and hail,-illuminated only by the occasional splendours of the aurora, or the mysterious lustre of the midnight sun. No flower-enamelled leas, no blossomy gardens, no leafy groves relieve the painful monotony of the whitely-gleaming landscape; and the silence is seldom broken, except by the sound of winds and waves, or the shrill clang of the ocean-birds. The land of the seal is also the land of Winter. There it reigns in all the awfulness of its terrible power; spreading a shroud of ice and snow around; withering every form of vegetable life; freezing the human breath as it passes into the air ; and killing in fatal slumber the unprotected man who may lie exposed to its fatal influence. Wherever you gaze, the sea is covered with a rough stratum of ice, intersected by channels of water, and rising here and there in irregular hummocks; while the bleak shores are burdened with snow-drifts, which the wind sometimes sweeps away in blinding showers, and sometimes accumulates in lofty masses. The cliffs are encumbered with colossal glaciers, descending like huge torrents of ice from the inland mountains, to break up, when the tardy summer comes, into towering icebergs, - floating mountains or iceislets of every size and shape,- -which the currents bear far away to dissolve in warm Atlantic waters or run aground on lonely barren shores. This is the land of the seal. 
Here, with the narwhal and the polar bear, the arctic fox and legions of ocean-birds, it breeds its young, and fulfils its part in the great economy of creation. Civilized man is yearly tempted to cross the inhospitable borders of this sombre region by greed of gain, or desire of knowledge, or love of adventure; yet, however well he may be assisted by the discoveries of science, he is forced to confess himself an intruder. He has done much, but much remains to be done. Leagues of sea remain unploughed by adventurous keel; leagues of frozen land have never been trodden by human foot. Thinking of those remote Polar solitudes, we are tempted to believe that Nature has there established her laboratory, and that to guard its secrets from the insatiable curiosity of science, she has thrown up around it an impenetrable barrier, made terrible by the hoarse roar of winds and waters, by the lurid glow of magnetic splendours, and the sound

\section{"Of thunder heard remote!"}

The seal, as we have said, lives chiefly on fish, but does not disdain crustaceans and molluses. It is exceedingly fond of basking in the sun on the summit of weedy rocks or the surface of the icy plains, though it experiences some difficulty in elimbing the slippery slopes. When thus enjoying its ease, the inexperienced voyager might suppose that it would fall an easy prey; but it is always on the alert, and at the slightest sign of danger throws itself into the sea, or glides through the hole which it has taken care to excavate in the ice. The Eskimos, in hunting them, use a canvas frame or screen, which they cautiously propel in advance of their persons, and, by a patient process of stalking, contrive to approach within 
rifle-shot. With a good glass, says Dr. Kane, you may study these animals in their natural habitudes without

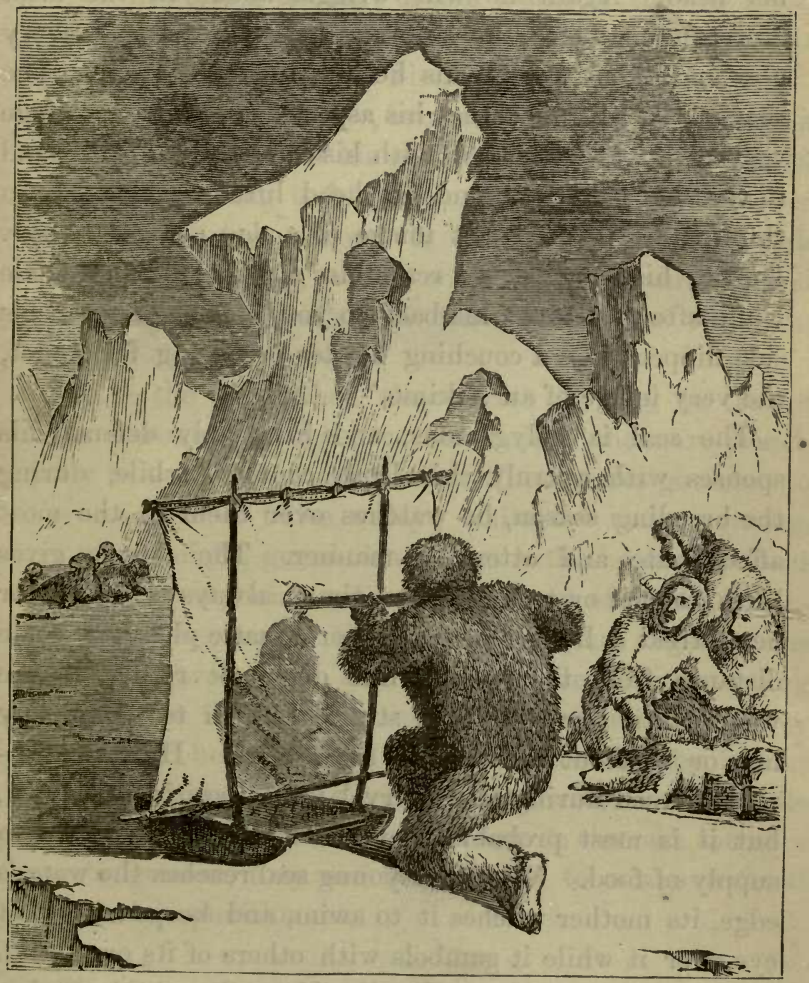

STALKING SEALS.

exciting their suspicion. As thus scen, in the centre of a large floe, and within retreating distance of his hole, the seal is "a perfect picture of solitary enjoyment, roll(502) 
ing not unlike a horse stretching his hide, awkwardly spreading out his flippers, and twisting his tail toward his head. Again he will wriggle about in the most grotesque manner - the sailors call it 'squirming'-every now and then rubbing his head against the snow. The shapes of a seal, or rather his aspects, are full of strange variety. At a side view, with his caudal end slued round to the side from you, and his head lifted suspiciously in the air, he is the exact image of a dog-chien de mer. During his wriggles, he resembles a great snail : a little while after, he turns his back to you, and rises up on his side flippers like a couching hunter preparing for a shot, the very image of an Eskimo."

- The seal is polygamous, and invariably defends his spouses with a truly chivalrous courage, while, during the breeding season, he watches over them in the most affectionate and attentive manner. The female gives birth to one or two cubs at a time; always selecting for her retreat a litter of sea-weed or aquatic plants at some distance from the shore. She does not return to the water until her young are strong enough to accompany her, or in about a fortnight after birth. How she supports herself during the interval is not positively known, but it is most probable that the male carries to her a supply of food. When the young seal reaches the water's edge, its mother teaches it to swim, and keeps a vigilant eye over it while it gambols with others of its own kind. Should signs of danger appear, she takes it upon her back, and hastens to convey it to a place of safety. The suckling-season lasts for four or five months; at the end of which, when the youngster can attend to its own wants, the old male drives it to a distance, and 
teaches it in the most practical manner the value of independence.

An interesting account of the habits of the fur seals, which migrate every spring to the Aleutian Islands, has been given by Sir George Simpson.

Each old male, he says, brings to this summer-station a herd of females under his protection, the herd varying in number according to his size and strength; the "weaker brethren" being obliged to content themselves with half-a-dozen wives, while some of the sturdier and fiercer fellows preside over harems that are two hundred strong.

From the time when they arrive in May to that of their departure in October, the whole of them are principally to be found on the beach. The females go down to the sea once or twice a day; while the male, morning, noon, and night, guards his charge with the most jealous vigilance, postponing even the pleasures of eating, drinking, and sleeping to the duty of keeping together his numerous favourites. And should any impertinent young seal venture by stealth to approach a senior chief"s "bevy of beauty," he is generally torn in pieces by the jealous sultan, and atones for his imprudence with his life; while should any of the "fair ones" have given the rash intruder encouragement, they are not suffered to escape without appropriate punishment.

The Common or Vituline Seal (Phoca vitulina) is the species generally pursued by the hunters in the Arctic regions. It measures from four to five feet in length, and is of a yellowish-gray colour, covered with irregular spots of black or blackish brown. Its form is cylindri- 
cal, or, more correctly speaking, conical, for it diminishes in bulk from the region of the chest towards the short broad muzzle in front and the rudimentary tail behind. Its large black shining eyes are protected by eyebrows, formed of a few stiff hairs; the ears, though scarcely

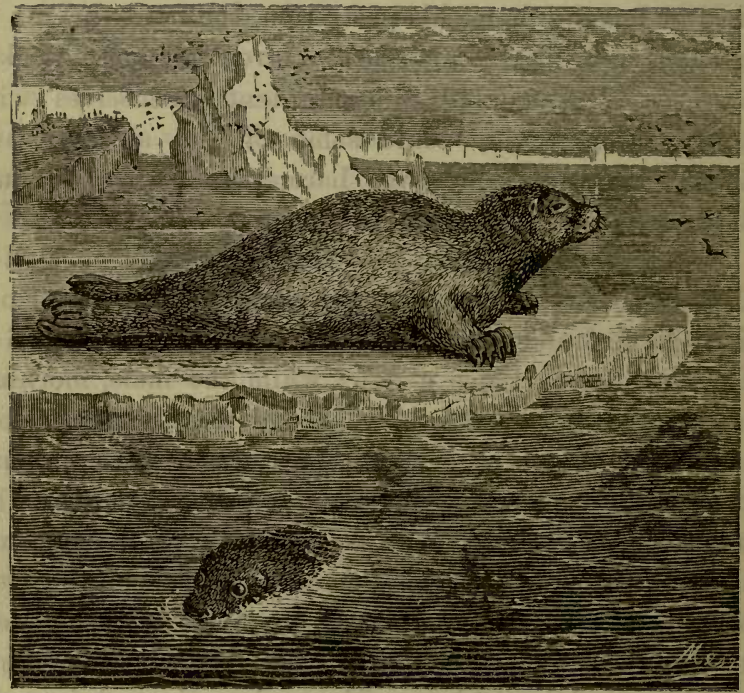

THE SEAL.

visible, are fully developed. The principal characteristic of the species seems to be the oblique disposition of the molar teeth, which cause them to overlap slightly at the extremities.

The common seal is found in all the northern waters of Europe, and at one time was a frequent visitor to the western coast of the British Islands and the shores of 
France. It is still not uncommon on the Scottish coast and among the Northern and Western Isles. Readers of Sir Walter Scott's "Antiquary" will remember the appearance of an individual of the species we are describing in the neighbourhood of Fairport (that is, Arbroath), to the signal discomfiture of Hector M'Intyre, the hero of the story, and the infinite amusement of the erudite Oldbuck.

"What is that yonder?" exclaimed Hector.

"One of the herd of Proteus," said the Antiquary; " a phoca, or seal, lying asleep on the beach."

Whereupon, we are told, M'Intyre snatched the walking-stick out of the hand of the astonished Antiquary, at some risk of throwing him down, and set off at full speed to get between the animal and the sea, to which element, having caught the alarm, she was rapidly retreating.

Not Sancho, when his master, Don Quixote, interrupted his account of the combatants of Pentapolin with the naked arm, to advance in person to the charge of the flock of sheep, stood more confounded than Oldbuck at this sudden escapade of his nephew.

"Hector-nephew - fool-let alone the phoca, let alone the phoca! They bite, I tell you, like furies.- - He minds me no more than a post. There-there they are at it; and, look, the phoca has the best of it! I am glad to see it," said he, in the bitterness of his heart, though really alarmed for his nephew's safety; "I am glad to see it, with all my heart and spirit."

In truth, the seal, finding her retreat intercepted by the light-footed soldier, confronted him manfully, and having sustained a heavy blow without injury, she 
knitted her brows, as is the fashion of the animal when incensed, and making use at once of her fore paws and her unwieldy strength, wrenched the weapon out of her assailant's hand, overturned him on the sands, and scuttled away into the sea without doing him any further injury. Captain M'Intyre, a good deal out of countenance at the issue of his exploit, just got to his feet in time to receive his uncle's ironical congratulations on his safety, and on a single combat worthy to be commemorated by Ossian himself, "since," said the Antiquary, "your magnanimous opponent hath fled, though not upon eagle's wings, from the foe that was low. She walloped away," he added, "with all the grace of triumph, and has carried my stick off also, by way of spolia opima."

The moral of which story is, that if the reader in his sea-side wanderings should ever fall in with a phoca, either asleep or awake, he will do well not to attack it, unless armed with some better weapon than a walkingstick.

On the dreary shores of Greenland and Iceland, and along the coast of the Arctic Ocean generally, from Newfoundland to the Sea of Kamtschatka, ranges the Harp or Greenland Saddleback Seal (Phoca Gronlandica). It is also found on the western shores of our own islands, being occasionally conveyed thither by the western currents. Its fur is of a grayish-white colour. The back is marked with a blackish horseshoe-shaped band, which curves backwards from the shoulder to a point within a few inches of the root of the diminutive tail. This band is of irregular outline, and broadens laterally. The same brownish-black shade colours the anterior part of the 
animal's head, imparting to its physiognomy a singularly characteristic look.

This species leaves the Greenland coast twice every year, namely, in March and July, returning to its

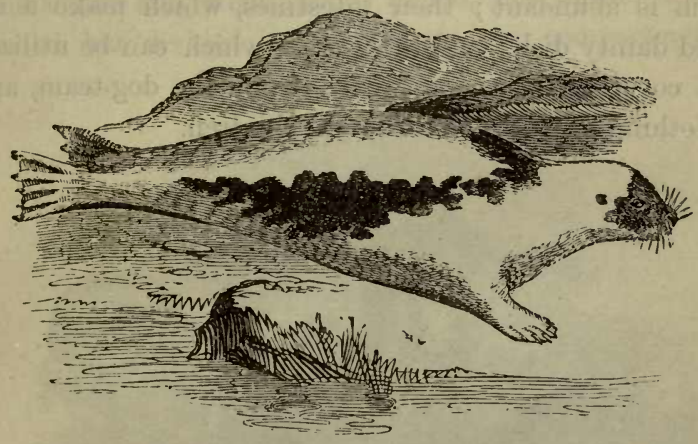

THE HARP SEAL.

haunt in May and September. Iike all the Phocidæ, it feeds upon fish and molluses, but is described as specially partial to salmon. Less intelligent than the vituline seal, it is more easily captured; and the seal-hunters value it highly on account of the excellent quality of its fur. In its habits it does not greatly differ from its congeners.

The Bearded or Great Neal (Phoca barbata) is considered by naturalists a distinct species; but the Danes look upon it as differing only in age from the Greenland saddleback. Adults frequently measure twelve and fourteen feet in length; and some orergrown, obese monsters weigh upwards of forty-five stone. The fur is very dark in colour, and somewhat coarse in texture. 
The bearded seals are found in all parts of the Arctic Ocean, resorting to the land in the spring months for breeding purposes. They are held in high esteem by the Greenlanders for their flesh, which is savoury; their fat, which is abundant; their intestines, which make a socalled dainty dish; and their skin, which can be utilized as a covering for tents, as harness for the dog-team, and as clothing for men, women, and children.

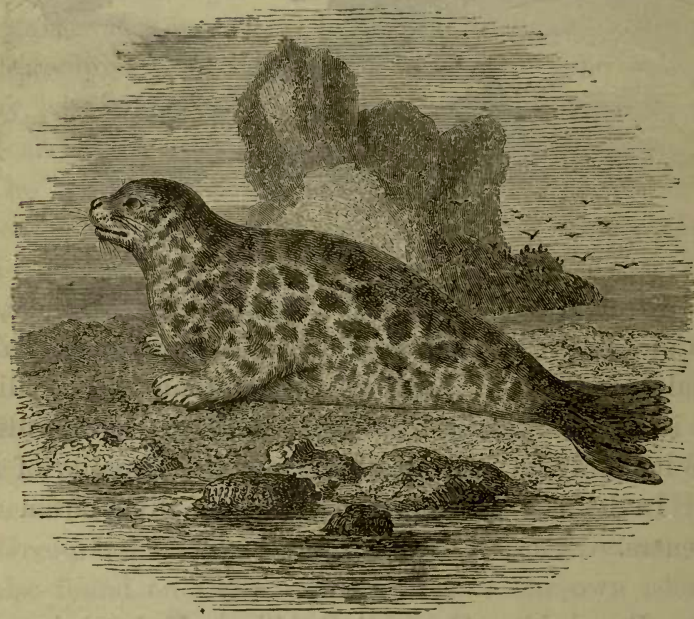

THE MARBLED SEAL.

The Marbled Seal (Phoca annulata) derives its name from the peculiar colouring of its fur. It frequents the French coast. Another species, the Gray Seal (Halichcerus gryphus), or Utscher of the Icelanders, not uncommon on our own shores, much more nearly resembles 
the walrus than the seal, though its canine teeth are not prolonged into tusks. A very remarkable species is the Crested or Hood-cap Seal (Otaria Falklandica), distinguished by the possession of a characteristic organ, a muscular and membranous pouch, not unlike a monk's hood, but divided internally into two compartments by

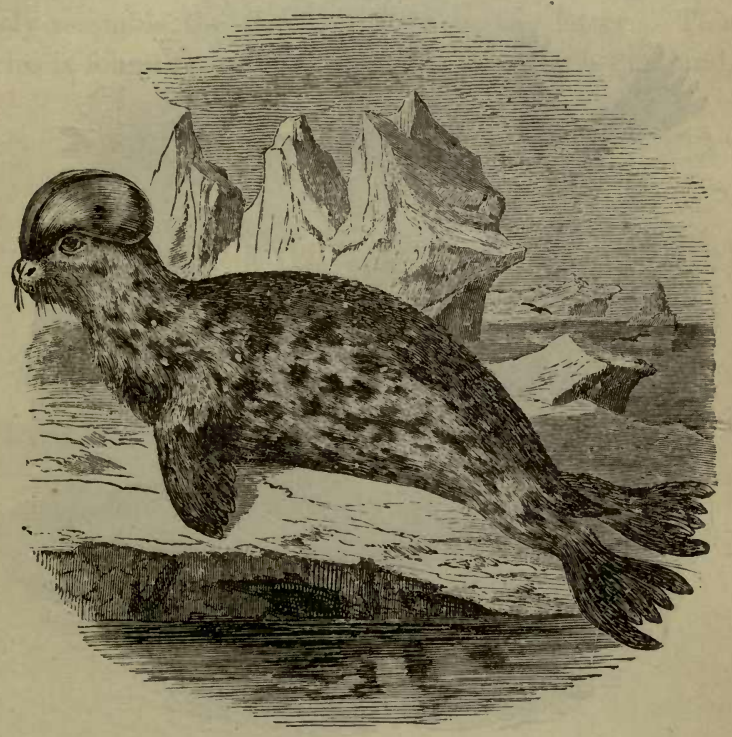

THE CRESTED OR HOODED SEAL.

the prolongation of the cartilaginous "septum" of the nose. By closing its nostrils the animal can inflate this pouch, like a bladder, so that it is distended over the skull, and swollen to a height of six or seven inches.

The hooded seal chiefly inhabits the vast ice-fields 
which lie off the coasts of Labrador and Greenland, and seldom visits the land, except in the months of April, May, and June. It measures seven or eight feet in length, and is considered a good capture by the sealhunters.

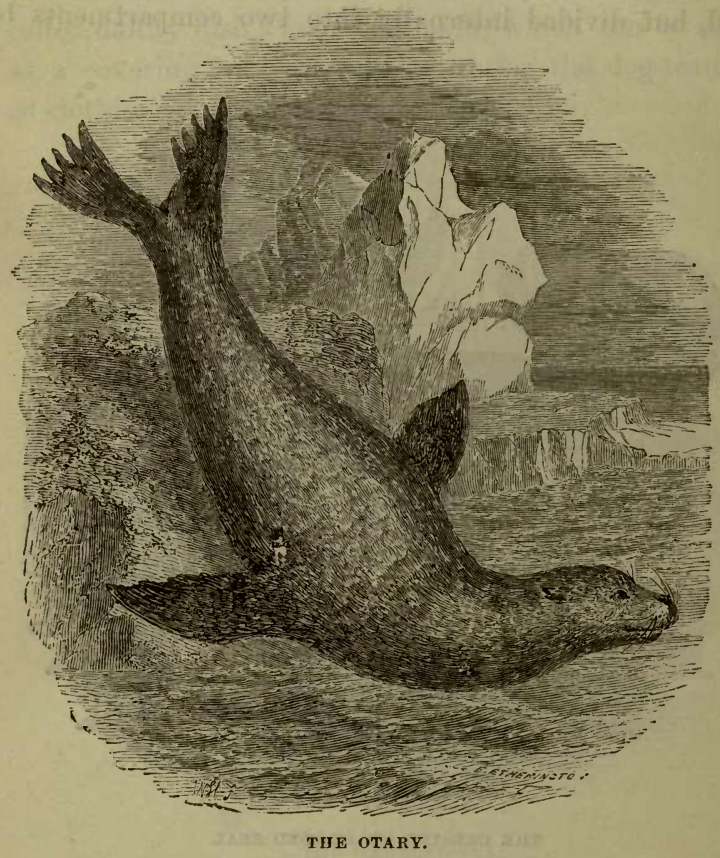

Hitherto we have confined ourselves to the Phocidx which belong exclusively to the northern regions. But south of the Equator are found two or three genera, which must be described in this connection, though the southern seals differ greatly from the northern. To the 
Fur Seal we have already alluded. It is one of the Otaries, which are distinguished from the rest of the Phocidæ by their projecting auricle, or "external ear," and by a peculiarity in their dentition-namely, a double cutting edge in the four middle incisor teeth of the upper jaw. The fore legs, moreover, are placed further back in the body than in the true seals; and the hind legs more closely resemble the fore legs than in the latter. This species is found on the Falkland Islands, South Shetland,

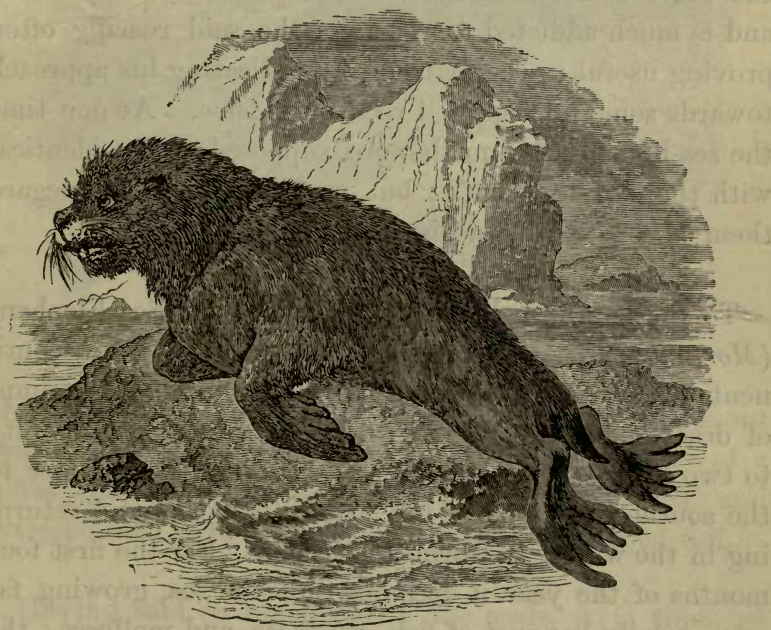

THE SEA-LION.

and in other parts of the Southern Ocean; and its soft brownish fur is much valued for ladies' mantles.

The Sea-Lions (Otaria jubata) of the South Pacific figure largely in a popular romance by the American novelist Cooper. They too are included among the 
Otaries; and their range includes the Falkland Archipelago, the coasts of Tierra del Fuego, and the neighbouring islands. Their average length is fifteen feet. They derive their picturesque popular designation from the shaggy yellowish-brown mane which clothes their neck, and gives them an imposing appearance; and it is fully justified by their fierce predatory habits.

Here we should state that a genus of sea-lions is found in the North Pacific, among the Kurile Islands, and on the coast of Kamtschatka. It has a thick, heavy mane, and is much addicted to. roaring; the said roaring often proving useful to the mariner, by indicating his approach tow ards some unsuspected rock or ice-floe. At one time the sea-lions of the north were supposed to be identical with those of the south; but modern naturalists regard them as constituting a distinct genus.

To the southern hemisphere belongs the Sea-Elephant (Morunga proboscidea), which haunts the great continental estuaries and the fresh-water lakes and swamps of desert islands ; living in herds of a hundred and fifty to two hundred individuals, migrating in the summer to the southern regions of the Antarctic world, and returning in the winter to warmer latitudes. For the first four months of the year it does not quit the sea, growing fat upon a daily banquet of fish, crustacea, and molluses ; the rest of the year it spends upon land. As it yields a large quantity of oil, it is much prized by the American sealers; and though a powerful animal, it does not often prove a dangerous opponent.

The average length of the sea-elephant is twenty-four feet. Its generic distinction is the proboscis-like muzzle 
or trunk of the male, to which its popular name alludes. Its skin is rough; of a bluish-gray, or, sometimes, a

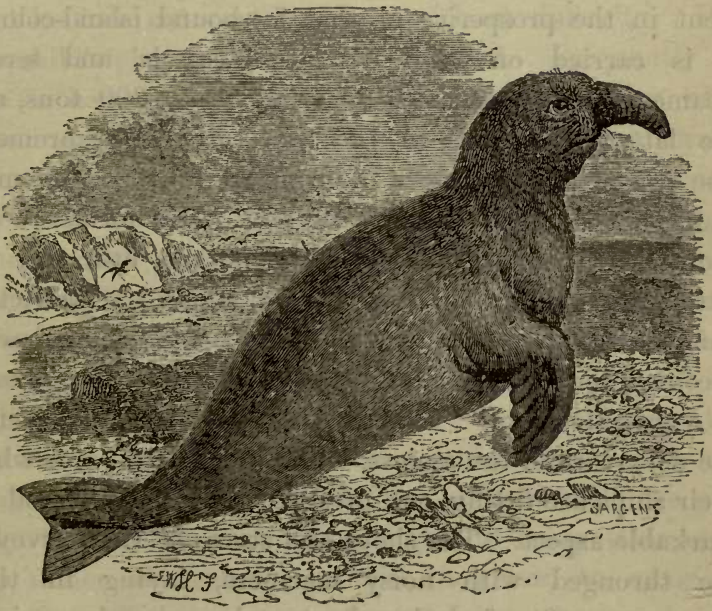

THE SEA-ELEPHANT.

blackish-brown colour. It has very large prominent eyes. The hairs in its moustache are rough, and of a spiral shape; its canine teeth are large, curved, and sharp-pointed. It has a short but fully developed tail.

Having said so much about the seals, it is time we turned our attention, and the reader's, to the sealers; that is, to the extensive commerce of which the unfortunate phocæ are the staple. The sealers pursue their adventurous calling in every part of the arctic waters, and belong to the chief maritime nations-England, France, Holland, Denmark, and the United States. One of the 
great centres from which they depart on their expeditions, and to which they bring back their spoil, is Newfoundland ; and the seal-fishery is, in fact, an important element in the prosperity of that fog-bound island-colony. It is carried on both by sailing-vessels and screwsteamers ; the former varying from 50 to 200 tons, and the latter from 350 to 700 tons gross measurement. The former muster crews of from 20 to 80 or 90 men, and the latter of from 120 to 250. The former begin their lucrative toil not earlier than the 5 th, and the latter not earlier than the 10th of March; a restriction enforced by the Colonial Legislature with the view of checking the indiscriminate slaughter of the young seals.

A graphic writer* tells us that for some days before the departure of the sealers, the principal sea-ports where their ships are fitting out present a very lively and remarkable aspect. The shops and stores of the purveyors are thronged with noisy mariners, laying in their necessary outfit of clothes, boots, tobacco, and a private stock of tea, coffee, and sugar. About and on board the vessels the uninitiated eye sees nothing but "chaos come again ;" a chaos of provisions, coals, punts, spare rudders, oars, gaffs, and sailing gear of all kinds and of unintelligible names. The yards are crowded with men, who are busily engaged in bending sails and overhauling rigging. And so the work goes on until the lawful sailing-day arrives; and then all hands are summoned on board-anchors are weighed-canvas is spread, or steam got up-and away speeds the adventurous flotilla, manned by gallant hearts accustomed to the perils of the arctic seas. Their course lies to the north or north-east until 
they approach the vast ice-field which, every spring, the southerly current brings down from the coast of Labrador. This ice-field swarms with the seal-hunter's victims; but he does not capture them without difficulty. It is no child's play in which he is engaged. Frequently the ice is hard and compact, and presents a barrier which the inexperienced voyager would pronounce insuperable. Then the ice-saws are got out, and a canal wide enough to admit the labouring ship is cut through the field, and she forces a passage under press of canvas, or with her engines working at their highest power, grinding the ice beneath her stem into so much diamond-dust, or heaved on her side by the pressure of the floating masses ; and all this amidst a driving storm of sleet and snow that blinds and bewilders the toiling sealers, and cruelly nips any exposed part of their bodies. Occasionally the wind blows so heavily that they are glad to bring their vessel up under an iceberg; careful, however, to moor her "stern on," that, in case of any mishap, she may be able to sail off without a moment's delay. For an iceberg, though apparently a friend in need, may prove an enemy in disguise.

Only four kinds of seals visit the Newfoundland waters; the harp, the hood, the "square fipper" (a rare visitant), and the dotard or ranger (a summer tourist). The harp seal whelps about the first week in March, and the hood seal about the second. Each gives birth to a single "calf," and breeds but once in a year. The seal-hunter greatly prizes the young harp or "whitecoat," its oil being the finest. It grows, as do all young seals, with astonishing rapidity; so that in a fortnight it attains its 
prime, and its skin and fat will weigh from forty to fiftysix pounds.

The seals are sometimes encountered in small companies, which have apparently separated from the main body; at other times, they form a dense population, to be numbered by hundreds of thousands. In their early days, and when the ice is close and compact, so as to afford an easy access, they fall before the hunter like grain before the sickle. A blow from his club, or a kick, is sufficient; and in a few seconds the skin and fat are stripped off, and slung over the hunter's shoulder. As soon as he has collected "a turn"- that is, four or five -he returns to the vessel with his booty, deposits it on board, and sallies forth intent upon another massacre. The work of destruction ends only at nightfall. But when the ice opens up beneath the influence of a genial breeze, and the young seal has grown strong and active, and takes to the water, prizes are not so easily obtained. Then the boats are launched, and pull up the various creeks and inlets in the ice, endeavouring to discover some floating isle on which a goodly number of the young phocæ have assembled, and then to surround it with an impassable cordon, and at "one fell swoop" capture the whole herd.

The young hood is caught in the same manner, but it is fiercer than the young harp, as well as rarer. Moreover, it comes into the world later, and after the ice is open, so that its chances of escape are more numerous.

The old dog hood displays a remarkable amount of courage, and does not hesitate to turn upon and give battle to his pursuers. He is tenacious of life, and his hood, which in his anger he inflates and erects on the 


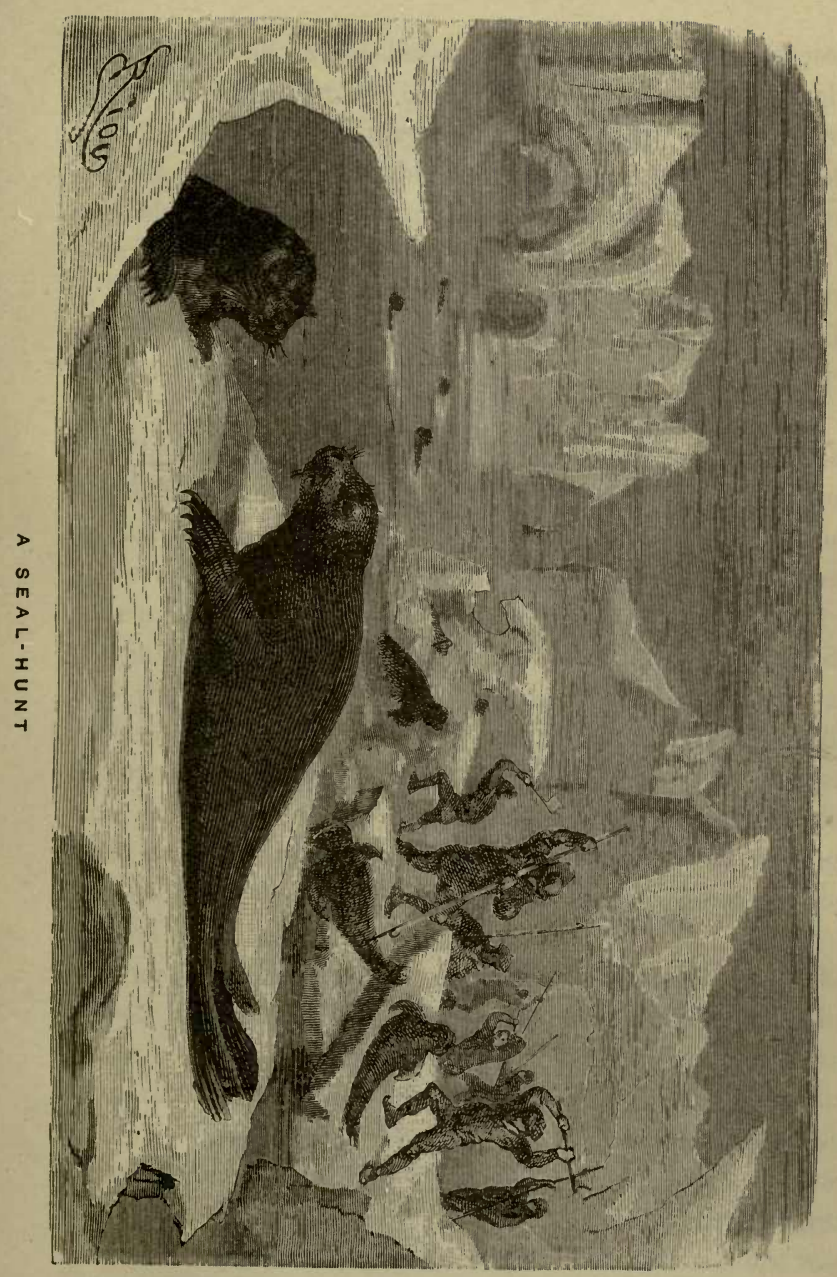




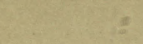

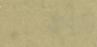

y.

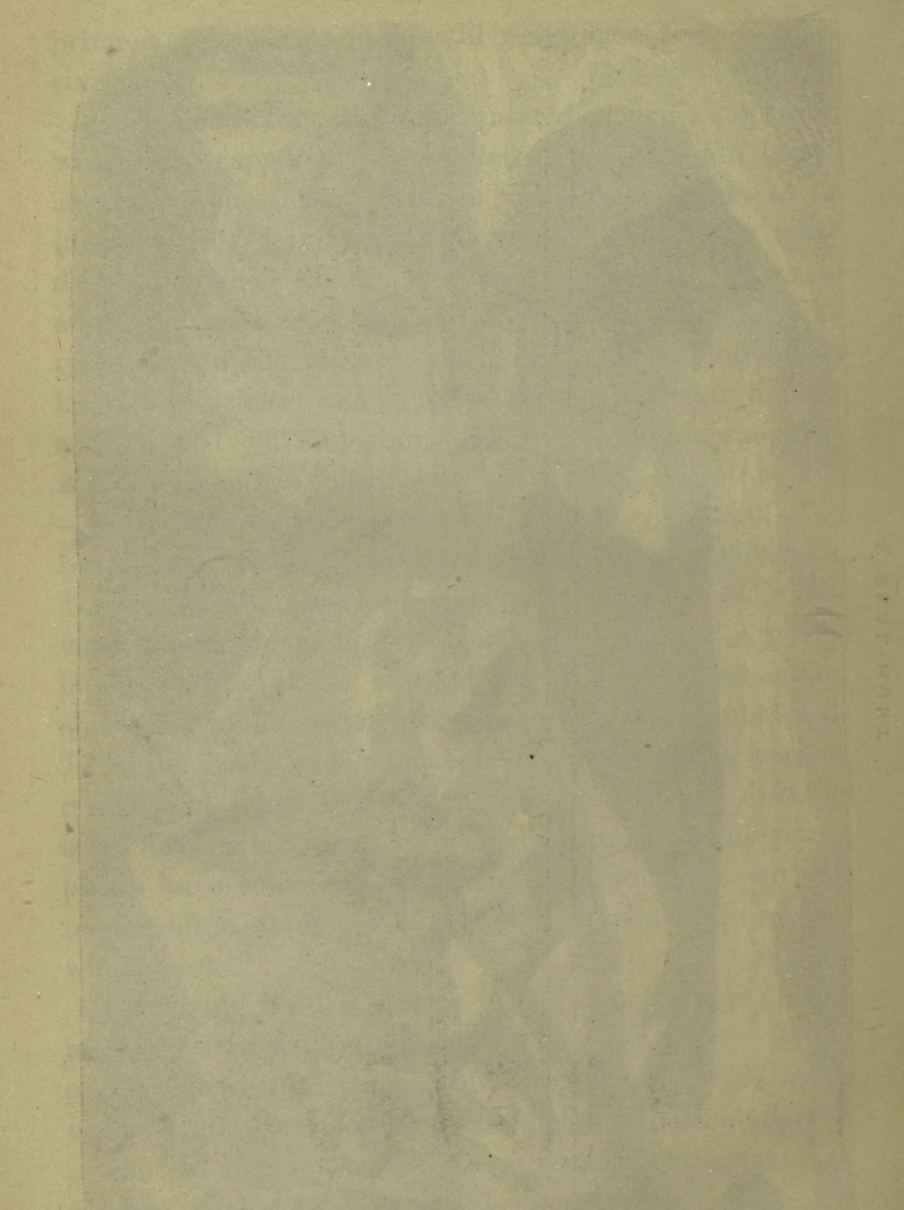


top of his head, being shot-proof, affords him great protec tion. But the victory, in a combat between man and the inferior animals, is always with the strong; and however gallant his resistance, he succumbs eventually to shots and blows, unless he can make his escape through some friendly hole in the ice.

The female hood is less courageous than her companion ; and as for the harp seals, both male and female are absolutely harmless.

When seals are plentiful, a vessel will soon complete its cargo, as many as one hundred seals having been put on board by a single man in one day. Such good fortune, however, is exceptional. The mode of loading has undergone a change since steamers were introduced. Formerly, it was usual to carry the seals on board as soon as killed; now the crew are divided into gangs, and work away at different stations on the ice; the steamer, as soon as the different loads, or "bulks," are ready, calling in succession at each station. This plan, of course, secures the least possible delay, but cannot be adopted by sailingvessels, from their inability to move freely amongst the broken ice.

Enormous cargoes are sometimes obtained, and the vessels loaded until their decks are nearly flush with the water. The following figures are borrowed from an authority already quoted:-In the spring of 1872, the steamer Commodore, belonging to Messrs. Panton and Mann, brought in 31,314 seals, weighing 655 tons, and valued in all at $£ 23,731,16 \mathrm{~s}$. 9d. This is the largest and most valuable cargo on record. The Commodore was only 290 tons, and as she sailed into port was very deep, 
the starboard side of her deck being actually in the water: had she been caught in a gale, and not been speedily lightened, she must have foundered. Her crew numbered 200, and shared upwards of $£ 39$ per man. In the spring of 1871, the sailing-brig Glengarry, belonging to the same owners, brought in 10,494 seals; but her crew, being fewer in number, shared $£ 53$ each. In 1873 , the steamer Eagle, owned by Browning Brothers, brought in over 30,000 seals: and about the same time, the steamer Neptune, belonging to Job Brothers and Co., gathered on her first trip 29,136 seals, and going out again, returned from her second trip with 12,326 ; the total weight being 913 tons, and the value $£ 27,906$, 5 s. 3 d.

The hazards of the sea are notorious, and the sealers are exposed to great variations of fortune, and numerous forms of peril. One day they will be rejoicing, for all around and about them are large herds of seals; the next day they may mourn, for not a phoca will be in sight! Of course, the reverse not infrequently occurs, and a vessel which one day has found the ice-fields as desolate as a volcanic peak, discovers them, next morning, swarming, teeming with life.

As for danger, the sealers have stout hearts and strong frames, are quick of eye and keen of wit; yet the ship that sailed from harbour in gallant trim often lies a shattered wreck among the ice-floes, and few of her crew return to tell the story of her fate. "The time for prosecuting the voyage is brief; therefore every hour is precious, and every mile gained of value. Accordingly, once under weigh, the skipper of a sealer enjoys no rest, 
spares neither men, vessel, nor gear. Everything is supposed to be of the best and strongest; and the strength of everything on board is well tested on the voyage. The skipper's constant thought is, - the seals are ahead, and ahead we must get, through fair weather or foul, sunshine or fog, rain, hail, or snowstorm; if the winds but blow and the canvas holds, on the vessel must go. The bold, daring hearts on board know no fear, heed not the storm, the icebergs around, or the dangers from the 'pans' and fields of ice enclosing them; undismayed and undaunted, they all beat in unison, and with determination to reach the golden prize ahead."

The great danger of the seal-fishery is the "running ice." In their pursuit of the seals the ships sometimes go inside the headlands of the bays. If the wind be blowing from the north-east, it greatly increases the force of the current which, in the spring of the year, always sets to the southward; and, accordingly, the ice is driven along with a tremendous whirl and crash, carrying with it any ressels unable to extricate themselves from the labyrinth and put out to sea. So long as the ice which holds the ressel prisoner keepis clear of the land, she is comparatively safe; but should it be caught by cape or promontory, it begins to accumulate, raft upon raft, and sheet upon sheet, grinding, tearing, crashing, splintering, with a din which appals the stoutest heart, and a force that menaces the stoutest ship with destruction. In such a case the crew endeavour to save their clothes, guns, and some provisions, and then take to the ice, with the view of effecting a passage to the nearest vessel, or to the land.

It is recorded that in the springs of 1862 and 1864 numerous disasters occurred from the running ice. From 
Harbour Grace alone, in 1862, went out twenty vessels which never returned; and the sufferings undergone by their unfortunate crews were very sad. In 1872, the Huntsman, sailing from Bay Roberts, was dashed by the running ice against a rock on the Labrador coast, and broken up into fragments. Forty-six of her crew perished; some being drowned, some crushed to death by falling spars, and some cut to pieces by the ice.

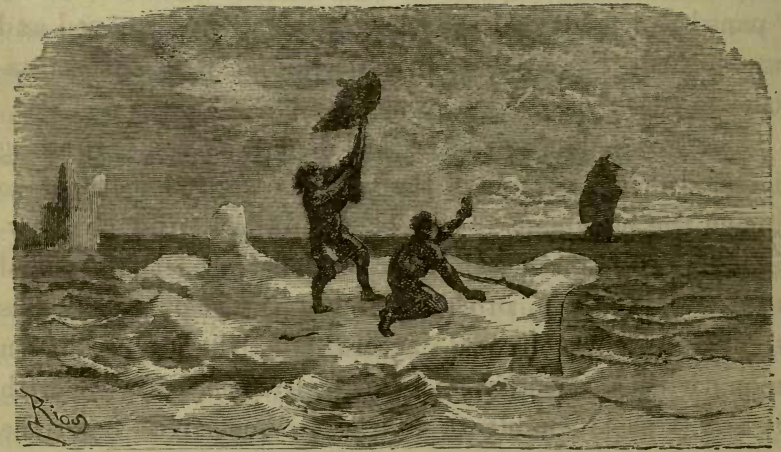

SEAL-HUNTERS ADRIF'T.

Then, again, while the seal-hunters are tracking their prey on the ice-field, it not infrequently opens up, and the floe on which they are collected is carried far away from the sealing-ship. Or some of the men, while in search of prey, or engaged in hauling their "turn" to the vessel, fall into the water, and perish miserably. Every sealer carries with him a seal-gaff; that is, a pole about nine feet long, with an iron hook at one end, and a sharp-pointed head of iron. With this he hooks into and drags the seals along the rugged ice; or he uses it as a 
leaping-pole in springing from one ice-floe to another; or when he finds himself sinking through some treacherously thin crust, he flings his gaff across it, and holds on until help arrives, or he succeeds in clambering on to a sounder piece of ice. Sometimes, however, the gaff gives way, and the sealer disappears for ever.

Every year a marked decrease is observable in the number of sailing-vessels employed in the fishery. On the other hand, the number and size of the steamers is constantly on the increase. The consequence is, that a large body of men will annually be thrown out of employment, since it is not probable that a sufficient fleet of steamers will ever be despatched to provide berths for so great a number of men as were employed by the sailing-ships. The steam fleet at present takes about 8500 men, and the sailing fleet about the same. Fifteen years ago the number employed was nearly 15,000 . As the quantity of seals that visit the coast cannot furnish remunerative cargoes for many more steamers. it may be assumed-says our authority - that on the extinction of the sailing fleet not more than 5000 men will obtain berths, fully an equál number thus losing, as they term it, "their chance at the ice"; a serious matter for consideration to the political economists of a country whose population is increasing. There are not wanting prophets of evil who predict that by the employment of steamers the seals will speedily be exterminated; and though this is probably an extreme supposition, it is certain that the supply is not inexhanstible, and that the seal-fishery, like the whale-fishery, if not more economically pursued, will grow less and less profitable. 
The weight of the different kinds of seals varies considerably. The young harp, in its prime, weighs from 45 to 60 pounds; the young hood, from 50 to 60 pounds; the one-year-old "bedlamer," * about the same as the young hood; the two-year-old "bedlamer," from 60 to 75 pounds; the old female harp, from 70 to 90 pounds ; the male, from 85 to 110 pounds; the old female hood, from 90 to 150 pounds; and the old dog hood, from 100 to 300 pounds. The square fipper, which is rare, sometimes weighs 650 pounds. "In these weights," says the writer in the Scotsman already quoted, "the skin and fat alone are meant; the carcass is of no use, and is always left on the ice when skinned. The value of the seals varies according to the demand for and the price of seal oil and skins; 35s. per cwt. is a good price for young harps, which are the highest in value. The others grade as follow, each 2 s. per cwt. under the preceding quality: -young hoods, bedlamers, old harps, and, lastly, old

- hoods."

After the seals have been brought into port and landed, they are weighed; next, they are placed in the hands of the skinner, who separates the fat from the skin. The fat is cut up by an apparatus of cutting-blades, set in motion by steam, and then steamed, so as to render up the oil more easily - the greater portion of the oil thus obtained being tasteless, inodorous, and clear as water. The residuum of blubber is stowed in bags, and submitted to a heavy pressure, which extracts a brown and inferior quantity of oil. From the steaming-pans the oil is drawn off into tanks, and thence into casks of various sizes,

\footnotetext{
* Seals when one or two years old, whatever their species, are called "bedlamers."
} 
ready for exportation to Canada, England, and the United States.

The skins are simply salted, and then stored until the time comes for shipping. They are sent to England, where they are manufactured into excellent leather, remarkable for its softness, its polish, and its waterproof qualities.

The average catch of seals in the Newfoundland fishery has amounted to about 350,000 annually for the last twenty years.*

The seal-fishery is of great antiquity. From various allusions in the Sagas, it was evidently pursued by the old Norsemen; and some of these very Sagas, we are told, are written upon seal-skin prepared in the same way as parchment. It was energetically conducted at the epoch of the Roman conquest of Germania, for Tacitus describes the warriors of Hermann or Arminius as clothed in the skins of seals. Of the same material were made the Roman tents, at least during the best days of the Empire; but it is probable that seals were then more numerous in the Mediterranean than they are now, unless their skins were procured from the north in the course of trade. From the employment of seal-skin as a covering for tents came the old superstition that it was a safeguard against lightning; and Augustus, whose nervous dread of thunderstorms is an historical fact, always wore a piece upon his person as a talisman. This curious lightning-nonconductor was in great favour with Septimius Severus, and eventually came into general use

* The number reached 463,531 in 1873 ; at least, that number of seal-skins was exported. 
among the Roman legions. The Scandinavian mariners made excellent cables of seal-skin for mooring their galleys, or fastening them, in combat, to those of their antagonists ; and the Finns and Lapps paid their annual tribute in these ingenious substitutes for ropes. And it is probable, also, that they employed them, as do the Greenlanders at the present day, in covering the framework of their ships.

In the fourteenth century the seal-fishery had attained to a position of considerable commercial importance. Not only was the animal hunted for the sake of its skin and oil, but also for its flesh, which in England and Scandinavia figured as a dainty on the tables of the wealthy. And here we may remark that modern voyagers, who have had occasion to live upon it, speak of it as not unsavoury, and as tasting much like veal. Dr. Kane writes that he and his men in course of time grew very fond of it. At first they disliked "the fishiness," but to this they became accustomed, and of its nutritiousness there can be no doubt. Captain Hall gives a very minute account of a seal-banquet, particularizing the different dishes with epicurean gusto :-

The head was first served up; and when the meat, skin, and hair were all despatched,-even the eyes, except the balls, which, according to an Inuit custom, were given to the youngest child,-Captain Hall and his Eskimo entertainers "tapped" the brain. He was surprised at the amount of a seal's brains, and equally so at the deliciousness of them! The skull, he noticed, was almost as thin as paper.

Afterwards came a portion of seal's liver. This, with a slice of ooksook (blubber), was handed to each person. 
Then came the ribs, enclosed in tender meat; and next, the entrails, served up in pieces of two to three feet long. "I saw at once," says Captain Hall, "that it was supposed I would not like to eat this delicacy, but having partaken of it before, I signified my wish to do so now; for, be it remembered, there is no part of a seal but is good."

This quotation is a digression, perhaps, but it serves to explain the great value of the seal to the Greenlanders. Their pastures are the billowy tracts of ocean; their fishery is their harvest; their herds of seals are as necessary to their maintenance as oxen and sheep to the Englishman, the palm-tree to the Arab, or the cocoa-nut to the islanders of the South Pacific.

Not only, as a Dutch writer remarks, do these animals supply them with food and clothing, but with roofs for their huts and tarpaulins for their canoes. They burn the seal-oil during the protracted darkness of the dreary arctic winter; they feed the fire with it which cooks their food, and use it to preserve their stock of dried fish. With the smaller fibres they manufacture sewingthread, not much inferior to the English housewife's silk or cotton. The same material is woven into screens or curtains for their doors, and into a kind of coarse stuff for their under garments. The bladders are used as vessels for holding liquids. And before the enterprise of European traders brought iron within their reach, they wrought their tools and implements out of the bones of the indispensable and multifarious seal.

In that yearly massacre which for four centuries has been carried on so vigorously, the Eskimos, therefore, 
play no unimportant part. They do not pursue it on the extensive scale adopted by the Americans or Europeans: but they know the value of the seal, and they continually hunt it down. The net, the harpoon, the club, the rifle, -all these weapons are employed against the unfortunate phoca. It is useful to man, and man, accordingly, has no mercy upon it. He watches by its air-hole in the ice, and prepares to strike it on its rising to the surface. Or he clothes himself in seal-skins, or in garments of the same colour and shape, and posting himself on a weedy, surf-beaten rock, he imitates its peculiar cry, and having enticed it within range, delivers a mortal blow. Does man ever spare any creature which is necessary to his comfort or his ease?

When a seal-hole is found, the Eskimo wraps himself in his warmest furs, and, with his spear in his hand, stations himself beside it; sitting there for hours, silent, motionless, vigilant, and occasionally thrusting his spear through the snow to strike, and make sure of, the small aperture leading through the ice. In aiming at a seal, it will not do to miss the exact spot where the animal comes to breathe; no, not by a quarter of an inch. To know this exact spot the Eskimo will frequently place over it some trifling mark, and then, when he hears the seal blow, down speeds the fatal spear, and the animal is captured.

"The shyness of the-seal," says Dr. Kane, "is proverbial. The Eskimos, trained from earliest youth to the pursuit of them, regard a successful hunter as the great man of the settlement. If not killed instantaneously, the seal sinks and is lost."

On one occasion, when near Ovinde Oerme, in Melville 


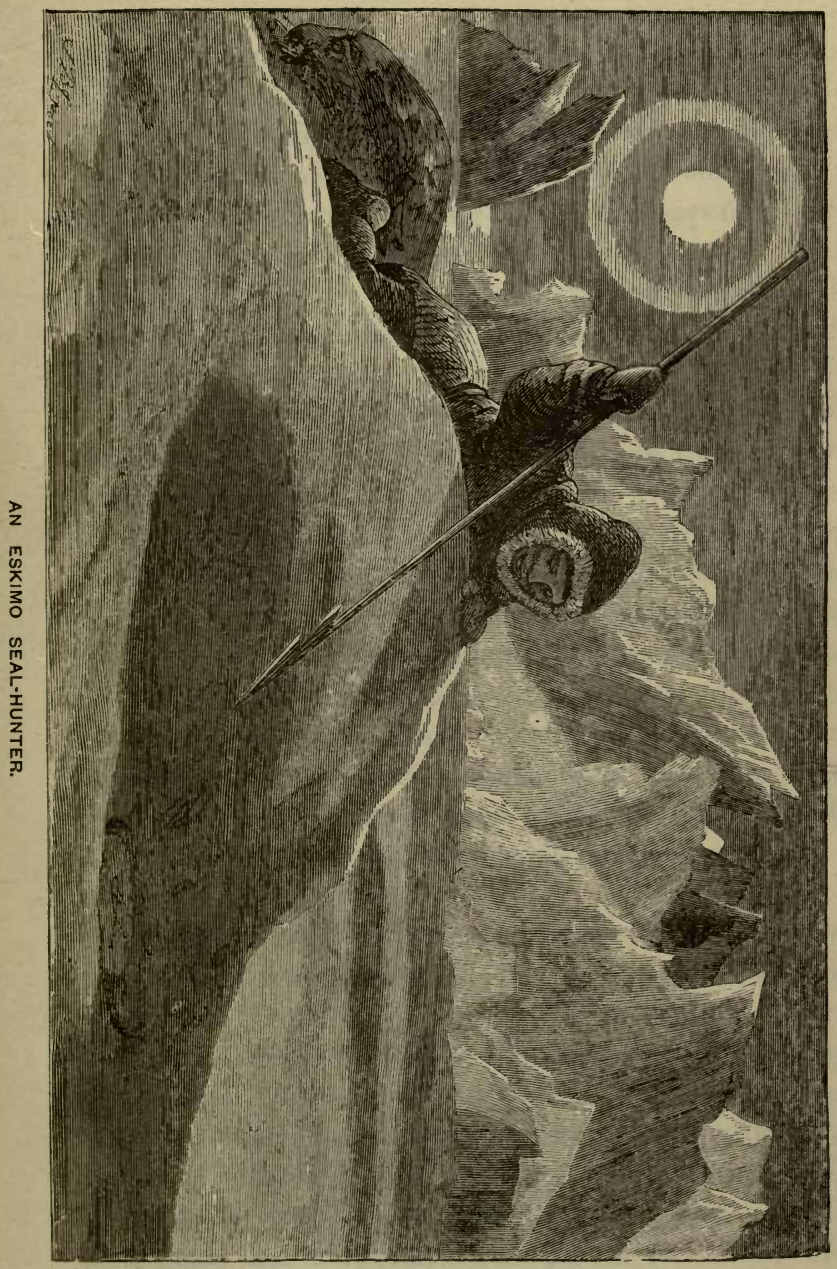



Bay, Dr. Kane fell in with a great company of seals. Hundreds of all varieties were disporting themselves in absolute freedom. Generally they were to be seen paddling about alone, but sometimes in groups, like a party of school-boys frolicking in the village-pond. One of their favourite sports was "treading water," rising breast-high, keeping up a boisterous and indefatigable splashing, and stretching out their necks in an attitude of eager curiosity.

Some of the younger of these poor sea-dogs had just the honest expression of their land-brethren, the Eskimos; in others, the truncation of the muzzle, with an external ear showing behind it, set their faces in almost perfect and human-like oval. Now and then, an imprudent seal would rise up out of the water near the hunters, and, lifting up his head and shoulders, that stooped like those of a hooded Eskimo, would gaze steadily at them with his liquid eye; then diving, come up a little nearer, and stare again; so gradually approaching, and rising and diving alternately, would come within musket-shot,-- to - fall a victim to his ungovernable curiosity.

A curious mode of fishing is practised by the natives of Gothland, and of the other isles in the upper waters of the Baltic.

In March and April, when the ice begins to give way, they assemble in numerous companies, and set forth on their seal-hunting expeditions in iron-keeled galleys, attended by light boats which draw but little water. They are provided with a supply of food, and with powder, shot, guns, and harpoons. Pushing to the northward, they get entangled in the narrow channels intersecting 
the ice, and hauling their vessels upon the floes, drag them across its hummocky surface by sheer physical labour. Meanwhile, the light craft go ahead to explore the labyrinth, while trained dogs disperse in all directions to drive the seals from their hiding-places. If the hunters encounter them upon the ice, they knock them down with their clubs before they can slip through the air-holes or escape to their retreats; but if they take to the water, the more experienced hunters spring into their boats, and endeavour to harpoon them; while others, posted on the ice, watch the various crevasses through which the animals disappear, or fire at them on their coming to the surface, and drag ashore the killed or wounded. Sometimes, when he misses his aim, the hunter fares ill at the hands of the phoca, which, ordinarily mild, and even timorous, grows furious under incessant provocation, and turns upon its assailant.

In the northern seal-fisheries the hardy seamen of the Shetland Isles participate. The Greenland ships, chiefly from Dundee and Peterhead, arrive in Lerwick harbour towards the end of February or the beginning of March, in order to complete their crews with these skilful and resolute sons of the sea. Their number is now from fifteen to twenty, though formerly much larger, and each vessel engages from twenty to thirty Shetlandmen. During their stay in Bressay Sound, writes Dr. Cowie, large numbers of men and lads flock to Lerwick from all parts of Shetland, each eager to obtain a berth. Since the number of ships employed in the fishery was reduced, berths have become more difficult to be obtained, and, consequently, the masters have been able to "pick" their 
crews. It is not uncommon, says Dr. Cowie, to see young men walking over the shoulders of their less favoured components of a crowd, in order to make their way to the office where a Greenland skipper is "feeing" his crew!

The sealing-fleet leaves Lerwick about the 10th of March, for the sealing-ground in the neighbourhood of the volcanic isle of Jan Mayen, which it reaches in a week or ten days. Then commences the destruction of the unfortunate phocæ; and the vessels, if successful, return home to discharge their cargoes of blubber and skins. But if their captures be few, they proceed to the whale-fishing at North Greenland or up Melville Bay.

A sealing-voyage generally occupies about six weeks. Each man employed receives about $£ 2,10$ s. a month, and 2s. $6 \mathrm{~d}$. for each ton of blubber brought home. Thus, should the vessel make, as is generally the case, a hundred tons, the seaman will receive $£ 16$ for his six weeks' work.

After landing their cargoes at Dundee or Peterhead, these ships generally sail for the whaling-ground at Davis Strait, calling again at Shetland to complete their crews. From this second voyage they usually return in the month of October, though sometimes a whaler gets frozen up, and is compelled to winter in the Arctic regions, at the risk of terrible suffering and even loss of life.

Such are the principal methods of seal-hunting to which man has had recourse. But the great fishery, as we have said, is almost entirely in the hands of the British and the Americans; and during the season from three to four (502) 
hundred sealing-ships, bearing the Union Jack or the Stars and Stripes, will be found off the rocky coast of Labrador.

"And there we hunted the walrus, The narwhal, and the seal;

Ha! 'twas a noble game!

And like the lightning's flame

Flew our harpoons of steel." 


\section{CHAPTER XIX.}

\section{CORAL: AND THE CORAL-FISHERY.}

"Where the red coral blushes 'neath the waves."

N a volume devoted to the Great Fisheries of the World, it would be impossible not to include a description of the coral-fishery; for though it adds nothing to our food-supplies, it forms the staple of a considerable industry, and provides occupation for a large portion of the human race.

Down to the last century ConaL was regarded as a vegetable product. As such it was described and classified by the ancient naturalists, by Theophrastus, Dioscorides, and Pliny. At a much later date, we find it included by Tournefort, along with various madrepores, in his seventeenth class. Such a mode of classification seemed more justifiable than ever after Marsigli's discovery of what he called the "flowers of coral." Marsigli, a native of Boulogne, where he founded the Institute of Science and Art, and a scientific inquirer of great ardour and industry, having directed his attention to the subject of coral, was induced to place a branch which he had received fresh from its ocean habitat in a vessel of sea-water. "Next 
morning," he writes, "I found my coral-sprays completely covered with white flowers, each about a line and a half

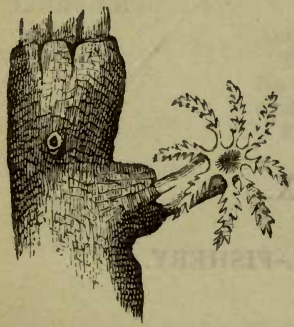

CORAL POLYPE. in length, supported on a white calyx, from which eight rays of the same colour issued, these rays being of equal length, and equidistant, and the whole forming a very beautiful star, resembling in colour and nearly in size the clovepink." He adds that this discovery procured him a reputation suspiciously like that of a magician, in his neighbourhood; no one, not even the fishers, ever having seen anything resembling this supposed efflorescence.

This incident occurred early in the eighteenth century. In 1725 a French physician, named Peysonnel, announced to the scientific world that the little stars described by Marsigli, and mistaken by him for flowers, were really and truly animals, identical in organization with those which were then called "sea-nettles," but are now known as "actinias" and "sea-anemones." This conclusion, though at first disputed, is now accepted by all zoologists; the coral is a polype, with polypids. It has since been investigated and confirmed by Darwin, Dana, and Lacaze-Deuthiers.

The word coral comes from the Greek, and signifies a "sea-ornament." The appellation is a proof of the high value set upon the substance by the ancient Greeks. It was celebrated by Orpheus in his "Hymns;" Ovid alludes to it in his "Metamorphoses." It was supposed to be gifted with valuable medicinal properties, and mysterious 
secret virtues ; the priests and soothsayers declared it was agreeable to the gods; and even at the present day some of the Eastern nations are accustomed to deposit a few grains of coral in the last resting-places of their dead to keep them safe from the infernal genii. But it is more particularly as an object of luxury that coral was, and is, sought after. According to Pliny, the Hindus esteemed it not less highly than the pearl; and they still retain the same partiality. The Gauls made use of it, as the Asiatics do even now, to decorate their swords and helmets. Everywhere women valued it for the purposes of personal ornament; and this may justly be said of it, that it harmonizes as well with the ebony black of the Ethiopian as with the dazzling fairness of the Circassian.

But now we come to the all-important question, What is coral?

We reply, a calcareous secretion or deposit of many kinds of zoophytes, belonging to the class Actinozoa.

These zoophytes are compound animals, which reproduce their kind by a process known as "germination:" that is, as buds spring from a plant, so do young coral-buds spring from the parent animal ; sometimes, on any part of its surface ; sometimes, only from its base, or from its upper circumference. They continue always in the same spot, even when the parent polype has perished, and they in their turn are throwing off fresh buds. While the zoophyte is still a simple polype, the process of calcareous deposition commences. It attaches itself to a rock or some other substance, and here its deposit agglutinates, and generation after generation enlarges the structure 
begun in so unpretending a manner. Sometimes, layer after layer, or ring after ring, of calcareous cells surround one another, like the concentric circles in the trunk of an aged oak; sometimes, layer is built upon layer, like courses of masonry; sometimes, the coral assumes the

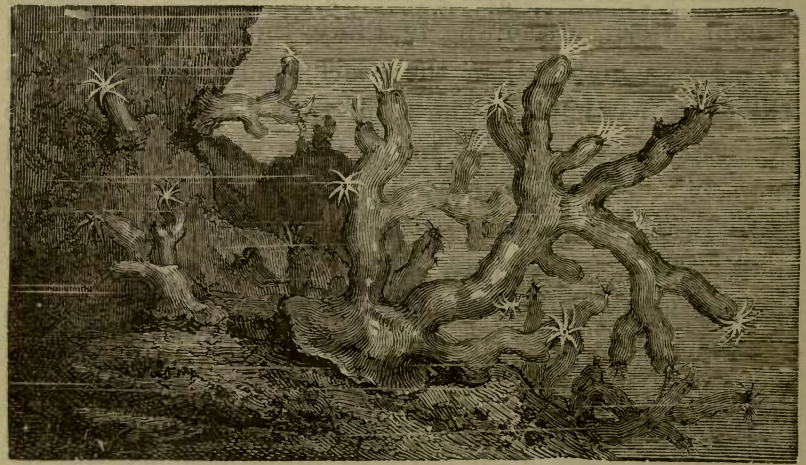

BRANCHES OF CORAL.

ramified aspect of a tree; sometimes it expands into the shape of a floral calyx. But always the structure is fanciful and elegant, and always the workmanship is consummate.

Numerous species are included in the interesting division of corallines, or coral-producing zoophytes ; most of which have been distributed by naturalists in the order Zoantharia, and the families Antipathidoe and Hyalonemadoe.

With respect to the modes in which the composite corals are produced, we may offer the following remarks, founded upon Professor Greene's elaborate examination of the subject. 
The production of the composite Actinozoa takes place either by germination or fission.

There are three kinds of germination, the basal, the parietal, and the calicular.

In the first-named the mode of increase is by means of a rudimentary coenosare, ${ }^{*}$ or common bond of connection, which is put forth by the original polype, and on which the young polype-buds are produced, like buds on a rosebranch. Its products are very different, according as the cœnosare remains soft, or deposits a calcareous tissue (coeneuchyma); appears under the form of offshoots or processes, or of stouter connecting stems ; or even spreads out in several directions as a continuous horizontal expansion.

In the second and commonest mode of germination, the parietal, the corals produced are chiefly of a dendroid, or tree-like form. As the word "parietal" indicates, the buds are thrown off from the sides of the original polype, and very often the process is repeated indefinitely.

Calicular germination was a process belonging to the primeval world. The primitive polype sent up from its oral disc two or more similar buds, which, in their turn, produced other young polypes; and so the process continued until an inverted pyramidal mass of considerable size was produced, every part of which rested upon the narrow base of the first budding polype.

Of reproduction by fission it seems necessary only to say, that it differs from germination chiefly in the fact that the polypes thus produced by the process of selfdivision resemble one another in organization, and often

* A coenosare is the common organized medium by which the separate polypites of a compound organism are united together. 
in size, as soon as they become distinct. In germination, on the other hand, the polype-bud consists at first of nothing more than an outer and inner skin, ectoderm and entoderm, enclosing a cœcal process of the body-cavity, and possessing neither mouth nor other structures.

The coral structures resulting from the fissiparous mode of reproduction are of two kinds, according as they tend to increase in a vertical or in a horizontal direction.

In the former case, the corallum, or calcareous skeleton, the bone or internal framework of the animal, is cespitose, or tufted, and may be resolved into a succession of short diverging pairs of branches, each the result of the selfdivision of a single corallite.

In the latter case, the corallum, or calcareous skeleton, becomes lamellar. Here the secondary corallites are united throughout their whole height, and being disposed in a linear series, the whole mass forms one continuous sheath or receptacle (theca).

But both kinds of corallum are frequently made massive by the union of several rows or tufts of corallites throughout the whole or a portion of their height. Professor Greene refers, as an illustration, to the large gyrate or convoluted corallum of the Meandrina, over the surface of whose spheroidal mass the combined corallites are wound and involved in a manner so complex as at once to suggest the resemblance to the convolutions of the human brain, which its popular name of brainstone coral indicates.

Many coral-producing organisms are also included in the Gorgonidae, or "sea-shrubs," the Porites, the Madreporidae, and the Milleporidae.

To the labours of these animals we owe the formation 
of the great coral banks and coral islands of the tropical seas. Their growth, if we may use the expression, is, under favourable circumstances, very rapid; so that a channel cut in the reef surrounding a coral island to permit the passage of a vessel, has been found blocked up with coral in ten years. The animals begin their work in water a few fathoms deep, the basement being laid by

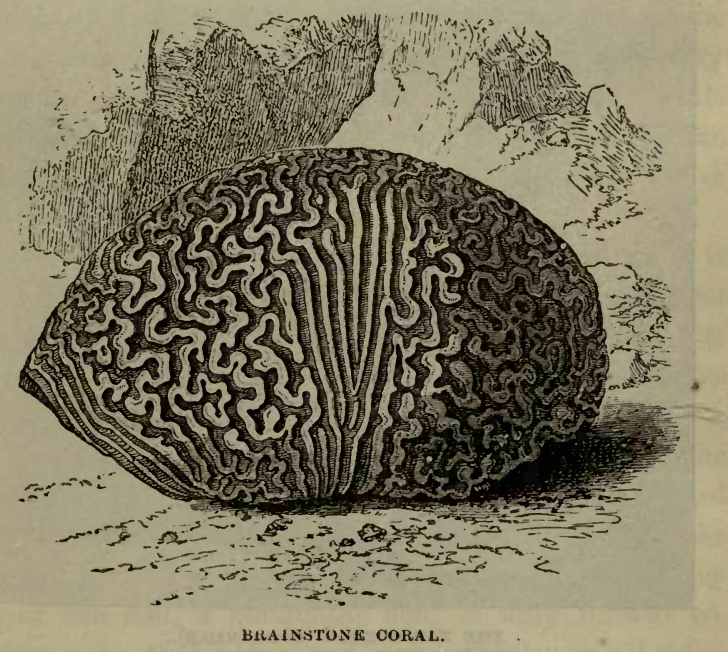

the Astraeans, generally upon some volcanic mountain, which past convulsions have upheaved beneath the surface of the sea; as soon as the edifice reaches the level of six fathoms, the task of building is undertaken by the Meandrinas and Porites; and these, in their turn, are succeeded by the Madreporidce, Milleporida, and Gorgonida, which carry the wonderful structure to the surface of the sea. 
The examination of a coral reef during the different stages of the tide is, as Captain Hall says,* particularly interesting. When the sea has left it for some time, it becomes dry, and appear's as a compact rock, exceedingly hard and rugged; but no sooner does the tide rise again, and the waves begin to wash over it, than millions of coral-worms protrude themselves from apertures on the

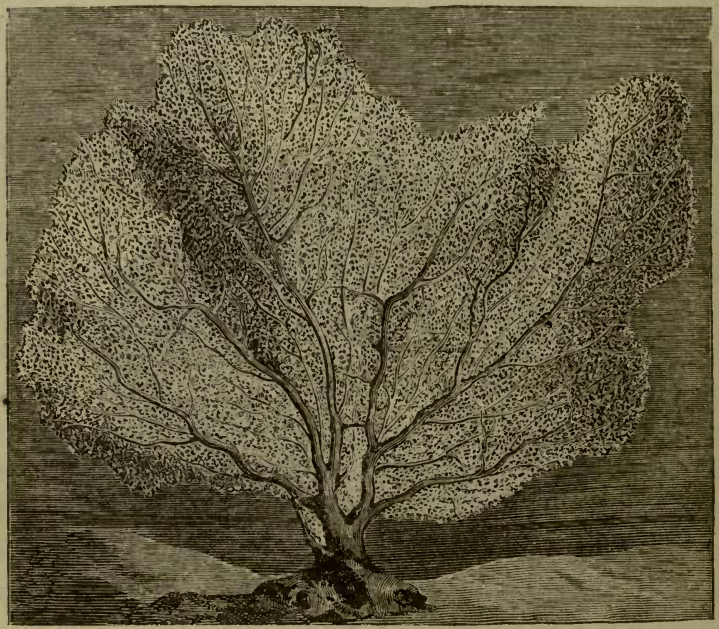

THE FAN GORGON (GORGONIDE).

surface which before were quite invisible. These animals are, as we have shown, of various shapes and sizes, and so prodigious in number, that in a short time the whole face of the rock seems alive and in motion. The most common form is that of a star, with arms, or rays, from four to six inches in length, which the animal moves

* Captain Hall, "Voyage to the Loo-Choo Islands." 
about rapidly in all directions, probably in quest of food. Others are so sluggish that they might be mistaken for pieces of the rock; these are generally of a dark colour, from four to five inches in length, and two to three inches in circumference. On breaking the coral mass from a spot near high-water mark, it was found to be a hard solid stone; but if any part were detached at a level which the tide regularly washed, it proved to be full of worms, all of different lengths and colours, some as fine as a thread, and several feet long, generally of a very bright yellow, but sometimes of a blue colour; while others resembled snails, and some were not unlike lobsters and prawns in shape, but soft, and not above a couple of inches long.

The coral ceases growing when the worm creating it is no longer exposed to the influence of the tide. A reef rises in the form of "a gigantic cauliflower," until its crest has gained the level of the highest waters, above which the corallite has no power to carry its operations, and the reef, consequently, extends no further. The surrounding parts, however, successively mount upward until they also reach the surface, and stop. Thus, as the level of the highest tide is the eventual limit to every part of the reef, a horizontal field is duly formed coincident with that plane, and perpendicular on all sides. But though the upward extension of the reef is at an end, not so with its lateral expansion; and this expansion being apparently as rapid at the upper edge as it is lower down, the face of the reef everywhere preserves its steepness; a circumstance which renders this class of rocks exceedingly dangerous to navigation. In the first place, they are seldom visible above water; and, in the second, 
their sides are so abrupt that a ship's bows may strike against the rock before any change of soundings indicates the approach of danger.

When the coral mass has finally gained the level of the waves, its surface undergoes disintegration through atmospheric and aqueous action. The sea-birds frequent the oasis among the boisterous waters, and deposit there the refuse of their food. Gradually a thin soil is formed, which the wind sows with the various seeds it bears upon its pinions. These germinate and fructify, and a carpet of verdure spreads over the hitherto rugged and dreary scene. In due time the palm rears its stately trunk upon it, and the work is consummated, after long, long years of patient elaboration, by the development of a coral island, an Eden of the waves, sunned by the glow of tropical skies, and encircled by a zone of sapphire sea. An Eden, but uninhabited by man or animal ; and silent, save for the sounds of air and ocean-

"'The myriad shriek of wheeling ocean-fowl,

The league-long roller thundering on the reef."

Different coral animals toil at different depths, and it has even been found that the species labouring on one side of a reef differ from those that labour on the other. When one class of workers give over the task of carrying upward the marvellous submarine fabric, it is continued by a second and robuster phalanx, who, in their turn, give place to a third, and these to a fourth. The character of the species depends upon the depth and temperature of the waters. Their modes of operation, however, are invariably the same, and a wonderful continuity pervades their work. 


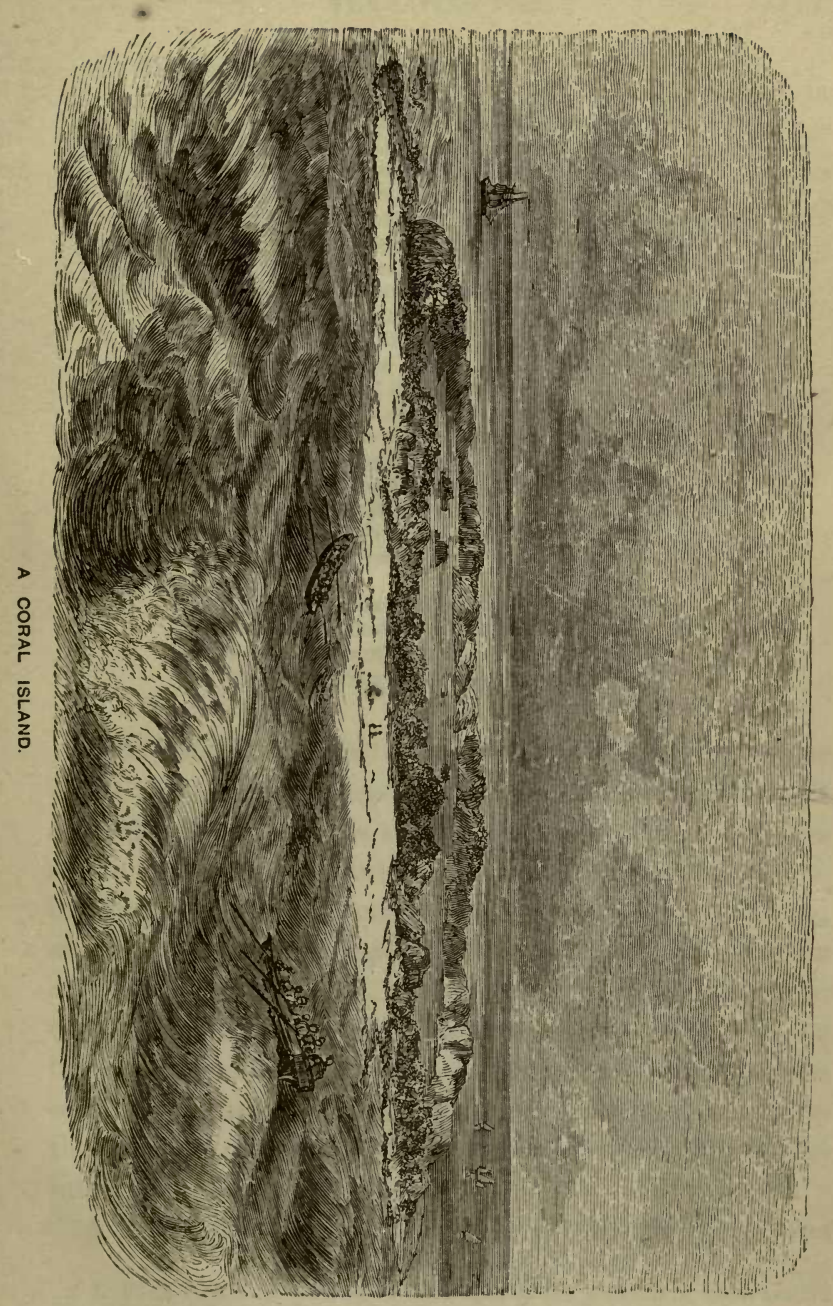





\section{As Montgomery finely says :-}

"Millions of millions thus, from age to age, With simplest skill, and toil unweariable, No moment and no movement unimproved, Laid line on line, on terrace terrace spread, To swell the heightening, brightening, gradual mound, By marvellous structure climbing towards the day. Each wrought alone, yet all together wrought, Unconscious, not unworthy, instruments, By which a Hand invisible was rearing

A new creation in the secret deep....

I saw the living pile ascend,

The mausoleum of its architects,

Still dying upwards as their labours closed....

Frail were their frames, ephemeral their lives,

Their masonry imperishable. All

Life's needful functions, food, exertion, rest,

By nice economy of Providence

Were overruled to carry on the process

Which out of water brought forth solid rock.

"Atom by atom thus the burthen grew, Even like an infant in the womb, till Time Delivered Ocean of that monstrous birthA Coral Island stretching east and west."

Corallines have recently been discovered, in the course of the deep-sea dredgings of Dr. Carpenter and others, at a depth of 600 fathoms and upwards; but these deep-sea corals are wholly different in character from the reefbuilding zoophyte. Some of the species now existing, as, for example, the Haplophyllia paradoxa and Geognia annulata, are identical with those which flourished in the ocean-waters of the Palæozoic age. We owe to Count Pourtales our earliest information of the deep-sea corals. Numerous stony corals were dredged up from the bottom of the Strait of Florida, under his superintendence, in 1868 and 1869.*

A new group of coral islands in the North Pacific was

* L. F. de Pourtales, Illustrated Catalogue of the Museum of Comparative Zoology, 1871; Contributions to the Fauna of the Gulf-Stream, 1870. 
surveyed by the United States Government towards the close of 1871 . These were: Ocean Island, lat. $28^{\circ} 25^{\prime} \mathrm{N}$., long. $178^{\circ} 25^{\prime} \mathrm{W}$.; Medway Island, lat. $28^{\circ} 15^{\prime} \mathrm{N}$. long. $178^{\circ} 20^{\prime} \mathrm{W}$.; Pearl and Hume's Islands, lat. $27^{\circ}$ $50^{\prime} \mathrm{N}$., and long. $175^{\circ} 50^{\prime} \mathrm{W}$. They are described as abounding in turtle and sea-birds; but only scantily clothed with vegetation. In this way the laborious corallines are continually filling up the vast intervals of Ocean, and stretching from continent to continent a chain of isles.

But we must return to the immediate subject of this chapter, from which the coral animals have led us far astray.

The coral of commerce is found principally in the Mediterranean (off the west coast of Sicily*) and the Red Sea, and at depths, and under conditions, which vary according to the nature of the locality. On the French shores it forms immense masses with a southward front, while it is seldom found on rocks facing towards the east and west, and never upon those which lie open to the north. According to Lamouroux, in this part of the Mediterranean coral does not occur at a lesser depth than 10 feet, and at a greater than 950 to 1000 feet. The usual depth at which the fishery is prosecuted is between 350 and 600 feet.

On the coast of Northern Africa, the coral adheres to the rocks which face the south, south-east, and southwest. Here the fishers carry on their operations three or four leagues out at sea, from a depth of 100 or 130 feet down to 800 and 900 feet.

\footnotetext{
* Rear-Admiral Smyth, "Sicily," p 25.
} 
In those places where the corallines labour near the shore, and at no great depth, the corallum is easily collected by the divers; but such localities are few. On the coast of Africa and in the Strait of Messina the fishery is conducted in a very different manner, as the following brief deseription will show.

The fishing-boats are inostly of Italian build, and good sailers. The largest, boats of sixteen tons or more, carry a crew of ten to twelve men; the smallest, of five to six. Their figure-head is always decorated with an image of Christ, the Virgin, or the owner's patron saint. The after part of the boat is reserved for the fishing operations and the stowage of the crew; the fore part is usually appropriated to the padrone, or proprietor. Midships are kept the stores of biscuit and water. The canvas consists of a broad lateen sail and a jib or stay sail. The crew is generally collected from Genoa, Leghorn, Naples, or Trapani.

The apparatus employed in the fishery is technically termed the "engine," and this engine is really a marvel of complex construction, considering the simplicity of its object.

Let the reader picture to himself a wooden cross of two arms securely lashed or bolted together at the centre, and each arm measuring from six to seven feet in length. This cross is ballasted with a heavy stone or block of lead, and to either arm is suspended a stout rope about thirty feet long. Each rope carries six nets fastened to it at equidistant points; nets rough and strong, with broad meshes loosely knotted together, and woven of the coarsest rope, about as thick as a man's finger. By (502) 
means of a cord passed through one row of meshes and fastened at the bottom, these nets are gathered up into a kind of coil, or "swab," which, when immersed in water, expands like a rosette. The result is, that the engine,

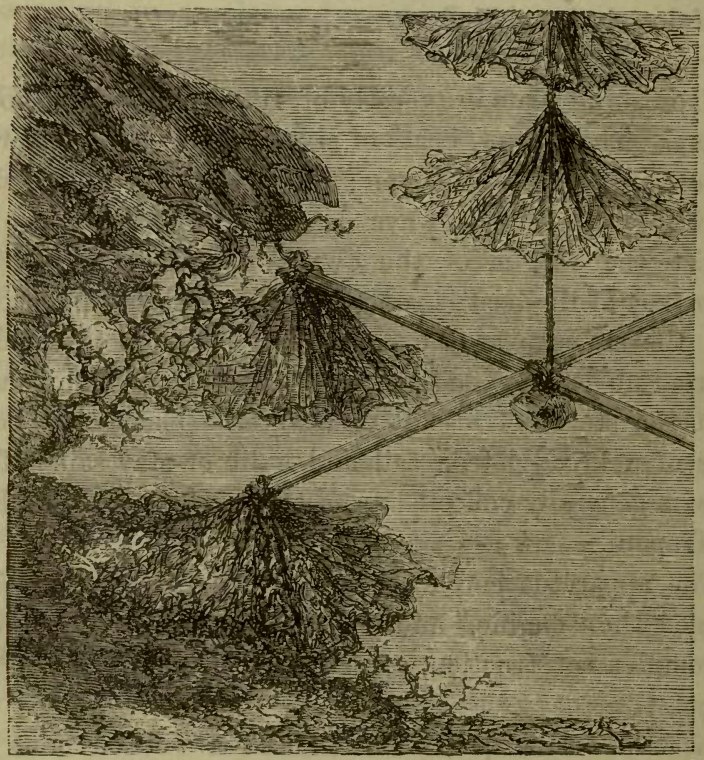

ENGINE USED IN CORAL-FISHERY.

when dragged along the bank of coral, catches at its projections with the meshes of its several nets, and, assisted by the onward impulse of the boat, tears them away, thus accumulating a large quantity of more or less valuable fragments.

When the season arrives, and the boats set sail, the first thing, necessarily, is to discover a coral bank. In 
this pursuit the padrones, or owners, acquire, through long experience, a remarkable degree of skilfulness. Without any chart or instrument, their knowledge of the character of the sea-bed and the irregularities of the neighbouring coasts is so complete, that it is said they can fish up from the depths an engine which they may have lost in the previous season.

Having arrived at a convenient spot, the padrone throws his engine overboard. The rope supporting it is liberally paid out, so that it may float freely on the waters. One end is fastened to the centre of the wooden cross ; the other is coiled round the capstan of the fishingboat. Seated on the gunwale, the master throws one leg over the side, the rope passing across his thigh, which is covered with a small thick piece of leather. According to the varying pressure of the rope, he judges of the state of the ground he is fishing, and determines the proper moment for abandoning the engine to the weight which tends to drag it downwards. The moment comes. $\mathrm{He}_{0}$ culls to the man at the capstan to let go; away flies the engine to the bottom, where it quickly entangles itself in the projections and fissures of the rock. , Now comes the tug of war. As the boat flies onward, the men toil at the lumbering capstan to haul in or let go the rope according to circumstances: half-naked, in the glare and glow of a Mediterranean sun, with the bead-drops trickling down their swarthy bodies, they ply their unremitting toil. Again and again the engine is brought to the surface, and the broken coral collected from its meshes. The weight is enormous, and as the capstan raises it through the opposing waters, the men are compelled to exercise all their strength, under the stimulus supplied by the blows 
the padrone liberully rains upon them. They would, indeed, sink under the toil if they did not incessantly recruit their energies by eating, without interrupting their task however, the supply of biscuit placed within their reach; so that it may justly be said, "the coral-fisher is always devouring." The expression has become proverbial.

Even in what are figuratively called their "hours of rest" they are not idle, for the work of repairing the nets, or weaving new ones, is necessarily continuous : in this their skill is remarkable, and when they are worn out with fatigue, and almost asleep, their fingers will mechanically tie the knots. Their working day is eighteen hours long; their rations, biscuit and water ad libitum, and, in the evening, some pâtes à l'Italienne; wine and meat twice a year, on Ascension Day and the Feast of Corpus Christi. First-class sailors are paid from 400 to 600 francs ( $£ 16$ to $£ 24$ ) for the season of six months; inferior men, about half this amount. The occupation is so laborious and the pay so indifferent, that the Sicilians have a saying, Only a thief or a murderer turns coralfisher.

But bad as their character generally is, they do not lack the customary devotion or superstition of the Italians; and when the net is cast, on the first day of the season, they fall on their knees, and the first fine branch of coral brought up they dedicate to the "Good Mother," the Blessed Virgin,-always provided the fishing proves abundant.

It is considered a good season when a large boat collects 300 kilogrammes (5 cwt., 3 qrs., 18 lbs. English) of coral, which is worth between $£ 80$ and $£ 120$; and a small boat, half that quantity. 


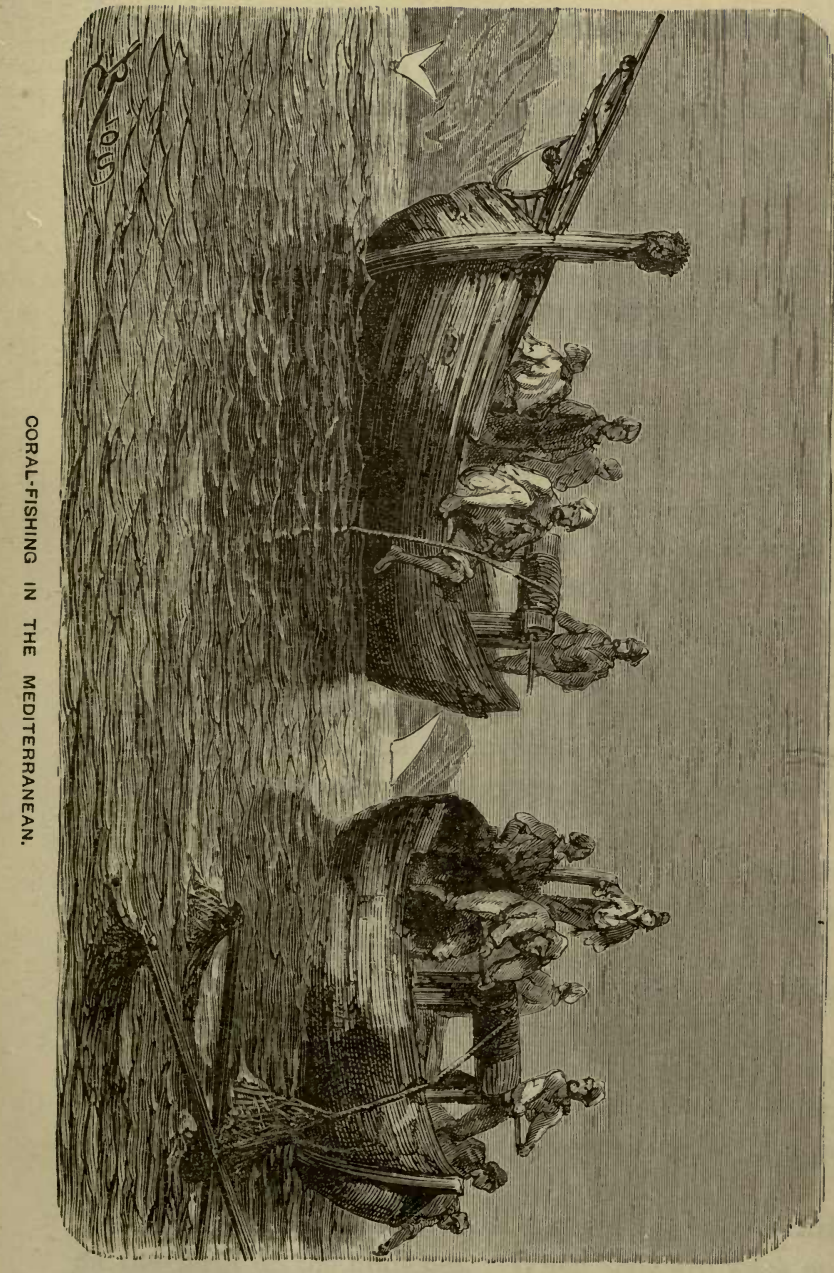



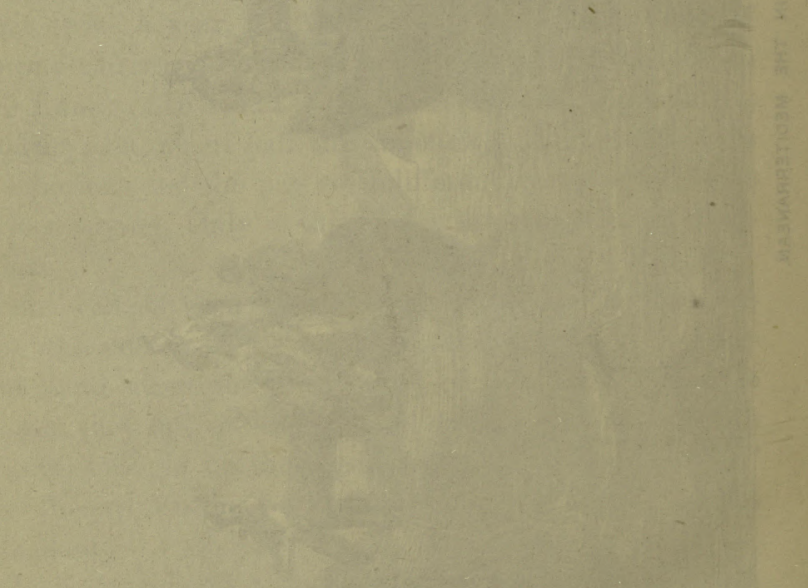

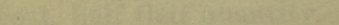

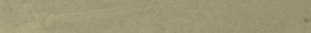

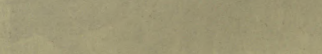


The coral is not sold by the fishermen themselves, but by the speculators who fit out the boats and hire the crews. The largest rnarkets are at Bona and La Calle, on the African coast, and at Trapani, in the island of Sicily.

The following kinds of coral enter into commerce :-

1. Dead or Rotten Coral, a name given to the so-called "roots" of the polypidom, which are covered with calcareous deposits and bryozoairia. It is worth from 1 s. $7 \mathrm{~d}$. to 4 s. the ton.

2. Black Coral; that is, coral loosened from the original mass, and embedded in the mud, where it undergoes a certain modification through the action of sulphurous exhalations. It is used as an ornament by ladies in mourning, and fetches the price of $4 \mathrm{~s}$. $6 \mathrm{~d}$. to $6 \mathrm{~s}$. per $\mathrm{lb}$.

3. Mass Coral is an aggregation of fragments of all sizes, the commonest refuse mixed with the finest branches; in other words, it is the natural coral, just as dredged up from the ocean depths. Its price varies greatly, being sometimes as low as $£ 1$ per lb., and sometimes as high as $£ 1,10$ s.

4. Picked Coral is, of course, the best branches, carefully picked out from the mass. It is sold by weight, at from $£ 5$ to $£ 10$ per $1 b$.

5. White Coral. This variety is not often met with; it differs from the red in nothing but colour.

There are other varieties, known by such names as "froth of blood," "flower of blood," "first blood," "second blood," and the like; but for these no great demand exists.

The commercial value of this material depends greatly on the form of the branches. When they are weak and 
bushy, as is generally the case with those collected on the coasts of France and Spain, the artists find the cutting much more difficult, and the waste is also greater. A primary requisite is, that they shall be intact. Now it frequently happens, and more particularly with the coral of Oran, that the branches are honeycombed by the perforations of small annelids or sponges. Such are of comparatively little use to the coral-worker. Again, the value also depends on the colour and transparency of the coral, the delicate rose-hued varieties being most highly esteemed in Western Europe.

The Algerine coral is principally wrought at Naples, Leghorn, and Genoa. Little trade is now done at Marseilles, and at Paris it is confined to mounting it for jewellery.

The coral issues from the manufactories in the following forms, which the jeweller utilizes at his pleasure :-

1. As pearls of all sizes, smooth, or cut with facets ;

2. Olives ;

3. Various sculptures ; and

4. As "Arabic coral," composed of portions of the stems, carefully polished, and perforated, for threading, in the direction of their axes.

In working the coral, it is first cleansed with lime, and afterwards "turned" upon horizontal dises, resembling the lathes employed by opticians in shaping glass and crystals, by means of a paste composed of water and emery. The turning process is several times repeated, the paste each time being of a finer composition.

The cutting of coral pearls, with facets, is a simple and very rapid operation. The workman whose duty it is to cut the branches makes a number of notches on the 
stem with a sharp file, and then, with a large pair of pincers, breaks off the branches. The small cylinders thus obtained are next pierced, in the line of their axes, with a vertical drill, and in the aperture thus made a handle is fitted, that the fragment may be more conveniently manipulated. Next, the coral is submitted to the action of a grindstone, until it is sufficiently rounded; and the "pearl" produced by this operation passes into the hands of the polisher, who exposes it to the friction of a metallic disc, made to revolve with great rapidity, and coated with emery of various degrees of fineness. The different facets are thus produced with a wonderful degree of regularity; after which the "pearl" receives a final polish.

Coral is now little valued in England as an article of ornament, and is chiefly seen on the tables and mantelpieces of old "sea-captains" and voyagers, who preserve it as a memorial of distant lands and past experiences. 


\section{CHAPTER XX.}

CURIOUS FISHES AND MODES OF FISHING.

VOLCANIC FISHES.

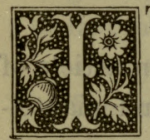

$\mathrm{T}$ is recorded that on several occasions, when those convulsions which precede violent volcanic eruptions in the great range of the Andes have shattered its enormous masses, and opened deep subterranean chasms and fissures, not only tufa and water have been vomited forth, but also fishes in very considerable quantities.

For instance, when an eruption took place of Garguarruijo, a mountain 17,500 feet in height, the surrounding country, over a radius of two miles, was covered with the ejected mud and fishes. And a pestilential fever which at one time desolated the town of Huera, was ascribed to a similar phenomenon in connection with the volcano of Imbaburu.

We are told that Cotopaxi, Tunguragua, and Sangay in like manner send forth showers of fishes; sometimes through their summit crater, sometimes through lateral fissures; and the Indians assert that these fishes are alive. It seems a fact that of the hundreds of fish cast 
out by Cotopaxi, along with floods of vapour, smoke, and seething water, very few are so disfigured as to induce

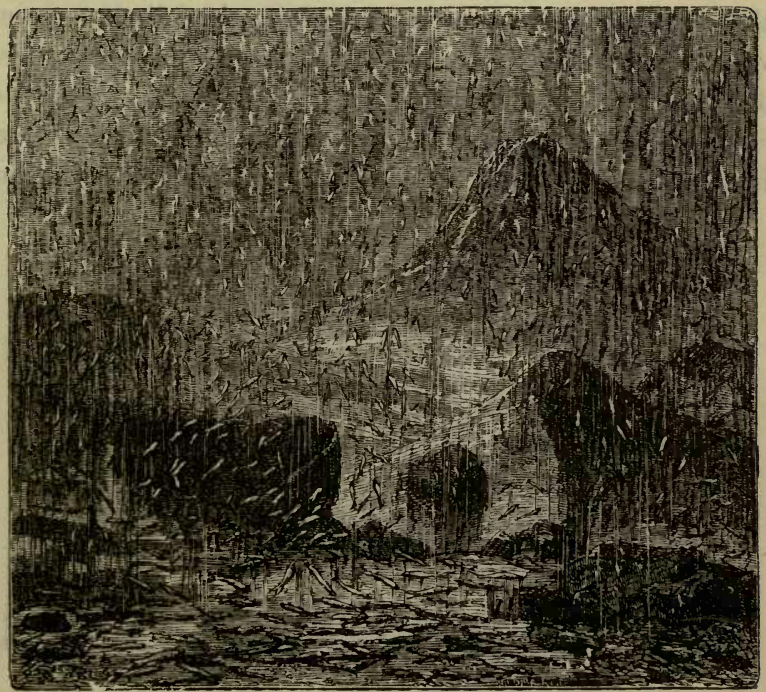

A SHOWER OF FISHES.

the belief that they have been exposed to the action of extreme heat.

A French writer offers the following explanation of this curious circumstance.

In the interval, frequently exceeding a century, between two consecutive eruptions, the volcanic crater closes up its rents and crevasses, and the bottom soon becomes, as Vesuvius shows us, a level, or nearly level plain.

In the course of time this plain is converted into a lake; and all the more easily because, far from being, 
like the European volcanoes, isolated mountain-peaks, those of the Andean chain are connected one with another in a long continuous series; so that not only do the rains collect in the crateral basins, but distant reservoirs also pour their contents into them through numerous subterranean channels.

Through these channels arrive various shoals of fish, to increase and multiply in the deep crateral lake. And

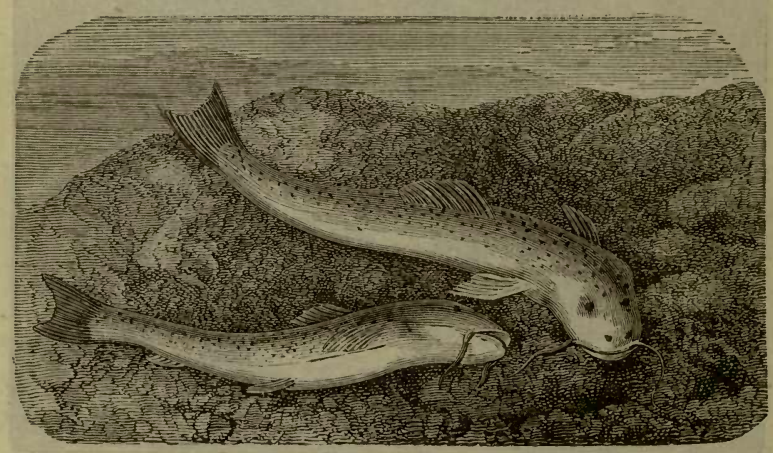

VOLCANIC FISH.

when, after a greater or less number of years, the volcano once more breaks out into activity, the bed of the crater is necessarily upheaved, and its waters are ejected with terrific violence, along with their finny inhabitants.

It has been observed that the fish thus ejected are identical in kind with those found in the streams in the neighbourhood of the volcano. The South Americans call them Prennadillas; they belong to the malacopterous family of Silurida. 


\section{FISH IN ARTESIAN WELLS.}

Many of the artesian wells which have been opened up by French engineers in the waterless districts of Algeria have furnished examples of a similar phenomenon. When the water rose to the surface of the Ain-Tala well, which is one hundred and forty-five feet in depth, some small fish were discovered among the sand thrown out at

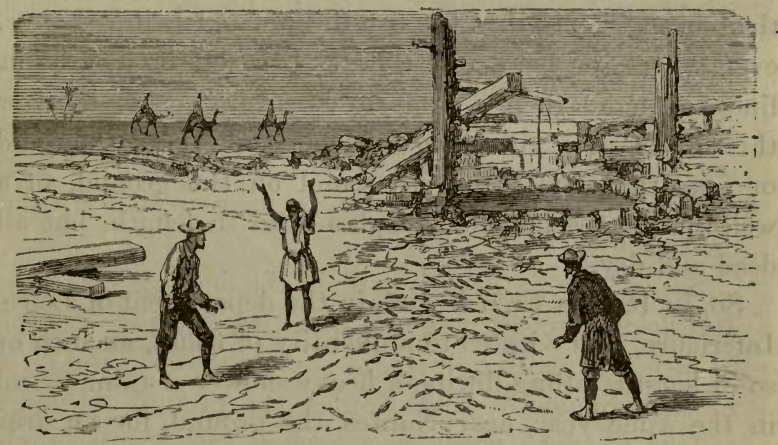

FISH EJECTED FROM A WELL.

the well's mouth. They did not exceed a couple of inches in length, were malacopterous, and, in general appearance, not unlike the familiar whitebait. The male was distinguished from the female by transversal bars. Though these little creatures spent their lives in the darkness, their eyes were regularly formed.

\section{SHOWERS OF FISH.}

Some incredulity has been expressed with reference to the reports of showers of fish which occasionally appear 
in the public prints, but many of them are well-authenticated.

On the 20th of September, 1839, an English officer, in the neighbourhood of Calcutta, saw a quantity of live fish descend in a storm of rain. They measured about three inches in length, and were all of the same species. Some, falling on hard ground, were killed; some, which fell on soft grass, continued in life. "The most strange thing that struck me in connection with this event," said the officer,* "was that the fish did not fall helter-skelter, everywhere, or here and there; they fell in a straight line, not more than a cubit in breadth." Shortly after this event, at a village near Allahabad, three thousand or four thousand fish were found on the ground, of a well-known species, and about a span in length, but all dead and dry.

So, in 1820, a French curé, in the department of LoireInférieure, was witness to a quantity of fishes, an inch or so in length, falling during a heavy shower of rain. And in the same year, near Nantes, the ground, for an area of four hundred yards, was covered with fish, each about an inch and a half in length.

Hasted, in his "History of Kent," records that about Easter 1666, in the parish of Stansted, which lies at some distance from the sea, and has no fish-ponds near it, a pasture-field was found strewed over with small fish.

On the 14th of April, 1828, Major Forbes Mackenzie, of Fodderty, Ross-shire, while walking in a meadow near his farm, saw a considerable portion of the ground covered with herring fry, three or four inches in length, fresh and uninjured. The spot was three miles distant from the

* Chambers, "Book of Days," ii., 361, 362. 


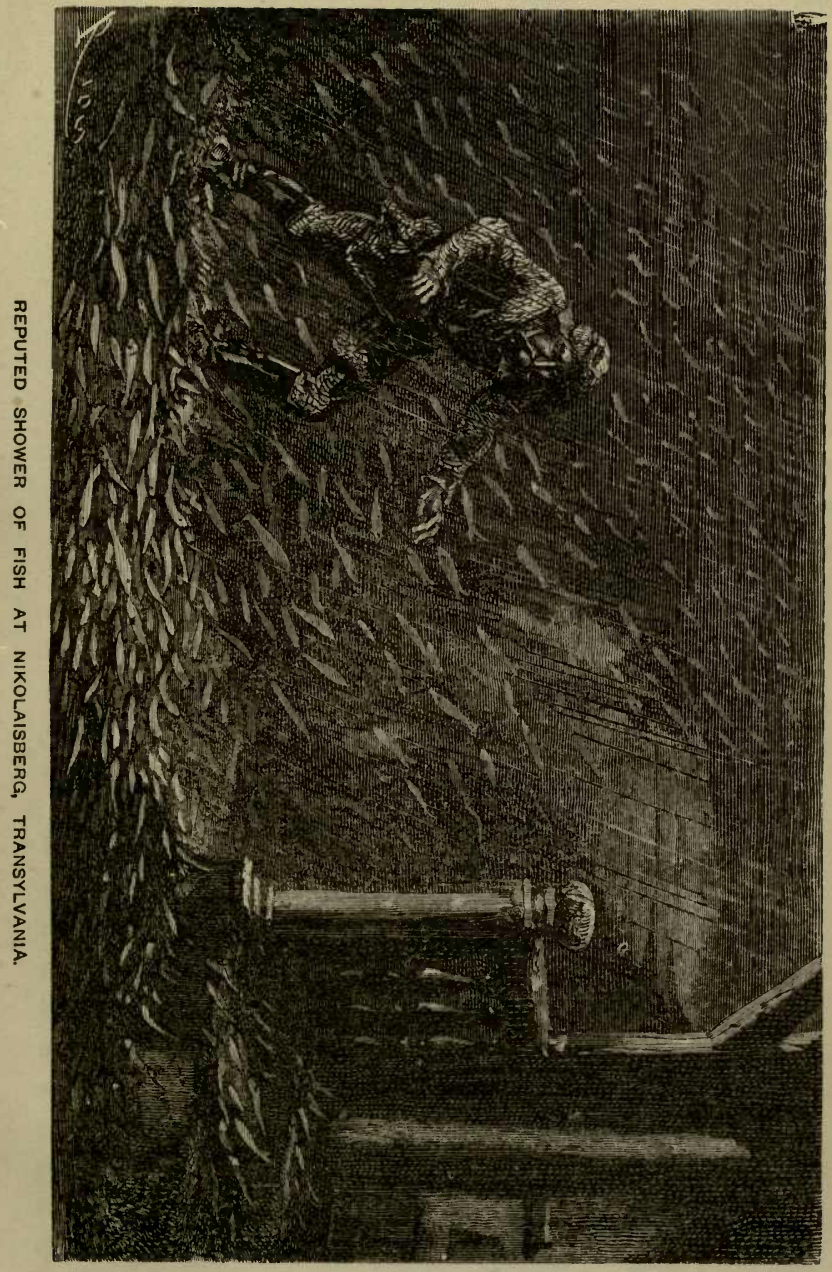




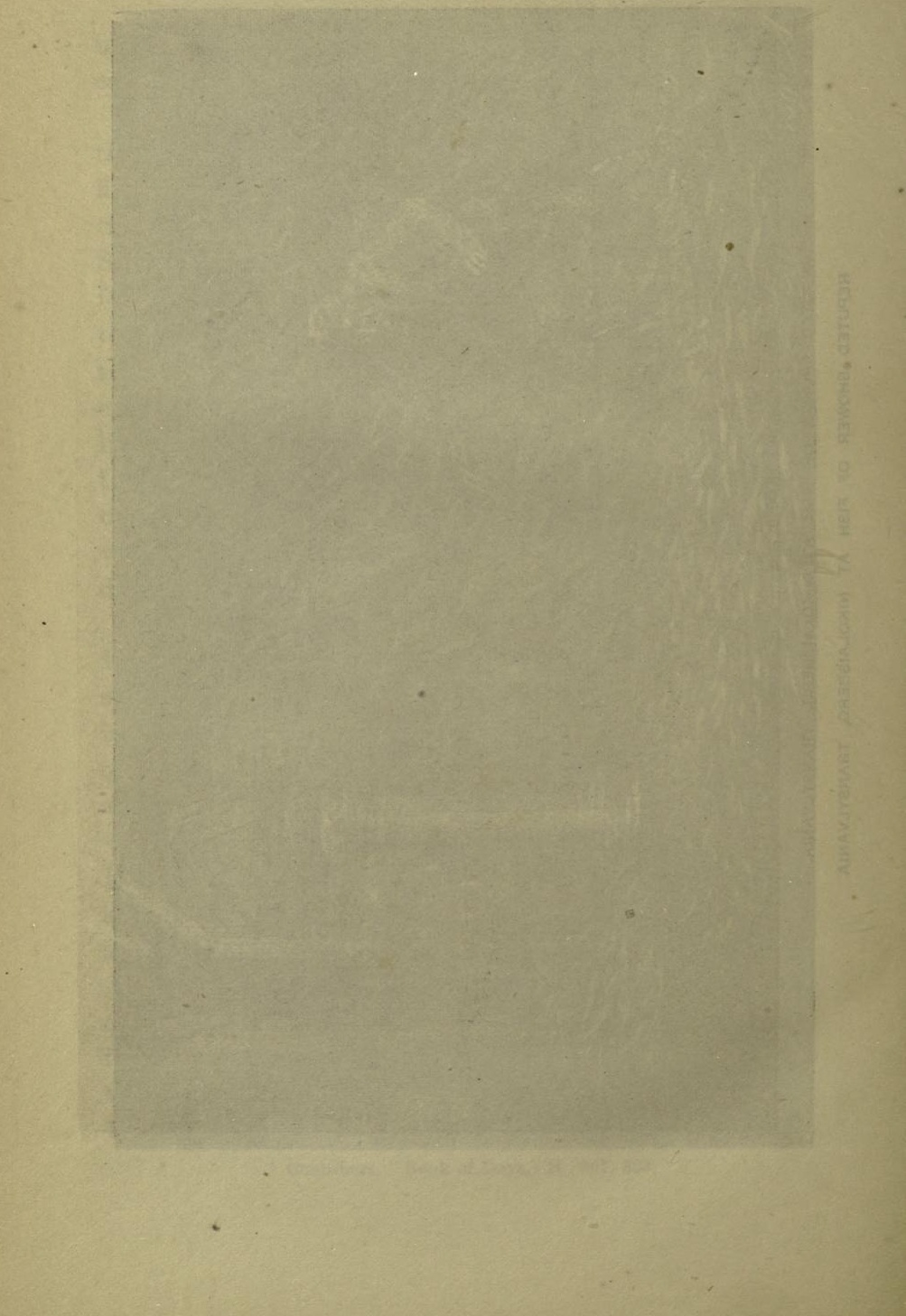


Firth of Dingwall. About two years afterwards, in the island of Islay, off the west coast of Argyleshire, the inhabitants were greatly surprised, after a day of violent rain, to discover a large number of herrings, small, perfectly fresh, some of them even alive, scattered over the fields. It is also on record that, on one occasion, during a strong gale, herrings and other fish were swept from the Firth of Forth as far as Loch Leven, a distance of ten miles. More recently, says Chambers, it was stated in a Wick newspaper that, on a particular morning, a large quantity of herrings were found in a garden about half a mile from the shore at that town. The peasants cooked and ate them; though the minds of some misgave them as to the possibility of Satanic agency having been concerned in the transmission of the clupeids to such a spot!

In 1858, during a night of violent tempest, thousands of fishes, each about four inches in length, fell in the streets of Nikolaisberg in Transylvania.

How are we to explain these phenomena? There can be little doubt that the agents producing them are winds, whirlwinds, and waterspouts. It was observed that the shower of herrings at Islay occurred after a day of heavy rain; and that at Loch Leven when a furious gale was blowing inland from the Firth of Forth. The incident at Wick was attributed by the more intelligent inhabitants to a waterspout; and at Calcutta the fish-fall was preceded and accompanied by a shower of rain. The results in each case were probably due to the circular or rotatory action of the wind, that action which on a more extensive scale is visible in the cyclone; which produces on land the whirlwind, and at sea the waterspout. 
THE ECHENEIS, REMORA, OR SUCKING-FISH.

No fish has been the subject of greater exaggeration on the part of those naturalists who delight in wonders, and eschew the calm research of science, than the remora or echeneis; yet its organization is in itself so curious and admirable, that it required no embellishments of fancy to render it an object of interest.

Let us hear, however, what the ancients had to say about it.

According to Pliny, it is a small fish accustomed to dwell among the rocks, which attaches itself to the keel of ships, and retards or arrests their progress; which is used in the composition of love-potions ; which, owing to some singular moral force inherent in it, can delay the action of justice and the jurisdiction of tribunals ; which can secure pregnant women from the dangers of premature delivery; and which, when preserved in salt, acquires a magnetic power, and extracts from the depths of wells whatever treasures they may contain.

The current of the sea is great, says the Latin naturalist,* its tides are mighty, the winds puissant and forcible, and, more than that, oars and sails withal to help forward the rest are mighty and powerful ; and yet there is one little silly fish, echeneis, that checketh, scorneth, and arresteth them all: let the winds blow as much as they will, rage the storms and tempests never so strong, even yet this little fish commandeth their fury, restraineth their puissance, and, maugre all their force, as great as it is, compelleth the ships to stand still! Why should our fleets and armadas at sea make such turrets

\footnotetext{
* Pliny, "Nat. Hist.," translated by Philemon Holland.
} 
on the walls and forecastles, when one little fish-see the vanity of man ! - is able to arrest and stay perforce our goodly and tall ships? Certes, reported it is, that in the naval battle before Actium, wherein Antony and Cleopatra were defeated by Augustus, one of these fishes stayed the admiral's ship, whereon Mark Antony was, at what time as he made all the haste and means he could devise, with help of oars, to encourage his people from ship to ship, and could not prevail, until he was forced to abandon the said admiral, and go into another galley. Meanwhile, the armada of Augustus Cresar, seeing the disorder, charged with greater violence, and soon defeated the fleet of Antony.

Of late days also, continues Pliny, and within our remembrance, the like happened to the royal ship of the Emperor Caius Caligula, at what time as he rowed back and made sail from Astura to Antium: and as soon as the vessel (a galley furnished with five banks of oars to a side) was perceived alone in the fleet to stand still, presently a number of bold fellows leaped out of their ships into the sea, to search after the said galley, what the reason might be that it stirred not, and found one of these fishes sticking fast to the very helm; which being reported to Caius Caligula, he fumed and sware as an emperor, taking a great indignation that so small a thing as this should hold her back perforce, and check the strength of all his warriors, notwithstanding there were no fower than four hundred lusty men in his galley, that laboured at the oar, all that ever they could do to the contrary. This fish presaged an unfortunate event, for no sooner was he arrived at Rome than some soldiers fell upon him [that is, upon Caligula], and stabbed him to death. 
After reading this veracious statement the reader will be disposed to think, perhaps, that Imperial Rome had its Munchausen!

But Allian is equally credulous, equally imaginative, and gravely records as facts what the veriest tyro in natural history would now denounce as fables. A galley, he says, was despatched to Corcyra by Periander, the tyrant of Corinth, with orders for the massacre of three hundred children born in the former city. In spite of a fair wind, the ship remained almost motionless; a result due to the combined efforts of a number of compassionate remoras. Great honours were paid at Cnidus, in the temple of Aphrodite, to the fish which had wrought so famous a miracle; and our own opinion is that the honours were well deserved!

In the "Halieutics" of Oppian we find a spirited description of the astonishment experienced by the crew of a vessel which, sailing before a favourable wind, with the advantage of a strong current, is suddenly arrested in the full force of its career! In vain the breeze puffs out the useless canvas; in vain the sails, and shrouds, and cordage creak and crack; in vain the swift tide hurries past the motionless keel :-

\footnotetext{
"The seamen run confused, no labour spared, Let fly the sheets, and hoist the topmast yard ;

The master bids them give her all the sails, To court the winds, and catch the coming gales :

But though the canvas bellies with the blast, And boisterous winds bend down the cracking mast, The bark stands firmly rooted on the sea, And all unmoved as tower or towering tree."
}

He elsewhere describes this wonder-working inhabitant of the deep :-

"Slender its shape, its length a cubit ends, No beauteous spot the gloomy race commends : 
An eel-like clinging kind, of dusky looks,

Its jaws display tenacious rows of hooks ;

The sucking-fish beneath, with secret chains

Beneath its teeth, the sailing ship detains."

Badham identifies the echineis with the lamprey; but we see no reason for disputing the usual classification of zoologists, and prefer to regard it as the same with our modern remora, or sucking-fish. That it is incapable of performing the marvels ascribed to it by Pliny, Oppian, and Elian, we need hardly say; on the other hand, its adhesive qualities are certainly remarkable. Its fins are so feeble as to afford it but little support, and therefore it attaches itself to various solid objects, to the keel of a ship, to whales, sharks, and other fishes; and so tenaciously does it cling, that it is exceedingly difficult to accomplish the work of separation without the destruction of the unfortunate remora.

It is principally an inhabitant of the Mediterranean and Atlantic waters. Its general colour is a dusky brown. The skin is smooth and destitute of scales, but punctured with numerous impressed points or pores. The mouth, which is of large size, is armed with a number of small teeth, and the lower jaw is longer than the upper. The eyes are small, with yellow irises. The lateral line begins above the pectoral fins, and from thence, descending somewhat abruptly, runs straight in the tail, which is slightly forked, or, more strictly speaking, cuneated.

The adhesion of the remora is not effected by its mouth, as in the case of the lamprey, whose mouth is a complete sucking apparatus, but by a very curious and even complex mechanism, which occupies the upper part of the head. This may be compared to the lattice of a small window of an elongated oval shape, the bars of the 
lattice being movable, and the whole being horizontally arranged. Two series of transverse osseous laminæ, or plates, parallel to each other, but separated by a longitudinal partition, and enclosed in an oval fleshy framework;

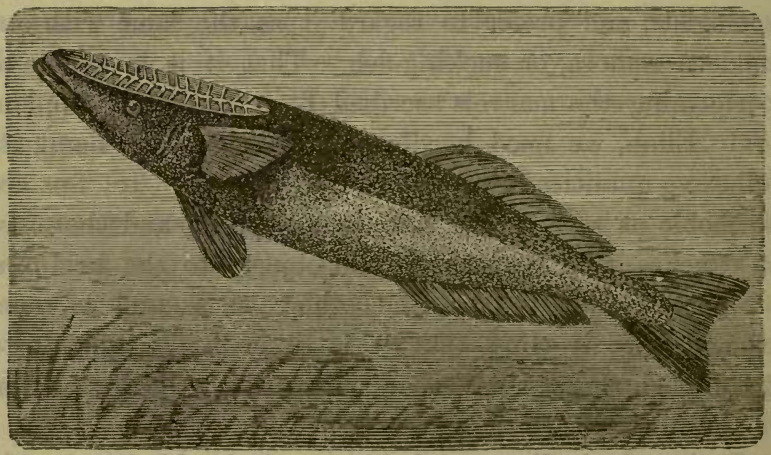

THE REMORA.

each lamina articulated at one end to the framework, at the other to the central partition, and furnished on its posterior edge, which it raises or lowers at will, with several rows of sharp spines; finally, a set of special muscles to set in motion these laminæ;-such is the adhesive apparatus of the remora.

By several eminent authorities it is referred to the fin type; and De Blainville regarded it as an imperfect medial fin, with half the rays inclined to the right, and the other half to the left. We need not trouble the reader with a scientific disquisition on this point. Suffice it to state, that it is through the apparatus we have described the remora makes good its holdfast on any special object. In what manner, however, the tenacious action 
of this organ takes place, our naturalists do not satisfactorily explain. According to some, the remora creates a vacuum between the laminæ of its disc, which would justify the name of "sucking-fish" frequently applied to it; according to others, it insinuates its spines into the objects to which it adheres. It seems probable that in one or other of these ways, or perhaps in both, the adhesion is produced.

The remora would seem to have been observed in the act of adhering to surfaces where its spines could not possibly take hold ; as, for example, to anchors, and to the keels of copper-bottomed ships. In this case, the adhesion was evidently due to the vacuum. On the other hand, the spines act in all cases where the disc comes in contact with a body they are able to penetrate: thus we render its contact only the more effectual when we attempt to pull away the remora, and can effect its removal only by impelling it forward. Otherwise, a man may spend his whole strength in vain. Commerson, having brought his thumb in contact with the plate of a remora, experienced a kind of stupor, or paralytic numbness, which did not pass away for some time after the experiment.

We may add that the remora floats upon its back. Bose affirmed that he had seen two or three remoras detach themselves from the ship he was on board of, to hasten after some roasted beans he had thrown into the sea; and they always floated in the water with their belly upwards.

Fishing with the Echeneis.-The echeneis is found in many seas, and makes its appearance simultaneously with the turtle. In some parts of the world, therefore, man employs the one to catch the other. 
So ingeniously simple a mode of fishing was in great vogue on the American coast in the sixteenth century, and reference is made to it both by Peter Martyr, who wrote in 1532, and Hernandez de Oviedo, who wrote in 1535.

The following description is founded upon Commerson's

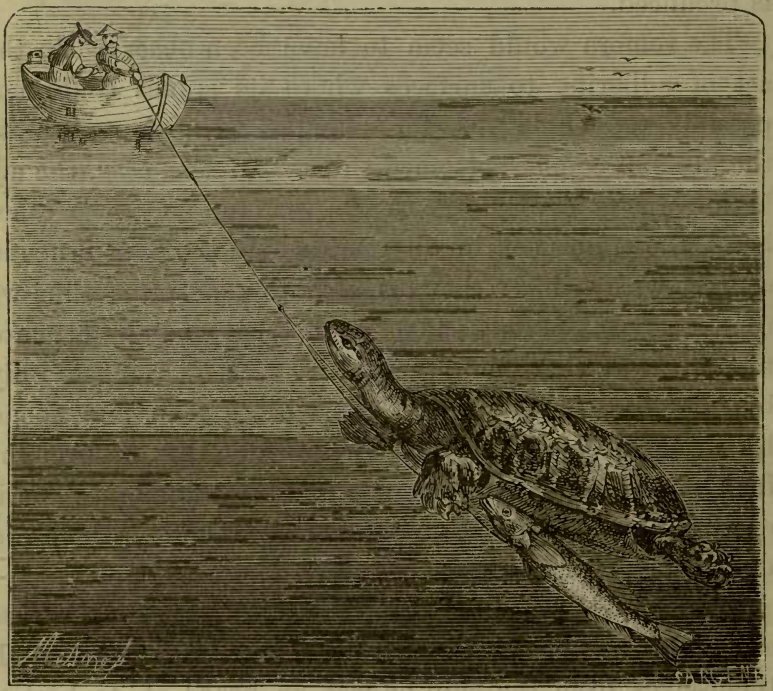

CATCHING TURTLE WITH THE ECHENEIS.

narrative. The fishermen, he says, attach to the tail of an echeneis a ring wide enough not to inconvenience the fish, and yet small enough to be kept in its place by the caudal fin. To this ring a long line is fastened. The echeneis is then placed in a vessel of sea-water, which is frequently renewed, and being carried on board the boat, 
the fishermen are ready for their expedition. They sail towards the favourite rendezvous of the turtles, which are accustomed to float asleep on the surface of the water, but are aroused by the slightest sound.

When the fishermen, therefore, catch sight of one at a distance, they drop their echeneis into the sea, holding fast one end of the cable attached to it. The fish, finding itself free, swims round about in search of an object to rest upon, and, after awhile, comes in contact with the turtle. Immediately it adheres to its carapace, thus providing the fishermen with an excellent grapnel, and enabling them to capture their prey by the simple process of hauling in the line.

THE PILOT-FISH.

As the remora so frequently accompanies both sharks and ships, and even precedes them in their course, it not infrequently receives the name of the pilot-fish. Hence arises an occasional confusion, against which it is necessary to put the reader on his guard ; for the name "pilot" is also bestowed on the Naucrates ductor, a fish which will sometimes attend a ship during its course at sea for weeks or even months in succession, and is often found in attendance upon the Squalido. In size and shape this fish resembles the mackerel; its general colour is a grayish-blue, with a kind of silvery tinge; the body is encircled by five dark-blue transversal bands; and both on the head and tail slight indications of another band are visible. It has a small head, with a rounded nose and an under jaw rather longer than the upper. The scales are small and oval; the ventral fins attached to the abdomen by a membrane through one-third of their 
length; the pectoral fins clouded with white and blue, the ventrals nearly black.

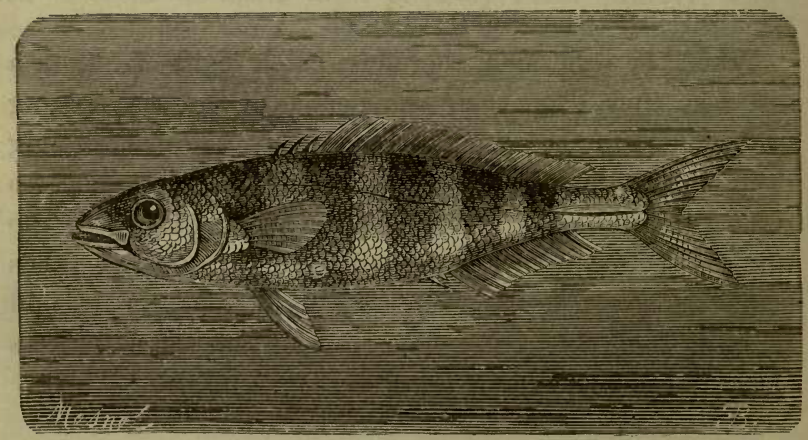

THE PILOT-FISH (NAUCRATES DUCTOR).

Strange tales are told of the habits of this fish; strange tales which we are by no means prepared to endorse. But the following, related by Geoffroy Saint-Hilaire, the great French naturalist, ueserves our attention on account of the reputation of its author:-*

"I found myself," he writes, "on board the frigate $\mathrm{Al}$ cestis, between Cape Bona and the island of Malta. The sea was tranquil ; and we passengers were growing weary of the protracted calm, when our attention was directed to a shark which was evidently making towards our vessel. It was preceded by its 'pilots,' which between each other and the shark preserved pretty exactly the same distance. The two pilots steered for the vessel's stern, surveyed it twice from one end to the other, and after assuring themselves there was nothing which could be

* G. Saint-Hilaire, in the "Bulletin des Sciences," No. 63, p. 113, et sq 
turned to their advantage, resumed the route they had previously held. During all their various movements, the shark did not lose sight of them,- or rather, followed them so closely, that you might almost have said it had been trained by them to do so.

"Its presence had no sooner been detected than a sailor on board prepared a great hook, which he baited with lard; but the shark and its companions were already seventy to eighty feet distant before the fisherman had completed his preparations. However, he threw at all hazards his bait into the sea. The noise occasioned by the fall was audible at a distance. Our voyagers heard it, were astonished, and checked their course; the two pilots turned about, and came to the vessel's stern in quest of information. During their absence, the shark disported itself after its fancy. It turned over on its back, righted itself, dived deep into the sea, but always reappeared at its point of departure. The two pilots, in their survey of the poop of the Alcestis, discovered the lard; which they had no sooner done, than they returned towards the shark much more swiftly than they had parted from it. When they had come up with their monstrous companion, the latter began to resume its course. Then the pilots, swimming one on its right side, the other on its left, used their utmost exertions to guide it in a different direction; and having at last succeeded, they suddenly returned in company, and a second time visited the vessel's stern, thus, through their sagacity, bringing the shark in sight of the prey intended for it.

"It has been asserted that the shark possesses a very fine sense of smell. I paid close attention to all that passed when it found itself in the neighbourhood of the pork, 
and it seemed to me that it was ignorant of its whereabouts until its guides had, as it were, pointed it out; it was then only that it increased its speed, or rather made a leap to seize the bait. It detached a portion at first without being hooked; but at its second attempt the hook penetrated the left lip: it was caught, and hauled on board."

Two hours afterwards, one of the two "pilots" was captured, and Geoffroy Saint-Hilaire recognized in it the fanfre of the French seamen-our "pilot-fish," or the Naucrates ductor. 


\section{I $\operatorname{ndex}$}

ACERBI, quoted, 45.

Elian, quoted, 11, 106, 330, 498.

Aiguillon, Bay of, mussel-farm at, $289,291$.

Aleutian Islands, fur seal at, 433 .

Alexander, Sir James E., quoted, 345.

All the Year Round, quoted, 150-152.

Ambrose, St., quoted, 12.

Anchovy, the, natural history of, 184.

Arcachon, mussel-culture at, 265 ; oyster-farm at, 265-268.

Aristotle, quoted, 104.

Artesian wells, fish in, 491.

Ascension Island, turtle-fishing at, $345,346$.

Athenæus, quoted, 11, 103.

Ausonius, quoted, 12, 189.

BADHAM, quoted, $63,92,95,102,103$, 119, 190, 200, 307.

Battle of the Herrings, 157

Bertram, quoted, $10,27,34,56,81$, 153, 211, 226, 243.

Black, William, quoted, 144.

Blackwood's Magazine, quoted, 174176.

Brill, the, described, 92.

Brittany, sardine-fishery of, 183.

Brydone, quoted, 124.

Bultow-process, the, a mode of catching cod, 63.

Слвот, visit of, to Newfoundland, 61. Cachalot, the, described, 377.

Calvert, Sir George, 61.
Caviare, description of, 192.

Ceylon, pearl-fishery at, 276-284.

Chambers, Dr. R., quoted, 492.

Châteaulin, in Lower Brittany, salmon-fisheries at, 47,48 .

Chausey, in Normandy, shrimping at, 230.

Coal-fish, the, described, 84.

Cod, the, natural history of, 50 ; wide range of, 51 ; voracity of, 52 ; usefulness of, 53 ; fishery and curing of, 54-77.

Comacchio, eel-fishery at, 208.

Commerson, quoted, 502.

Copais, Lake, famous eels of, 200.

Coral-fishery, the, described, 478,485 .

Coral, its classification, 465 ; its production, 467; its various kinds, 485 .

Coral-producing animalcules, characteristies of, 467; their reproduction by gemmation, 469 ; by fission, 469 .

Coral reef, formation of, described, 470-474.

Cornhill Magazine, quoted, 251, 333337.

Cortereal, the discoverer of Newfoundland, 60 .

Coste, M., the pisciculturist, 265.

Couch, quoted, 170, 312, 328.

Cowie, Dr., quoted, 78, 463.

Crab, the, described, 224, 225.

Crantz, quoted, 96, 326.

Curing herrings, processes of, described, 157-160.

Cuvier, quoted, 53. 
DAB, the, described, 96.

Dampier, quoted, 343.

Darwin, C., quoted, 344.

Deslandes, quoted, 13, 47.

Dogger-Bank, the, cod-fisheries of, 54 .

Doran, Dr., quoted, 173.

Dorse, the, 85 .

Drayton, quoted, 15.

Dugong, the, 424.

Dumont d'Urville, quoted, 299

Echrneis, the, characteristics of, 496 , et $s q q$.

Eeleries, modern, 201.

Eel, the, natural history of, 199-202; its slipperiness, 205 ; fishery of, 207.

FABYAN, quoted, 82.

Faroe, cod-fishery of, 77.

Fayot, anecdote from, 12.

Finland, salmon-fishing in, 42, 43.

"Finnan haddocks," how prepared, 81.

Fish, showers of, 496 .

Flies, artificial, described, 19, 20.

Flounder, the, described, 95.

Fly-fishing for salmon, 19.

Franks, quoted, 95.

Frere, Hookham, quoted, 13.

Fuller, Thomas, quoted, 14, 173.

Fusaro, Lake, oyster-farm at, 258.

GADIDA, the, natural family of the class Pisces, 50.

Gallapagos Islands, the, turtles at, 343,344 .

Gilbert, Sir Humphrey, 61.

Greene, Professor, quoted, 468.

Greenland, salmon-fishing in, 42.

Greenland whale, the, described, 368377.

HADDOCK, the, described, 80-82; tradition connected with, 81 .

Hake, the, described, $85,86$.

Halibut, the, described, 96.

Hall, Captain Basil, quoted, 317, 472.

Hall, Captain C. F., 374, 456.

Hammer-head shark, the, described, $330,331$.

Harling, a mode of catching salmon, described, 41.

Herring-fishery, the, description of, 136.
Herring, the, natural history of, 127129 ; its supposed migrations disproved, 130; its different races, 133; its spawning, 134; its four different stages, 135.

Holothuria, the, natural history of, 295-299 ; fishing for, on coast of Australia, 299-303; British species of, 303.

Horace, quoted, 89, 185, 426.

ICELAXD, salmon-fishing in, 42.

KANE, Dr., quoted, 431, 458, 459461.

Kerr, quoted, 163.

King, Captain, quoted, 314.

LABRADOR, cod-fishery of, 73.

Lacépède, quoted, 62, 168.

Lcrwick, Dutch fishing-boats at, 162164.

L'Estrange, Sir Roger, quoted, 168.

Ling, the, 85.

Lobster, the, natural history of, 214222 ; different kinds, 222.

Lobster-trap, the, described, 226.

Loch Boisdale, Scotland, herringfishery in, 149-152.

Loch Fyne, Scotland, herring-fishery in, 142-147.

Lovat, Lord, anecdote of, 40.

MACKerke, the, range of, 114; migrations of, 115.

Madrague, the, a mode of fishing, described, 108.

Manatee, the, described, 423.

Markham, Captain, quoted, 357, 361$363,383,384,391-394$.

Mermaids, origin of, 422 .

Milton, quoted, 273.

Montgomery, James, quoted, 477.

Moore, Thomas, quoted, 272.

Mussel-farm in Bay of Aiguillon, 283.

Mussel, the, natural history of, 285288; culture of, 288-294.

NewfoundLand, cod-fisheries of, 5865 ; their value, 76 .

Newlyn, pilchard-fishery at, 177.

Nicholson, Professor, quoted, 219.

Norway, the cod-fishery of, 77. 
Olaus Magnus, quoted, 13.

Once a Week, quoted, 266-269.

Oppian, quoted, 104, 123, 124, 313, 330, 498.

Orata, Sergius, his epicureanism, 257.

Owen, Professor, quoted, 309.

Oyster - culture, described, 255-257, 260-264.

Oyster-farms, at Whitstable, 249 ; in the Colne, 250; in the Firth of Forth, 251 ; in Ireland, 252 ; in Italy, 258; in France, 264.

Oyster, the, its ancient and modern repute, 238-240 ; its associations, 241, 242 ; its physiology, 243-246 ; its spawn, 247, 248.

PARr, the young of the salmon, 25.

Pearl-oyster, the, natural history of, 270.

Pearls, British, fishery for, 282.

Pearl, the, what it is, 269-271 ; its ancient celebrity, 272 ; some celebrated specimens, 274,275 ; its fishery, 275, 284.

Pennant, quoted, 102.

Phocidæ, the.-See Seal.

Pilchard, the, natural history of, 169 ; on the Cornish coast, 170 ; modes of catching, 171.

Plaice, the, described, 92.

Pleuronectidæ, the, or flat-fish, physical characters of, 86.

Pliny, quoted, 272, 273, 305, 467, 496, 497.

Poaching for salmon, 37.

Pollack, described, 84.

Pontoppidan, quoted, 117.

Prawn, the, natural history of, 236, 237.

"Quarterly Review," quoted, 405408.

REMORA, the, fables respecting, 496499 ; its sucking-apparatus, 499 501 ; used in catching turtle, 502506.

Russel, A., quoted, 19.

SAINT-Gilles-sun-Vic, shrimp-fishing at, 233.

Saint-Hilaire, Geoffroy, quoted, 504.
Salmon, the, natural history of, 10 ; its migrations, 13 ; its mode of leaping, 14; ascending a stream, 15; fishing for, at night, 16 ; canght by rod and line, 20,21; spawning of, 24 ; growth of, 25 ; velocity of, 26 ; its return to the sea, 27 ; in Alaska, 29 ; in Canada, 31 ; in Great Britain, 33 ; Greenland, 42.

Sardine, the, natural history of, 182 , 183.

Scomberidæ, the, physical characters of, $100,101$.

Scoresby, Dr., quoted, 326, 366, 370, $372,374,417-419,420,421$.

Scotsman, The, quoted, 444.

Scott, Sir Walter, quoted, 18, 435.

Sea-elephant, the, described, 442.

Seal-fisheries of Newfoundland, 444, et sqq.

Seal-fishery, the, antiquity of, 455 .

Sea-lion, the, described, 441, 442.

Seal, the, its characteristics, 427 ; its habitat, 429 ; its food, 430 ; sealstalking, 431 ; the common seal, 433; harp seal, 436; bearded seal, 437; other species, 438-440; its flesh, 456.

Shad, the, described, 186.

Shakespeare, quoted, 192, 273.

Shark, the, description of, 304 ; its range, 305 ; its organization, 309 ; the British species, 311 ; the blue shark, voracity of, 313 ; the white shark, 314 ; its capture, 316-321 ; its destructiveness, 323 ; the thrasher, described, 324 ; the Greenland shark, 326 ; the basking shark, 327 ; the hammer-head, 330 .

Shetland, herring-fishery at, 161 ; whalehunt at, 403,404; seal-fishery of, 462 .

Shoshony Indians, the, salmon-fishing by, 45 .

Shrimp, the, characteristics of, 228 . 230.

Simpson, Sir George, quoted, 433.

Smyth, Admiral, quoted, 478.

Sole, the, delicacy of, 90 ; natural history of, 91 ; range of, 91 ; ancient celebrity of, 91 ; in mythology, 02.

Sophocles, quoted, 118.

Spallanzani, quoted, 126.

Spearing salmon, described, 18.

Spermaceti, its nature, 379 . 
Sperm whale, the, described, 377. Spey, the, salmon-fishing in, 17.

Sprat, the, natural history of, 180182.

Stewart, quoted, 283.

St. Ives, pilchard-fishery at, 178-180.

St. James's-day, oysters upon, 241.

St. John, C., quoted, 15, 16, 18.

Story, W. W., quoted, 281.

Sturgeon, the, characteristics of, 187, 188 ; species of, 189 ; spawning of, 190 ; value of, 191 ; fisheries of, $192-$ 198.

Sun-fishing in Ireland, 332-337.

Sword-fish, the, description of, 117 ; its fury, 118; its enmity to the whale, 119; modes of capture of, 124, 125.

TAY, the, salmon-fishing in, 17.

Tennent, Sir Emerson, quoted, 281, $309,346,348,349$.

Tennyson, quoted, 274, 423, 474 .

Tonnaire, the, mode of fishing, described, 106.

Tortoise-shell, 348.

Trawling, supposed evils of, 146,165 167.

Trawl-net, the, described, 56,57 .

Trepang-fishery, the, description of, 299-303.

Tunny, the, characteristics of, 101; migrations of, 104; capture of, by the ancients, 105; modern fishing for, 106.

Turbot, the, natural history of, 86-90.

Turtle, the, characteristics of, 338 340 ; the green turtle, 340 ; turtle in Ceylon, 346, 347; hawksbill turtle, 347-349; its instinct, 349 ; coriaceous turtle, 350 ; loggerhead, 351 ; in Polynesia, 351.

Tweed, the; salmon-fisheries of, 35-39.

UTrentr, Treaty of, 62.

VADsö, in Norway, whale-fishery at, 399.

Volcanic fishes, 498.

Volga, the, sturgeon-fishing in, 197, 198.

"Vox Piscis," curious anecdote of a tract so called, 63.

WALLER, quoted, 363-365.

Walton, Izaak, quoted, 12.

Walton, J., the inventor of musselculture, 288.

Whale-fishery, the, history and anecdotes of, 381 , et $s q q$.

Whale, the, natural history of, 352 361 ; its habits, $361-366$; its different species, 356-381.

Whaling-ship, equipment and crew of, 383-385.

Whitebait, the, described, 184.

White-fish, what they are, 50.

Whiting, the, described, 84.

Wick, scenes of the herring-fishery at, 153, 156.

Wilson, Professor, his description of a salmon-hunt, 22-24; on oysters, 240.

YARMOUTH, herring-fishery at, 148, 157-160.

Yarrell, quoted, 86, 115, 120, 203.

ZYGena, the - See HAMMrR-HEAD SHAR k. 



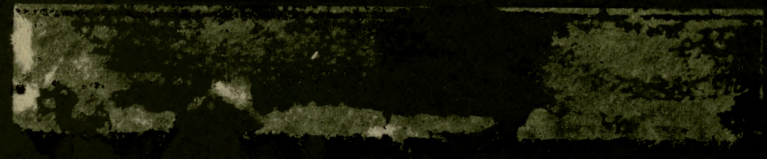


